\title{
UMA CONTRIBUIÇÃO AO ESTUDO DAS PONTES EM VIGAS MISTAS
}

\section{GELAFITO EDUARDO RENÉ GUTIÉRREZ KLINSKY}

Dissertação apresentada à Escola de Engenharia de São Carlos, da Universidade de São Paulo, como parte dos requisitos para obtenção do Título de Mestre em Engenharia de Estruturas.

ORIENTADOR: Prof. Dr. Roberto Martins Gonçalves

São Carlos

1999 
Class. TESF - EEX,

Cutt.

Tombo $2 0 8 \longdiv { 9 9 }$

Ficha catalográfica preparada pela Seção de Tratamento da Informação do Serviço de Biblioteca - EESC/USP

Gutiérrez Klinsky, Gelafito Eduardo René

Uma contribuição ao estudo das pontes em vigas mistas / Gelafito Eduardo René Gutiérrez Klinsky. -- são Carlos, 1999.

Dissertação (Mestrado) -- Escola de Engenharia de São Carlos-Universidade de são paulo, 1999.

Área: Engenharia de Estruturas.

orientador: Prof. Dr. Roberto Martins Gonçalves.

1. Tabuleiros mistos. 2. Análise estrutural. 3. Viga mista. 4. Estrutura mista. 5. Pontes. 6. Redundância estrutural. 7. Fratura. 8. Elementos finitos. 9. ANSYS. 9. Carga móvel. I. Título. 


\section{FOLHA DE APROVAC̄̃̃O}

Candidato: Engenheiro GELAFITO EDUARDO RENE GUTIERREZ KLINSKY

Dissertação defendida e aprovada em 10-06-1999

pela Comissão Julgadora:

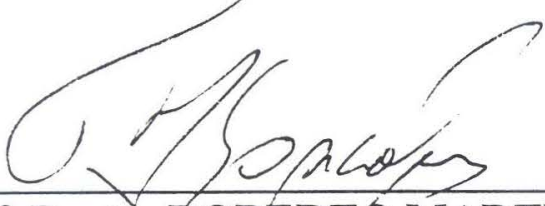

Prof. Doutor ROBERTO MARTINS GONÇALVES (Orientador)

(Escola de Engenharia de São Carlos - Universidade de São Paulo)

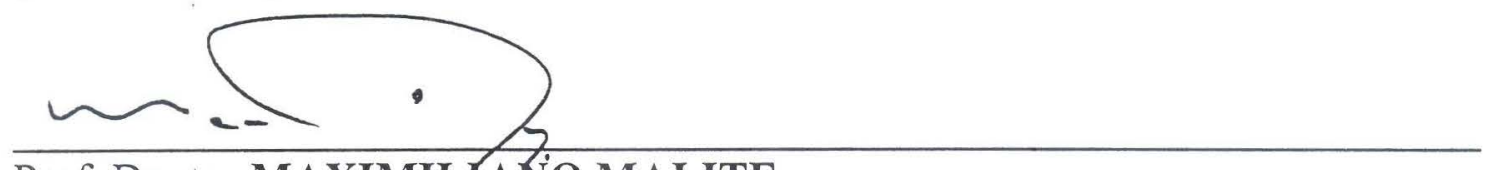

Prof. Doutor MAXIMILIANOO MALITE

(Escola de Engenhariz de São Carlos - Universidade de São Paulo)

\section{henc}

Prof. Doutor JULIO FRUCHTENGARTEN

(Escola Politécnica - Universidade de São Paulo)

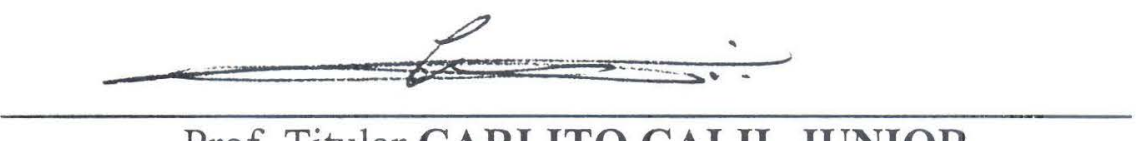

Prof. Titular CARLITO CALIL JUNIOR

Coordenador da Área de Engenharia de Estruturas

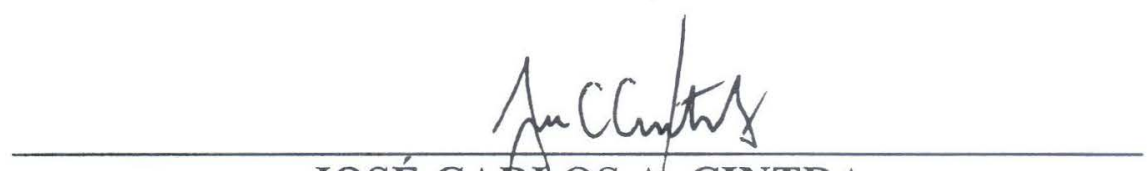

JOSÉ CARILOS A. CINTRA

Presidente da Comissãd de Pós-Graduação da EESC 
Aos meus pais, à minha tia Carmela e Dudú 


\section{AGRADECIMENTOS:}

Ao meu orientador, Professor Dr. Roberto Martins Gonçalves, pela paciência na orientação fornecida e pela amizade conquistada durante a elaboração deste trabalho.

Ao Conselho Nacional de Desenvolvimento Tecnológico - CNPq pela bolsa de estudos concedida.

Aos meus pais, Edgard Gutiérrez e Maria Klinsky de Gutiérrez e à minha tia Carmen Klinsky pelo apoio e carinho dados ao longo de toda minha vida.

Aos meus avôs Gelafio (in memorian) e Efigenia Gutiérrez (in memorian), Guillermo e Lola Klinsky pelo exemplo de vida.

Á Fernanda pelo carinho, companhia e compreensão ao longo destes anos.

Ao pessoal da minha república e da república "los chocos"; em especial Diego Alcalá, Oscar Tonelli, Eduardo Achá e Enrique López, pela grande amizade e apoio cedidos em todo momento.

Aos professores, colegas e funcionários do Departamento de Estruturas por todo o apoio e amizade desenvolvidos nestes anos de convívio. 


\section{SUMÁRIO}

RESUMO

ABSTRACT__ II

RESUMEN __III

LISTA DE FIGURAS___ IV

LISTA DE GRÁFICOS __ X

LISTA DE TABELAS __ XII

LISTA DE SÍMBOLOS __ XIV

LISTA DE MAIÚSCULAS ___ XVII

CAPÍTULO 1: INTRODUÇÃO__ 1

CAPÍTULO 2: HISTÓRICO E ASPECTOS GERAIS ___ 5

2.1 - O início da construção mista aço concreto e o seu desenvolvimento _ـ 5

2.2 - Aspectos gerais sobre pontes em vigas mistas __ 9

2.2.1 - Largura efetiva da laje de concreto___ 13

2.2.2 - Conectores de cisalhamento___ 14

2.3 - Tipos de construção___ 20

2.3.1 - Sistemas construtivos _ 20

2.4 - Normalização e materiais empregados __ 28

2.4.1 - Materiais empregados__ 28

2.4.1.1 - Aços utilizados na construção de pontes __ 29 
2.4.2 - Concreto

3.1 - Cargas móveis 37

3.2 - Efeitos de temperatura 41

3.3 - Efeitos de retração e fluência 47

3.3.1 - Considerações sobre o comportamento viscoelástico da estrutura 48

3.3.2. - Métodos algébricos simplificados 50

3.3.2.1 - Método do Módulo elástico 50

3.3.2.2 - Método do Módulo Elástico Ajustado com a idade do Concreto 51

3.3.2.3 - Método da taxa de fluência 52

3.4 - Efeitos de fadiga 53

3.4.1 - Estudos experimentais 54

3.4.2 - Fraturas de fadiga em vigas de pontes 57

3.4.3 - Efeito de fadiga em conectores de cisalhamento 61

3.5 - Considerações adicionais 66

CAPÍTULO 4: ANÁLISE ESTRUTURAL 68

4.1 - Aspectos gerais 68

4.2- Tipos de análise 72

4.2.1 - Analogia de grelha 73

4.2 .2 - Estruturas prismáticas laminares (folded plate analysis) 74

4.2.3 - Análise proposta pela AASHTO 76

4.2.3.1 - Aspectos relacionados á redundância estrutural 78

4.2.4 - Aplicação do método dos elementos finitos 82

4.2.4.1 - Modelagens de tabuleiros de pontes encontradas na literatura 82 
5.1 - Generalidades 100

5.2 - Modelagem das vigas de aço 101

5.3 - Modelagem da Laje de concreto 106

5.4 - Ligação entre elementos de viga e elementos de laje 107

5.5 - Modelagem dos contraventamentos 110

5.6 - Condições de apoio 112

5.7 - Propriedades dos materiais 114

5.8 - Exemplos dos tabuleiros modelados 114

CAPÍTULO 6: ANÁLISES REALIZADAS E RESULTADOS OBTIDOS 115

6.1 - Estudo da influência dos contraventamentos 115

6.2 - Estudo da influência da geometria do tabuleiro na distribuição de cargas 126

6.2.1 - Influência do vão 126

6.2.2 - Influência da espessura da laje na distribuição de tensões 129

6.2.3 - Relação entre parâmetros geométricos e estruturais

6.3 - Linhas de influência de distribuição de carga nas vigas 133

6.4 - Aplicação da técnica de Analogia de grelha 138

6.5 - Estudo da redundância estrutural 143

6.5.1 - Redundância do tabuleiro sobre quatro vigas 148

6.5.2 - Redundância do tabuleiro sobre duas vigas 155

CAPÍTULO 6: CONCLUSÕES E COMENTÁRIOS FINAIS 162

REFERÊNCIAS BIBLIOGRÁFICAS 168

BIBLIOGRAFIA COMPLEMENTAR 184 ANEXOS 
GUTIÉRREZ-KLINSKY, G. E. (1999). Uma contribuição ao estudo das pontes em vigas mistas. São Carlos. Dissertação (Mestrado) - Escola de Engenharia de São Carlos, Universidade de São Paulo.

Este estudo fundamenta-se na análise numérica, via elementos finitos, de pontes em vigas mistas; considera-se a interação de todos os elementos que compõem a estrutura na transferência dos esforços até os apoios.

Inicialmente apresenta-se um estado da arte sobre o projeto, execução e análise de pontes em vigas mistas, identificando as simplificações e deficiências existentes no cálculo destas estruturas.

O estudo do comportamento estrutural de tabuleiros mistos foi abordado do ponto de vista tridimensional, sendo para isto modelados e analisados tabuleiros com 8, 10, 12, 14, 16, 18, 20, 22, 24 e 26 m. de vão mediante a utilização do programa ANSYS, versão 5.4. Foi estudada a influência que a presença de contraventamentos, espessura da laje, vão e posição da carga móvel na seção transversal exercem na distribuição de cargas nas vigas, sendo para isto considerado comportamento elásticolinear.

Realizou-se também uma abordagem ao estudo da redundância estrutural de tabuleiros mistos considerando as não linearidades física e geométricas do conjunto. Foi verificado que tabuleiros sobre duas e quatro vigas mantêm o equilíbrio estático após que uma das vigas sofre fratura, sem experimentar grandes deslocamentos (inferiores ou ligeiramente superiores ao limite L/500).

Palavras chave: tabuleiros mistos, análise estrutural, viga mista, estrutura mista, pontes, redundância estrutural, fratura, elementos finitos, ANSYS, carga móvel. 


\section{ABSTRACT}

KLINSKY, G. E. R. G. (1999). A contribution to the study of composite steelconcrete bridges decks. São Carlos. Dissertation (Master) - São Carlos School of Engineering, University of São Paulo.

This work is based in the numerical analysis, by finite elements, of bridge decks with composite beams; in this study the interaction of all the elements that compose the structure is considered in the transference of the efforts to the supports.

Initially, a state of the art on the design, construction and analysis of composite bridge decks is presented, identifying the simplifications adopted, lack of information at the present on the subject and aspects that need further studies on this bridges.

The study of the structural behavior of composite bridge decks was approached from a three-dimensional point of view, modeling and analyzing composite decks with $8,10,12,14,16,18,20,22,24$ and $26 \mathrm{~m}$ of span by using the software ANSYS, version 5.4. The influence that the bracing system, thickness of the slab, span and live load position on the deck, over the load distribution in the composite beams, considering linear-elastic behavior, was studied.

An approach to the study of the structural redundancy of composite bridge decks was also made, considering the physical and geometric nonlinearities of the structure. It was verified that decks consisting of two and four composite beams maintain the static equilibrium after the fracture of one of the beams, without large displacements (inferior or lightly superior to the limit L/500).

Key words: composite decks, structural analysis, composite beam, composite structure, bridges, structural redundancy, fracture, finite elements, ANSYS, live load. 


\section{RESUMEN}

GUTIÉRREZ-KLINSKY, G. E. (1999). Una contribución al estudio de puentes en vigas mixtas. São Carlos. Disertación (Maestría) - Escuela de Ingeniería de São Carlos, Universidad de São Paulo.

Este estudio se basa en el análisis numérico, por elementos finitos, de puentes en vigas mixtas, siendo considerada la interacción de todos los elementos que forman la estructura en la transferencia de los esfuerzos hasta los apoyos.

Inicialmente se presenta el estado del arte sobre el proyecto, ejecución y análisis de puentes en vigas mixtas, identificándose las simplificaciones y deficiencias existentes en el cálculo de este tipo de estructura.

El estudio del comportamiento estructural de tableros mixtos fue abordado desde el punto de vista tridimensional, siendo para tal modelados y analisados tableros com $8,10,12,14,16,18,20,22,24$ y $26 \mathrm{~m}$. de luz através del programa ANSYS, versión 5.4. Fue estudiada la influencia que la presencia de sistemas de arriostramiento, espesura de la losa, luz y localización de la carga móbil en la sección transversal, ejercen en la distribución de las cargas transferidas para las vigas, siendo considerado para esto comportamiento linear-elástico.

También se realizó un estudio sobre la redundancia estructural de tableros mixtos considerando las no linearidades física y geométrica del conjunto. Fue verificado que tableros sobre dos y cuatro vigas mantienen el equilibrio estático después de que una de las vigas sufre una fractura, sin sufrir grandes desplazamientos (menores o poco mayores al límite de L/500).

Palabras clave: tableros mixtos, análisis estructural, viga mixta, estructura mixta, puentes, redundancia estructural, fractura, elementos finitos, ANSYS, carga, móbil. 


\section{LISTA DE FIGURAS}

\section{CAPÍTULO 2}

FIGURA 2.1 - Linha Vermelha. COSIPA 7

FIGURA 2.2 - Ponte rodoferroviária sobre o rio Paraná. 8

FIGURA 2.3 - Comparação entre ação não mista e mista 9

FIGURA 2.4 - Processo automatizado de incorporação de "studs"mediante pistola de solda. HACKETT\&ASSOCIATES (1998) 10

FIGURA 2.5 - Construção de viaduto em estrutura mista. HACKETT \& ASSOCIATES (1998). 12

FIGURA 2.6 - Construção de viaduto em estrutura mista em Örbyhus,

Suécia. COLLIN et al (1998) 12

FIGURA 2.7 - Ponte rodoferroviária sobre o rio Paraná. 13

FIGURA 2.8 - Efeito de "shear lag" 13

FIGURA 2.9 - Tipos de conectores de cisalhamento 18

FIGURA 2.10 - a) Modelo de ensaio de "push-out"; b) curvas de força

aplicada versus escorregamento.AN \& CEDERWALL (1997) _ 19

FIGURA 2.11 - Utilização de treliça para lançamento das vigas. 21

FIGURA 2.12 - Técnicas de escoramento da laje. HACKETT \& ASSOCIATES. 21

FIGURA 2.13 - Comparação entre o sistema de laje com forma de aço incorporada e o sistema tradicional 22

FIGURA 2.14 - Utilização de pré-lajes como formas permanentes 23

FIGURA 2.15 - Execução do tabuleiro mediante elementos pré-moldados de laje 23

FIGURA 2.16 - Detalhe de ligação entre painéis pré - moldados. JOHNSON \& BUCKBY (1986) 24

FIGURA 2.17 - Sistema Steel Free Deck. NEWHOOK et al (1997) 25

FIGURA 2.18 - Sistema Exodérmico em tabuleiros de pontes.

EXODERMICC BRIDGE DECK, INC (1999) 25 
FIGURA 2.19 - Detalhes para execução da laje de tabuleiros exodérmicos.

EXODERMIC BRIDGE DECK, INC (1999)

FIGURA 2.20 - Elevação e seção transversal da Ponte Lauffen, Alemanha.

(TROITSKY, 1990)

FIGURA 2.21 - Ancoragens de protensão em vigas de aço. TROITSKY 28

FIGURA 2.22 - Fluxo de produção de aço. CSN (1998) 29

\section{CAPÍTULO 3}

FIGURA 3.1 - Modelo analisado e resultados obtidos. SIMKO (1979) 42

FIGURA 3.2 - Gradientes de temperatura na seção transversal, propostos

por diferentes autores e regulamentos. 43

FIGURA 3.3 - Análise do efeito de temperatura em vigas mistas. SOLIMAN \& KENNEDY (1986) 44

FIGURA 3.4 - Integração da equação de Sieltjes através da regra do trapézio. AMÁDIO (19993) 49

FIGURA 3.5 - Locais que podem desenvolver o fenômeno da fadiga. SMITH (1991) 54

FIGURA 3.6 - Curvas S-N adotadas pela AASHTO. FISHER \& MENZEMER (1991) 55

FIGURA 3.7 - Detalhes construtivos que podem apresentar fadiga em tabuleiros em vigas mistas. 56

FIGURA 3.8 - Fissuras por fadiga observadas em pontes. MAEDA et al 58

FIGURA 3.9 - Fissura induzida por deformações fora do plano. FISHER (1981) 59

FIGURA 3.10 - Fissura observada na conexão entre longarina e transversina. FISHER (1981) 59

FIGURA 3.11 - Fissura observada ao longo da conexão entre a mesa superior e a alma. FISHER (1981). 60

FIGURA 3.12 - Fissura na base do filete de solda entre a alma da viga e a chapa de ligação do diafragma. FISHER (1981) 60 
FIGURA 3.13 - Fissura no sistema de ligação de contraventamentos horizontais. FISHER (1981).

FIGURA 3.14 - Variação da resistência estática do conector segundo os ciclos de carregamento aplicado. OEHLERS et al (1995) 63

FIGURA 3.15 Comparação de tensões normais $(\mathrm{kN} / \mathrm{cm} 2)$ em vigas mistas com interação parcial e completa. SOTIROPOULOS \& GANGA RAO (1992) 65

FIGURA 3.16 - Deformação elástica em conectores de cisalhamento. GATTESCO \& GIURIANI (1996). 66

\section{CAPÍTULO 4}

FIGURA 4.1 - Deslocamento de corpo rígido da seção transversal do tabuleiro HAMBLY (1991) 69

FIGURA 4.2 - Representação de tabuleiros mistos através de modelos bidimensionais. 70

FIGURA 4.3 - Representação de tabuleiros mistos através de modelos tridimensionais formados por elementos lineares, planos e sólidos.

FIGURA 4.4 - a) Excentricidade entre os C.G. da viga e da laje; b) analogia de grelha considerando os C.G. coincidentes. 74

FIGURA 4.5 - Representação de uma viga mista através de lâminas prismáticas retangulares. JAEGER \& BAKHT (1989) 75

FIGURA 4.6 - Condições de compatibilidade de deslocamentos.

KRISTEK \& STUDNICKA (1988). 76

FIGURA 4.7 - Seção transversal da ponte I-40 sobre o Rio Grande.

IDRISS et al (1995). 80

FIGURA 4.8 - Localização dos extensômetros nas vigas principais. IDRISS et al (1995). 81

FIGURA 4.9 - Modelagem de viga mista de ponte. BISHARA et al (1993)_83

FIGURA 4.10 Comparação entre deslocamentos teóricos e experimentais. KENNEDY et al (1989) 84 
FIGURA 4.11 - Modelo tridimensional utilizado por TARHINI \& FREDERICK (1992).

FIGURA 4.12 - Condições de compatibilidade na interface aço - concreto.

ANSOURIAN \& RODERICK (1978) 86

FIGURA 4.13 - Comparação entre resultados teóricos e experimentais.

ANSOURIAN (1975).

FIGURA 4.14 - Elementos finitos utilizados por RAZAQPUR \& NOFAL

(1990). 88

FIGURA 4.15 - a) elevação e seção transversal da viga mista; b) modelagem por elementos finitos; c) comparação entre resultados teóricos e experimentais. RAZAQPUR \& NOFAL (1990). 90

FIGURA 4.16 - Modelo analisado por HELWIG et al (1993). 91

FIGURA 4.17 - Elemento finito proposto por AMADIO \& FRAGIACOMO (1993). 91

FIGURA 4.18 - Modelagem de uma seção de viga mista.

BROCKENBROUGH (1986). 92

FIGURA 4.19 - Linhas de influencia para tabuleiro curvo em planta.

BROCKENBROUGH (1986). 93

FIGURA 4.20 - Discretização de seção mista em várias camadas. OÑATE (1992). 94

FIGURA 4.21 - Prova de carga na ponte Stoney Creek. BAKHT \& JAEGER (1992). 96

FIGURA 4.22 - Fatores de distribuição de carga para cada nível de carregamento. BAKHT \& JAEGER (1992). 96

FIGURA 4.23 - a) Seção transversal da ponte Wilson Memorial Bridge; b) tensões atuantes nas vigas. NOWAK et al (1993). 97

FIGURA 4.24 - a) Seção transversal da ponte; b) distribuição de forças axiais. MOORE et al (1990). 98

\section{CAPÍTULO 5}

FIGURA 5.1 - Modelo tridimensional de uma viga de aço com seção I _ 101 FIGURA 5.2 - Elemento de casca elástica SHELL63. ANSYS. 102 
FIGURA 5.3 - Seção transversal da viga modelada. 103

FIGURA 5.4 - Cálculo do momento fletor na seção. _ 105

FIGURA 5.5 - Modelagem da viga de aço. 105

FIGURA 5.6 - Modelagem da laje por elementos de casca SHELL63. 107

FIGURA 5.7 - Elemento de viga tridimensional. "BEAM4". ANSYS. 108

FIGURA 5.8 - Seção transversal e características geométricas da viga mista 109

FIGURA 5.9 - Modelagem da viga mista. 110

FIGURA 5.10 - Elemento de treliça espacial "LINK8" 111

FIGURA 5.11 - Modelagem do sistema de contraventamentos por elementos de barra "LINK8". Tabuleiros de 20 m de vão. 112

FIGURA 5.12 - Condições de apoio da estrutura. 113

FIGURA 5.13 Tabuleiro sobre três vigas. 114

\section{CAPÍTULO 6}

FIGURA 6.1 - Deslocamentos das vigas do tabuleiro de 22 m quando existe sistema de contraventamentos. Carregamento assimétrico. 124

FIGURA 6.2 - Deslocamentos das vigas do tabuleiro de $22 \mathrm{~m}$ quando o sistema de contraventamentos é removido. Carregamento assimétrico.

FIGURA 6.3 - Esquema de carregamento da estrutura para obtenção das linhas de influência. 134

FIGURA 6.4 - Modelos de grelha analisados. Dim. em cm. 139

FIGURA 6.5 - Grelha analisada por elementos de viga "BEAM4". 140

FIGURA 6.6 - Modelagem da fratura na mesa inferior. 144

FIGURA 6.7 - Modelagem da fratura na alma. 145

FIGURA 6.8 - Localização da fratura na viga. 146

FIGURA 6.9 - Posição das cargas móveis na seção transversal. Dimensões em $\mathrm{cm}$. 147

FIGURA 6.10 - Curva de tensão-deformação adotada para as vigas de aço.

Comportamento bi-linear. 147

FIGURA 6.11 - Redistribuição das tensões atuantes. 148 
FIGURA 6.12 - Tensões atuantes nas vigas antes da fratura. 149

FIGURA 6.13 - Deslocamentos obtidos nas vigas com a viga 1 fraturada. 151

FIGURA 6.14 - Deslocamentos obtidos com a viga 1 sem fratura. 151

FIGURA 6.15 - Esforços normais nas barras do contraventamento mais próximo do local da fratura (região central). 153

FIGURA 6.16 - Reações noa apoios antes e depois da fratura. 153

FIGURA 6.17 - Tensões atuantes nas vigas de aço após a fratura. 155

FIGURA 6.18 - Tensões obtidas nas vigas de aço antes da ocorrência da fratura. 156

FIGURA 6.19 - Deslocamentos das vigas após a fratura. 156

FIGURA 6.20 - Deslocamentos das vigas antes da fratura. 157

FIGURA 6.21 - Esforços normais antes e depois da fratura. 158

FIGURA 6.22 - Reações nos apoios antes e depois da fratura.. 158

FIGURA 6.23 - Abertura da fissura por flexão da viga. 161

FIGURA 6.24 - Fissura antes e depois que a viga deforma. 161 


\section{LISTA DE GRÁFICOS}

GRÁFICO 6.1 - Distribuição de tensões em tabuleiros sobre quatro vigas.

Carregamento simétrico

GRÁFICO 6.2 - Distribuição de tensões em tabuleiros sobre três vigas.

Carregamento simétrico.

GRÁFICO 6.3 - Distribuição de tensões em pontes sobre quatro vigas

GRÁFICO 6.4 - Distribuição de tensões em tabuleiros sobre três vigas.

Carregamento assimétrico.

GRÁFICO 6.5 - Deslocamentos das vigas do tabuleiro de $12 \mathrm{~m}$.

Carregamento assimétrico.

GRÁFICO 6.6 - Deslocamentos das vigas do tabuleiro de $12 \mathrm{~m}$.

Carregamento simétrico.

GRÁFICO 6.7 - Deslocamentos das vigas do tabuleiro de $22 \mathrm{~m}$.

Carregamento simétrico.

GRÁFICO 6.8 - Deslocamentos das vigas do tabuleiro de $22 \mathrm{~m}$.

Carregamento assimétrico.

GRÁFICO 6.9 - Influência da variação do vão em tabuleiro sobre quatro vigas. Carregamento assimétrico.

GRÁFICO 6.10 - Influência da variação do vão em tabuleiro sobre três vigas. Carregamento assimétrico.

GRÁFICO 6.11 - Ingluência da variação da espessura da laje em tabuleiros sobre quatro vigas. Carregamento assimétrico.

GRÁFICO 6.12 - Influência da variação da espessura da laje em tabuleiros sobre três vigas. Carregamento assimétrico.

GRÁFICO 6.13 - Fatores de distribuição de carga para as vigas externas. Tabuleiros sobre quatro vigas. 
GRÁFICO 6.14 - Fatores de distribuição de carga para as vigas internas.

Tabuleiros sobre quatro vigas.

GRÁFICO 6.15 - Fatores de distribuição de carga para as vigas externas.

Tabuleiros sobre três vigas.

GRÁFICO 6.16 - Fatores de distribuição de carga para a viga interna.

Tabuleiros sobre três vigas.

GRÁFICO 6.17 - Tensões normais no caso de carregamento simétrico.

Tabuleiro sobre três vigas; $\mathrm{L}=20 \mathrm{~m}$.

GRÁFICO 6.18 Tensões normais no caso de carregamento assimétrico.

Tabuleiro sobre três vigas; $\mathrm{L}=20 \mathrm{~m}$.

GRÁFICO 6.19 - Tensões normais no caso de carregamento assimétrico.

Tabuleiro sobre três vigas; $\mathrm{L}=20 \mathrm{~m}$.

GRÁFICO 6.20 - Tensões normais no caso de carregamento simétrico.

Tabuleiro sobre três vigas; $L=20 \mathrm{~m}$.

GRÁFICO 6.21 - Comparação de tensões antes e depois da fratura. 150

GRÁFICO 6.22 - Comparação de deslocamentos antes e depois da fratura.

GRÁFICO 6.23 - Variação das tensões nas vigas a cada acréscimo de carga.

GRÁFICO 6.24 - Variação dos deslocamentos das vigas a cada acréscimo de carga.

GRÁFICO 6.25 - Comparação de deslocamentos antes e depois da fratura.

GRÁFICO 6.26 - Variação da tensão na viga 2 a cada acréscimo de carga. 159

GRÁFICO 6.27 - Variação do deslocamento da viga 2 a cada acréscimo de carga. 


\section{LISTA DE TABELAS}

\section{CAPÍTULO 2}

TABELA 2.1 - Aços estruturais da série NBR permitidos pela NBR 8800 _30 TABELA 2.2 - Aços estruturais especificados pela ASTM e permitidos pela NBR 8800 31

TABELA 2.3 - Aços patináveis produzidos pela COSIPA. 32

TABELA 2.4 - Resistência dos conectores de cisalhamento segundo a BS 5400. MALITE (1993) 33

\section{CAPÍTULO 3}

TABELA 3.1 - Comparação entre veículos tipo utilizados em diferentes países. 38

TABELA 3.1 - Comparação entre veículos tipo utilizados em diferentes países. (Continuação). 39

TABELA 3.2 - Coeficientes de impacto. 41

TABELA 3.3 - Categoria dos detalhes. (AASHTO). 56

\section{CAPÍTULO 4}

TABELA 4.1 - Métodos de análise para o estudo de tabuleiros de pontes. QUIROGA (1983). 72

TABELA 4.2 - Comparação entre valores teóricos e experimentais. BISHARA et al (1993). 83 


\section{CAPÍTULO 5}

TABELA 5.1 - Comparação dos resultados obtidos para vários tipos de malha com os da teoria de flexão de vigas. 104

TABELA 5.2 - Comparação entre as tensões e deslocamentos obtidos pelo MEF e pela teoria de vigas mistas. 110

\section{CAPÍTULO 6}

TABELA 6.1 - Tensões admissíveis de fadiga em estruturas redundantes e não redundantes. 143. 


\section{LISTA DE SÍMBOLOS}

\section{Letras romanas minúsculas:}

a: semi - espessura da laje de concreto

b: largura da laje

$b_{e}$ : largura da laje equivalente

$b_{y}$ : espessura da alma da viga de aço na fibra y

$d_{f}$ : distância da fibra superior de aço ao centróide da seção de aço

$d_{2}$ : distância da fibra inferior de aço ao centróide da seção de aço

e: excentricidade existentes entre os centros de gravidade da laje e da viga

$f_{c k}$ : resistência característica do concreto à compressão

$f_{y}$ : resistência de escoamento do aço à tração

$f_{u}$ : resistência última do aço à tração

q: fluxo de cisalhamento longitudinal atuante entre o tabuleiro de concreto e a viga de aço.

t: espessura da laje, alma ou mesas da viga de aço

$u_{i, j}$ : deslocamento longitudinal dos nós i e j da ligação

$w_{i, j}$ : deslocamento vertical dos nós i e j da ligação

$y_{1}$ : distância do centróide da seção de aço à fibra onde as tensões ocasionadas por gradiente de temperatura são calculadas 
y: distância do centróide da seção de aço à fibra onde as tensões ocasionadas por gradiente de temperatura são calculadas.

\section{Letras romanas maiúsculas:}

$A_{c}$ : área da seção de concreto

$A_{s}$ : área da seção de aço

D: rigidez á flexão da laje, fator de distribuição de carga

$E_{c}$ : módulo de elasticidade do concreto

$E_{c, e f}$ : módulo de elasticidade efetivo do concreto

$E_{c, 28}$ : módulo de elasticidade do concreto aos 28 dias

$E_{c}(t)$ : módulo de elasticidade do concreto na idade $\mathrm{t}$

$E_{s}$ : módulo de elasticidade do aço

F: força de cisalhamento atuante no conector

$\mathrm{H}$ : relação entre a rigidez longitudinal das vigas e a rigidez transversal da laje

$I_{c g}:$ momento de inércia da viga mista

$I_{s}:$ momento de inércia da seção de aço

L: vão livre do tabuleiro

M: momento fletor atuante no tabuleiro

$\mathrm{N}$ : número de ciclos de carga aplicados

$P$ : carga concentrada aplicada na laje do tabuleiro

R: amplitude de força aplicada

$S$ : espaçamento entre as vigas longitudinais

$T_{0}$ : temperatura da viga mista no período de construção

$T_{y l}$ : temperatura de uma determinada fibra da laje de concreto 


\section{LISTA DE MAIÚSCULAS}

$\begin{array}{ll}\text { AASHTO } & \text { American Association of State Highway Oficcials } \\ \text { ABNT } & \text { Associação Brasileira de Normas Técnicas } \\ \text { ACI } & \text { American Concrete Institute } \\ \text { AISC } & \text { American Institute of Steel Construction } \\ \text { ASTM } & \text { American Standardts of Testing Materials } \\ \text { BS } & \text { British Standardts } \\ \text { EC } & \text { Eurocode } \\ \text { LRFD } & \text { Load Rating Factor Design } \\ \text { MEF } & \text { Método dos elementos finitos } \\ \text { MF } & \text { Mecânica da fratura }\end{array}$




\section{Letras gregas:}

$\alpha_{c}$ : coeficiente de dilatação térmica do concreto

$\alpha_{s}$ : coeficiente de dilatação térmica do aço

$\chi\left(t, t_{0}\right)$ : coeficiente de envelhecimento do concreto

$\varepsilon_{c}\left(t, t_{0}\right)$ : deformação total do concreto no período $\left(\mathrm{t}, t_{0}\right)$

$\varepsilon_{s h}(t)$ : deformação do concreto na idade t ocasionada por retração

$\varepsilon_{x c}$ : deformação longitudinal total na fibra inferior da laje de concreto

$\varepsilon_{x s}$ : deformação longitudinal total na fibra superior da viga de aço

$\phi$ : coeficiente de impacto

$\phi(t, \tau)$ : função de viscosidade do concreto

$\lambda$ : escorregamento entre aço e concreto na interface destes materiais

$\theta$ : rotação da ligação em relação ao plano da alma da viga de aço

$\sigma_{c}(\tau)$ : tensão aplicada no concreto na idade $\tau$

$\sigma_{\max }:$ máxima tensão normal na largura $b_{e}$

$\sigma_{\text {med }}:$ tensão normal média na largura $b_{e}$

$v$ : coeficiente de poisson 


\section{INTRODUÇÃO}

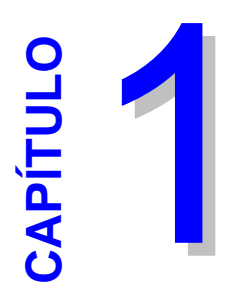

O notável desenvolvimento das cidades na atualidade, acelerado por políticas de globalização e livre comércio estimula a construção de estradas, pontes e túneis que facilitem o transporte de pessoas e produtos entre cidades e países, melhorando o relacionamento entre estes. Perante esta situação torna-se necessário realizar uma abordagem ao cálculo estrutural das pontes do ponto de vista o mais realista possível, compatível este com os recursos de análise disponíveis hoje em dia, visando obter uma melhor compreensão do comportamento deste tipo de estrutura e a elaboração de projetos que forneçam maior economia sem comprometer a segurança; fatores determinantes na construção civil.

Neste trabalho, a consideração de pontes de pequenos vãos apenas é realizada no intuito de apresentar resultados que sejam aplicáveis na prática. Em pontes de pequenos vãos, a influência que os fatores geográficos exercem na definição do sistema estrutural não varia notoriamente de um local a outro, esta situação não se reflete em pontes de grandes vãos onde são necessários estudos complementares que podem variar drasticamente a natureza do sistema estrutural de uma ponte para outra.

Nos capítulos 2, 3, e 4 é realizado um estudo de tabuleiros de pontes em vigas mistas, de maneira a fornecer ao leitor subsídios que permitam um maior conhecimento sobre a análise estrutural e dimensionamento deste tipo de estrutura. Isto permitirá um maior entendimento da modelagem realizada no capítulo 5 e das análises realizadas no capítulo 6 . 
Um histórico sobre o início e desenvolvimento da construção de tabuleiros em estrutura mista é inicialmente apresentado no capítulo 2 , sendo também apresentados conceitos básicos sobre os elementos constituintes e princípio de funcionamento de uma estrutura mista. Finalizando o capítulo são apresentados vários sistemas construtivos que podem substituir ao sistema tradicional de construção mista e os materiais utilizados na construção deste tipo de tabuleiro.

No capítulo 3 estão apresentados os principais aspectos das ações atuantes num tabuleiro misto; prestando-se particular importância às ações de carga móvel e os efeitos de temperatura, retração e fluência do concreto e efeitos de fadiga. Neste capítulo apresentam-se também vários estudos experimentais, encontrados na literatura, direcionados à caracterização e localização de regiões que podem desenvolver o fenômeno da fadiga ou ainda concentrações de tensões que possam ocasionar problemas estruturais.

Uma abordagem à análise estrutural de tabuleiros de pontes é apresentada no capítulo 4, sendo inicialmente estabelecidos conceitos de modelos unidimensionais, bidimensionais e tridimensionais e as hipóteses sobre as quais estes se baseiam. A seguir, são apresentadas as técnicas de análise de maior divulgação no meio técnico para a análise de tabuleiros em vigas mistas, sendo brevemente descritas a técnica de analogia de grelha e a de estruturas prismáticas laminares (folded plate analysis).

Apresenta-se também neste capítulo, a metodologia de análise proposta pela AASHTO, sendo dada particular importância ao conceito de redundância estrutural e aos estudos teóricos e experimentais encontrados na literatura sobre este assunto.

Neste mesmo capítulo apresenta-se a aplicação do Método dos Elementos Finitos (MEF) na análise de tabuleiros em vigas mistas; para isto foram descritos vários tipos de elementos finitos propostos na literatura para a modelagem dos tabuleiros, sendo também apresentadas várias comparações dos resultados obtidos através destes elementos com valores experimentais. 
Finalizando o capítulo 4, apresentam-se alguns resultados de análises experimentais de tabuleiros mistos encontrados na literatura, com o intuito de ilustrar o atual estágio das pesquisas experimentais.

No capítulo 5 apresentam-se as hipóteses e simplificações adotadas para a representação de tabuleiros mistos, sendo também estabelecidos os tipos de elementos que foram escolhidos para a análise. As justificativas, tanto da escolha do tipo de elemento como das dimensões destes são também descritas, assim como o tipo de vinculação do tabuleiro e propriedades dos materiais.

As análises realizadas e os resultados obtidos com os modelos construídos são apresentados no capítulo 6. Este capítulo apresenta, basicamente, duas partes distintas: uma primeira na qual são realizadas várias análises que consideram o comportamento elástico-linear da estrutura, visando estudar o comportamento tridimensional do tabuleiro e qualificar a influência que a presença de contraventamentos, variação do vão, espessura da laje e posição da carga móvel na seção transversal exercem na distribuição transversal de cargas para as vigas de aço. Para isto foram considerados tabuleiros sobre quatro e três vigas.

A segunda parte do capítulo 6 apresenta os estudos considerando as não linearidades física e geométrica do conjunto, visando estudar o comportamento estático do tabuleiro após a ocorrência de fratura em uma das vigas. Para isto foram considerados tabuleiros sobre duas e quatro vigas.

No capítulo 7 apresentam-se as conclusões obtidas no desenvolvimento deste trabalho.

De maneira a complementar e permitir uma maior fluidez da leitura do texto, foram incluídos três anexos no final. No ANEXO A apresentam-se as seções transversais e arranjo estrutural dos tabuleiros considerados nos capítulos 5 e 6; o ANEXO B complementa o anterior apresentando as características geométricas das vigas de aço e vigas mistas equivalentes dos tabuleiros. No ANEXO C são apresentados vários gráficos que mostram 
a variação da tensão máxima de tração nas vigas em função da variação da localização do trem tipo na seção transversal estudada (meio do vão). 


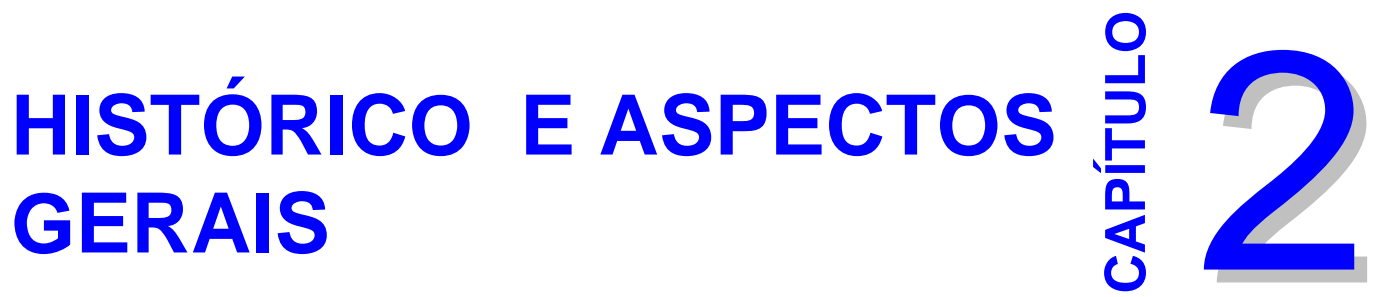

2.1 - O início da construção mista aço-concreto e seu desenvolvimento

O início da construção mista aço - concreto é marcado pela patente "Composite Beam Construction" (Construção em viga mista), pertencente a J. Khan no ano 1926 e aos estudos pioneiros de R. A. Caughey, publicados em 1929. A partir destas publicações a construção mista foi empregada numa grande quantidade de pontes rodoviárias nas décadas de 1930 e 1940.

As primeiras publicações sobre o projeto de estruturas mistas aço concreto em pontes rodoviárias foram realizadas pela American Association of State Highway Officials (AASHO) no ano 1944. A apresentação de critérios de projeto implementou rapidamente este novo tipo de construção.

Extensas pesquisas, somadas a uma larga experiência acumulada, fizeram com que os princípios básicos de funcionamento e comportamento das pontes mistas fossem estabelecidos na década seguinte, na medida que demandavam uma necessidade crescente de especificações mais detalhadas.

As especificações da norma americana foram atualizadas em 1961, neste período a Alemanha introduz os critérios e normalização para o projeto da construção mista no código DIN 1078. 
Mais recentemente, VIEST (1974) apresentou uma revisão do trabalho realizado até então sobre o assunto em questão. Posteriormente, o comportamento estrutural de pontes mistas foi estudado por vários pesquisadores como: Fisher, Daniels \& Slutter (1979), Johnson \& Hope-Gill (1976); Botzler \& Colville (1979); Salani, Duffield, Mc Bean \& Baldwin (1982, 1983), Grace \& Kennedy (1986). Uma comissão formada por representantes da ASCE - AASHTO (1985) publicou uma revisão de todo o escopo disponível até então sobre o projeto e execução de pontes em vigas mistas.

DUBAS (1987) estudou vários aspectos relacionados ao projeto e construção de pontes mistas, em especial as pontes em vigas curvas. Alguns dos aspectos tratados por este foram o enrijecimento da alma de vigas I e vigas caixão, arranjo dos enrijecedores transversais, arranjo estrutural e comportamento estático de pontes mistas em vigas curvas.

DANIELS, BREKELMANS \& STARK (1993) publicaram uma revisão dos avanços realizados no projeto e execução de pontes em vigas mistas entre 1970 e 1992, sendo abordados por estes os seguintes tópicos: superestrutura de aço, laje de concreto, conectores de cisalhamento, cargas e distribuição de cargas, utilização, manutenção, reabilitação e reparo.

Os autores identificaram ainda vários aspectos que precisam ser estudados com maior profundidade, estes são enumerados a seguir:

- utilização de lajes de espessura reduzida;

- novos tipos de conectores de cisalhamento;

- diferentes técnicas de montagem e construção;

- desenvolvimento de métodos de avaliação e controle da fissuração da laje;

- utilização de protensão interna e externa em tabuleiros.

Durante os últimos 20 anos foram construídas no Brasil várias pontes mistas utilizando vigas I ou vigas caixão. Tem-se por exemplo a ponte da Linha Vermelha, sobre a avenida Brasil, no Rio de Janeiro (Figura 2.1) cuja superestrutura consiste principalmente de traves em seção caixão e tabuleiros em vigas mistas, uma das inovações realizadas na construção da 
Linha Vermelha foi a introdução do aço de alta resistência mecânica tipo AR-COR, desenvolvido no Brasil.

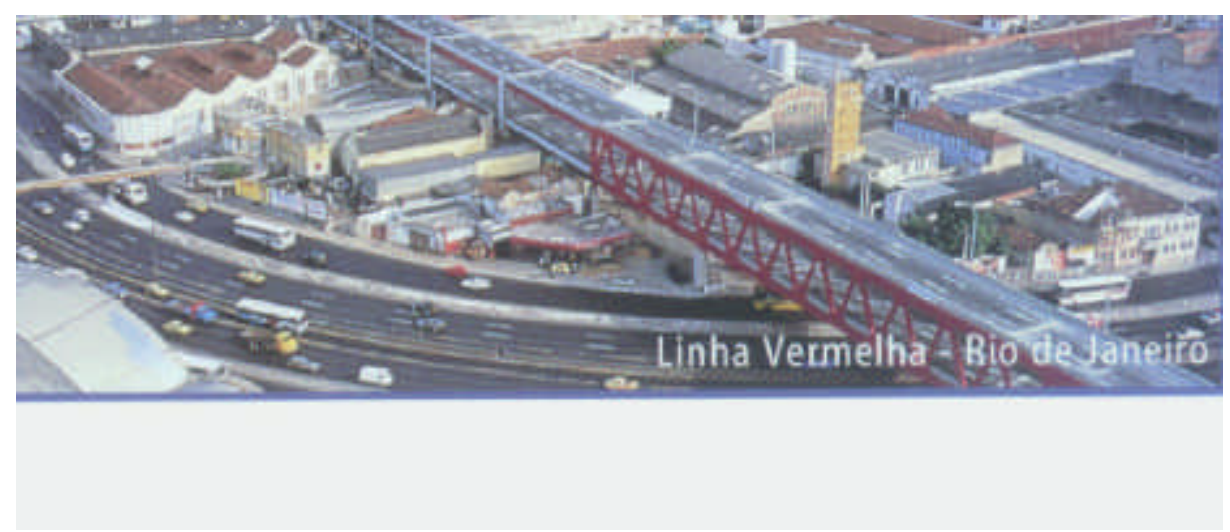

FIGURA 2.1 - Linha Vermelha. COSIPA

Um exemplo digno de nota, construído em estrutura mista no Brasil, é a ponte Pedro Ivo; assim denominada a segunda etapa da travessia entre a Ilha de Santa Catarina e o continente em Florianópolis. Esta ponte é constituída de perfis metálicos de aço Corten e lajes de concreto, nos tramos de 75 m e menores, e de estrutura totalmente em aço nos trechos maiores, vence um vão de $1252 \mathrm{~m}$.

$\mathrm{Na}$ construção dos tramos mistos as lajes foram moldadas no local e ligadas à estrutura metálica por meio de conectores tipo pino com cabeça, soldados nas mesas superiores dos perfis. Por tratar-se de uma estrutura contínua, onde os momentos negativos são geralmente maiores que os positivos, a espessura das lajes é de $22 \mathrm{~cm}$ nos vãos e $35 \mathrm{~cm}$ nos apoios (VASCONCELOS, 1993).

Outro exemplo de construção mista no Brasil é a ponte rodo ferroviária sobre o rio Paraná (Figuras 2.2 e 2.7), situada entre os municípios de Rubinéia - SP e Aparecida do Taboado - MS.

A estrutura metálica da referida ponte consiste de duas traves treliçadas de banzos paralelos, contraventadas entre si, com o tabuleiro ferroviário em via única no nível do banzo inferior e o tabuleiro rodoviário em duas vias, no nível do banzo superior. É formada por 26 tramos de $100 \mathrm{~m}$ cada, perfazendo um total de $2600 \mathrm{~m}$. 
Todas as barras das traves principais são em seção caixão, e o material utilizado em toda a estrutura metálica é o aço USI-SAC 50 (alta resistência mecânica e à corrosão atmosférica), produzido pela USIMINAS. Todas as conexões das barras que compõem as traves, as transversinas e o sistema de contraventamento foram executadas pelo processo de soldagem elétrica com eletrodo revestido ${ }^{1}$.

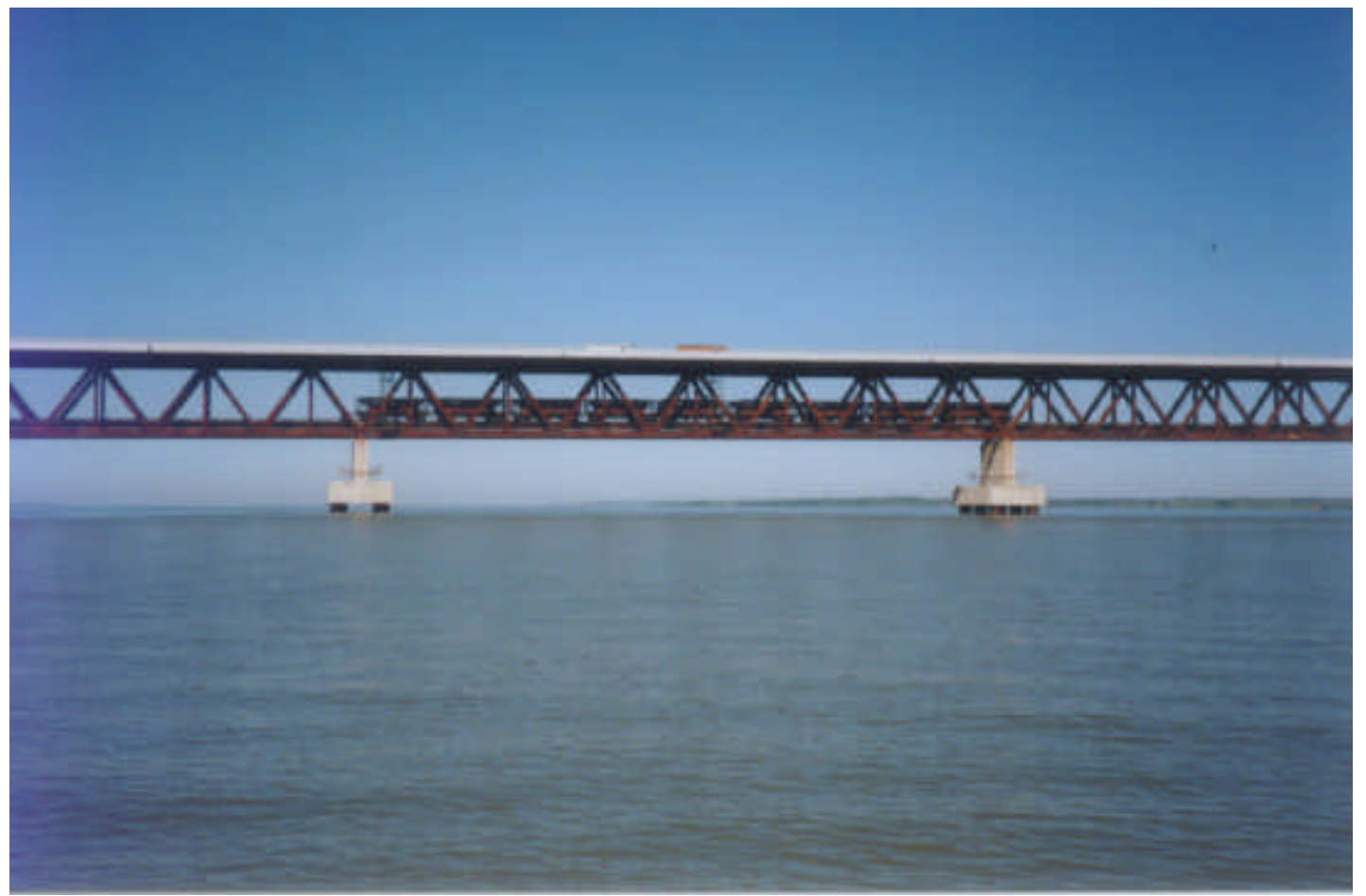

FIGURA 2.2 - Ponte rodo - ferroviária sobre o rio Paraná.

O tabuleiro ferroviário é constituído por longarinas de aço apoiadas nas transversinas, e os trilhos assentados sobre dormentes de madeira. $O$ tabuleiro rodoviário é constituído por vigamento metálico (transversinas e longarinas), pré-lajes de concreto com capeamento executado no local e finalmente capa asfáltica de acabamento.

MASON \& GHAVAMI (1994) apresentaram outros exemplos de pontes em estrutura de aço e mista executados no Brasil.

Muitos séculos se passaram antes que o homem desenvolvesse os cinco tipos básicos de construção de pontes: viga, balanço, arco, suspensão e treliça (TROITSKY, 1994); atualmente a constante pesquisa e

\footnotetext{
${ }^{1}$ Extraído do Relatório Técnico SET/EESC-USP.
} 
desenvolvimento dos materiais de construção, o refinamento da análise estrutural e o aprimoramento dos processos construtivos proporcionam uma infinidade de alternativas e recursos para a construção de pontes. A construção mista aço - concreto destaca-se entre estes pelas vantagens que apresenta em relação ao tempo e custo de execução e pela otimização no uso dos materiais.

\subsection{Aspectos gerais sobre pontes em vigas mistas}

De maneira geral, uma estrutura mista é constituída por materiais que possuem diferentes características mecânicas, para objeto deste trabalho entende-se por estrutura mista a viga de aço solidarizada à laje de concreto junto à mesa superior.

O princípio de funcionamento de uma ponte em vigas mistas consiste na associação da laje de concreto armado, ou protendido, às vigas metálicas que lhe servem de suporte. A associação entre vigas e laje é conseguida se os deslocamentos relativos na interface aço - concreto são impedidos ou pelo menos reduzidos consideravelmente, de maneira que exista transferência do fluxo de cisalhamento entre laje e vigas. Esta transferência de esforços se traduz em um comportamento misto do conjunto no qual, tanto as vigas de aço como a laje de concreto, atuam solidariamente para resistir às ações aumentando assim a resistência e a rigidez da ponte ( Figura 2.3).

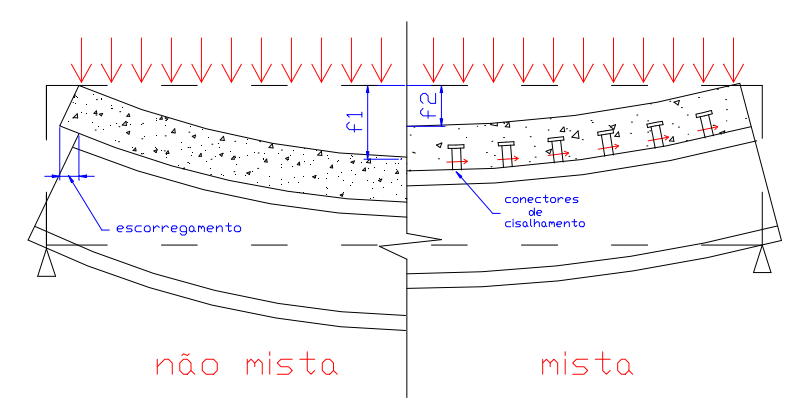

FIGURA 2.3 - Comparação entre ação não mista e mista

A limitação dos deslocamentos na interface aço - concreto é conseguida através da incorporação, mediante solda, de pequenas peças de aço no topo da mesa superior das vigas. Estas peças recebem o nome 
genérico de conectores de cisalhamento e ficam imersas na massa de concreto após a concretagem. Na figura 2.4 ilustra-se o processo de incorporação de conectores de cisalhamento tipo "stud" ${ }^{1}$ mediante pistola automática de solda.

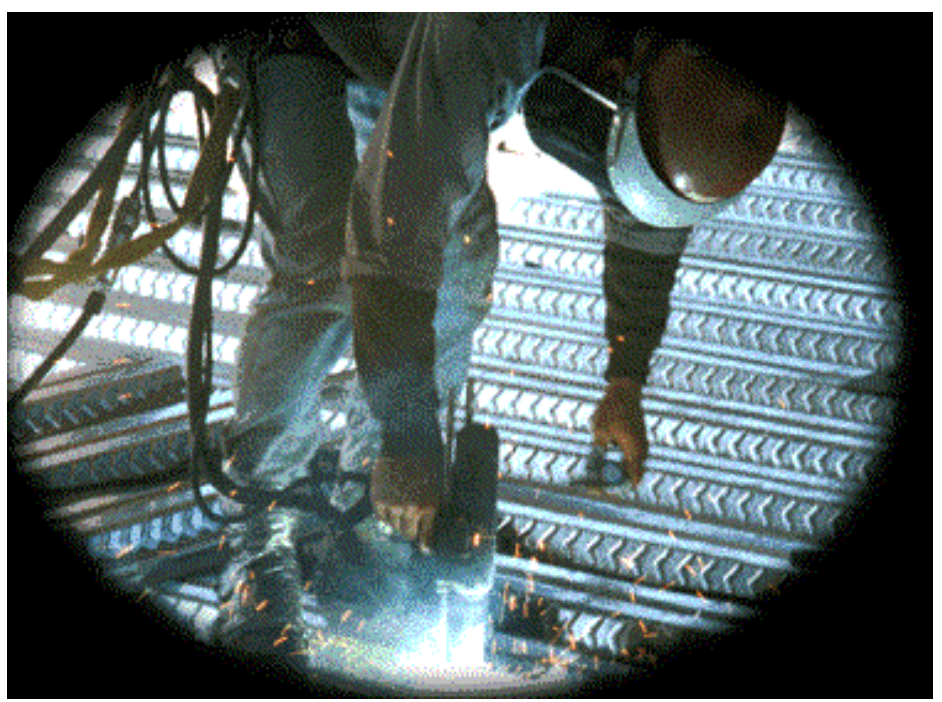

FIGURA 2.4 - Processo automatizado de incorporação de "studs" mediante pistola de solda. HACKETT\&ASSOCIATES (1998) ${ }^{2}$

A função dos conectores de cisalhamento consiste na transferência de tensões tangenciais que surgem na interface aço - concreto, fazendo com que os dois materiais trabalhem como um conjunto único. Basicamente, o tabuleiro de uma ponte em viga mista é constituído pelos seguintes elementos estruturais:

1. Vigas de aço: realizam a transferência de cargas na direção paralela ao eixo longitudinal da ponte;

2. laje de concreto: responsável pela distribuição transversal de carga, sob condições normais de utilização recebe as ações das cargas móveis;

\footnotetext{
1 "studs": conectores de cisalhamento formados por uma haste e uma cabeça. O diâmetro da haste deste tipo de conector varia entre 13 e $25 \mathrm{~mm}$ e a altura entre 65 e $100 \mathrm{~mm}$, o comprimento da haste não deve ultrapassar quatro vezes o diâmetro desta. A cabeça deste conector tem dupla função: impedir o afastamento vertical entre o aço e o concreto e melhorar a resistência do conector, estabelecendo uma melhor ancoragem no concreto circundante. Ver também JOHNSON e BUCKBY (1986).

${ }^{2}$ http//:www.hackettassociates.com
} 
3. conectores de cisalhamento: responsáveis pela ligação viga - laje e pela transferência do fluxo de cisalhamento.

A associação de dois materiais de comportamento estrutural diferente, o aço apresenta excelente resistência à tração enquanto o concreto é altamente resistente à compressão, leva a uma série de vantagens sobre estruturas que não apresentam comportamento misto, entre as mais importantes pode-se citar:

1. economia no consumo de aço, de 30 a $50 \%$ segundo OWENS \& KNOWLES (1992), pois a maior rigidez da estrutura permite a utilização de vigas de menor altura;

2. rapidez de construção em relação ao tempo de execução de tabuleiros sobre vigas de concreto moldadas no local.

A principal desvantagem que este sistema apresenta é a necessidade de incorporar conectores de cisalhamento na interface dos materiais.

Nas figuras 2.5 a 2.7 apresentam-se alguns exemplos de tabuleiros de pontes construídos em vigas mistas.

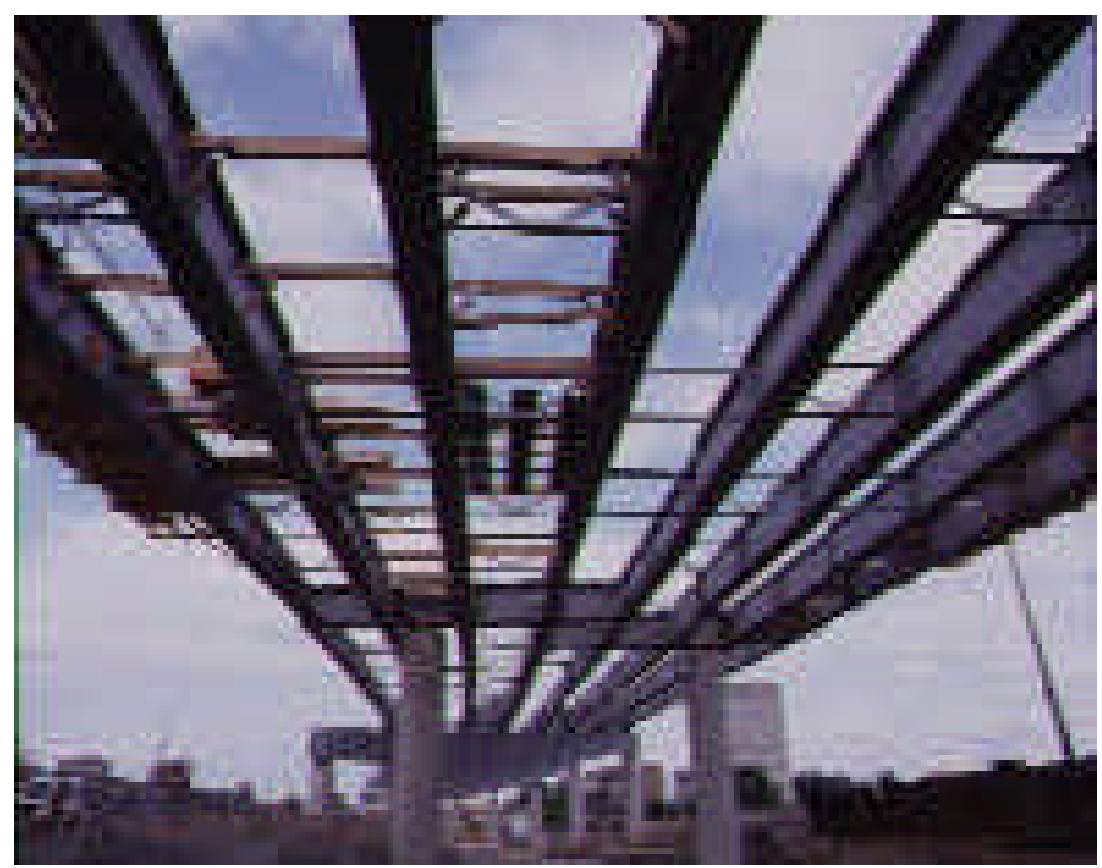

FIGURA 2.5 - Construção de viaduto em estrutura mista. HACKETT \& ASSOCIATES (1998). 


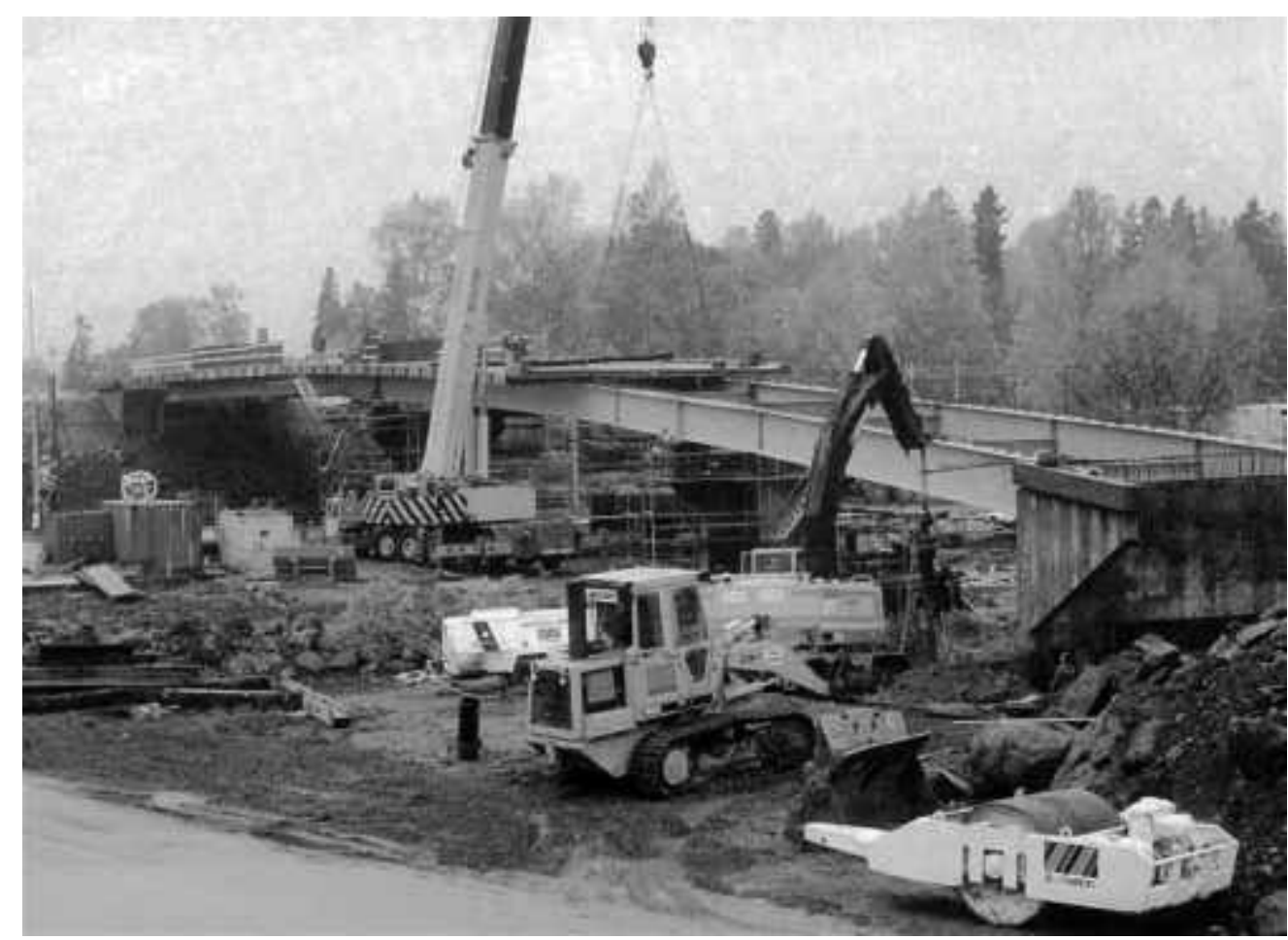

FIGURA 2.6 - Construção de viaduto em estrutura mista em Örbyhus, Suécia. COLLIN et al (1998) ${ }^{1}$

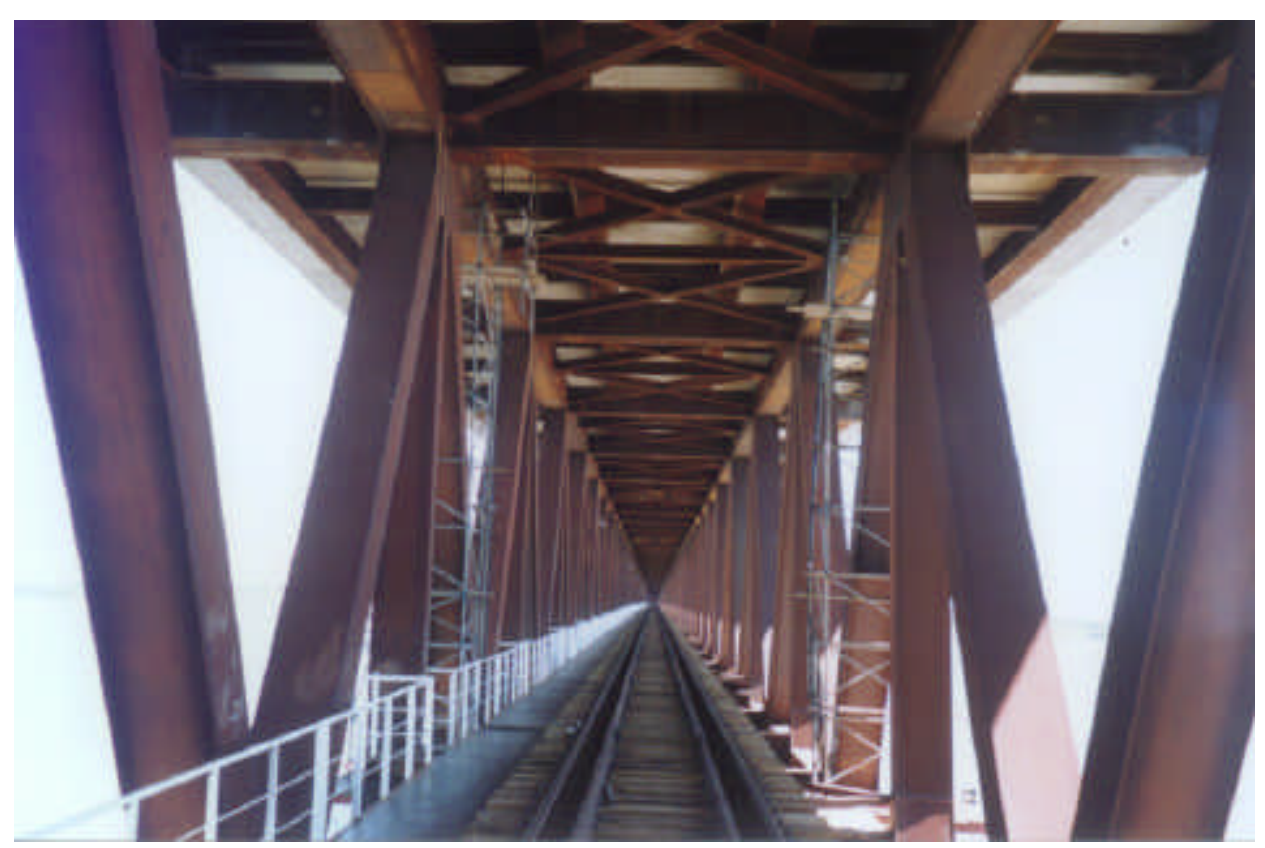

FIGURA 2.7 - Ponte rodo - ferroviária sobre o rio Paraná.

\footnotetext{
${ }^{1}$ http//:www.sbi.se/bergen4.html.
} 


\subsection{1 - Largura efetiva da laje de concreto}

A associação entre vigas e laje, por meio de conectores de cisalhamento, ocasiona uma transmissão de tensões concentradas de corte ao longo da conexão, sendo esta responsável pelo aumento de tensões normais na laje naquela região. Estas tensões diminuem gradativamente para ambos os lados conforme ilustra a figura 2.8; este fenômeno é denominado comumente na literatura por efeito de "shear lag".

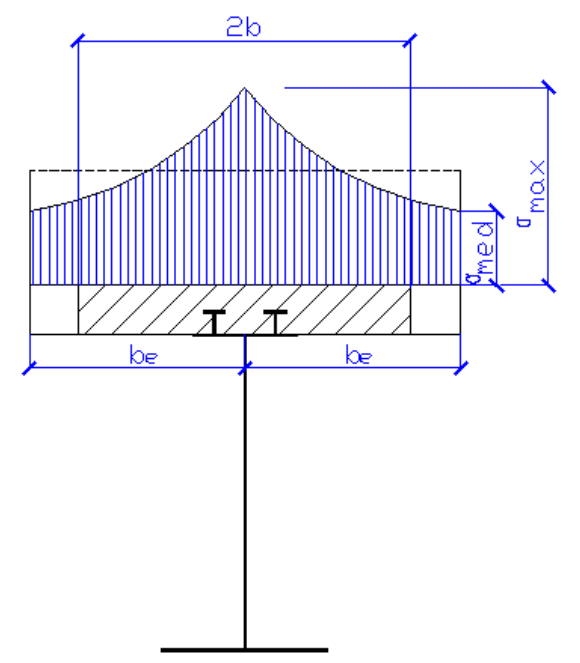

FIGURA 2.8 - Efeito de "shear lag"

Para avaliar a rigidez efetiva das vigas de aço e determinar os valores das tensões máximas, continuando a utilizar as expressões da teoria de flexão geral, é comum recorrer ao artifício de considerar vigas mistas equivalentes, com banzos de largura reduzida.

No projeto de tabuleiros mistos a largura efetiva da laje e a viga de aço formam uma viga mista aço - concreto, (Figura 2.8); a determinação analítica da largura efetiva em regime elástico implica em cálculos laboriosos e depende, entre outros, da geometria da estrutura, o tipo de carregamento, condições de apoio e armadura da laje.

$\mathrm{Na}$ prática, a largura efetiva da laje é obtida através das recomendações fornecidas pela normalização.

Para o cálculo das tensões (Figura 2.8), a largura efetiva é definida da seguinte maneira (MALITE, 1993): 


$$
\mathrm{b}=\frac{\sigma_{\mathrm{med}}}{\sigma_{\mathrm{max}}} \cdot \mathrm{b}_{\mathrm{e}}
$$

onde $\sigma_{\mathrm{m} \text { ed }}$ representa a tensão média na largura $b_{\mathrm{e}}$ e $\sigma_{\mathrm{m} \text { ax }} \mathrm{o}$ valor máximo desta.

O estudo do efeito de "shear lag" foi realizado inicialmente em estruturas de navios, sendo posteriormente aplicado a aeronaves e pontes. DOWLING \& BURGAN (1987) publicaram um estado da arte do efeito de "shear lag" neste tipo de estruturas. Os pesquisadores abordaram ainda 0 problema da determinação da parcela de laje equivalente no caso de pontes mistas com conexão parcial.

\subsection{2 - Conectores de cisalhamento}

Os conectores de cisalhamento exercem grande influência no comportamento estrutural de vigas mistas, podendo estes ser rígidos ou flexíveis.

Segundo o EUROCODE 4, parte 1-1, são conectores flexíveis aqueles que possuem deformabilidade suficiente para tornar válida a hipótese de comportamento plástico ideal da conexão na estrutura considerada.

Os conectores tipo "stud", com um comprimento total, após serem soldados, não inferiores a quatro vezes o diâmetro da haste, sendo este diâmetro compreendido entre 16 e 22 mm, podem ser considerados flexíveis dentro dos seguintes limites, segundo o grau de conexão definido pela relação $N / N_{f}$.

Para seções metálicas com abas iguais:

$$
\begin{array}{ll}
L \leq 5 & \frac{N}{N_{f}} \geq 0,4 \\
5 \leq L \leq 25 & \frac{N}{N_{f}} \geq 0,25+0,03 L
\end{array}
$$




$$
L \geq 25 \quad \frac{N}{N_{f}} \geq 1,0
$$

Para seções metálicas nas quais a aba inferior tem uma área inferior ao triplo da aba superior:

$L \leq 20$

$$
\frac{N}{N_{f}} \geq 0,4+0,03 L
$$

$L \geq 20$

$$
\frac{N}{N_{f}} \geq 1,0
$$

onde:

$L=$ vão em metros;

$N_{f}=$ número de conectores determinado segundo o item 6.2.1.1 para

o vão da viga;

$N$ = número de conectores dispostos na viga

Os seguintes tipos de conectores podem ser considerados com a mesma flexibilidade que os "studs" considerados acima:

a) parafusos protendidos dimensionados de acordo com o item 6.5 desta norma;

b) outros conectores que possuam capacidade característica de escorregamento não inferior a $6 \mathrm{~mm}$ para sua resistência característica, determinada a partir de ensaios de cisalhamento realizados de acordo ao item 10.2 do regulamento.

Os conectores de cisalhamento tipo pino com cabeça podem ser considerados como flexíveis para variações de vão superiores às dadas anteriormente se: 
a) os conectores, após soldados, possuem altura não inferior a 76 $\mathrm{mm}$ e haste com diâmetro entre 19 e 20 mm;

b) a seção metálica é laminada em I ou H com abas iguais;

c) a laje de concreto é mista com chapa nervurada perpendicular à viga e continua sobre ela;

d) existe um conector por nervura da chapa, centrado em relação a esta;

e) para a chapa nervurada $b_{o} / h_{p} \geq 2$ e $h_{p} \leq 60 \mathrm{~mm}$;

f) a força $F_{c}$ calculada segundo o item 6.2.1.1 (3) da norma.

Onde $F_{c f}$ é o menor dos seguintes valores:

$$
\begin{aligned}
F_{c f} & =\frac{A_{a} \cdot f_{y}}{\gamma_{a}} \\
F_{c f} & =\frac{0,85 \cdot A_{c} \cdot f_{c k}}{\gamma_{c}}+\frac{A_{s e} \cdot f_{s k}}{\gamma_{s}}
\end{aligned}
$$

onde:

$\mathrm{A} a$ : área do aço estrutural;

$A_{c}$ : área efetiva de concreto;

$A_{s e}$ : área de quaisquer armadura longitudinal comprimida que seja considerada no cálculo da resistência a flexão.

Estas áreas são referentes à seção transversal da viga mista no ponto de máximo momento fletor positivo.

Se as condições acima são cumpridas, a relação $\mathrm{N} / N_{f}$ deverá satisfazer: 


$$
\begin{array}{ll}
L \leq 10 & \frac{N}{N_{f}} \geq 0,4 \\
10 \leq L \leq 25 & \frac{N}{N_{f}} \geq 0,04 L \\
L \geq 25 & \frac{N}{N_{f}} \geq 1,0
\end{array}
$$

A distribuição dos conectores de cisalhamento deve ser realizada ao longo da conexão da viga de maneira a transmitir o fluxo de cisalhamento e impedir a separação entre a laje de concreto e as vigas de aço

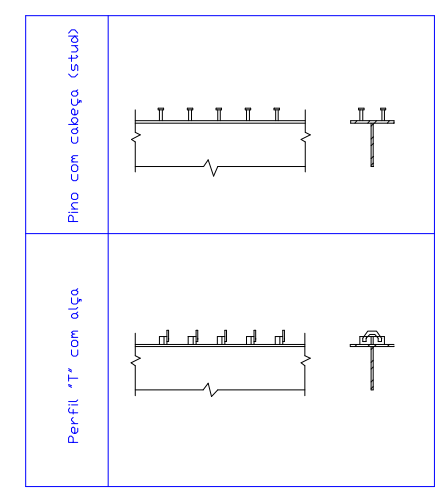

FIGURA 2.9 - Tipos de conectores de cisalhamento

O escorregamento de um determinado tipo de conector é determinado em função da resposta deste à ação do fluxo longitudinal de tensões que se gera entre o perfil de aço e a laje de concreto. Esta resposta tem sido extensamente estudada em ensaios de vigas mistas (YEN et al, 1997) e de "push-out"1 (AN et al, 1997) e caracterizada através do relacionamento entre força no conector e deslocamento relativo na interface aço - concreto.

\footnotetext{
1 "push -out": Ensaio realizado para obter a resistência ao cisalhamento dos conectores. Basicamente consiste em duas lajes apoiadas na região inferior de uma máquina de ensaio à compressão e ligadas a uma viga de aço através de conectores de cisalhamento. Na viga é aplicada uma carga axial mediante um atuador hidráulico e medido o escorregamento ocasionado na interface; através dos resultados obtidos são traçadas as curvas de força aplicada - escorregamento dos conectores. Ver também OEHLERS e COUGHLAN (1986).
} 
Na figura 2.10.a apresenta-se um modelo típico de ensaio de "push out" utilizando conectores tipo "stud"; na figura 2.10.b apresenta-se a curva experimental que caracteriza a relação existente entre força aplicada e escorregamento relativo (AN \& CEDERWALL, 1997) para concreto de alto desempenho e concreto comum, observa-se nesta figura que a resistência característica do concreto influencia na natureza da curva e que uma maior resistência deste aumenta a rigidez do conector.
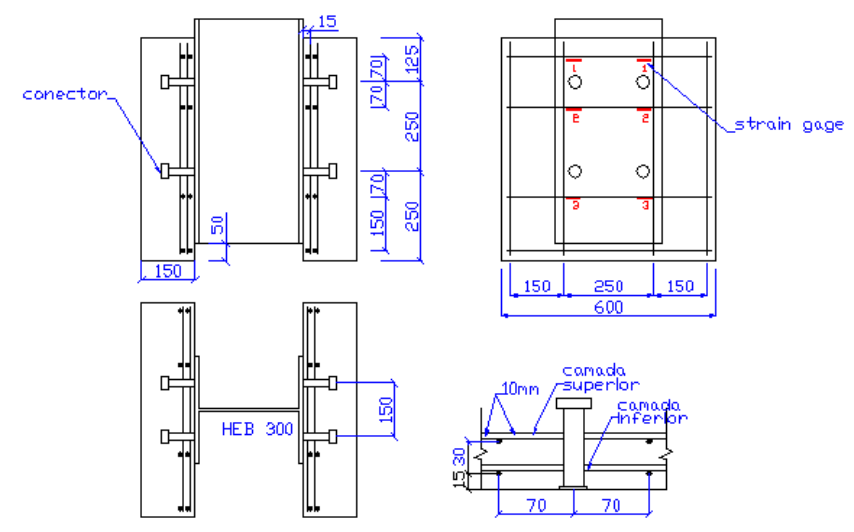

(a)

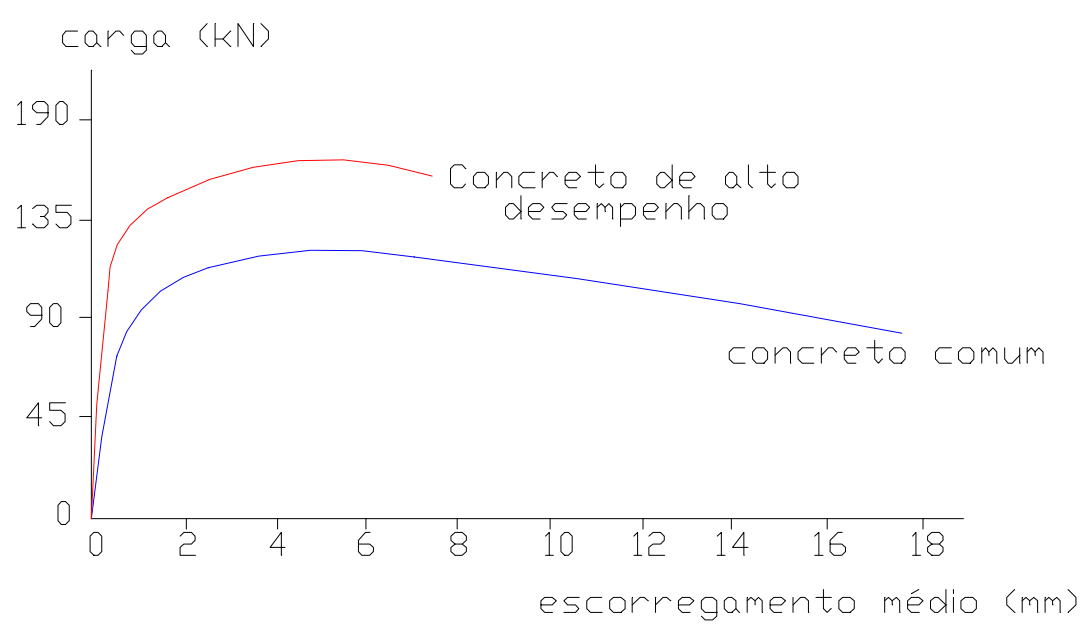

(b)

FIGURA 2.10 - a) Modelo de ensaio de "push-out"; b) curvas de força aplicada versus escorregamento.AN \& CEDERWALL (1997) para concreto de alto desempenho (CAD) e concreto comum. 


\subsection{Tipos de construção}

Uma ponte em vigas mistas pode ser construída com o uso de escoramento para as vigas de aço durante a concretagem e cura da laje. Quando isto acontece pode-se assumir que todas as cargas aplicadas são suportadas pela ação mista aço-concreto.

Se as vigas não são escoradas, estas são submetidas a tensões resultantes de cargas de peso próprio, fôrmas e peso da laje; somente após a laje atingir a resistência adequada, a viga passa a ter comportamento misto sob ação do carregamento móvel.

Ao se determinar o uso de escoramento deve-se levar em consideração a influência deste no custo global da obra e prever a possibilidade de ocorrência de recalques e assentamentos do terreno, problemas sempre presentes na construção de pontes.

Resultados publicados pelo ASCE - ACI apud XANTHAKOS (1994) mostraram que a presença ou ausência de escoramento em vigas mistas não impede que estas desenvolvam a sua resistência última à flexão. A principal influência que o escoramento exerce no comportamento das vigas é nos deslocamentos que estas sofrem.

\subsection{1 - Sistemas construtivos}

Geralmente a estrutura metálica é inicialmente montada, as vigas são posicionadas sobre os pilares mediante guindastes ou sistemas de treliças "lançadeiras" (Figura 2.11); a seguir a superestrutura de aço é aproveitada para suportar as cargas de construção da laje de concreto (Figura 2.12).

A utilização de escoramento às vezes pode resultar vantajosa pois facilita a imposição de um deslocamento inicial (contra-flecha) no sentido oposto ao de aplicação das cargas permanentes e móveis. 


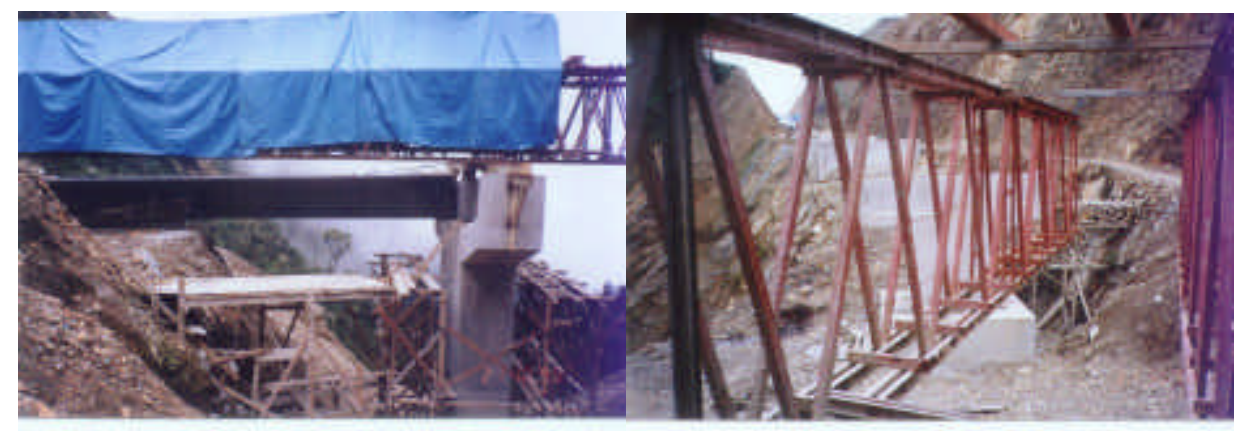

FIGURA 2.11 - Utilização de treliça para lançamento das vigas.
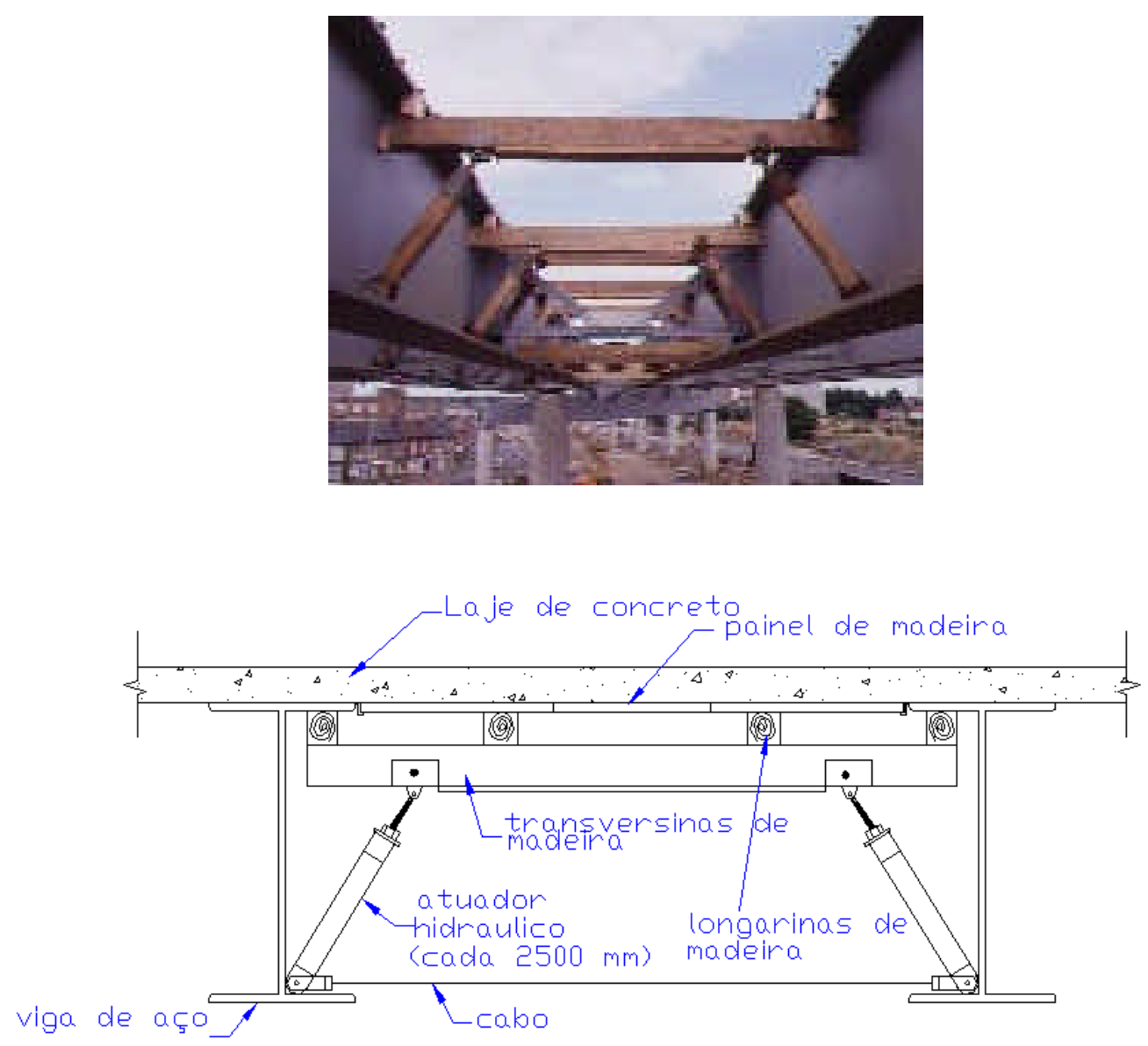

FIGURA 2.12 - Técnicas de escoramento da laje. HACKETT \& ASSOCIATES.

O escoramento da laje é indispensável quando o concreto é moldado no local (in loco). Existem ainda vários sistemas construtivos que podem ser utilizados com vantagem sobre o sistema tradicional, principalmente no 
relacionado a economia de forma e diminuição do tempo de execução; alguns destes são citados na continuação.

\section{Lajes com forma de aço incorporada ou "Steel Deck"}

Este sistema tem sido utilizado principalmente na construção mista de edifícios e consiste numa chapa de aço nervurada que serve de fôrma para realizar a concretagem da laje. Esta chapa possui na sua superfície saliências que ficam imersas na massa de concreto garantindo assim a aderência entre os dois materiais (ver Figura 2.13). A existência de aderência entre aço e concreto ocasiona que laje e fôrma se comportem como um conjunto misto, o que leva a um aumento de resistência, possibilitando consumos menores de armadura.

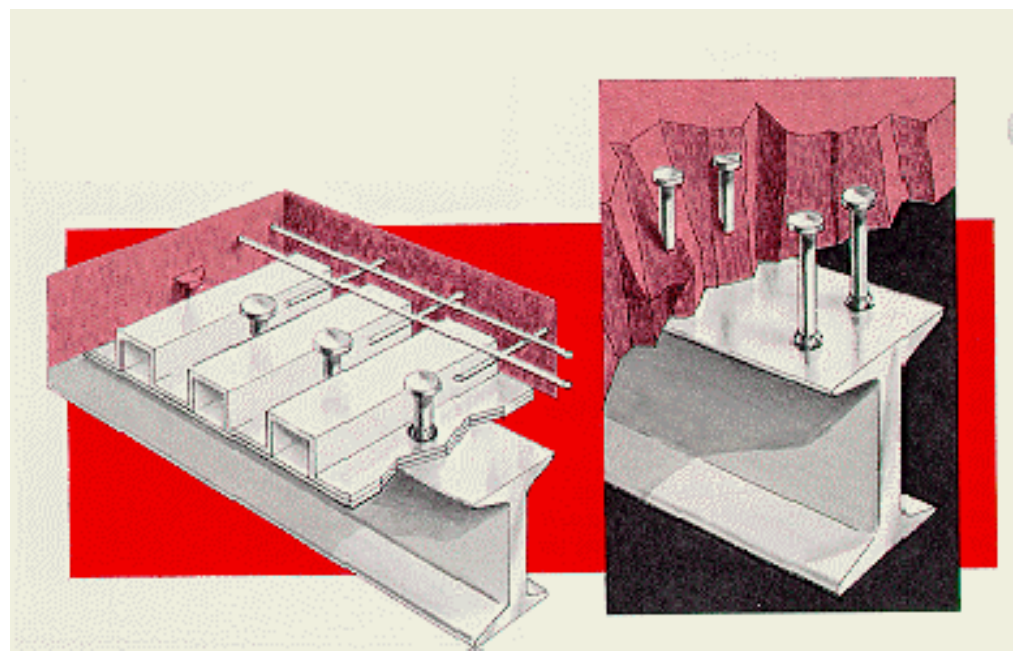

FIGURA 2.13 - Comparação entre o sistema de laje com forma de aço incorporada e o sistema tradicional - HACKETT \& ASSOCIATES

\section{Utilização de pré-lajes como forma permanente}

A utilização destes elementos elimina por completo a necessidade de utilização de formas convencionais e reduz consideravelmente os tempos de execução. As pré-lajes são posicionadas entre as vigas de aço, sendo posteriormente lançado o concreto conforme ilustrado na Figura 2.14. 


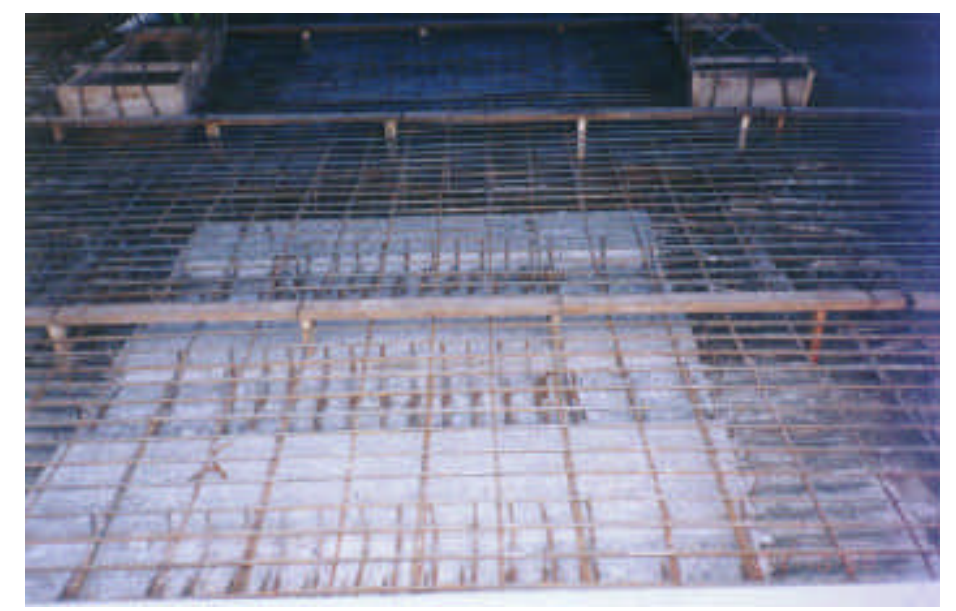

FIGURA 2.14 - Utilização de pré-lajes como formas permanentes

\section{Lajes pré-moldadas}

A utilização de elementos pré-moldados de laje reduz de maneira considerável o tempo de execução do tabuleiro. Estes elementos possuem vazios destinados a alojar os conectores de cisalhamento (Figura 2.15), estes vazios são concretados após os painéis serem posicionados adequadamente sobre as vigas.

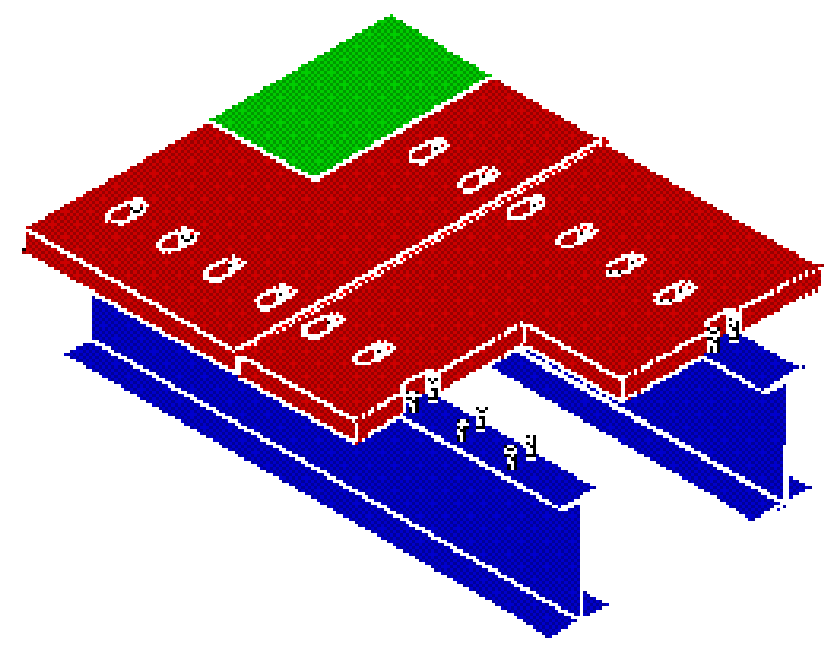

FIGURA 2.15 - Execução do tabuleiro mediante elementos pré-moldados de laje 
O principal inconveniente encontrado na utilização deste sistema consiste na ligação entre os painéis adjacentes, JOHNSON e BUCKBY (1986) apresentaram vários detalhes construtivos adotados na Europa para resolver este problema; na Figura 2.16 apresenta-se um destes.

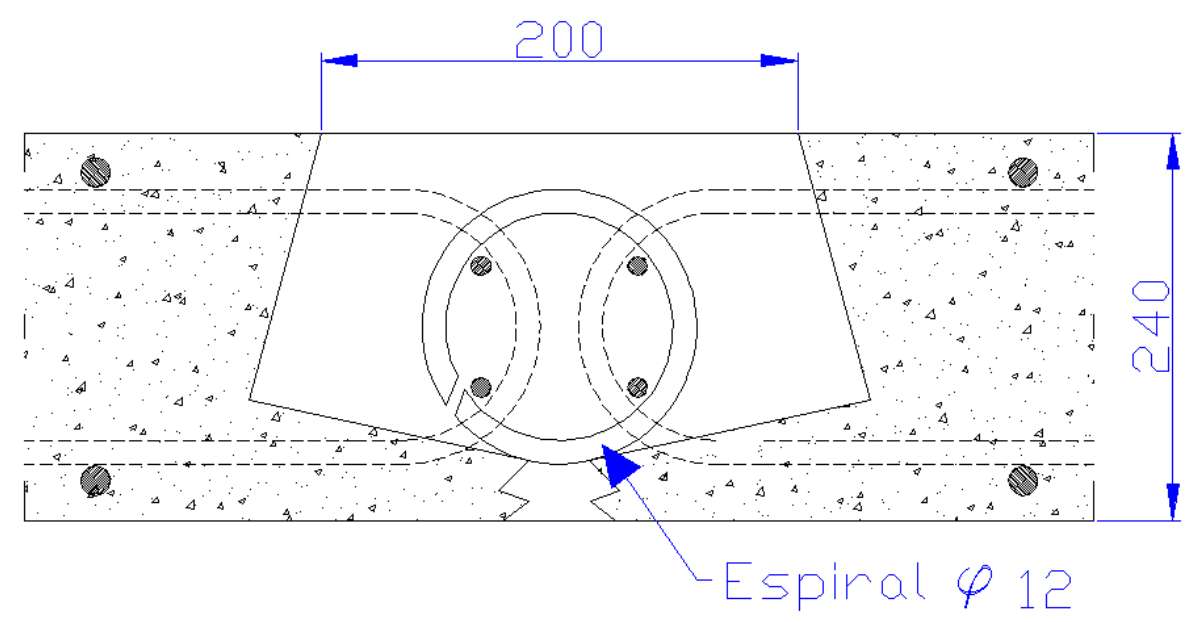

FIGURA 2.16 - Detalhe de ligação entre painéis pré - moldados. JOHNSON \& BUCKBY (1986)

\section{Sistema Steel Free Deck (Laje sem armadura)}

Este sistema de execução de tabuleiros de pontes foi apresentado por NEWHOOK et al (1997) e consiste basicamente na incorporação, mediante solda, de tirantes de aço entre as mesas superiores das vigas, conforme mostrado na Figura 2.17. Neste sistema a armadura do tabuleiro é parcial ou totalmente eliminada, restando aos tirantes auxiliar à laje na transferência de cargas para as vigas mediante efeito de arqueamento ${ }^{1}$.

\footnotetext{
${ }^{1}$ Ensaios realizados em tabuleiros de pontes mistas (CSAGOLY \& LYBAS, 1989) mostraram que a laje de concreto é capaz de transferir grandes parcelas de carga mediante efeito de arqueamento. PETROU \& PERDIKARIS (1996), após realizar vários ensaios experimentais em modelos reduzidos de tabuleiros de concreto, estabeleceram que o modo de ruptura da laje, desde que esta possua uma relação espessura-vão adequada e esteja convenientemente vinculada lateralmente, pode ser associado ao mecanismo de instabilidade de uma treliça tri-articulada e vinculada lateralmente a molas elásticas. Ver também JIANG \& SHEN (1986).
} 


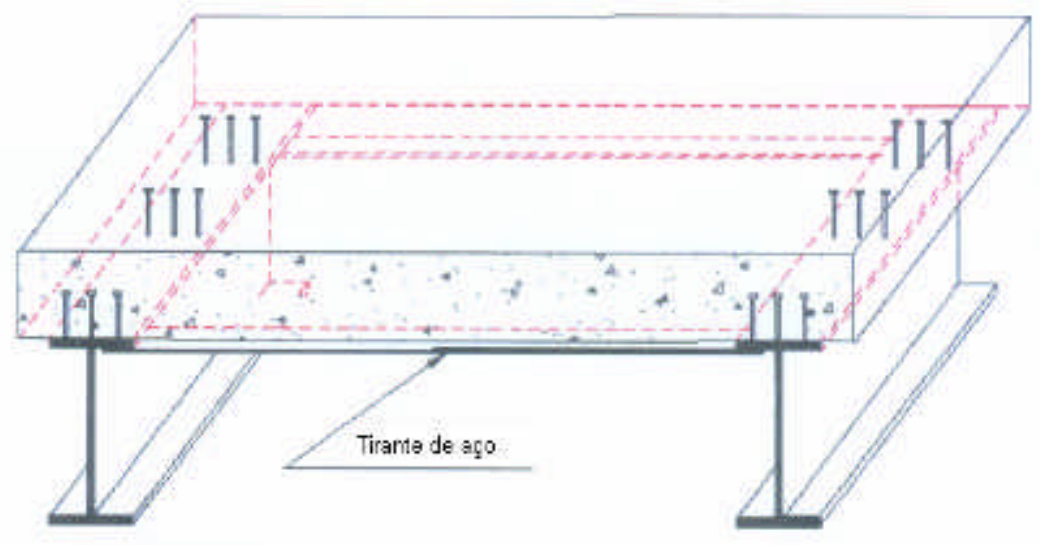

FIGURA 2.17 - Sistema Steel Free Deck. NEWHOOK et al (1997)

Sistema "tipo grelha metálica" (Exodermic Bridge Deck)

Um tabuleiro "tipo grelha metálica" é constituído basicamente por uma laje de concreto apoiada sobre uma grelha de aço (Figura 2.18). O desenvolvimento da ação mista entre laje e grelha é garantido através da ligação do concreto com dois elementos da grelha: as barras terciárias e os conectores de cisalhamento.

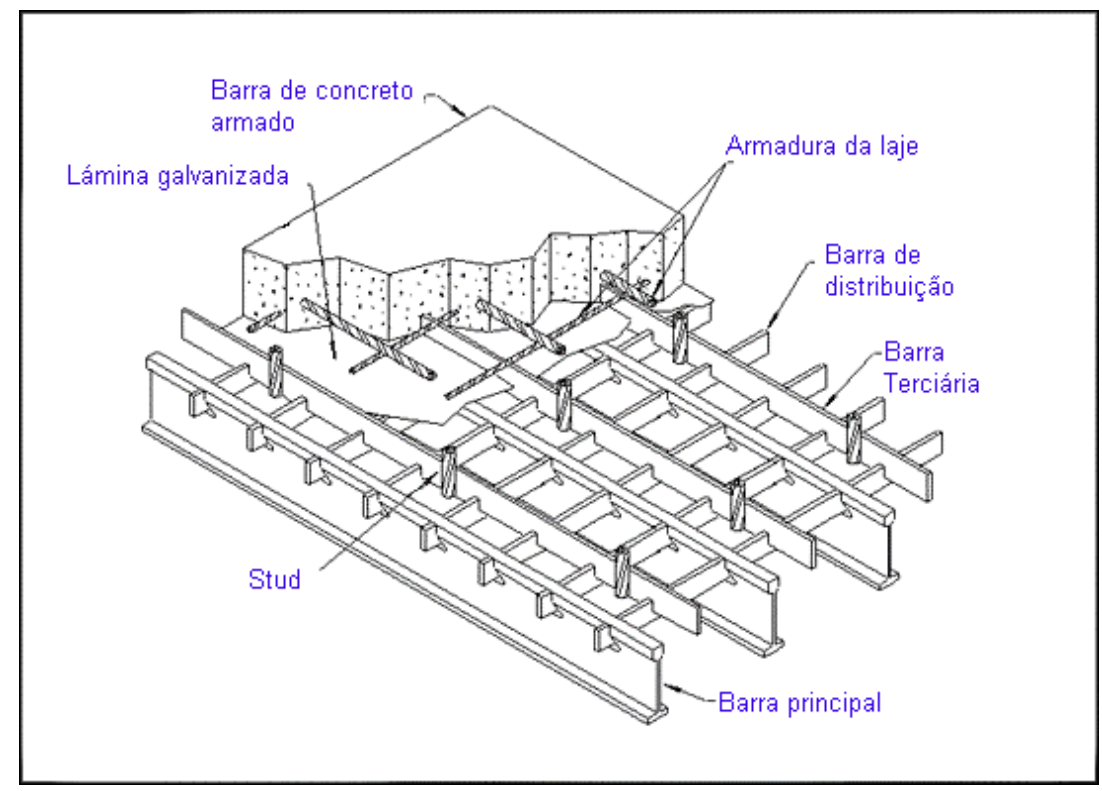

FIGURA 2.18 - Sistema "tipo grelha metálica" em tabuleiros de pontes. EXODERMICC BRIDGE DECK, INC (1999) ${ }^{1}$ 
O concreto deste tipo de tabuleiro pode ser moldado in loco ou prémoldado. Na figura 2.19 apresentam-se alguns detalhes de execução da laje utilizando estes dois sistemas.

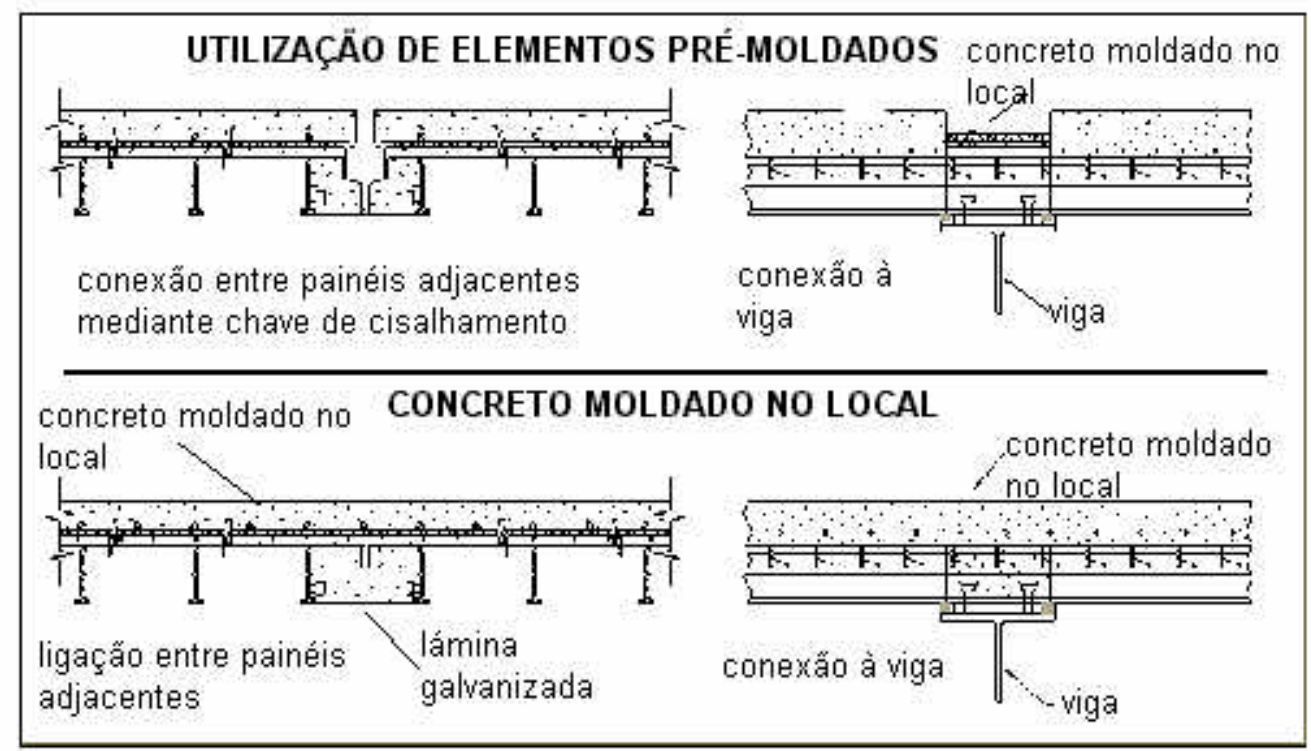

FIGURA 2.19 - Detalhes para execução da laje de tabuleiros "tipo grelha metálica". EXODERMIC BRIDGE DECK, INC (1999)

Aplicação de protensão em vigas mistas

A aplicação de protensão em vigas mistas é uma das melhores técnicas existentes para reduzir o consumo de aço na construção de tabuleiros mistos (TROITSKY, 1990). Esta técnica tem sido bastante utilizada tanto na reabilitação e reforço de pontes existentes, como na construção destas.

Embora a utilização de protensão em pontes de concreto tenha tido maior divulgação no meio técnico a nível nacional, a protensão de pontes metálicas e mistas tem sido utilizada com sucesso em países altamente industrializados como Estados Unidos, Inglaterra e Alemanha.

Na figura 2.20 apresenta-se um exemplo de aplicação de protensão em tabuleiros mistos, trata-se da ponte Lauffen (Alemanha) construída em 
1955 (TROITSKY, 1990). Esta ponte possui um só vão de $34 \mathrm{~m}$, sendo o tabuleiro constituído por duas vigas de aço sobre as quais é apoiada a laje de concreto. A protensão nas vigas foi aplicada através de quatro cabos, sendo cada um destes constituído por 52 cordoalhas de 5,3 mm de diâmetro cada uma.

A utilização de protensão nas vigas reduziu em $28 \%$ as tensões atuantes na mesa superior e em $61 \%$ as atuantes na mesa inferior.
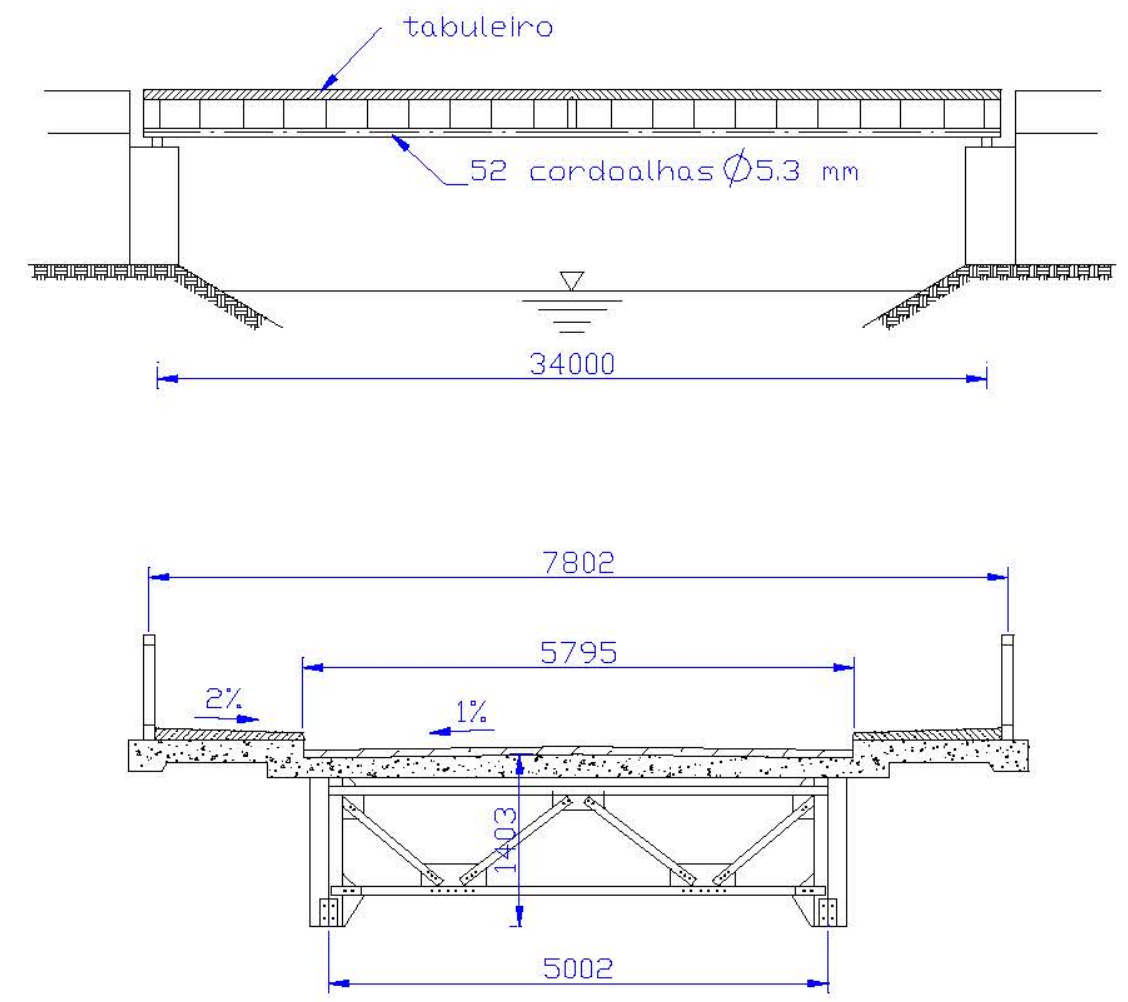

FIGURA 2.20 - Elevação e seção transversal da Ponte Lauffen, Alemanha. (TROITSKY, 1990)

$\mathrm{Na}$ figura 2.21 apresentam-se alguns detalhes construtivos das ancoragens de protensão em vigas de aço. 


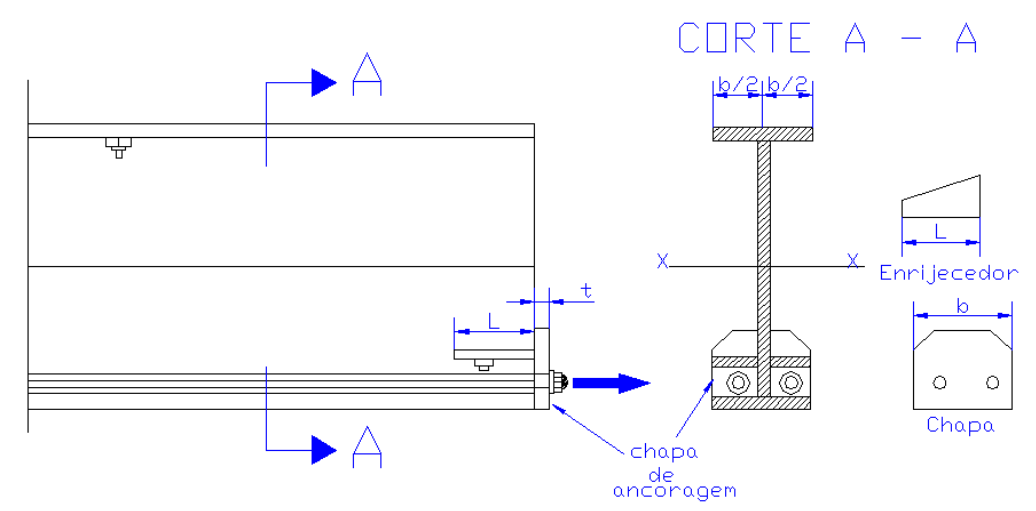

FIGURA 2.21 - Ancoragens de protensão em vigas de aço. TROITSKY (1990)

\section{3 - Normalização e materiais empregados}

As especificações publicadas sobre o projeto e execução de pontes mistas variam de um país a outro, isto deve-se em parte a que os materiais de construção são fabricados de acordo com especificações internas e que os ensaios realizados para determinar as propriedades dos materiais podem também variar.

Os fatores que talvez maior influência exercem no conceito e projeto de um sistema estrutural são a história e a geografia; JOHNSON e BUCKBY (1979) apud JOHNSON (1994), observaram que as principais diferenças existentes na concepção estrutural de pontes mistas construídas na Suíça e na Inglaterra durante a década de 1970, deviam-se principalmente à natureza do carregamento atuante, este era decorrente dos diferentes tipos de tráfego de cada país e do diferente desenvolvimento histórico dos sistemas de transportes.

\subsubsection{Materiais empregados}

Os materiais empregados na construção de pontes mistas são basicamente $\mathrm{o}$ aço e o concreto. $\mathrm{Na}$ análise estrutural de pontes $\mathrm{o}$ comportamento destes pode ser elástico ou plástico, segundo o grau de solicitação no material, o tipo e a qualidade. 


\subsubsection{1 - Aços utilizados na construção de pontes}

O aço é uma liga de ferro (98\%) com pequenas quantidades de carbono, silício, enxofre, fósforo, manganés, etc. O carbono é o componente que maior influência exerce nas propriedades do aço, podendo este ser dividido nos seguintes grupos: aços carbono, aços de baixa liga e aços patináveis; atualmente estes aços são fabricados pelas seguintes usinas nacionais:

- Companhia Siderurgica Nacional (CSN)

- Companhia Siderúrgica Paulista (COSIPA)

- USIMINAS

As usinas produzem o aço na forma de chapas e bobinas que podem ser laminados a quente ou frio, a CSN por exemplo apresenta o fluxo de produção mostrado na figura 2.22 .

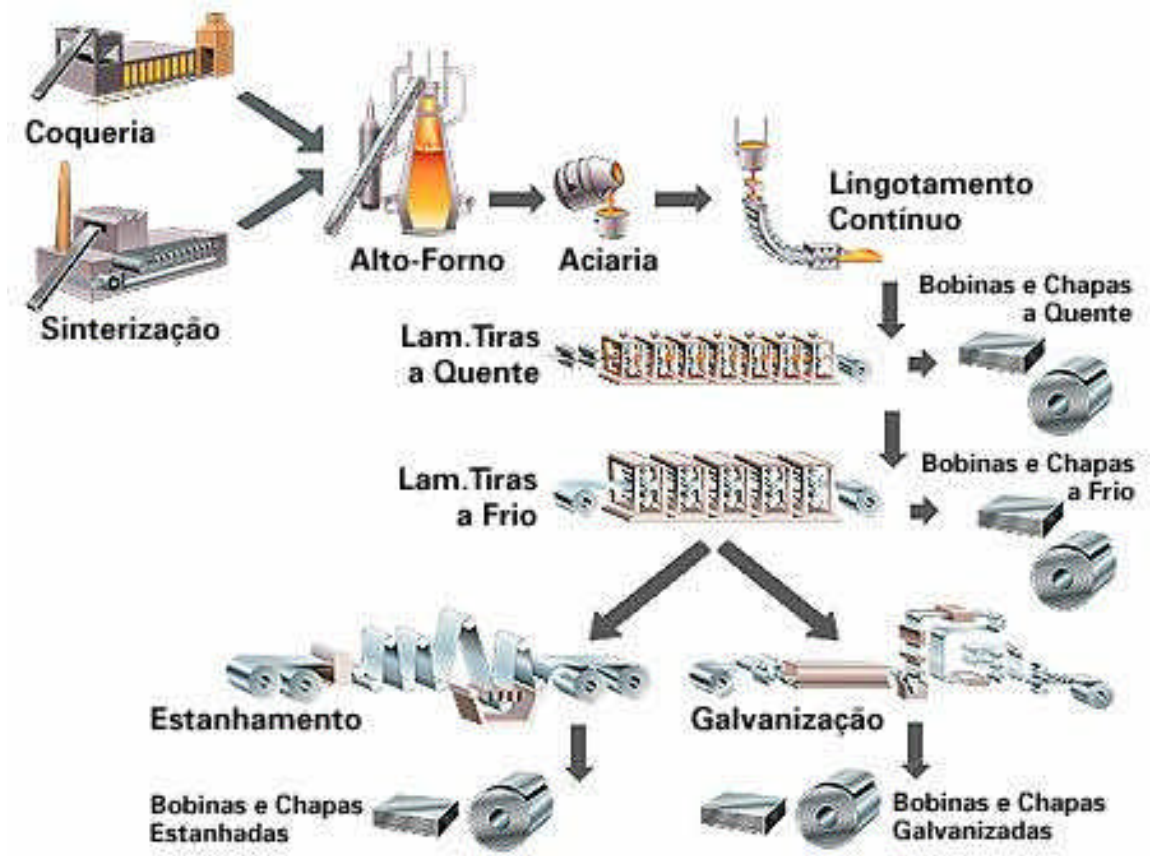

FIGURA 2.22 - Fluxo de produção de aço. CSN (1998) ${ }^{1}$

Os aços estruturais mais comumente utilizados no Brasil são os das especificações ABNT e ASTM.

\footnotetext{
${ }^{1} \mathrm{http} / /$ :www.csn.com.br
} 
Nas tabelas 2.1 e 2.2 são apresentados os tipos de aço das especificações NBR e ASTM, respectivamente, permitidos pela NBR-8800

TABELA 2.1 - Aços estruturais da série NBR permitidos pela NBR-8800

\begin{tabular}{|c|c|c|c|c|c|c|c|c|c|c|c|}
\hline \multicolumn{3}{|c|}{ NBR 7007} & \multicolumn{3}{|c|}{ NBR 6648} & \multicolumn{3}{|c|}{ NBR 6650} & \multicolumn{3}{|c|}{ NBR 5000} \\
\hline \multicolumn{3}{|c|}{$\begin{array}{l}\text { Aços para perfis laminados } \\
\text { para uso estrutural }\end{array}$} & \multicolumn{3}{|c|}{$\begin{array}{l}\text { Chapas grossas de aço } \\
\text { carbono para uso } \\
\text { estrutural }\end{array}$} & \multicolumn{3}{|c|}{$\begin{array}{l}\text { Chapas finas de aço - } \\
\text { carbono para uso estrut. } \\
\text { (a frio / quente ) }\end{array}$} & \multicolumn{3}{|c|}{$\begin{array}{l}\text { Chapas grossas de } \\
\text { aço de baixa liga e alta } \\
\text { resistência mecânica }\end{array}$} \\
\hline $\begin{array}{c}\text { Classe/ } \\
\text { Grau }\end{array}$ & $\begin{array}{c}f y \\
(\mathrm{MPa})\end{array}$ & $\begin{array}{c}\mathrm{fu} \\
(\mathrm{MPa})\end{array}$ & $\begin{array}{c}\text { Classe/ } \\
\text { Grau }\end{array}$ & $\begin{array}{c}\mathrm{fy} \\
(\mathrm{MPa})\end{array}$ & $\begin{array}{c}\mathrm{fu} \\
(\mathrm{MPa})\end{array}$ & $\begin{array}{c}\text { Classe/ } \\
\text { Grau }\end{array}$ & $\begin{array}{c}\text { fy } \\
(\mathrm{MPa})\end{array}$ & $\begin{array}{c}\mathrm{fu} \\
(\mathrm{MPa})\end{array}$ & $\begin{array}{c}\text { Classe/ } \\
\text { Grau }\end{array}$ & $\begin{array}{c}\mathrm{fy} \\
(\mathrm{MPa}) \\
\end{array}$ & $\begin{array}{c}\mathrm{fu} \\
(\mathrm{MPa}) \\
\end{array}$ \\
\hline MR - 250 & 250 & 400 & & & & & & & $G-30$ & 300 & 415 \\
\hline AR - 290 & 290 & 415 & $C G-24$ & 235 & 380 & $C F-24$ & 240 & 370 & G-35 & 345 & 450 \\
\hline AR - 345 & 345 & 450 & $C G-25$ & 255 & 410 & $C F-26$ & 260 & $400(a)$ & & & \\
\hline $\begin{array}{l}\text { AR - COR - } \\
345 \text { A ou B }\end{array}$ & 345 & 485 & & & & & & 410 (b) & & & \\
\hline
\end{tabular}

\begin{tabular}{|c|c|c|c|c|c|c|c|c|c|}
\hline \multicolumn{3}{|c|}{ NBR 5004} & \multicolumn{4}{|c|}{ NBR 5008} & \multicolumn{3}{|c|}{ NBR 5920 / NBR 5921} \\
\hline \multicolumn{3}{|c|}{$\begin{array}{l}\text { Chapas finas de aço de } \\
\text { baixa liga e alta resistência } \\
\text { mecânica }\end{array}$} & \multicolumn{4}{|c|}{$\begin{array}{l}\text { Chapas grossas de aço de baixa liga } \\
\text { e alta resistência mecânica, resistentes } \\
\text { à corrosão atmosférica, para usos } \\
\text { estruturais }\end{array}$} & \multicolumn{3}{|c|}{$\begin{array}{l}\text { Chapas finas de aço de } \\
\text { baixa liga e alta resistência } \\
\text { mecânica, resistentes à } \\
\text { corosão atmosférica p/ uso } \\
\text { estrutural (a frio / a quente ) }\end{array}$} \\
\hline $\begin{array}{l}\text { Classe/ } \\
\text { Grau }\end{array}$ & $\begin{array}{c}f y \\
(\mathrm{MPa})\end{array}$ & $\begin{array}{c}\mathrm{fu} \\
(\mathrm{MPa})\end{array}$ & $\begin{array}{c}\text { Classe/ } \\
\text { Grau }\end{array}$ & $\begin{array}{c}\text { Faixa de } \\
\text { espessura }\end{array}$ & $\begin{array}{c}\text { fy } \\
\text { (MPa) }\end{array}$ & $\begin{array}{c}\mathrm{fu} \\
(\mathrm{MPa})\end{array}$ & \begin{tabular}{c|} 
Classe/ \\
Grau
\end{tabular} & $\begin{array}{c}\mathrm{fy} \\
(\mathrm{MPa}) \\
\end{array}$ & $\begin{array}{c}\mathrm{fu} \\
(\mathrm{MPa})\end{array}$ \\
\hline $\begin{array}{l}F-32 \text { / Q32 } \\
F-32 \text { / Q35 }\end{array}$ & 310 & 410 & 1,2 e $2 A$ & $\begin{array}{c}t<=19 \\
19<t<=40 \\
40<t<=100\end{array}$ & $\begin{array}{l}345 \\
315 \\
290\end{array}$ & $\begin{array}{l}480 \\
460 \\
435\end{array}$ & \begin{tabular}{|c} 
Laminados a \\
frio / bobinas a \\
quente \\
Laminados a \\
quente (não for- \\
necidas bobinas
\end{tabular} & 340 & 480 \\
\hline
\end{tabular}

\begin{tabular}{|c|c|c|c|c|}
\hline \multicolumn{5}{|c|}{ NBR 8261} \\
\hline \multicolumn{5}{|c|}{$\begin{array}{c}\text { Perfil tubular de aço carbono formado a frio com e sem } \\
\text { costura, de seção circular,quadrada ou retangular, } \\
\text { para usos estruturais }\end{array}$} \\
\hline $\begin{array}{c}\text { Classe/ } \\
\text { Grau }\end{array}$ & \multicolumn{2}{|c|}{ seção circular } & \multicolumn{2}{|c|}{ seção quadrada ou retangular } \\
\cline { 2 - 5 } & fy (MPa) & fu (MPa) & fy (MPa) & fu ( MPa) \\
\hline B & 290 & 400 & 317 & 400 \\
C & 317 & 427 & 345 & 427 \\
\hline
\end{tabular}
(a) laminados a frio
(b) laminados a quente
(c) limitações de espessura: ver normas correspondentes 
TABELA 2.2 - Aços estruturais especificados pela ASTM e permitidos pela NBR-8800

\begin{tabular}{|c|c|c|c|c|c|c|}
\hline Classif. & Denominação & Produto & \multicolumn{2}{|c|}{ Grupo/Grau } & $\mathrm{fy}^{*}$ & $\mathrm{fu}^{\star}$ \\
\hline \multirow{3}{*}{ Carbono } & \multirow{3}{*}{$\begin{array}{l}\text { A36 - É o mais utilizado na construção de } \\
\text { estruturas metálicas podendo ser usado na } \\
\text { construção de ponte e edifícios. Este tipo } \\
\text { de aço corresponde ao M270, Grau } 36 \text { na } \\
\text { classificação da AASHTO. Possui no maxi- } \\
\text { mo } 1.65 \% \text { de manganés e cobre entre } 0.4 \\
\text { e } 0.6 \% \text {. }\end{array}$} & Perfis & \multicolumn{2}{|c|}{ Todos os grupos } & \multirow{3}{*}{25} & \multirow{3}{*}{$40-55$} \\
\hline & & Barras & \multicolumn{2}{|c|}{$\mathrm{t}<=200$} & & \\
\hline & & Chapas & \multicolumn{2}{|c|}{$\mathrm{t}<=100$} & & \\
\hline \multirow{4}{*}{$\begin{array}{l}\text { Aços de } \\
\text { baixa liga } \\
\text { e alta } \\
\text { resitência } \\
\text { mecânica }\end{array}$} & \multirow{4}{*}{$\begin{array}{l}\text { A572 -É usado onde é necessário um grau } \\
\text { de resistência maior sendo apresentado em } \\
\text { vários graus, pode ser empregado em qual- } \\
\text { quer tipo de estrutura com ligações soldadas } \\
\text { ou parafusadas. Corresponde ao aço M270, } \\
\text { Grau } 50 \text { na classificação da AASHTO. }\end{array}$} & \multirow[t]{2}{*}{ Perfis } & \multirow{2}{*}{$\begin{array}{c}\text { Todos } \\
\text { os } \\
\text { Grupos } \\
\end{array}$} & Grau 42 & 29 & 41,5 \\
\hline & & & & graus 50 & 34,5 & 45 \\
\hline & & \multirow{2}{*}{$\begin{array}{c}\text { Chapas } \\
\text { e } \\
\text { Barras }\end{array}$} & \multicolumn{2}{|c|}{ Grau $42(\mathrm{t}<=150)$} & 29 & 41,5 \\
\hline & & & \multicolumn{2}{|c|}{ Grau 50 ( t50 ) } & 34,5 & 45 \\
\hline \multirow{6}{*}{$\begin{array}{l}\text { Aços de } \\
\text { baixa liga } \\
\text { alta resist. } \\
\text { mecânica e } \\
\text { à corrosão } \\
\text { atmosférica }\end{array}$} & \multirow{4}{*}{$\begin{array}{l}\text { A588- É empregado onde se requer redução } \\
\text { de peso e maior resistência à corrosão que } \\
\text { é } 4 \text { vezes maior que a do aço carbono. Muito } \\
\text { empregado em pontes viadutos e obras es- } \\
\text { peciais, pode dispensar pintura exceto em } \\
\text { ambientes agressivos. Pode ser empregado } \\
\text { em estruturas parafusadas ou soldadas. } \\
\text { Corresponde ao aço M270 Grau 50W na cla- } \\
\text { ssificação da AASHTO. }\end{array}$} & Perfis & \multicolumn{2}{|c|}{ Todos os Grupos } & 34,5 & 48,5 \\
\hline & & Chapas & \multicolumn{2}{|c|}{$\mathrm{t}<=100$} & 34,5 & 48,5 \\
\hline & & e & \multicolumn{2}{|c|}{$100<t<=127$} & 31,5 & 46 \\
\hline & & Barras & \multicolumn{2}{|c|}{$127<t<=200$} & 29 & 43,5 \\
\hline & $\begin{array}{l}\text { A852- Contém ligas de elementos em maiores } \\
\text { quantidades que os aços carbonos, tratado a } \\
\text { quente para adquirir maior resistência e tena- } \\
\text { cidade. Corresponde ao aço M270, Grau } 70 \\
\text { W na classificação da AASHTO }\end{array}$ & Chapas & \multicolumn{2}{|l|}{ - } & 48,2 & 62,05 \\
\hline & $\begin{array}{l}\text { A-514- Tratado a quente para obter maior re- } \\
\text { sistência e tenacidade, corresponde ao aço } \\
\text { M 270, Graus 100/100W na classificação da } \\
\text { AASHTO. }\end{array}$ & Chapas & \multicolumn{2}{|c|}{$\begin{array}{l}63,5<t<150 \\
6,35<t<50\end{array}$} & $\begin{array}{l}62,05 \\
68,48\end{array}$ & $\begin{array}{c}68,48 \\
75,8-89,6\end{array}$ \\
\hline
\end{tabular}

${ }^{*} \mathrm{kN} / \mathrm{cm}^{2}$

A norma americana AASHTO na tabela 10.2A apresenta a classificação dos aços estruturais utilizados em pontes e as propriedades que estes devem apresentar. No item 10.2.2 esta norma assume que todos os graus dos aços apresentados nesta tabela possuem um módulo de elasticidade igual a 200.000 MPa. 
Durante os últimos anos tem sido desenvolvidos os aços patináveis, assim denominados devido a que na superfície é formada uma pátina ao longo do tempo que aumenta a resistência à corrosão. Na tabela 2.3 apresenta-se os aços patináveis produzidos pela COSIPA.

TABELA 2.3 - Aços patináveis produzidos pela COSIPA.

\begin{tabular}{|c|c|c|c|c|c|}
\hline PRODUTO & GRAU & ESPESSURA (mm) & fy (Mpa) & fu (Mpa) & fy a $600 \mathrm{C}(\mathrm{Mpa})$ \\
\hline $\begin{array}{c}\text { chapas finas } \\
\text { Laminadas a Frio }\end{array}$ & COS AR COR 500 & 1,30 A 2,00 & 320 & 480 & - \\
\hline $\begin{array}{c}\text { Chapas } \\
\text { Laminadas a quente }\end{array}$ & $\begin{array}{l}\text { COS AR COR } 400 \\
\cos A R \text { COR } 400 E \\
\text { COS AR COR } 500\end{array}$ & $\begin{array}{c}2,00 \text { a } 9,52 \\
2,00 \text { a } 12,50 \\
2,00 \text { a } 9,52\end{array}$ & $\begin{array}{l}250 \\
300 \\
375\end{array}$ & $\begin{array}{l}380-520 \\
380-520 \\
490-630\end{array}$ & $\begin{array}{l}- \\
-\end{array}$ \\
\hline Chapas Grossas & $\begin{array}{c}\text { COS AR COR } 400 \\
\text { COS AR COR 400E } \\
\text { COS AR COR } 500 \\
\text { COS AR COR FIRE } 500\end{array}$ & $\begin{array}{c}6,00 \text { a } 50,80 \\
6,00 \text { a } 16,00 \\
6,00 \text { a } 50,80 \\
10,00 \text { a } 32,00\end{array}$ & $\begin{array}{l}250 \\
300 \\
375 \\
375\end{array}$ & $\begin{array}{l}380-520 \\
380-520 \\
490-630 \\
490-640\end{array}$ & $\begin{array}{c}- \\
- \\
- \\
250\end{array}$ \\
\hline
\end{tabular}

Como exemplo dos aços utilizados nos conectores de cisalhamento podemos referenciar a norma inglesa, BS 5400, que apresenta as resistências nominais de três tipos de conectores de cisalhamento: pino com cabeça, perfil "U" e barra com alça. Na tabela 2.4 é reproduzida esta tabela (MALITE, 1993). 
TABELA 2.4 - Resistência dos conectores de cisalhamento segundo a BS 5400. MALITE (1993)

\begin{tabular}{|c|c|c|c|c|c|c|}
\hline \multirow{2}{*}{\multicolumn{2}{|c|}{\begin{tabular}{|l} 
Tipo de conector \\
Pino com cabeça (stud)
\end{tabular}}} & Material do conector & \multicolumn{4}{|c|}{$\begin{array}{l}\text { Resist. Nominal por } \\
\text { conector em kN, para concreto } \\
\text { de resist. fck, N/mm2 }\end{array}$} \\
\hline & & & \\
\hline Diâmetro & Altura & \multirow{9}{*}{$\begin{array}{l}\text { Tensão Escoam. = } 385 \text { Nmm2 } \\
\text { Along. } \text { Mínimo = 18\% } \\
\text { Tensão ruptura = } 495 \text { Nmm2 }\end{array}$} & 20 & 30 & 40 & 50 \\
\hline$(\mathrm{mm})$ & $(\mathrm{mm})$ & & & & & \\
\hline & & & & & & \\
\hline 25 & 100 & & 139 & 154 & 168 & 183 \\
\hline 22 & 100 & & 112 & 126 & 139 & 153 \\
\hline 19 & 100 & & 90 & 100 & 109 & 119 \\
\hline 19 & 75 & & 78 & 87 & 96 & 105 \\
\hline 16 & 75 & & 66 & 74 & 82 & 90 \\
\hline 13 & 65 & & 42 & 47 & 52 & 57 \\
\hline \multicolumn{2}{|c|}{ Barra com alça $(\mathrm{mm})$} & Grade $43 \mathrm{da}$ & & & & \\
\hline \multicolumn{2}{|c|}{$50 \times 40 \times 200$} & BS4360: 1972 & 697 & 830 & 963 & 1096 \\
\hline \multicolumn{2}{|c|}{$25 \times 25 \times 200$} & & 348 & 415 & 482 & 548 \\
\hline \multicolumn{2}{|c|}{ Perfil "U" (mm) } & Grade $43 \mathrm{da}$ & & & & \\
\hline \multirow{2}{*}{\multicolumn{2}{|c|}{$\begin{array}{l}127 \times 64 \times(14,90) \times 150 \\
102 \times 51 \times(10,42) \times 150\end{array}$}} & BS 4360: 1972 & 351 & 397 & 419 & 442 \\
\hline & & & 293 & 337 & 364 & 390 \\
\hline \multicolumn{2}{|c|}{$76 \times 38 \times(6,70) \times 150$} & & 239 & 283 & 305 & 326 \\
\hline
\end{tabular}

\subsection{3 - Concreto}

A norma americana AASHTO considera na divisão II, item 4.5, oito classes de concreto cujas resistências à compressão variam de 1,5 a 2,75 $\mathrm{kN} / \mathrm{cm}^{2}$, segundo a finalidade estrutural do elemento. A tabela 4.1 desta norma apresenta as exigências em relação à proporção água - cimento, porosidade, tamanho do agregado, etc. que cada tipo de concreto deve satisfazer. No item 8.7 estabelece os valores do módulo de elasticidade e de poisson do concreto.

No Brasil o concreto estrutural deve satisfazer as especificações estabelecidas pela NBR-6118.

\subsection{4 - Desenvolvimento de novos materiais}

Atualmente vem sendo realizada uma extensa pesquisa no desenvolvimento de novos materiais, embora muitos destes consistem na 
otimização do concreto de alto desempenho (CAD) e dos aços de alta resistência mecânica e à corrosão.

O concreto de alto desempenho, desenvolvido na atualidade, pode alcançar resistências superiores aos $100 \mathrm{MPa}$ (CEB), sendo sua principal característica a maior durabilidade que apresenta em relação ao concreto comum.

O melhoramento nos processos de produção e fabricação do aço, assim como na execução de conexões e tratamentos de proteção, permitem que o material apresente maior resistência mecânica, à corrosão e à fadiga. Aços facilmente soldáveis e novos processos de soldagem podem reduzir consideravelmente os custos de execução que, associados à maior ductilidade e tenacidade do material, viabilizam cada vez mais a sua utilização na construção de pontes. Estes aços associados a outros materiais como polímeros, concreto e cabos de protensão viabilizam inúmeras técnicas de execução que otimizam os processos construtivos tradicionais, com a conseguinte redução de custos.

Polímeros reforçados com fibra (FRP) apresentam a vantagem de serem mais leves, minimizando o peso próprio em pontes de grandes vãos e oferecendo maior resistência à ação deletéria do meio ambiente. As principais vantagens da utilização destes materiais em tabuleiros de pontes são: diminuição de peso próprio, resistência à corrosão e possibilidade de pré-fabricação em unidades modulares que permitem rapidez de montagem sem a necessidade de escoramento ou formas. PODOLNY (1998) estabeleceu que podem ser alcançadas economias de execução de até $80 \%$ utilizando este novo tipo de material em tabuleiros de pontes.

Embora os novos materiais desenvolvidos possuam maior resistência, durabilidade e menor peso, estes podem apresentar o problema de instabilidade local ou global em função da adoção de seções transversais menores que levam a uma diminuição de rigidez. Sem dúvida alguma, existe um ponto em que torna-se simplesmente inviável aproveitar ao máximo as vantagens destes materiais em virtude de que os limites de utilização são excedidos, ou do risco da estrutura tornar-se instável. Estes problemas são 
superados através de soluções estruturais inovadoras que emergem com o uso de novas tecnologias. 


\section{AÇÕES E SOLICITAÇÕES}

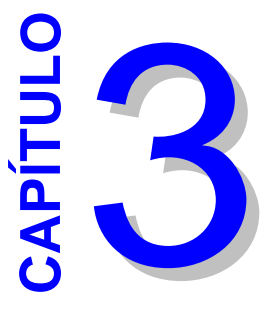

A principal característica das ações que atuam em pontes é que estas possuem variada natureza, a forma em que atuam e a intensidade máxima podem variar em função da geografia, tipo de utilização, estação do ano, etc. A determinação das cargas e a compreensão de como estas são aplicadas e distribuídas até os apoios e fundações, constitui um dos aspectos mais importantes na análise e dimensionamento de tabuleiros de pontes.

Determinar as ações que provocam solicitações no tabuleiro constitui um problema complicado, cuja solução deveria ser obtida através de estudos probabilísticos que considerem parâmetros como densidade de tráfego, tipos de veículos, vias de circulação, vão, vento, neve, sismo, etc.

De maneira resumida, as ações podem ser enumeradas da seguinte maneira:

- Ações permanentes: peso próprio, pavimentação, barreiras de proteção, passeios para pedestres, guarda - rodas e demais acessórios;

- Ações de utilização: cargas móveis que provocam efeitos de fadiga, impacto vertical e esforços longitudinais de aceleração e frenagem;

- Ações provocadas por elementos naturais: pressões e deslocamentos ocasionados pela água, ar e terra;

- Deformações internas: variações de temperatura, retração e fluência do concreto. 
Neste trabalho resulta inviável revisar de maneira detalhada cada uma das ações mencionadas, razão pela qual serão abordadas apenas as cargas móveis, e os efeitos de temperatura, retração, fluência e fadiga; maiores detalhes sobre outras ações podem ser encontrados em EL DEBS \& TAKEYA (1995).

\section{1 - Cargas móveis}

São denominadas assim as cargas ocasionadas pela passagem de veículos ao longo do tabuleiro. Na prática resulta inviável considerar num mesmo projeto todos os tipos de veículos que circulam ao longo do vão, por este motivo os regulamentos tem adotado um carregamento representativo denominado trem tipo; a natureza deste pode sofrer variações notáveis de um país a outro.

De maneira a garantir a segurança da estrutura, deve ser realizado algum tipo de controle para evitar a passagem de veículos com excessos de carga, pelo geral cada país estabelece através de órgãos públicos as cargas máximas legais para cada tipo de veículo.

$\mathrm{Na}$ tabela 3.1 apresenta-se uma comparação entre os trens tipos adotados em diferentes países. 
TABELA 3.1 - Comparação entre trens tipos utilizados em diferentes países.

\begin{tabular}{|c|c|c|c|c|c|c|c|c|c|c|c|c|c|c|c|c|c|c|}
\hline País & $\begin{array}{l}\text { Tipo de } \\
\text { Carga }\end{array}$ & $\mathrm{N} 1$ & N2 & D & A1 & A2 & $P$ & S & $\mathrm{P} 1$ & P2 & P3 & P4 & P5 & d1 & d2 & d3 & $\mathrm{d} 4$ & Observaçãoes \\
\hline $\begin{array}{l}\text { Alemanha } \\
\text { Ocidental }\end{array}$ & Classe 60 & 3 & 2 & 2 & 0,6 & 0,2 & 600 & 3 & 200 & 200 & 200 & - & - & 1,5 & 1,5 & - & - & $\begin{array}{l}\text { Veículo ocupa uma superfície } \\
6,0 \times 3,0 \mathrm{~m} \text {. Resto da vía } \\
5 \mathrm{kN} / \mathrm{m} 2 \text {, outras vias } 3 \mathrm{kN} / \mathrm{m} 2\end{array}$ \\
\hline Brasil & $\begin{array}{l}\text { Classe } 45 \\
\text { Classe } 30 \\
\text { Classe } 12\end{array}$ & $\begin{array}{l}3 \\
3 \\
2\end{array}$ & $\begin{array}{l}2 \\
2 \\
2\end{array}$ & $\begin{array}{l}2 \\
2 \\
2\end{array}$ & $\left|\begin{array}{c}0,5 \\
0,4 \\
0,2(1)\end{array}\right|$ & $\begin{array}{l}0,2 \\
0,2 \\
0,2\end{array}$ & $\begin{array}{l}450 \\
300 \\
120\end{array}$ & $\begin{array}{l}3 \\
3 \\
3\end{array}$ & $\begin{array}{c}150 \\
100 \\
40\end{array}$ & $\begin{array}{l}150 \\
100 \\
80\end{array}$ & $\begin{array}{c}150 \\
100 \\
-\end{array}$ & $\begin{array}{l}- \\
- \\
-\end{array}$ & $\begin{array}{l}- \\
- \\
-\end{array}$ & $\begin{array}{c}1,5 \\
1,5 \\
3\end{array}$ & $\begin{array}{l}1,5 \\
1,5 \\
-\end{array}$ & $\begin{array}{l}- \\
- \\
-\end{array}$ & $\begin{array}{l}- \\
- \\
-\end{array}$ & $\begin{array}{l}\text { Veículo ocupa uma superfície } \\
6,0 \times 3,0 \mathrm{~m} \text {. Resto da vía } \\
5 \mathrm{kN} / \mathrm{m} 2 \text { para os tipos } 45 \text { e } 30 \\
\text { e } 4 \mathrm{kN} / \mathrm{m} 2 \text { para o tipo } 12 \text {. Nos paseios } \\
\text { adota-se } 3 \mathrm{kN} / \mathrm{m} 2 \text { para todos. }\end{array}$ \\
\hline Espanha & - & 3 & 2 & 2 & 0,6 & 0,2 & 600 & 3,5 & 200 & 200 & 200 & - & - & 1,5 & 1,5 & - & - & $\begin{array}{l}\text { A carga do veículo soma-se } \\
4 \mathrm{kN} / \mathrm{m} 2 \text { em todas as vias } \\
\text { de circulação }\end{array}$ \\
\hline França & $\mathrm{BC}$ & 3 & 2 & - & - & - & 300 & 3 & 60 & 120 & 120 & - & - & 4,5 & 1,5 & - & - & $\begin{array}{l}\text { São dispostos dois veículos } \\
\text { separados } 10,50 \mathrm{~m} .\end{array}$ \\
\hline $\begin{array}{l}\text { Reino } \\
\text { Unido } \\
\end{array}$ & $\mathrm{HB}$ & 4 & 4 & 0,9 & 0,37 & 0,07 & 1800 & 3 & 450 & 450 & 450 & 450 & - & 4,5 & 1,5 & - & - & $\begin{array}{l}\text { Este veículo considera-se } \\
\text { com um } 1 / 3 \text { da carga HA nas } \\
\text { outras vías. }\end{array}$ \\
\hline Itália & - & - & - & - & - & - & - & 3,5 & - & - & - & - & - & - & - & - & - & $\begin{array}{l}\text { Não especifica veículo } \\
\text { extraordinário. }\end{array}$ \\
\hline
\end{tabular}

\section{P1 P2 P3 P4 P5 \\ $\begin{array}{llll}\text { d1 } & \text { d2 } & \text { d3 } & \text { d4 }\end{array}$}

Notas:

N1: Número de eixos

N2: Número de rodas por eixo

S: largura da via $(\mathrm{m})$

D: separação transversal entre rodas
A1: largura de contato da roda $(\mathrm{m})$

A2: Comprimento de contato da roda $(\mathrm{m})$ $\mathrm{P}$ : carga total $(\mathrm{kN})$

$\mathrm{Pi}(\mathrm{kN}), \mathrm{i}=1,2, \ldots, 5$

di $(m), i=1,2, \ldots, 5$ 
TABELA 3.1 (continuação) - Comparação entre trens tipos utilizados em diferentes países.

\begin{tabular}{|c|c|c|c|c|c|c|c|c|c|c|c|c|c|c|c|c|c|c|}
\hline País & $\begin{array}{c}\text { Tipo de } \\
\text { Carga }\end{array}$ & $\mathrm{N} 1$ & N2 & D & A1 & A2 & $P$ & $S$ & P1 & P2 & P3 & P4 & P5 & d1 & d2 & d3 & $\mathrm{d} 4$ & Observaçãoes \\
\hline Japão & $\mathrm{T}-20$ & 2 & 2 & 1,75 & $\begin{array}{c}0,12 \\
0,5\end{array}$ & $\begin{array}{l}0,2 \\
0,2\end{array}$ & 200 & 2,75 & 40 & 160 & - & - & - & 40 & - & - & - & $\begin{array}{l}\text { A carga T é apenas utilizada } \\
\text { para lajes. O veículo principal } \\
\text { seguidos por outros com } \\
\text { fator } 0,75, \text { separados } 14,0 \mathrm{~m}\end{array}$ \\
\hline $\begin{array}{c}\text { Nova } \\
\text { Zelanda }\end{array}$ & |120-S16-T1 & 5 & 2 & 1,8 & - & - & 462 & 3 & 36,3 & 14,5 & 14,5 & 72,5 & 72,5 & 4,3 & 4,27 & 4,3 & 3,7 & $\begin{array}{l}\text { Veículo considerado sobre cada } \\
3 \text { m de via. Para veículo com carga } \\
\text { excepcional, considera-se } 100 \% \\
\text { da sobrecarga em apenas uma via }\end{array}$ \\
\hline Suécia & - & 5 & - & - & - & 3 & 100 & 3 & 200 & 200 & 200 & 200 & 200 & 3 & 1,5 & 1,5 & 3 & $\begin{array}{l}\text { A posição transversal do } \\
\text { veículo depende da largura } \\
\text { da via. Eixos das rodas são } \\
\text { distribuídos uniformemente }\end{array}$ \\
\hline Rússia & NK-80 & 4 & 2 & 2,7 & 0,8 & 0,2 & 800 & 3 & 200 & 200 & 200 & 200 & - & 1,2 & 1,2 & 1,2 & - & $\begin{array}{l}\text { Cargas nas calçadas de } 7 \\
\mathrm{kN} / \mathrm{m} 2 \text { e carga concebtrada } \\
\text { de } 3 \mathrm{kN}\end{array}$ \\
\hline $\begin{array}{l}\text { Estados } \\
\text { Unidos }\end{array}$ & $\begin{array}{l}\text { HS20-44 } \\
\text { HS15-44 } \\
\text { H20-44 } \\
\text { H15-44 }\end{array}$ & $\begin{array}{l}3 \\
3 \\
2 \\
2\end{array}$ & $\begin{array}{l}2 \\
2 \\
2 \\
2\end{array}$ & $\begin{array}{l}1,8 \\
1,8 \\
1,8 \\
1,8\end{array}$ & $\begin{array}{l}- \\
- \\
-\end{array}$ & $\begin{array}{l}- \\
- \\
-\end{array}$ & $\begin{array}{l}326 \\
242 \\
178 \\
134\end{array}$ & $\begin{array}{l}3 \\
3 \\
2 \\
27\end{array}$ & $\begin{array}{c}36 \\
28 \\
36 \\
107\end{array}$ & $\begin{array}{c}145 \\
107 \\
142 \\
-\end{array}$ & $\begin{array}{c}145 \\
107 \\
- \\
-\end{array}$ & $\begin{array}{l}- \\
- \\
-\end{array}$ & $\begin{array}{l}- \\
- \\
-\end{array}$ & $\begin{array}{l}4,3 \\
4,3 \\
4,3 \\
4,3\end{array}$ & $\begin{array}{c}4,27-9 \\
4,27-9 \\
- \\
-\end{array}$ & $\begin{array}{l}- \\
- \\
-\end{array}$ & $\begin{array}{l}- \\
- \\
-\end{array}$ & $\begin{array}{l}\text { Um comboiop por via de circu- } \\
\text { lação. A distância entre as as duas } \\
\text { rodas trraseiras pode variar entre } \\
4,29 \text { e } 9 \mathrm{~m} \text {. Os veículos podem ser } \\
\text { substituídos por uma carga } \\
\text { distribuida e uma concentrada. }\end{array}$ \\
\hline
\end{tabular}

\section{P1 P2 P3 P4 P5 \\ $\begin{array}{llll}\text { d1 } & \text { d2 } & \text { d3 } & \text { d4 }\end{array}$}

Notas:

N1: Número de eixos

N2: Número de rodas por eixo

$\mathrm{S}$ : largura da via $(\mathrm{m})$

D: separação transversal entre rodas
A1: largura de contato da roda $(\mathrm{m})$

A2: Comprimento de contato da roda $(\mathrm{m})$

$\mathrm{Pi}(\mathrm{kN}), \mathrm{P}$ : carga total $(\mathrm{kN})$

di $(\mathrm{m}), \mathrm{i}=1,2$, 
O percurso de veículos em tabuleiros de pontes ocasiona efeitos dinâmicos que produzem vibrações e efeitos de deslocamento e solicitação, maiores que os que seriam ocasionados por cargas estáticas equivalentes, principalmente se a superfície do tabuleiro é irregular. Forças de natureza humana entram também dentro da classificação de cargas móveis, constituindo uma importante fonte de excitação dinâmica; pedestres caminhando, marchando ou correndo podem ocasionar vibrações de ordem importante.

O estudo do comportamento dinâmico de tabuleiros de pontes mistas tem sido abordado por SMITH (1988), WANG et al (1993), HUANG et al (1992), CHANG et al (1994). A maioria destes estudos consistem na determinação da influência que a rugosidade da pista, massa do veículo, sistema de suspensão, etc, exercem na resposta da estrutura e na determinação de coeficientes de impacto que permitam simplificar a análise estrutural.

Apesar da natureza do problema ser puramente dinâmica, os regulamentos consideram as cargas móveis através de um incremento da carga estática. De maneira geral, a ponte é analisada localizando o veículo em diferentes partes do tabuleiro e multiplicando as solicitações calculadas por um coeficiente de impacto; este coeficiente é determinado a partir de valores obtidos experimentalmente e de modelagens de veículos e pontes utilizadas em estudos analíticos.

$\mathrm{Na}$ tabela 3.2 apresentam-se as especificações que alguns regulamentos fornecem para a determinação do coeficiente de impacto. 
TABELA 3.2 - Coeficientes de impacto

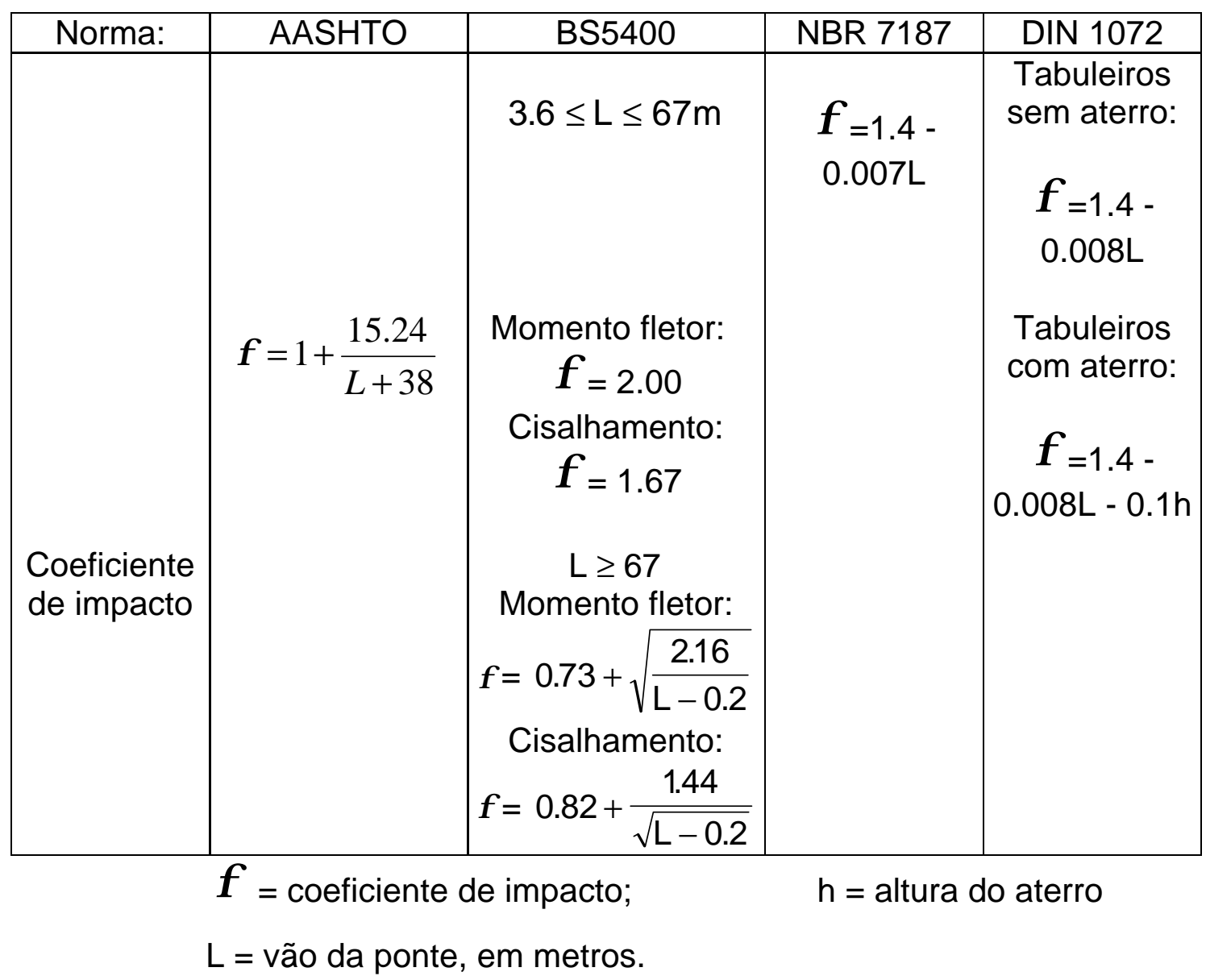

Nas análises realizadas neste trabalho as ações de carga móvel foram majoradas mediante coeficientes de impacto conforme as recomendações da NBR 7187.

\section{2 - Efeitos de temperatura}

A grande diferença entre as condutividades térmicas do concreto e do aço pode ocasionar gradientes elevados de temperatura em uma mesma seção transversal. Uma das principais interrogações sobre este assunto tem sido a forma em que a temperatura é distribuída ao longo da altura do tabuleiro. 
SIMKO (1979) apud FU \& CHEUNG (1990), realizou estudos experimentais para determinar a maneira em que a temperatura é distribuída na seção transversal de um tabuleiro misto. Para isto foi construído um modelo reduzido (escala 0,354) do tabuleiro da ponte sobre o rio Red, Canadá. A experiência consistiu no resfriamento da laje através da aplicação de gelo, numa sala com temperatura constante a $25^{\circ} \mathrm{C}$.

$\mathrm{Na}$ figura 3.1 ilustra-se a seção transversal do modelo reduzido analisado e a distribuição de temperaturas obtidas ao longo da seção.

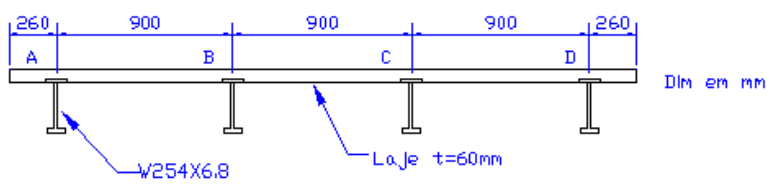

Seçao transversal do modelo reduzldo

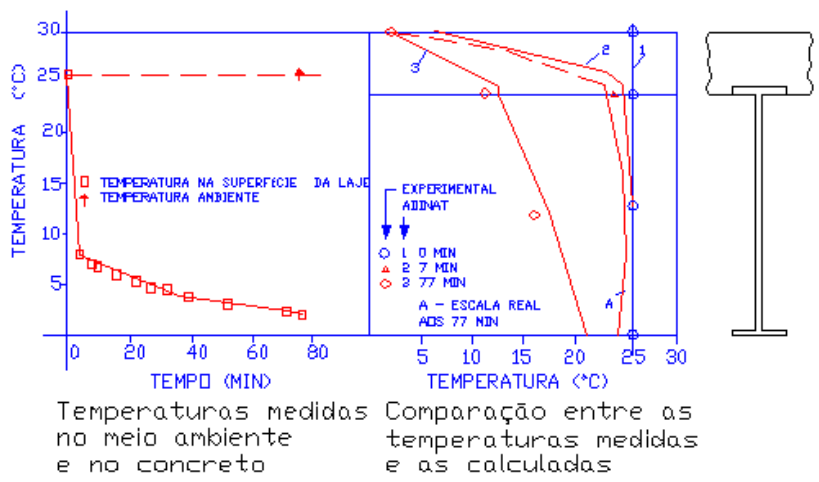

FIGURA 3.1 - Modelo analisado e resultados obtidos. SYMKO (1979)

A partir dos resultados apresentados na figura 3.1 pode-se deduzir que a temperatura ao longo da altura da seção varia de forma não linear.

O trabalho descrito acima foi complementado por FU \& CHEUNG (1990), que, após realizar vários estudos analíticos baseados em equações diferenciais de transferência de calor, identificaram alguns aspectos que influenciam na distribuição de temperaturas; alguns destes são transcritos a seguir: 
- a variável que mais influência exerce na distribuição de temperaturas é aparentemente a relação entre a porção em balanço da laje e altura do tabuleiro misto, esta variável controla a área de aço exposta à radiação solar;

- picos de temperatura durante o dia tem grande influência no comportamento térmico de tabuleiros mistos;

- existe uma relação direta entre gradientes de temperatura e tensões induzidas: quanto maior o gradiente, maior a tensão provocada por este;

- a temperatura inicial aparentemente não influencia de maneira sensível a distribuição de temperaturas na estrutura, quando esta é submetida a radiação solar.

Na figura 3.2 apresenta-se algumas variações de temperatura, ao longo da altura da seção transversal, propostas por diferentes regulamentos. Tanto a AASHTO (1989) como a NBR 7187 não fornecem informações sobre a distribuição transversal de temperaturas.

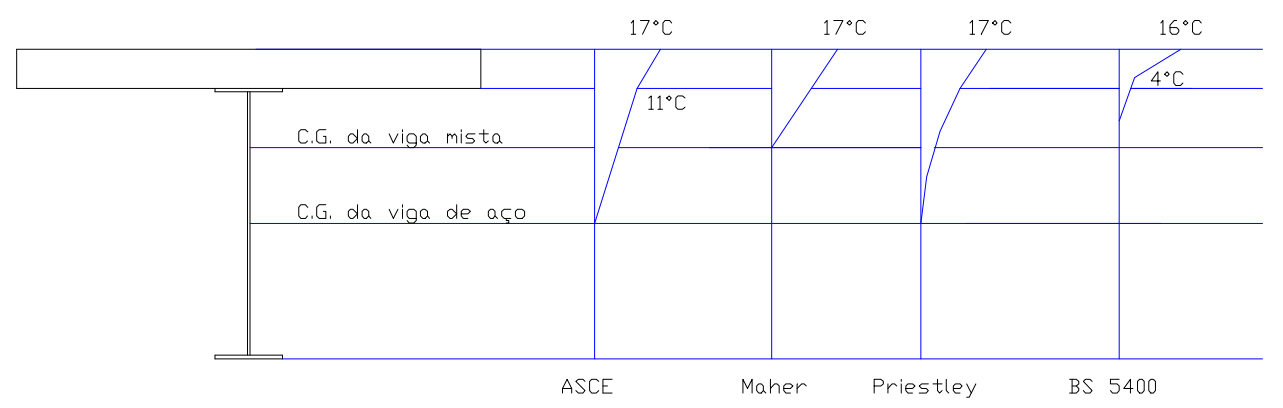

FIGURA 3.2 - Gradientes de temperatura na seção transversal, propostos por diferentes autores e regulamentos. 
As tensões obtidas através das distribuições de temperatura propostas pela BS 5400 e EUROCODE 4 foram comparadas por MIRAMBELL \& COSTA (1997) a tensões obtidas experimentalmente em tabuleiros de pontes, segundo estes a distribuição proposta pela BS5400 se aproxima mais da realidade pois leva a resultados mais próximos dos experimentais.

A determinação das tensões ocasionadas por efeitos de temperatura tem sido estudada por SOLIMAN \& KENNEDY (1986) os quais estabeleceram que gradientes de temperatura ao longo da altura da seção ocasionam pares de forças de cisalhamento (V) e de momentos (M) (Figura 3.3). As deformações resultantes na fibra inferior da laje e superior das vigas podem ser calculadas através das expressões 3.1 e 3.2.

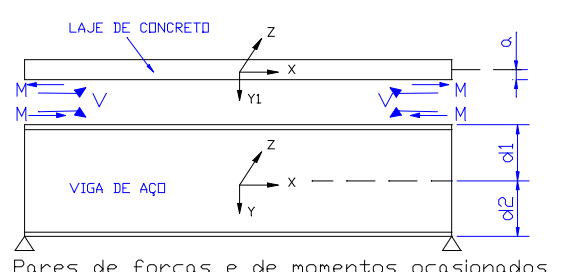

pelo gradiente de temperatura através da altura da seçäo
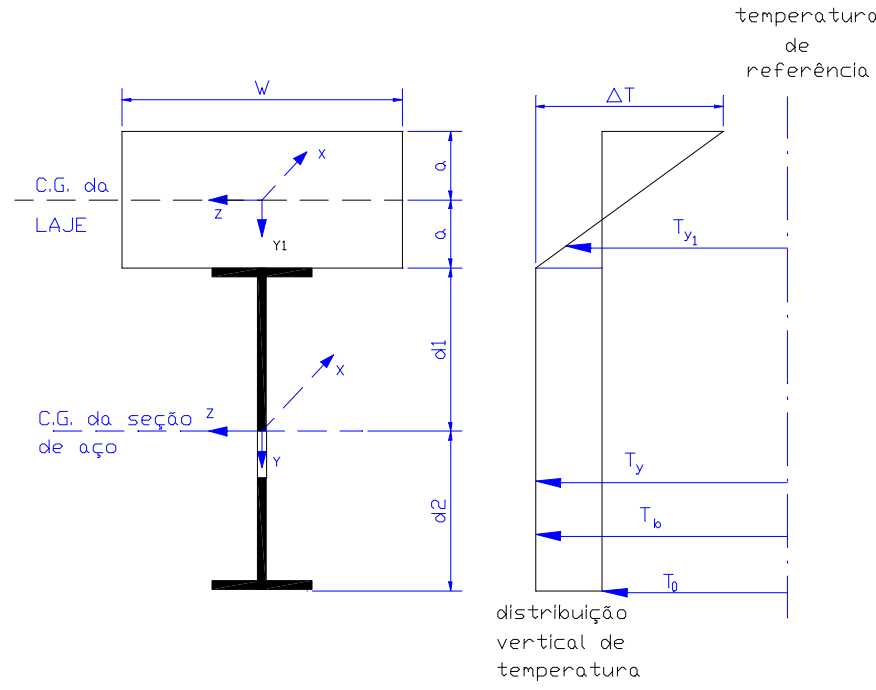

FIGURA 3.3 - Análise do efeito de temperatura em vigas mistas. SOLIMAN \& KENNEDY (1986) 


$$
\begin{aligned}
& \varepsilon_{x c}=\left[\frac{2 \cdot\left(1-v^{2}\right)}{A_{c} \cdot E_{c}}\right] \cdot\left[2 \cdot V-\left(\frac{3 \cdot M}{2 \cdot A}\right)\right]+\left[\frac{(1+\mathrm{v})}{2 \cdot A}\right] \cdot \alpha_{c} \cdot \int_{-a}^{a}\left(T_{y 1}-T_{0}\right) \cdot d_{y 1} \\
& +\left[\frac{3 \cdot(1+\mathrm{v})}{2 \cdot a^{2}}\right] \cdot \alpha_{c} \cdot \int_{-a}^{a}\left(T_{y 1}-T_{0}\right) \cdot y_{1} \cdot d_{y 1} \\
& \varepsilon_{x s}=-\left(\frac{M \cdot d_{1}}{I_{s} \cdot E_{s}}\right)-\left(\frac{V}{E_{s}}\right) \cdot\left[\left(\frac{d_{1}^{2}}{I_{s}}\right)+\left(\frac{1}{A_{s}}\right)\right]+\left(\frac{\alpha_{s}}{A_{s}}\right) \cdot \int_{-d_{1}}^{d_{2}}\left(T_{y}-T_{0}\right) \cdot b_{y} \cdot y \cdot d_{y}
\end{aligned}
$$

As solicitações $M$ e V são obtidas através de condições de compatibilidade (na interface aço-concreto a deformação e o raio de curvatura devem ser os mesmos para a laje e as vigas) que levam às expressões 3.3 e 3.4 .

$$
\begin{gathered}
A V+B M=\left[-\frac{1+\mathrm{v}}{2 \cdot a}\right] \cdot \alpha_{c} \cdot\left[\int_{-a}^{a}\left(T_{y 1}-T_{0}\right) \cdot d_{y 1}+\left(\frac{3}{a}\right) \cdot \int_{-a}^{a}\left(T_{y 1}-T_{0}\right) \cdot y_{1} \cdot d_{y 1}\right]+ \\
+\alpha_{s} \cdot\left[\frac{1}{A_{s}} \cdot \int_{-d_{1}}^{d_{2}}\left(T_{y}-T_{0}\right) \cdot b_{y} \cdot d_{y}-\frac{d_{1}}{I_{s}} \cdot \int_{-d_{1}}^{d_{2}}\left(T_{y}-T_{0}\right) \cdot b_{y} \cdot y \cdot d_{y}\right] \\
K V+R M=E_{c} \cdot E_{s} \cdot w \cdot\left[\begin{array}{l}
\left.3 \cdot(1+v) \cdot \alpha_{c} \cdot I_{s} \cdot \int_{-a}^{a}\left(T_{y 1}-T_{0}\right) \cdot y_{1} \cdot d_{y 1}-2 \cdot a^{3} \cdot\right] \\
\alpha_{s} \int_{-d_{1}}^{d_{2}}\left(T_{y}-T_{0}\right) \cdot b_{y} \cdot y d_{y}
\end{array}\right]
\end{gathered}
$$

Os coeficientes $A, B, K$ e $R$ são obtidos através das relações 3.5. As expressões 3.3 e 3.4 permitem calcular de maneira explícita o valor dos pares $\mathrm{F}$ e $\mathrm{Q}$ ocasionados por qualquer distribuição de temperatura. 


$$
\begin{aligned}
& A=\frac{1}{E_{s} \cdot A_{s}}+\frac{d_{1}^{2}}{I_{s} \cdot E_{s}}+\left[2 \cdot \frac{1-v^{2}}{w \cdot a \cdot E_{c}}\right] \\
& B=\frac{d_{1}}{E_{s} \cdot I_{s}}-\left[1,5 \cdot \frac{1-v^{2}}{a^{2} \cdot w \cdot E_{c}}\right] \\
& K=2 \cdot w \cdot d_{1} \cdot a^{3} \cdot E_{c}-3 \cdot\left(1-v^{2}\right) \cdot a \cdot I_{s} \cdot E_{s} \\
& R=2 \cdot w \cdot a^{3} \cdot E_{c}+3 \cdot\left(1-v^{2}\right) \cdot I_{s} \cdot E_{s}
\end{aligned}
$$

Conhecidos os valores de $\mathrm{F}$ e $\mathrm{Q}$ é possível determinar os valores das tensões atuantes na laje e nas vigas através das expressões 3.6 e 3.7.

$$
\begin{aligned}
& \sigma_{x c}=\frac{V}{2 \cdot a \cdot w}+\left[3 \cdot \frac{(V \cdot a-M) \cdot y_{1}}{2 \cdot a^{3} \cdot w}\right]-\left[\frac{\alpha_{c} \cdot E_{c}}{1-v}\right] \cdot\left(T_{y 1}-T_{0}\right)+ \\
& +\left[\frac{\alpha_{c} \cdot E_{c}}{2 \cdot a \cdot(1-v)}\right] \cdot \int_{-a}^{a}\left(T_{y 1}-T_{0}\right) \cdot d_{y 1}+\left[\frac{3 \cdot \alpha_{c} \cdot E_{c}}{2 \cdot a^{3} \cdot(1-v)}\right] \cdot y_{1} \cdot \int_{-a}^{a}\left(T_{y 1}-T_{0}\right) \cdot y_{1} \cdot d_{y 1} \\
& \sigma_{x s}=-\alpha_{s} \cdot E_{s} \cdot\left(T_{y}-T_{0}\right)+\frac{\alpha_{s} \cdot E_{s}}{A_{s}} \cdot \int_{-d_{1}}^{d_{2}}\left(T_{y}-T_{0}\right) \cdot b_{y} \cdot d_{y}+\frac{\alpha_{s} \cdot E_{s}}{I_{s}} \cdot \int_{-d_{1}}^{d_{2}}\left(T_{y}-T_{0}\right) \cdot b_{y} \cdot d_{y}+ \\
& +\frac{M}{I_{s}} \cdot y+V \cdot\left[\frac{d_{1}}{I_{s}} \cdot y-\frac{1}{A_{s}}\right]
\end{aligned}
$$

Exemplos de aplicação destas equações podem ser encontrados em SOLIMAN \& KENNEDY (1986). 


\section{3 - Efeitos de retração e de fluência}

O concreto apresenta comportamento diferente segundo a duração do carregamento aplicado. Sob ações permanentes a deformação deste aumenta com o tempo, podendo atingir magnitudes superiores à experimentada inicialmente.

A deformação do concreto em uma idade $t>t_{0}$, é constituída por três parcelas de deformação: deformação instantânea, deformação lenta ou fluência e deformação por retração.

Tanto a deformação instantânea como a deformação por fluência são ocasionadas pelas tensões que o concreto é submetido. A deformação por retração ocorre mesmo na ausência de carregamento e deve-se a outros efeitos, entre estes, a evaporação da água confinada na massa de concreto e reações químicas como a carbonatação.

Em um sistema misto estes efeitos são de grande importância pois as vigas de aço, através dos conectores, impedem que o concreto deforme livremente. Isto leva a um acréscimo da curvatura das vigas mistas e a uma redistribuição de tensões entre aço e concreto.

O estudo da retração e fluência é um problema complexo. Para ANDERSON (1988) a previsão do comportamento do concreto, submetido a ações de longa duração, pode ser tratada através de modelos viscoelásticos, cuja aplicação somente é possível através de técnicas numéricas. A maioria dos regulamentos contorna esta dificuldade fornecendo métodos algébricos simplificados que permitem avaliar de maneira aproximada a resposta da estrutura. Os métodos mais utilizados são o Módulo Efetivo, Módulo Efetivo Ajustado com a Idade do Concreto e o Método da Taxa de Fluência, estes são brevemente descritos no item 3.3.2.

A NBR 7197 fornece critérios para estimar tanto a deformação por retração, como também a deformação por fluência. 


\subsection{1 - Considerações sobre o comportamento visco-elástico da} estrutura

A principal dificuldade encontrada na análise de um problema viscoelástico consiste em que não é possível aplicar as relações clássicas de tensão-deformação da teoria da elasticidade, no lugar destas, a hipótese de viscosidade linear tem sido extensamente utilizada através da integral de Stieltjes (AMADIO, 1993):

$$
\varepsilon_{C}(t)=\varepsilon_{C}\left(t, t_{0}\right)=\sigma_{C}\left(t_{0}\right) \cdot \phi\left(t, t_{0}\right)+\int_{t_{0}}^{t} \phi(t, \tau) \cdot d \sigma_{C}(\tau)+\varepsilon_{s h}(t)
$$

A função $\phi(t, \tau)$ é denominada função de viscosidade (ou de fluência) e representa a deformação visco - elástica total ocasionada pela aplicação de uma tensão unitária constante na idade $\tau$, nos modelos do CEB esta função é definida da seguinte maneira:

$$
\phi(\mathrm{t}, \tau)=\frac{\varepsilon_{\mathrm{C}}(\mathrm{t}, \tau)}{\sigma_{\mathrm{C}}(\tau)}=\frac{1}{\mathrm{E}_{\mathrm{c}}(\tau)}+\frac{\varphi_{28}(\mathrm{t}, \tau)}{\mathrm{E}_{\mathrm{c} 28}}
$$

O valor da função de fluência varia de zero, no início da aplicação da carga, a um valor final que varia entre 1,5 e 4 para $t=\infty$ (GILBERT, 1989).

A solução da equação 3.8 não é "fechada", a determinação da deformação no instante t somente é possível através de técnicas numéricas de integração passo a passo. Uma forma simples para resolver este problema consiste em aproximar a integral de Stieltjes através da regra dos trapézios (Figura 3.4): A deformação ocasionada no intervalo $\left(t_{0}, t_{k}\right)$ por uma função $\sigma_{\mathrm{c}}(\tau)$, definida no intervalo $\left(\mathrm{t}_{0}, \mathrm{t}_{\mathrm{k}}\right)$, é dada por:

$$
\varepsilon_{\mathrm{c}}\left(\mathrm{t}_{\mathrm{k}}\right)=\sum_{\mathrm{i}=1}^{\mathrm{k}} \frac{1}{2} \cdot\left[\phi\left(\mathrm{t}_{\mathrm{k}}, \mathrm{t}_{\mathrm{i}}\right)+\phi\left(\mathrm{t}_{\mathrm{k}}, \mathrm{t}_{\mathrm{i}-1}\right)\right] \cdot \Delta \sigma_{\mathrm{ci}}+\varepsilon_{\mathrm{sh}}\left(\mathrm{t}_{\mathrm{k}}\right)
$$




$$
\Delta \sigma_{\mathrm{C}_{\mathrm{i}}}=\sigma_{\mathrm{c}}\left(\mathrm{t}_{\mathrm{i}}\right)-\sigma_{\mathrm{c}}\left(\mathrm{t}_{\mathrm{i}-1}\right)
$$
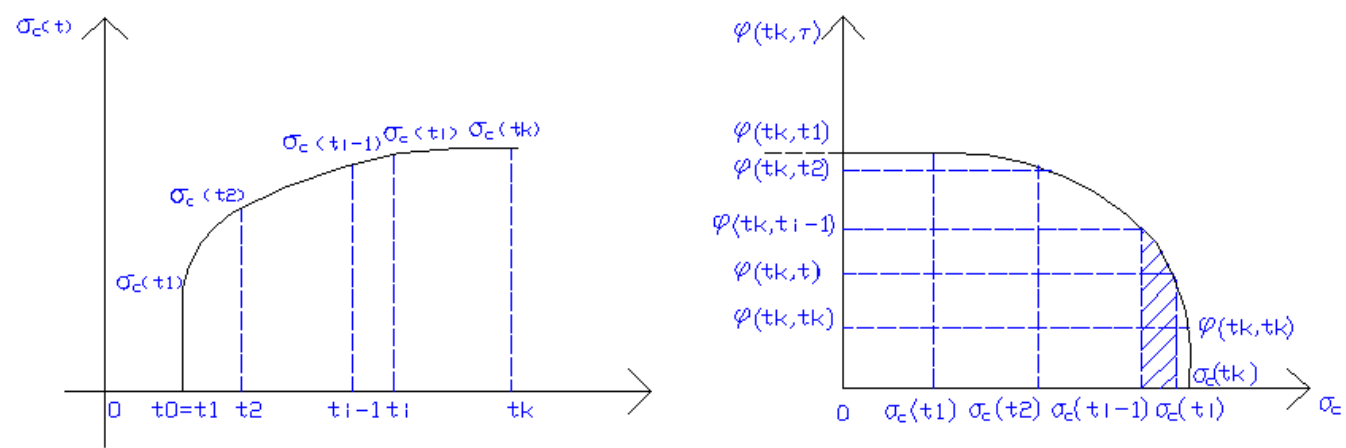

FIGURA 3.4 - Integração da expressão de Stieltjes através da regra do trapézio. AMÁDIO (1993)

A regra do trapézio tem sido empregada por AMÁDIO (1993) para a montagem de rotinas de cálculo que permitam resolver o problema.

Existem ainda vários métodos iterativos que dividem o período de tempo em intervalos, sendo realizados cálculos por separado para cada intervalo. Nestes métodos assume-se que a tensão permanece constante no intervalo no qual a deformação é calculada. O aprimoramento dos resultados obtidos depende da dimensão escolhida para cada intervalo de tempo, sendo os cálculos sucessivos baseados nos obtidos nos intervalos precedentes.

Os principais métodos iterativos utilizados para resolver o problema da fluência do concreto são:

- Método de superposição;

- Método da taxa de fluência;

- Strain Hardening ;

- Taxa de fluxo.

Temos por exemplo o modelo de DIBSI apud BANGASH (1989) 0 qual é baseado no método de Strain Hardening pelo qual a variação da taxa de deformação por fluência é definida conforme a seguinte expressão: 


$$
\frac{d \varepsilon_{c}}{d t}=0,31 \cdot\left[\sigma F(T)^{3,225} \cdot \varepsilon_{c}^{2,225}\right]
$$

Esta técnica pode ser incorporada com sucesso no método dos elementos finitos para obter resultados mais aprimorados. A implementação de sub-rotinas, baseadas em processos numéricos, para considerar os efeitos de retração e fluência em interface com o programa ANSYS seria um trabalho interessante o qual não foi abordado neste texto pois foge aos objetivos principais.

\subsection{2 - Métodos algébricos simplificados}

\subsubsection{1 - Método do Módulo Elástico}

A deformação por fluência é determinada considerando o módulo de elasticidade efetivo:

$$
E_{c, e f}=\frac{E_{c}\left(t_{0}\right)}{1+\phi_{\left(t, t_{0}\right)}}
$$

Se determinada tensão é aplicada no concreto no instante $\tau$ e permanece constante no período $t>\tau$, a deformação $\varepsilon(t, \tau)$ no instante $t$ pode ser expressa como a soma das deformações instantânea, de fluência e de retração:

$$
\varepsilon_{(t, \tau)}=\frac{\sigma_{(\tau)}}{E_{c}(\tau)}+\frac{\sigma_{(\tau)}}{E_{c}(\tau)} \cdot \phi(t, \tau)+\varepsilon_{s h}(\tau)
$$

Este método é o mais antigo de todos, a principal desvantagem consiste em que a deformação por fluência na idade t é influenciada apenas 
pela tensão atual $\sigma$, desconsiderando a história de tensões no intervalo. $\bigcirc$ envelhecimento do concreto é também ignorado neste método, somando-se ainda a consideração incorreta de que o concreto se comporta de maneira elástica sob os efeitos de fluência.

Se por exemplo no instante $\tau$ a tensão é nula, na equação 3.13 , a deformação ocasionada por fluência também é nula, isto leva a que a deformação seja superestimada para a aplicação de um carregamento crescente com o tempo e subestimada no caso inverso.

\subsubsection{2 - Método do Módulo Elástico Ajustado com a Idade do} Concreto

Este método tem sido largamente utilizado na literatura para analisar os efeitos de retração e fluência em vigas mistas (BRADFORD \& GILBERT, 1989), basicamente consiste na consideração de um coeficiente de fluência reduzido $\chi \cdot \phi(\mathrm{t}, \tau)$ no cálculo da deformação lenta produzida por um carregamento aplicado em incrementos.

O valor da deformação total no instante $t$ é obtido somando as deformações ocasionadas pela tensão $\sigma_{0}$ às ocasionadas pelos incrementos de tensão $\Delta \sigma(\mathrm{t})$ e por retração:

$$
\varepsilon_{(t)}=\frac{\sigma_{0}}{E_{c}\left(t_{0}\right)} \cdot\left[1+\phi\left(t, t_{0}\right)\right]+\frac{\Delta \sigma_{(t)}}{E_{c(}\left(\tau_{0}\right)} \cdot\left[1+\chi\left(t, t_{0}\right) \cdot \phi\left(t, \tau_{0}\right)\right]+\varepsilon_{s h}(t)
$$

O coeficiente de envelhecimento $\chi\left(t, \tau_{0}\right)$ varia entre 1,0 e 0,6 , sendo que na maioria dos casos práticos oscila entre 0,75 e 0,85 (GILBERT, 1989).

A aplicação deste método no estudo dos efeitos de retração e fluência em vigas mistas foi apresentado de forma detalhada por GHALI \& FAVRE (1986) e GILBERT (1989). 


\subsubsection{3 - Método da taxa de fluência}

Neste método assume-se que a taxa de variação de fluência com o tempo, $\frac{\mathrm{d} \phi(\mathrm{t}, \tau)}{\mathrm{dt}}$, não depende da idade do carregamento (DILGER, 1982). Esta hipótese permite a utilização de apenas uma curva de fluência para calcular a deformação lenta ocasionada por qualquer história de carregamento, desta maneira temos que:

$$
\frac{d \varepsilon}{d t}=\frac{\sigma_{(t)}}{E_{c}\left(t_{0}\right)} \cdot \frac{d \phi\left(t, \tau_{0}\right)}{d t}
$$

Assumindo que a retração é ocasionada na mesma proporção que a fluência tem-se então:

$$
\varepsilon_{\mathrm{sh}}(\mathrm{t})=\frac{\varepsilon_{\mathrm{sh}}(\infty)}{\phi\left(\infty, \tau_{0}\right)} \cdot \phi\left(\mathrm{t}, \tau_{0}\right)
$$

Exemplos de aplicação deste método foram apresentados por GILBERT (1989).

Os métodos até aqui descritos são baseados na hipótese de que existe conexão rígida entre os dois materiais; estes não são aplicáveis no caso de existir escorregamento na interface. A consideração de deslocamento relativo entre $\mathrm{o}$ aço e o concreto somente pode ser tratada através de técnicas numéricas de integração (AL-AMERY \& ROBERTS, 1990; AMÁDIO \& FRAGIACOMO, 1993). 


\section{4 - Efeitos de Fadiga}

A ação repetida de veículos atravessando o vão ocasiona variações de tensões nos elementos do tabuleiro, podendo ainda produzir alternância de tração para compressão e/ou vice versa. Sob estas condições existe o risco do aço sofrer o fenômeno de fadiga, caracterizado pelo enfraquecimento dos elementos estruturais, propagação de fissuras e que pode levar a estrutura ao colapso por ruptura frágil (RAVI \& RANGANATHAN, 1991).

O termo fadiga é definido segundo PASTOUKHOV \& VOORWALD (1995) da seguinte maneira:

“...a fadiga na linguagem comum, é o cansaço, um estado que torna impossível suportar mais algumas condições. Com respeito aos materiais estruturais, essas condições são as de carregamento, da temperatura e ambientais... sendo natural, nestas condições, considerar que o material simplesmente "cansou"de operar nas condições atuais".

Os principais fatores que ocasionam o aparecimento de fissuras são o volume de tráfego, idade da ponte, magnitude das variações de tensão ocasionadas pelas cargas móveis e impacto, tipo de detalhe, qualidade do detalhe executado e a tenacidade do material à ruptura (FISHER, 1981).

Em geral, as estruturas de aço soldadas são mais suscetíveis de desenvolver o fenômeno de fadiga do que estruturas de aço parafusadas ou rebitadas; isto deve-se a que no processo de solda é inevitável a introdução de tensões residuais e microfissuras adjacentes ao cordão de solda (SMITH, 1991).

As ligações e conexões realizadas mediante solda constituem pontos potenciais para apresentar fadiga, isto deve-se às altas concentrações de tensões, induzidas por processos de soldagem deficientes e/ou deformações fora do plano ocasionadas em elementos principais. Na figura 3.5 ilustra-se alguns locais suscetíveis ao efeito de fadiga. 


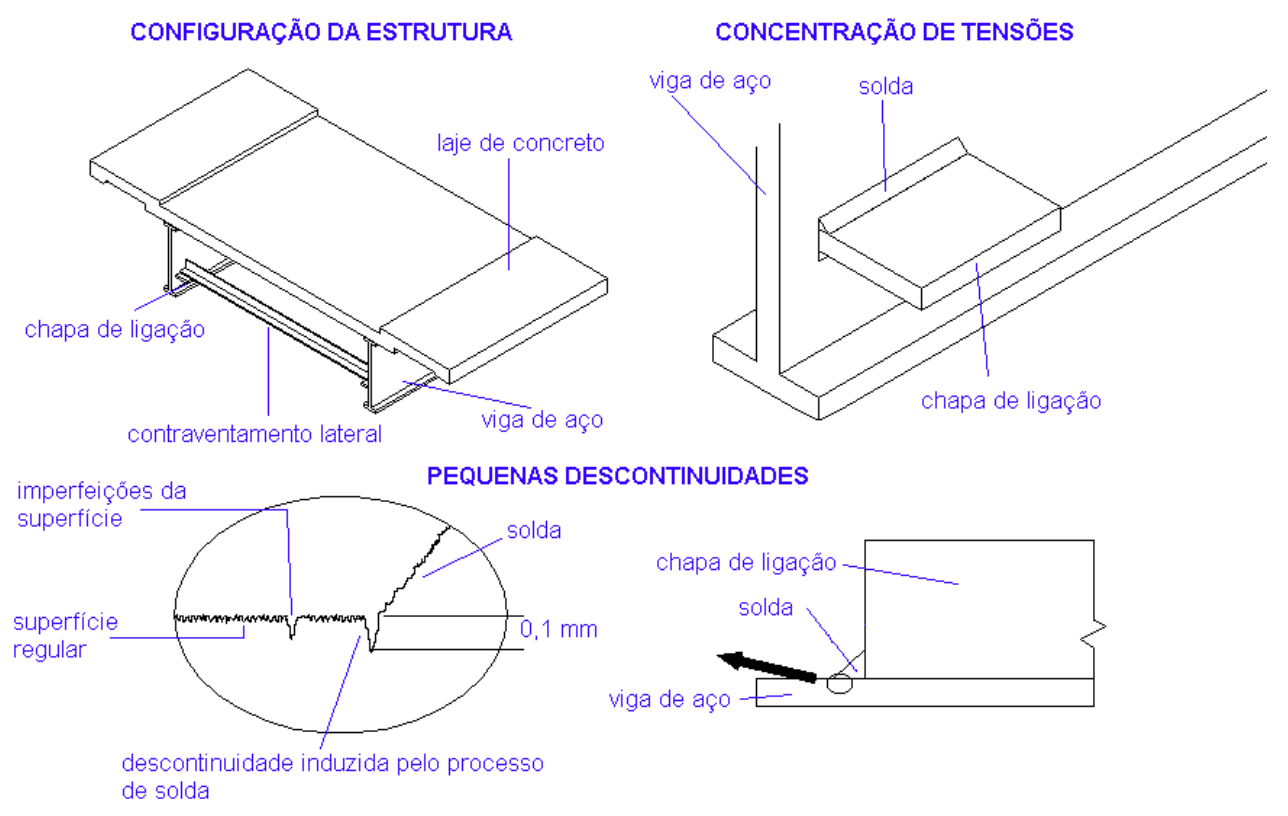

FIGURA 3.5 - Locais que podem desenvolver o fenômeno de fadiga. SMITH (1991)

O efeito da fadiga em pontes parafusadas e rebitadas é menos nocivo, isto deve-se à utilização de varias chapas e elementos nas ligações, de forma a que quando um componente fissura, este não ocasiona diretamente fissuras nos restantes. A perda de resistência neste tipo de estrutura é principalmente ocasionada pela corrosão do aço e por efeitos secundários como deslocamentos nas direções de menor rigidez dos elementos.

\subsection{1 - Estudos experimentais}

Uma conexão de ponte deve possuir resistência adequada à fadiga para absorver as solicitações ocasionadas por todos os ciclos de carga durante a vida útil da estrutura, sem comprometer as condições de serviço e a segurança. A resistência à fadiga de ligações é determinada através de ensaios de fadiga nos quais estas são submetidas a vários ciclos de carga 
de amplitude constante. Os resultados obtidos são representados através de curvas S-N, que mostram a resposta da ligação.

O trabalho desenvolvido por Fisher na Universidade de Lehigh constitui talvez uma das maiores contribuições realizadas ao estudo da fadiga em pontes, o pesquisador realizou ensaios em vários tipos de ligações, constituindo os resultados a base das especificações que a AASHTO faz sobre o dimensionamento à fadiga de ligações de pontes (MADUGULA, 1991). Na figura 3.6 são reproduzidas as curvas S-N adotadas pela AASHTO, nesta figura os diferentes tipos de ligações são classificados em sete categorias.

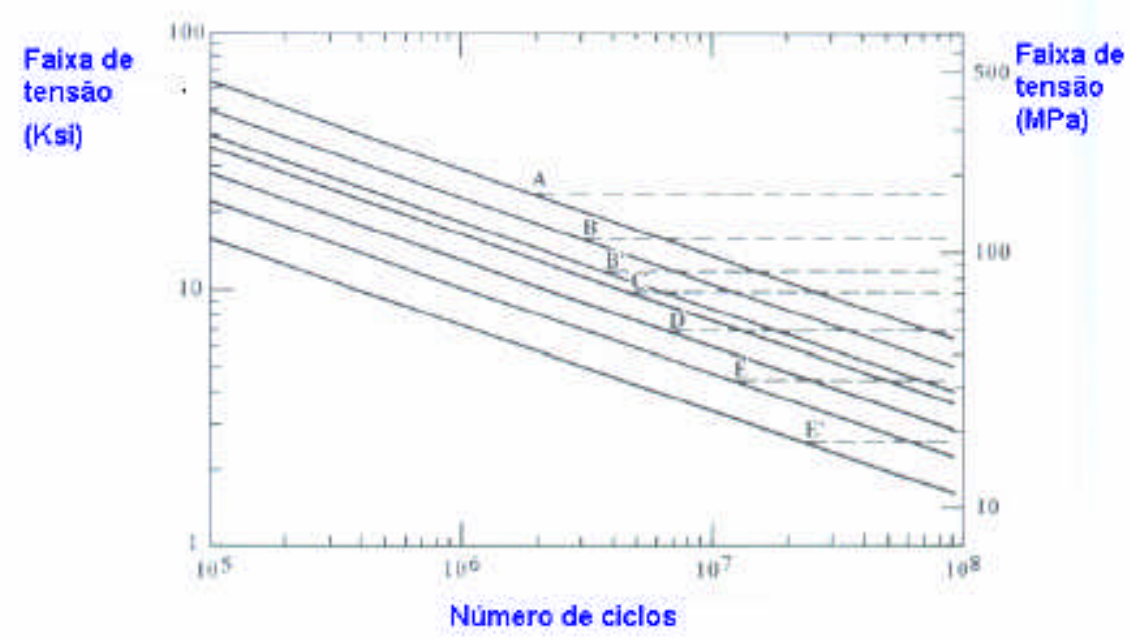

FIGURA 3.6 - Curvas S-N adotadas pela AASHTO. FISHER \& MENZEMER (1991)

No dimensionamento de ligações tanto a AASHTO como a BS 5400 consideram apenas o tipo de ligação, número de ciclos aplicados e faixa de variação de tensão. Na figura 3.7 apresenta-se alguns exemplos de detalhes comumente utilizados em tabuleiros em viga mista, que podem apresentar fadiga, sendo apresentado na tabela 3.3 a categoria destes . 


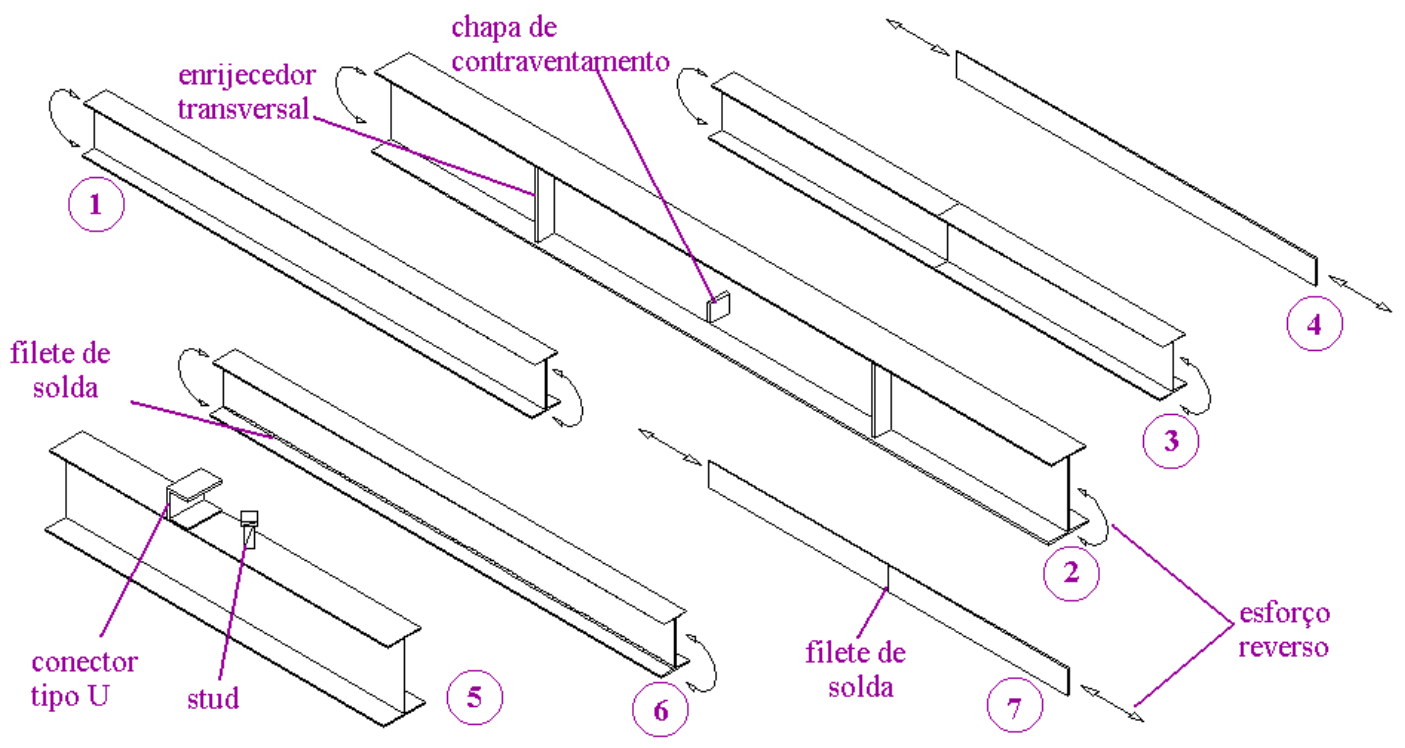

FIGURA 3.7 - Detalhes construtivos que podem apresentar fadiga em tabuleiros em vigas mistas.

Tabela 3.3 - Categorias dos detalhes (AASHTO)

\begin{tabular}{|c|c|c|c|c|}
\hline Condição geral & Situação & $\begin{array}{l}\text { Tipo de } \\
\text { tensão }\end{array}$ & $\begin{array}{l}\text { Categoria } \\
\text { de tensão }\end{array}$ & $\begin{array}{l}\text { Exemplo } \\
\text { ilustrativo }\end{array}$ \\
\hline Elementos planos & $\begin{array}{l}\text { Metal base com superfície limpa } \\
\text { ou laminada. }\end{array}$ & $\mathrm{Tou} \mathrm{R}^{*}$ & $A$ & 1,4 \\
\hline \multirow{3}{*}{$\begin{array}{l}\text { Perfis construídos } \\
\text { por chapas soldadas }\end{array}$} & $\begin{array}{l}\text { Tensão de flexão calculada na } \\
\text { base do cordão de solda dos } \\
\text { enrijecedores transversais na } \\
\text { alma ou nas mesas. }\end{array}$ & $\mathrm{T}$ ou R & $\bar{C}$ & 2 \\
\hline & $\begin{array}{l}\text { Metal base e metal solda de perfis } \\
\text { soldados conectados por soldas } \\
\text { de topo com penetração total ou } \\
\text { por filetes continuos de solda } \\
\text { paralelos à tensão aplicada }\end{array}$ & Tou R & $\bar{B}$ & 2,6 \\
\hline & $\begin{array}{l}\text { Metal base e metal solda de perfis } \\
\text { soldados conectados por soldas } \\
\text { de topo com penetração total ou } \\
\text { soldads de topo continuas com } \\
\text { penetração paracial paralela à } \\
\text { tensão aplicada. }\end{array}$ & $\mathrm{T}$ ou R & $\mathrm{B}^{\prime}$ & 2,6 \\
\hline \multirow{2}{*}{$\begin{array}{l}\text { Chapas com solda } \\
\text { de topo carregadas } \\
\text { axialmente }\end{array}$} & $\begin{array}{l}\text { Metal base adjacente a detalhes } \\
\text { ligados por soldas de topo com } \\
\text { penetração parcial ou total quando } \\
\text { o comprimento do detlahe na } \\
\text { direção da tensão é inferior a } 5 \mathrm{~cm}\end{array}$ & $\mathrm{~T}$ ou R & $\bar{C}$ & 2 \\
\hline & $\begin{array}{l}\text { Metal base e metal solda com } \\
\text { penetração parcial ou total na } \\
\text { direção da tensão aplicada. }\end{array}$ & $\mathrm{T}$ ou R & $\bar{B}$ & 3,7 \\
\hline $\begin{array}{l}\text { Chapas com filete de } \\
\text { solda carregadas } \\
\text { longitudinalm ente }\end{array}$ & $\begin{array}{l}\text { Metal base adjacente a detalhes } \\
\text { incorporados por filete de solda } \\
\text { com comprimento de solda na } \\
\text { direção da tensão inferior a } 5 \mathrm{~cm} \text {. } \\
\text { e para conectores tipo "stud". }\end{array}$ & $\mathrm{T}$ ou R & $\bar{C}$ & 5 \\
\hline
\end{tabular}

* "T" significa variação de tensão de tração apenas. "R" significa uma variação de tensão que envolve tanto tração como compressão durante um ciclo de tensão. ** "carregadas longitudinalmente" significa que direção da tensão aplicada é paralela à direção longitudinal do filete de solda 
A norma da AISC apresenta categorias de detalhes semelhantes aos fornecidos pela AASHTO, exemplos de detalhese categorias podem ser encontrados em ANDREW \& CHEN (1985).

A redundância estrutural da ponte é um fator de grande importância no dimensionamento à fadiga, este aspecto é abordado com maior detalhe no capitulo 4.

\subsection{2 - Fraturas de fadiga em vigas de pontes}

O principal problema que a fadiga ocasiona em pontes soldadas é o aparecimento de fissuras próximas aos locais de solda. MAEDA et al (1991) classifica estas fissuras da seguinte forma (ver Figura 3.8):

- Fissuras ${ }^{1}$ tipo 1: surgem na base do filete de solda situado entre a alma e a mesa superior e são ocasionadas por deformações fora do plano;

- Fissuras tipo 2: iniciadas na base do filete de solda entre a alma e o enrijecedor vertical; a propagação deste tipo de fissura ocasiona a ruptura da mesa tracionada e pode levar a viga ao colapso;

- Fissuras tipo 3: ocorre no filete de solda entre a alma e a mesa tracionada. O início desta é ocasionado pela penetração incompleta do filete de solda ou por descontinuidades na superfície;

- Fissuras tipo 4: ocorrem em vigas submetidas a esforços de cisalhamento, são iniciadas nos extremos onde supostamente é ancorado o campo de tração. Este tipo de fissura ocasiona perda da capacidade resistente da viga por redução da ação do campo de tração².

\footnotetext{
${ }^{1}$ Utilizar-se-á os termos fraturas ou fissuras de fadiga indistintamente.

${ }^{2}$ Se a alma da viga sofre flambagem, esta perde a capacidade de transmitir forças de compressão; as tensões ocasionadas por forças de cisalhamento são resistidas através do comportamento de membrana que a alma desenvolve ao longo da diagonal de tração. Esta ação de membrana ocasiona o surgimento de forças laterais nas mesas podendo ocasionar a formação de rótulas plásticas e inclusive levar a viga ao colapso. ROCKEY (1971) estabeleceu que a rigidez das mesas determina a resistência ultima deste tipo de vigas, podendo estas, em conjunto com os enrijecedores transversais, formar uma viga Vierendel. Ver também DUBAS (1986).
} 

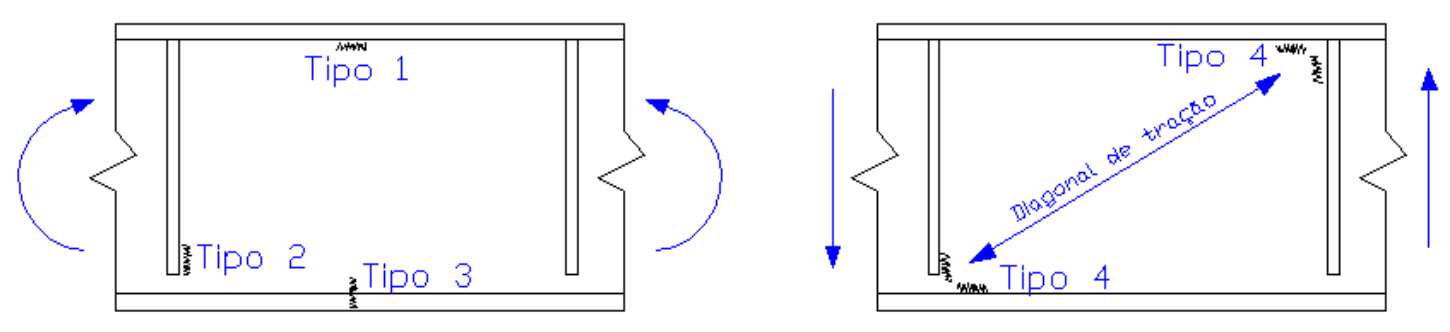

FIGURA 3.8- Fissuras por fadiga observadas em pontes. MAEDA et al (1991)

Na Figura 3.9 ilustra-se um caso muito comum de fissura por fadiga em ligações entre longarinas e transversinas, a ligação é realizada com o auxilio de chapas de aço que são soldadas à alma da longarina, estas chapas são cortadas um pouco abaixo do cordão de solda entre a alma e a mesa da longarina, isto ocasiona que um pequeno trecho da alma (ver detalhe A da figura 3.8) possua rigidez muito inferior na direção transversal em comparação ao trecho enrijecido. Quando a extremidade da transversina sofre uma rotação, ocasionada pela passagem de veículos, esta induz no trecho não enrijecido um deslocamento fora do plano que pode ocasionar fraturas.

O método dos elementos finitos tem sido utilizado por NAGAl et al (1996) para estudar as concentrações de tensões que surgem neste tipo de ligação, as tensões máximas obtidas pelos pesquisadores, no caso da chapa ser soldada à mesa superior da viga, foram inferiores a $120 \mathrm{MPa}$. 

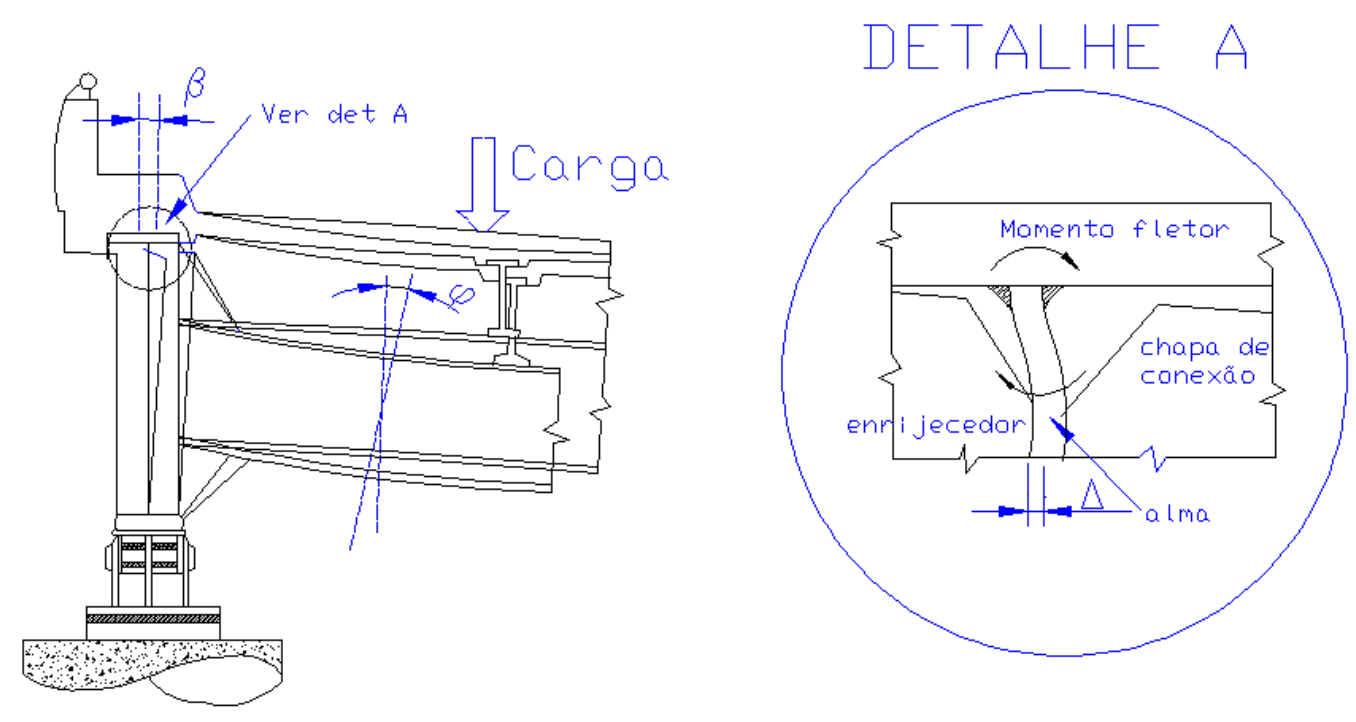

FIGURA 3.9 - Fissura induzida por deformações fora do plano.

FISHER (1981)

Ensaios experimentais realizados em pontes tem mostrado que um deslocamento fora do plano de 0,64 $\mathrm{mm}$, ocasiona tensões de aproximadamente $138 \mathrm{MPa}$ em conexões com comprimentos de trechos não enrijecidos entre 6,4 e 19 mm (FISHER, 1987).

Nas figuras 3.10 a 3.13 apresentam-se várias fraturas por fadiga detectadas por FISHER $(1981,1987)$.

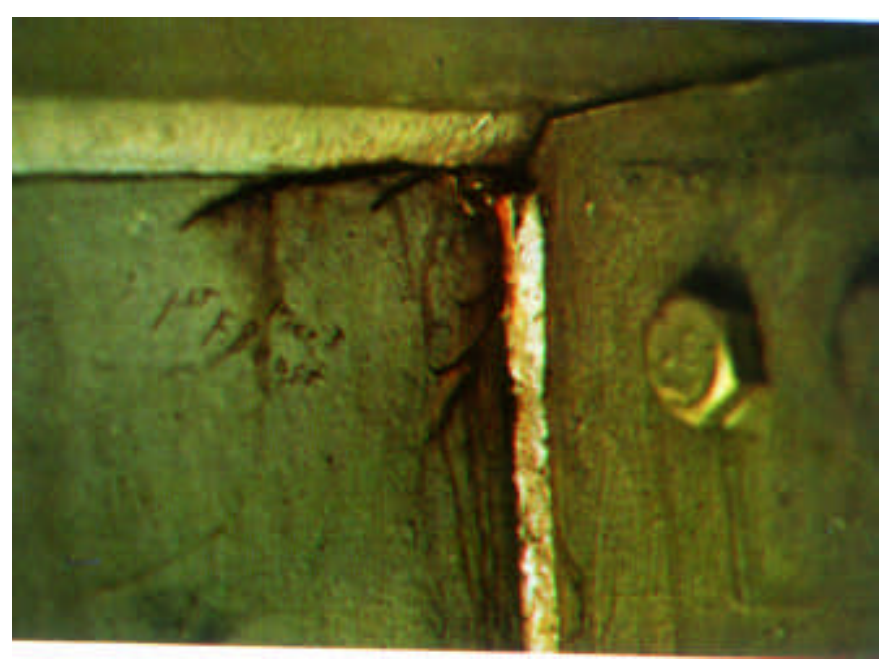

FIGURA 3.10 - Fissura observada na conexão entre longarina e transversina. FISHER (1981) 


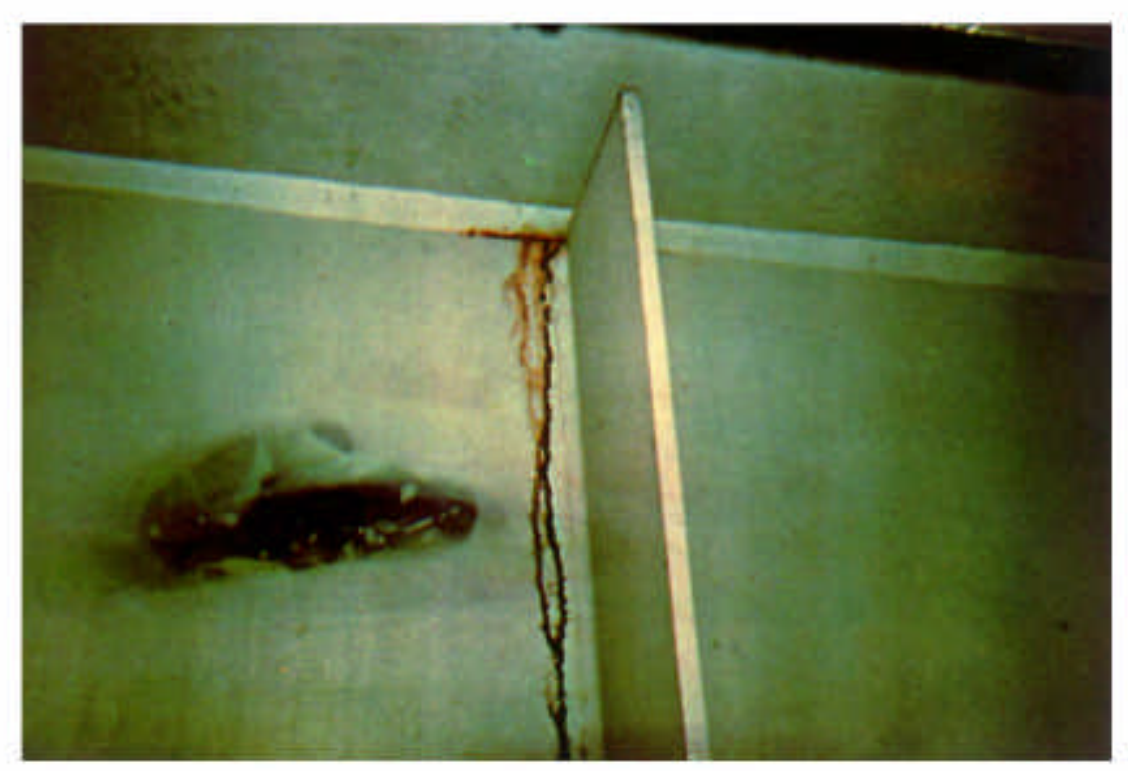

FIGURA 3.11 - Fissura ao longo da conexão entre a mesa superior e a alma. FISHER (1981)

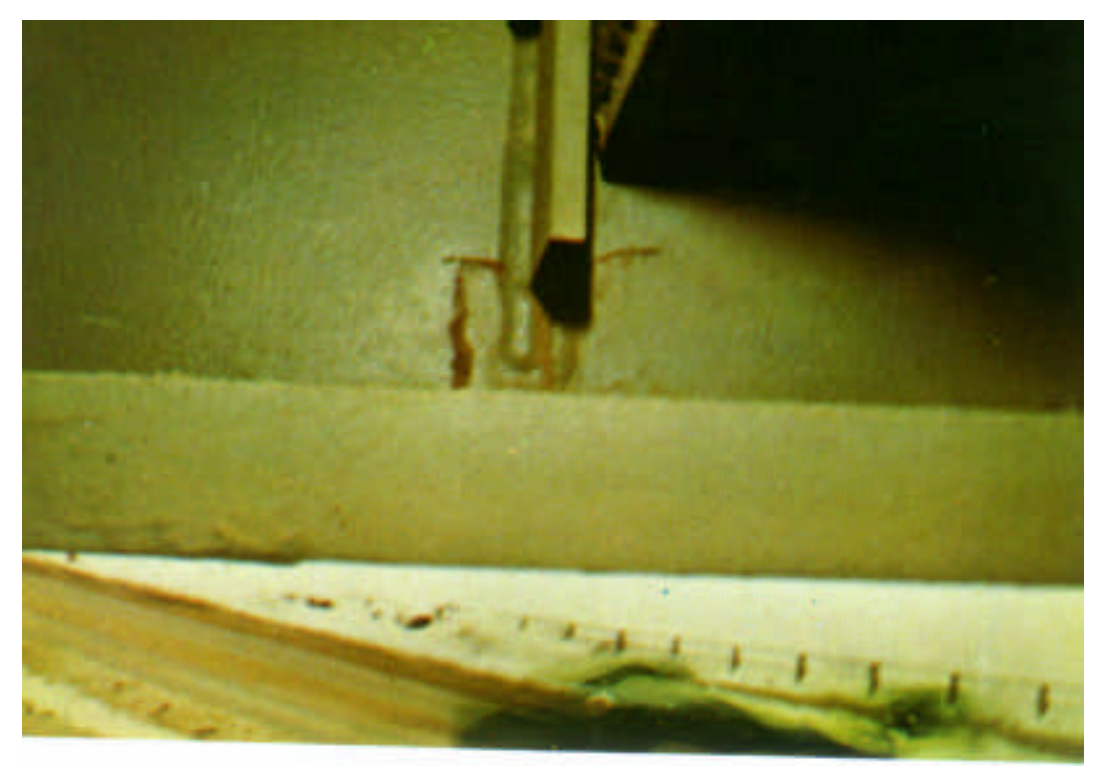

FIGURA 3.12 - Fissura na base do filete de solda entre a alma da viga e a chapa de ligação do diafragma. FISHER (1981) 


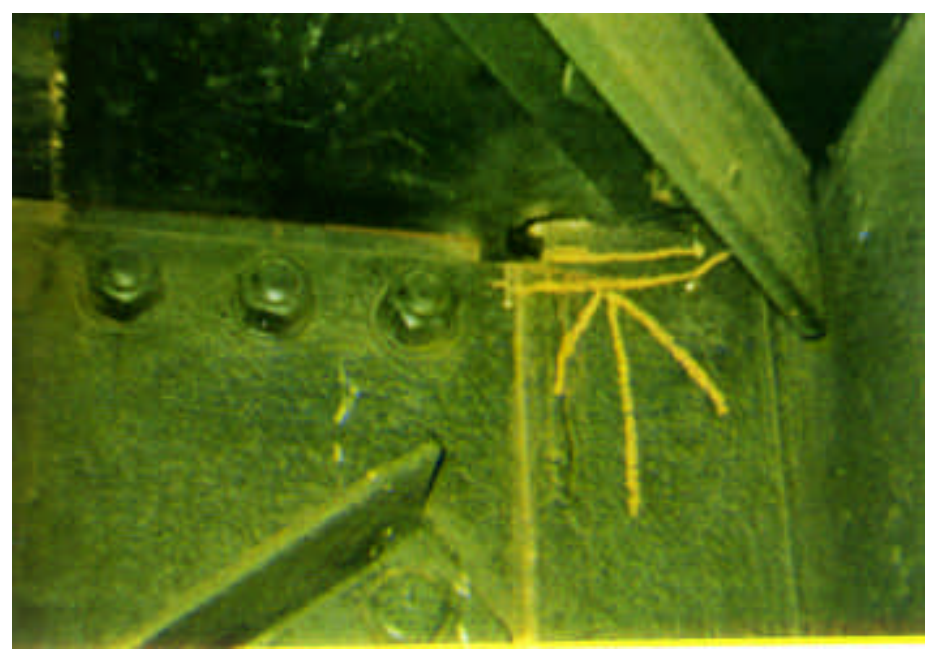

FIGURA 3.13 - Fissura no sistema de ligação de contraventamentos horizontais. FISHER (1981).

Atualmente é possível estudar analiticamente o problema da fadiga; modelos de dano, obtidos a partir de dados experimentais, e a aplicação dos conceitos da mecânica da fratura, permitem hoje em dia avaliar o nível de dano induzido por fadiga numa estrutura e estimar a vida útil desta.

Não é objeto deste trabalho revisar os modelos teóricos que permitem o estudo analítico da fadiga, estes podem ser encontrados de maneira detalhada em SMITH (1991), ZWENERMANN (1991), PASTOUKHOV \& VOORWALD (1995).

\subsection{3 - Efeito de fadiga em conectores de cisalhamento}

A resistência à fadiga dos conectores de cisalhamento é determinada com base nas variações de tensão que estes são solicitados durante a vida útil da estrutura. Basicamente, o dimensionamento de elementos de aço segundo a AASHTO e a BS 5400 segue o seguinte critério:

a) a estrutura é projetada para ter resistência necessária para as solicitações de projeto;

b) de maneira independente aos critérios considerados em a) é verificado o comportamento da estrutura sob solicitações de fadiga; 
c) a interação entre a) e b) é garantida assegurando que o elemento assim dimensionado é regularmente inspecionado.

Uma série de ensaios estáticos e de fadiga, realizados por OEHLERS (1990) em conectores de cisalhamento tipo "stud", mostraram que a resistência dos conectores diminui sob a aplicação de cargas cíclicas, esta situação indica que as praticas atuais de projeto não representam o comportamento real da conexão ao longo do tempo.

Outra incoerência nas proposições acima consiste em que é inviável a inspeção de conectores de cisalhamento em tabuleiros de pontes, em virtude da localização destes na estrutura; esta situação impede que a condição estabelecida em c) seja satisfeita. Nos próximos parágrafos transcreve-se alguns resultados e conclusões obtidos por OEHLERS et al (1995).

O estudo realizado pelo pesquisador consistiu na determinação da resistência estática de conectores tipo "stud"; esta foi obtida a partir de ensaios de "push-out", nos quais foi aplicada uma amplitude de força $R_{1}$ (ver figura 3.14) com carga máxima $P_{1}$ durante $N_{2}$ ciclos, a seguir o modelo foi carregado com controle de deslocamento até ocasionar a ruptura do conector com uma carga $\mathrm{P}_{3}$, ficando assim determinada a variação de resistência deste por fadiga.

Se a amplitude de força $R_{1}$ com pico $P_{1}$ for aplicada até a ruptura do conector com $\mathrm{N}_{1}$ ciclos de carga pode-se concluir que a resistência estática do conector tem sido reduzida de $P_{s}$ a $P_{1}$. Este tipo de procedimento é utilizado para determinar o desempenho do conector sob a aplicação de uma determinada faixa de carga cíclica. 


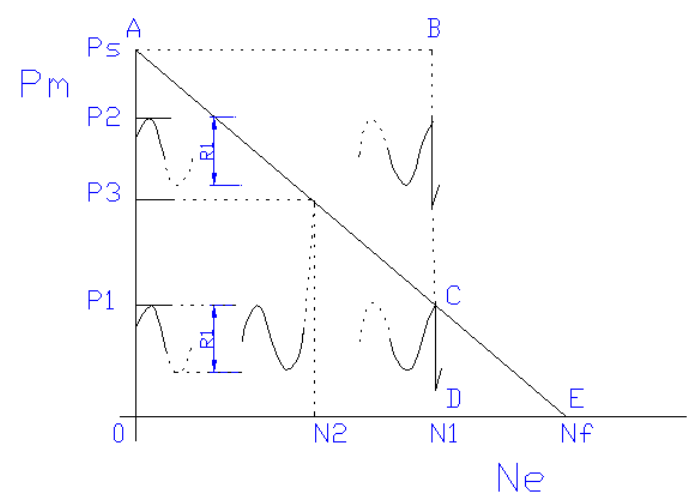

FIGURA 3.14 - Variação da resistência do conector segundo os ciclos de carregamento aplicado. OEHLERS et al (1995)

Os procedimentos fornecidos por diferentes normas como a BS 5400 (1980), AASHTO (1989) e EUROCODE 3 (1984) estabelecem que a resistência depende apenas da amplitude de força cíclica $R$ e não da carga pico P. Segundo estas normas, se for aplicado um carregamento cíclico com amplitude $R_{1}$ com um pico de carga $P_{2}$ obtém-se a mesma resistência estática $\mathrm{P}_{\mathrm{s}}$ do conector ao alcançar $\mathrm{N}_{1}$ ciclos de carga.

Esta hipótese assume que ao ser atingidos $\mathrm{N}_{1}$ ciclos de carga há uma rápida queda da resistência do conector caracterizada pela linha definida pelos pontos B-C-D da figura 3.13. Ao admitir como válida esta hipótese, assume-se que a envoltória de falha determinada pelos pontos A - B - D é aplicável. Os resultados da pesquisa mostram claramente que esta situação não se verifica, pois a envoltória de falha dos conectores é definida pela linha A - C - E.

OEHLERS et al (1995) propuseram uma metodologia para dimensionamento dos conectores à fadiga, baseada em resultados experimentais, podendo esta ser aplicada nas seguintes formas:

a) Projeto: consiste em determinar a resistência ao fluxo de cisalhamento $Q_{o f}$ que a estrutura deve possuir quando é construída de maneira a resistir à solicitação $Q_{0}$ ocasionada pelas cargas cíclicas no 
final da vida de projeto. A diferença entre $Q_{o f}$ e $Q_{0}$ é a perda de resistência no conector devida às solicitações de fadiga.

b) Inspeção: consiste em verificar a resistência e endurance residuais das conexões de cisalhamento em uma ponte existente.

SOTIROPOULOS \& GANGARAO (1992) após verificarem que a deterioração de tabuleiros é um fator determinante na vida útil e condições de serviço de pontes mistas, identificaram uma série de anomalias de projeto. A perda da ação mista entre laje e vigas foi considerada como uma das mais críticas.

O mecanismo de deterioração assumido pelos pesquisadores baseiase no aparecimento de microfissuras no concreto ao redor dos conectores. Estas podem ser ocasionadas por fluência ou retração do concreto ou, ainda, por corrosão prematura dos conectores.

Sob a aplicação de continuados ciclos de carga e descarga os conectores começam a esmagar o concreto no qual encontram-se imersos, reduzindo a resistência deste e aumentando tanto a densidade como o tamanho das microfissuras. Sob estas condições de solicitação o conector pode experimentar deslocamentos relativos, caracterizados pelo escorregamento entre aço e concreto, ocasionando uma queda da resistência da solda que liga o conector com a viga de aço. As cargas cíclicas provocam desta forma esmagamento do concreto e, provavelmente, ruptura dos conectores por fadiga. A perda parcial da ação mista em tabuleiros de pontes é inevitável.

As fórmulas da AASHTO baseiam-se na hipótese de interação completa entre vigas e lajes, sendo que na realidade a deterioração do concreto ao redor dos conectores permite certo escorregamento sob a aplicação de cargas cíclicas. Esta situação não se ajusta às hipóteses de projeto pois existe uma redução da rigidez à flexão do conjunto, podendo este experimentar deslocamentos e tensões que ultrapassam os limites admissíveis.

$\mathrm{Na}$ figura 3.15 ilustra-se um exemplo comparativo entre as tensões obtidas através das especificações da AASHTO e as obtidas a partir 
formulação proposta por KNOWLES apud SOTIROPOULOS \& GANGA RAO (1992). O estudo comparativo refere-se a uma ponte mista de $7.3 \mathrm{~m}$ de largura por $17.4 \mathrm{~m}$ de comprimento, com um tabuleiro de $18.5 \mathrm{~cm}$ de espessura. A carga móvel considerada foi equivalente ao caminhão HS2044 especificado pela AASHTO, incluído o impacto.
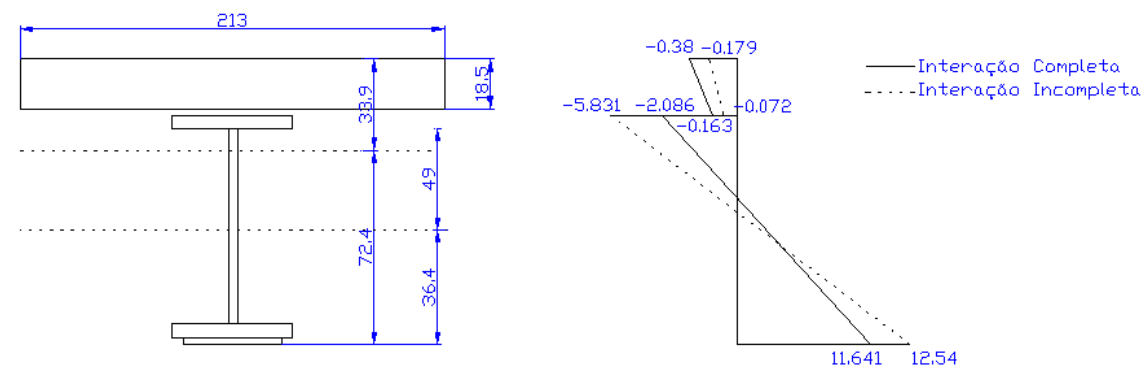

FIGURA 3.15 - Comparação de tensões normais $\left(\mathrm{kN} / \mathrm{cm}^{2}\right)$ em vigas mistas com interação parcial e completa. SOTIROPOULOS \& GANGA RAO (1992)

Na figura 3.15 observa-se que a perda de ação mista ocasiona um fluxo de tensões do concreto para o aço, ou seja, o alívio das tensões atuantes no concreto provoca acréscimo de solicitação no aço.

O comportamento inelástico de conectores de cisalhamento submetidos a carregamento cíclico tem sido estudado por GATTESCO et al (1997), segundo os pesquisadores o comportamento inelástico do conector pode alterar o comportamento da estrutura da seguinte maneira: redistribuição das forças de cisalhamento ao longo da conexão, alternância das forças de cisalhamento devido ao escoamento dos conectores de cisalhamento.

Ensaios realizados pelos pesquisadores mostraram que, dependendo do tipo de carregamento, vão e número de conectores por unidade de comprimento, pode se apresentar a situação em que a tensão nos conectores ultrapassa o limite elástico destes enquanto a viga continua trabalhando em regime elástico. 
Quando a carga aplicada é removida, a tendência da estrutura é retornar à posição inicial, na qual o escorregamento na interface aço concreto é nulo. Nestas condições, os conectores são forçados a eliminar parte da deformação inelástica sofrida, dando lugar ao aparecimento de forças de cisalhamento de sinal oposto conforme ilustrado na figura 3.16.

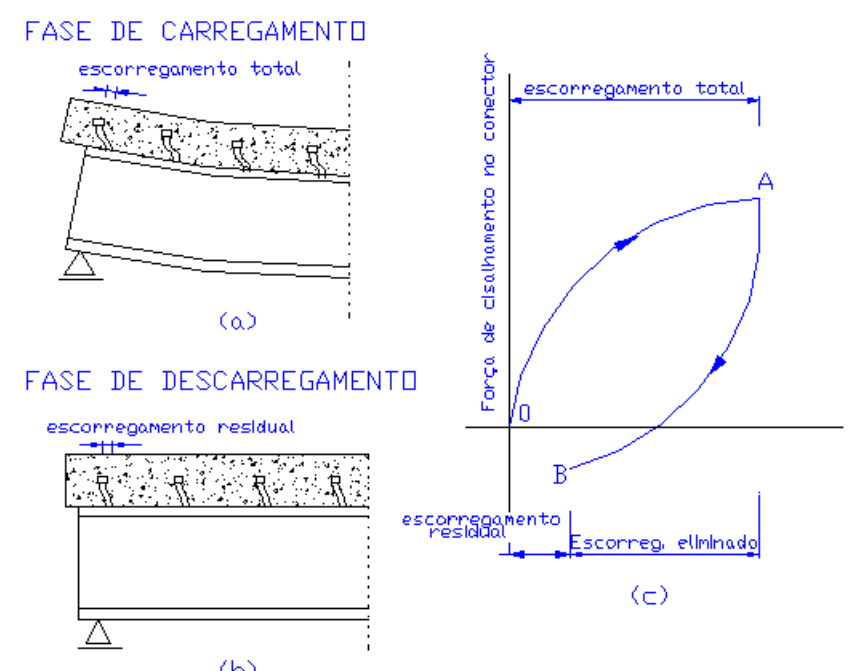

(b)

FIGURA 3.17 - Deformação inelástica em conectores de cisalhamento.

GATTESCO \& GIURIANI (1996)

Poucos estudos tem sido realizados sobre o comportamento inelástico de conectores de cisalhamento submetidos a cargas cíclicas. GATTESCO \& GIURIANI (1996) propuseram um modelo de ensaio alternativo ao modelo de push - out para analisar este problema; contudo são necessários maiores estudos para obter maiores informações.

\section{5 - Considerações adicionais}

Apresentou-se, neste capítulo, várias ações e efeitos secundários que produzem solicitação em tabuleiros de pontes. Como o leitor deve ter observado, alguns destes efeitos (o de carga móvel por exemplo) podem ser facilmente considerados na análise clássica de estruturas; outros efeitos (os de fadiga, retração e fluência por exemplo) não podem ser considerados numa simples análise, sendo necessário recorrer a métodos mais 
elaborados de análise como os elementos finitos, ou ainda, à análise experimental para que, a partir dos resultados obtidos e comportamento observado na estrutura, possam ser adotados valores limites de tensão e deformação ou expressões simplificadas que facilitem o cálculo.

Os efeitos de retração, fluência e fadiga não foram considerados nos modelos analisados em função da dificuldade encontrada para incorpora-los no programa, pois implicaria na introdução de rotinas adicionais de cálculo e de resultados experimentais para comparações, estes podem ser objeto de estudo em trabalhos futuros. 


\section{ANÁLISE ESTRUTURAL}

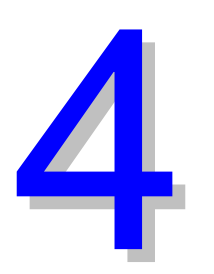

\section{DE TABULEIROS DE PONTES}

\section{1 - Aspectos gerais}

A resposta estrutural de um tabuleiro pode ser analisada de duas formas: matematicamente e experimentalmente; se o estudo é abordado do ponto de vista matemático, o modelo que representa o problema é chamado de modelo matemático, se é realizado do ponto de vista experimental, o modelo é denominado de físico (JAEGER \& BAKHT, 1989).

Tanto na análise matemática, como na experimental, o tabuleiro e as cargas atuantes devem ser modeladas. Com frequência costuma-se estudar o comportamento de pontes existentes através de "prova de carga", que consiste na passagem de um ou mais veículos ao longo do tabuleiro.

Neste trabalho foi abordada apenas a análise matemática, onde os diferentes modelos de cálculo foram adotados com base em idealizações, obtidas através de hipóteses simplificadoras.

$\mathrm{Na}$ atualidade existem várias técnicas de análise estrutural, aplicáveis ao estudo das pontes. QUIROGA (1983) indica que os parâmetros característicos que determinam a eleição do método de cálculo mais adequado podem ser agrupados em três categorias:

a) forma da seção transversal;

b) geometria em planta;

c) condições de apoio. 
Um mesmo tabuleiro de ponte pode ser representado mediante diferentes modelos matemáticos, estes podem ser lineares, bidimensionais e espaciais.

O modelo linear é constituído por elementos unidimensionais. Estes são definidos por dois nós e podem modelar barras e vigas, segundo as coordenadas locais ${ }^{1}$ que estes possuam em cada nó. O elemento unidimensional constitui uma idealização de volumes que possuem duas dimensões muito inferiores a uma terceira denominada comprimento.

Um tabuleiro de ponte pode ser idealizado como viga se este possui um vão muito superior à sua largura (HAMBLY, 1991). Neste caso pode-se considerar válida a hipótese de que os efeitos de flexão e torção atuantes numa seção transversal ocasionam deslocamentos relativos, entre um ponto e outro desta, inferiores aos ocasionados na direção longitudinal (ver figura 4.1). No caso dos deslocamentos relativos dos pontos da seção transversal serem consideravelmente inferiores aos longitudinais, resulta válida a consideração de que a seção transversal da viga não sofre deformações.

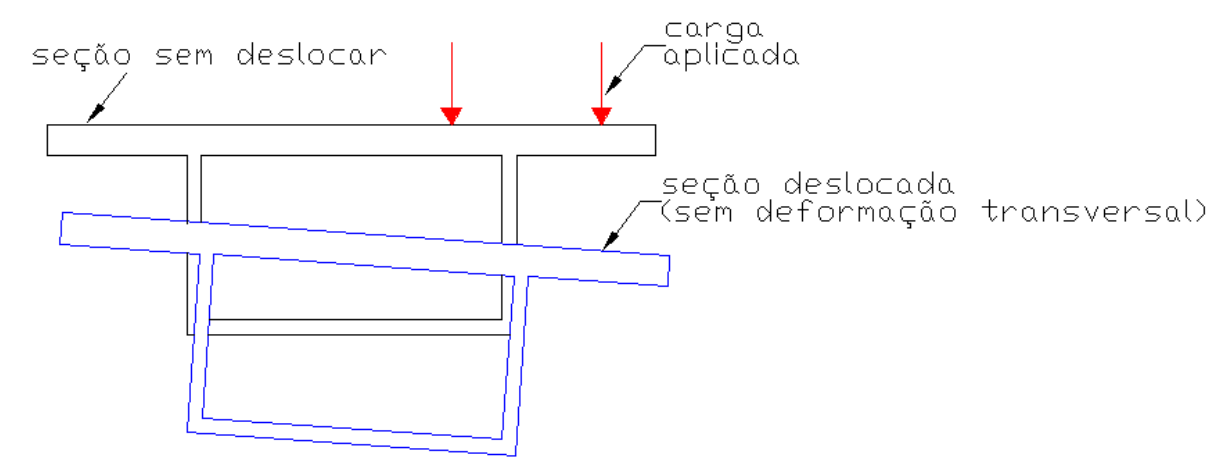

FIGURA 4.1 - Deslocamento de corpo rígido da seção transversal do tabuleiro. HAMBLY (1991)

O modelo bidimensional é composto por elementos planos e lineares, este surge da idealização de um volume que possui duas dimensões muito superiores a uma terceira, denominada espessura. Na figura 4.2 ilustram-se

\footnotetext{
${ }^{1}$ Ver MOREIRA (1977)
} 
duas formas de representação de tabuleiros mistos através de modelos bidimensionais: a) através da associação no plano de elementos de viga, de maneira a formar uma grelha; b) através de elementos de placa enrijecidos por elementos de vigas.

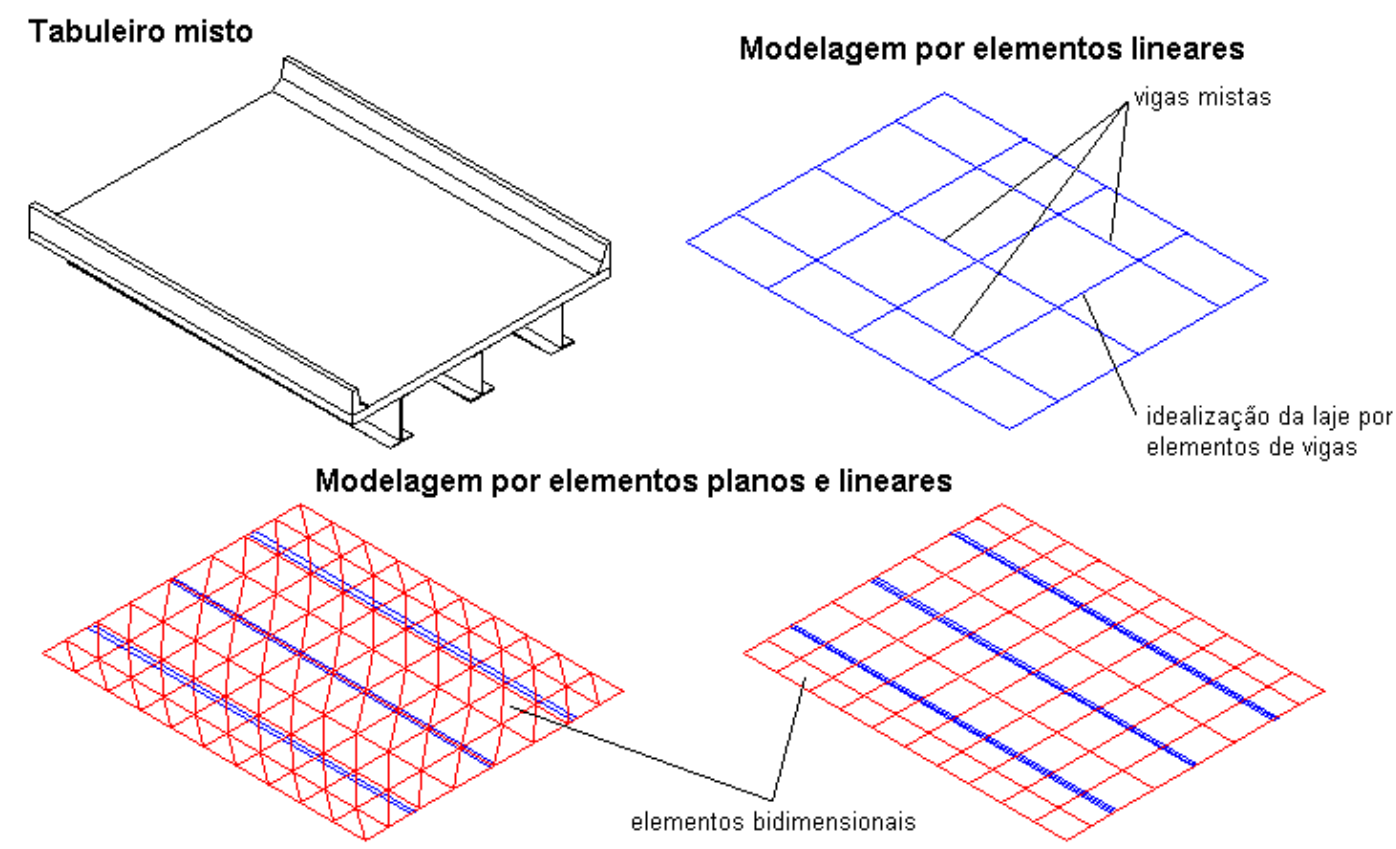

FIGURA 4.2 - Representação de tabuleiros mistos através de modelos bidimensionais.

O modelo tridimensional é o mais completo e, em geral, é utilizado para estudar efeitos localizados na estrutura. Este modelo é constituído por elementos lineares, planos e tridimensionais. $O$ elemento tridimensional surge da idealização de volumes nos quais nenhuma dimensão predomina sobre as outras. $\mathrm{Na}$ figura 4.3 apresentam-se algumas modelagens tridimensionais de um tabuleiro, estas podem ser montadas a partir de um tipo de elemento ou da combinação de dois ou três. 

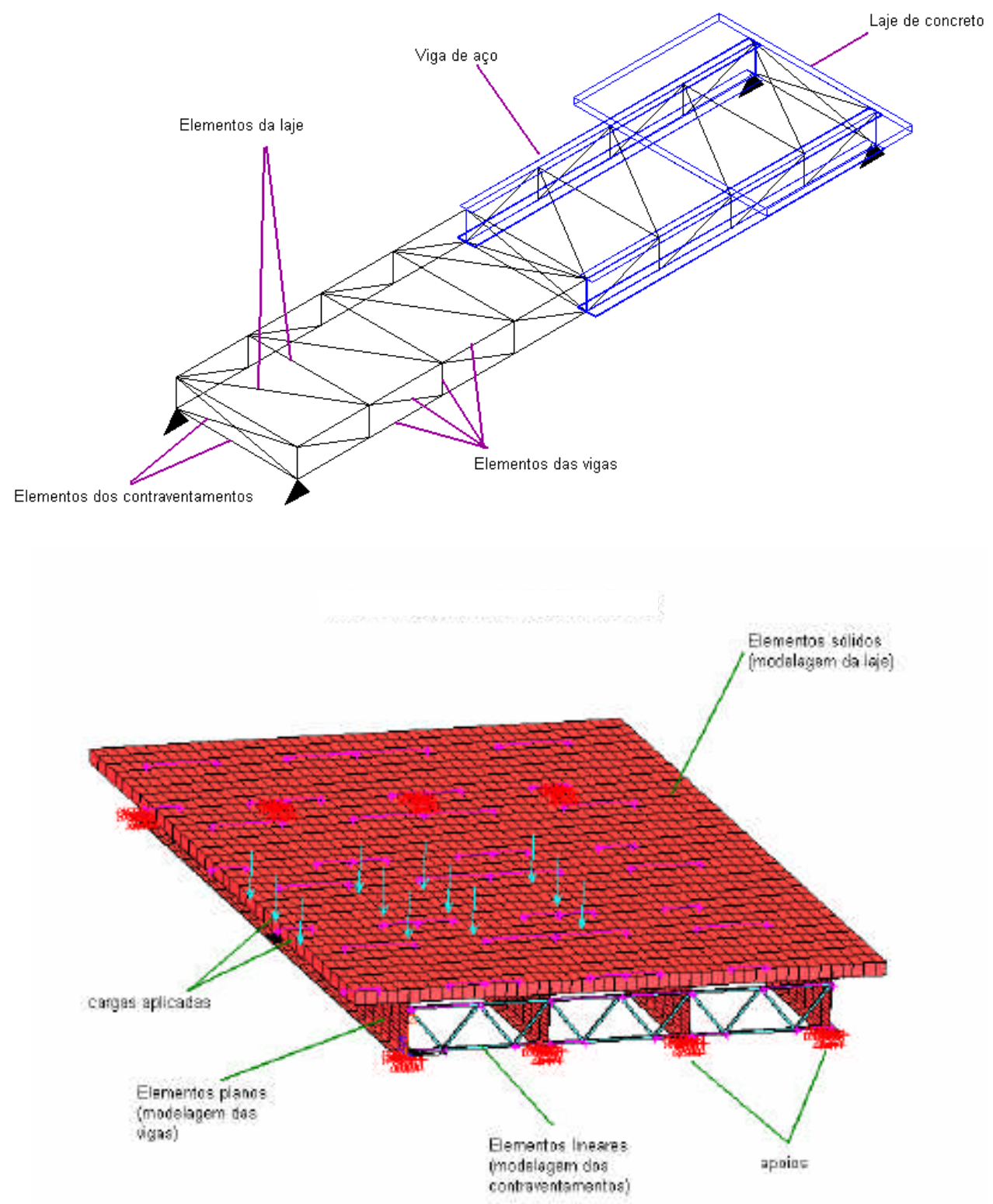

FIGURA 4.3 - Representação de tabuleiros mistos através de modelos tridimensionais formados por elementos lineares, planos e sólidos.

O estudo analítico de modelos bidimensionais e tridimensionais, mediante técnicas manuais de análise, resulta extremamente laborioso e, na maioria das vezes, inviável; isto deve-se à complexidade que implica a solução das equações matemáticas que regem a natureza do problema (muitas vezes estas equações não possuem solução fechada).

Muitas técnicas de análise têm surgido nos últimos 50 anos para contornar, ou, pelo menos simplificar o problema; entre estas destacam-se 
as técnicas baseadas em métodos numéricos que permitem a formulação do problema na forma matricial. Com o advento dos computadores e a implementação de rotinas baseadas em técnicas numéricas de análise, é possível hoje em dia analisar o comportamento estrutural de um tabuleiro de ponte, considerando este como um conjunto único e não mais elementos isolados (lajes, vigas, contraventamentos).

\section{2 - Tipos de análise}

Pelo exposto no item anterior, pode-se observar que o modelo adotado para representar uma ponte pode variar em função das características da estrutura, os recursos de análise e os resultados que se pretende obter.

$\mathrm{Na}$ tabela 4.1 apresentam-se várias técnicas de análise estrutural, aplicáveis ao estudo do comportamento global de tabuleiros em vigas mistas. Não é objeto deste trabalho apresentar de maneira detalhada todos os procedimentos mostrados na tabela, maiores detalhes podem ser obtidos nos excelentes textos publicados por QUIROGA (1983); HAMBLY (1991), CUSSENS \& PAMA (1975), JAEGER \& BAKHT (1989).

TABELA 4.1 - Métodos de análise para o estudo de tabuleiros de pontes. QUIROGA (1983)

\begin{tabular}{|c|c|c|}
\hline Modelo Estrutural & Procedimento de análise & Método \\
\hline 1. Laje Ortótropa & \begin{tabular}{|l|} 
Tabelas \\
Séries de Fourier \\
Séries de Fourier generaliza \\
Numérico: diferenças finitas \\
Numérico: elementos finitos \\
Numérico: bandas finitas \\
Numérico: métodos indireto
\end{tabular} & $\begin{array}{l}\text { 1.1. Guyon - Massonet - Rowe } \\
\text { 1.2. Laje ortótropa } \\
\text { 1.3. Laje ortótropa sem torção } \\
\text { 1.4. Laje ortótropa (d.f. })^{*} \\
\text { 1.5. Laje ortótropa (e.f.) } \\
\text { 1.6. Laje ortótropa }(\text { b.f. })^{* * *} \\
\text { 1.7. Laje ortótropa }(m . i)^{* * * *}\end{array}$ \\
\hline $\begin{array}{l}\text { 2. Estruturas prismátic } \\
\text { laminares }\end{array}$ & \begin{tabular}{|l|} 
Séries de Fourier \\
Séries de Fourier generaliza \\
Numérico: solução aproxim \\
Numérico: elementos finitos \\
Numérico: bandas finitas
\end{tabular} & $\begin{array}{l}\text { 2.1. Láminas prismáticas } \\
\text { 2.2. Lámina prismática intermédia } \\
\text { 2.3. Lámina prismática comprida } \\
\text { 2.4. Lámina prismática (e.f.) } \\
\text { 2.5. Lámina prismática (b.f.) }\end{array}$ \\
\hline 3. Grelha plana & Numérico: métodos matricia & Grelha plana \\
\hline 4. Pórtico espacial & Numérico: métodos matricia & Pórtico espacial \\
\hline 5. Estrutura 2-D & Numérico: elementos finitos & Elementos finitos (láminas) \\
\hline 6. Estrutura 3-D & Numérico: elementos finitos & Elementos finitos (volumes) \\
\hline
\end{tabular}

Nota: * diferenças finitas; ${ }^{* *}$ elementos finitos; ${ }^{* * *}$ bandas finitas; ${ }^{* * * *}$ métodos indiretos. 


\subsection{1 - Analogia de grelha}

Esta técnica talvez seja a mais popular de todas para a análise de tabuleiros, entende-se por analogia de grelha a associação de vigas longitudinais e transversais submetidas a cargas atuantes no plano perpendicular ao da associação.

A aplicação desta técnica é realizada supondo que as vigas mistas equivalentes do tabuleiro representam as vigas longitudinais da grelha, a laje de concreto e os contraventamentos das vigas representam as vigas transversais.

JAEGER e BAKHT (1982) apresentaram uma série de critérios que auxiliam na representação das cargas concentradas e na determinação do tamanho ideal da malha da grelha, de maneira que os momentos resultantes neste modelo sejam coincidentes com os obtidos através de modelos mais elaborados.

Com relação às propriedades geométricas dos elementos de grelha, o momento de inércia à flexão das vigas longitudinais é calculado em função das características de cada viga mista, levando em consideração o tipo de carregamento, os efeitos de retração e da fluência. Para os perfis metálicos de seção I a rigidez à torção e muito inferior à rigidez à flexão, segundo HAMBLY (1991) da ordem de 1/60, sendo por conseguinte, na maioria dos casos, desprezada.

As características geométricas das vigas transversais da grelha são calculadas em função da rigidez à flexão da placa de concreto e da rigidez do contraventamento, se este existir.

$\mathrm{Na}$ prática, a laje de concreto tem sido considerada como placa isotrópica, embora esta possua taxas de armadura diferentes nas direções transversal e longitudinal.

A aplicação da analogia de grelha desconsidera a excentricidade existente entre o centro de gravidade da laje e da viga; geralmente estes centros de gravidade são considerados coincidentes conforme mostra a figura 4.4. Outra simplificação realizada nesta técnica consiste em que os 
apoios das vigas são posicionados no centro de gravidade destas, na estrutura real estes se encontram sob as mesas inferiores.

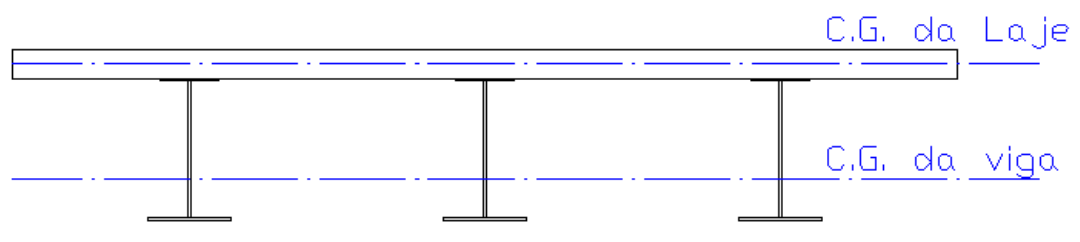

(a)

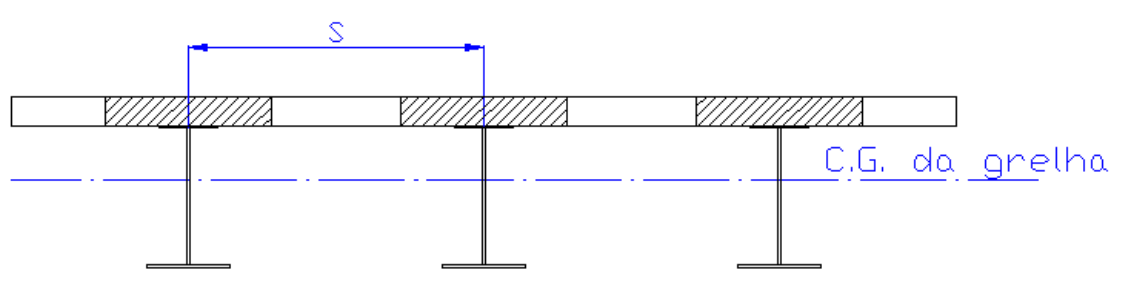

Viga Mista

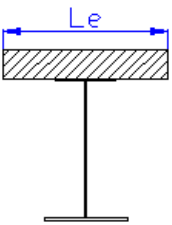

(b)

Figura 4.4 - a) Excentricidade entre os C.G. da viga e laje; b) analogia de grelha considerando os C.G. coincidentes.

Um modelo de grelha tridimensional foi apresentado por HAMBLY (1991) para considerar a excentricidade entre viga e laje; este consiste na introdução de barras rígidas nos pontos de interseção de vigas transversais e longitudinais.

\subsubsection{Estruturas prismáticas laminares (folded plate analysis)}

Esta técnica baseia-se na teoria elástica dos estados planos de tensão e de flexão de placas; o tabuleiro é considerado como uma casca composta por uma série de placas retangulares, interligadas entre si ao longo de um eixo longitudinal. Os primeiros a desenvolver esta técnica foram Goldberg \& Leve (1957) e posteriormente De Fries-Skene \& Scordelis (1964).

KRISTEK \& STUDNICKA (1988) aplicaram esta técnica para modelar vigas mistas através de lâminas, conforme ilustrado na figura 4.5, os pesquisadores estabeleceram que a ligação das lâminas da laje à da viga, deve possuir rigidez elevada na direção vertical; devendo também representar de maneira adequada a flexibilidade dos conectores. 


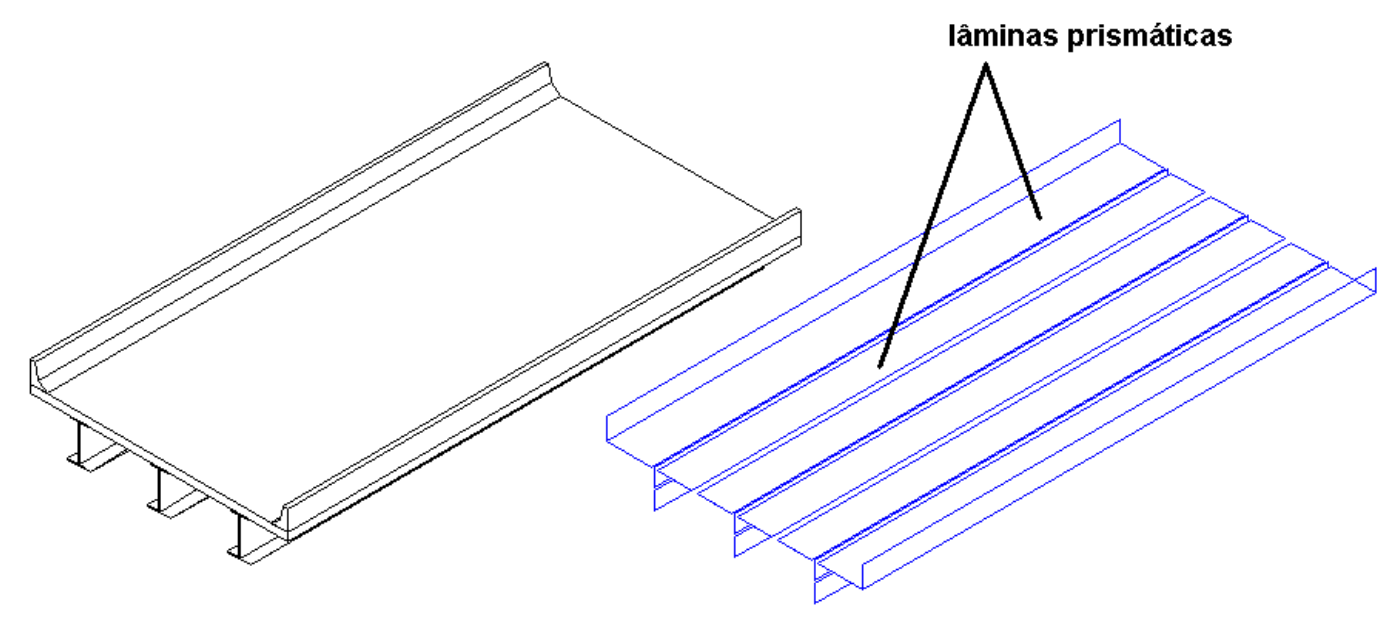

FIGURA 4.5 - Representação de uma viga mista através de lâminas prismáticas retangulares. JAEGER \& BAKHT (1989)

Para satisfazer as condições do parágrafo anterior deve-se impor as seguintes condições de compatibilidade de deslocamentos (ver figura 4.6):

$$
\begin{gathered}
v_{j}=v_{i}-\Phi \cdot a \\
w_{j}=w_{i}=w \\
\Phi_{j}=\Phi_{i}=\Phi \\
u_{j}=u_{i}-\frac{d w}{d x} \cdot a+q \cdot k
\end{gathered}
$$

onde $v_{\mathrm{i}}, \mathrm{w}_{\mathrm{i}}, \mathrm{u}_{\mathrm{i}}$ e $v_{\mathrm{j}}, \mathrm{w}_{\mathrm{j}}, \mathrm{u}_{\mathrm{j}}$ são os deslocamentos horizontal, vertical e longitudinal dos nós i e j respectivamente. $\Phi_{i}, \Phi_{j}$ são as rotações da ligação no plano da seção transversal; q é o fluxo de cisalhamento longitudinal atuante entre o tabuleiro de concreto e a viga de aço e a é a distância vertical entre os nós $i$ e $j$. Na montagem da matriz de rigidez da estrutura devem ser consideradas estas condições. 


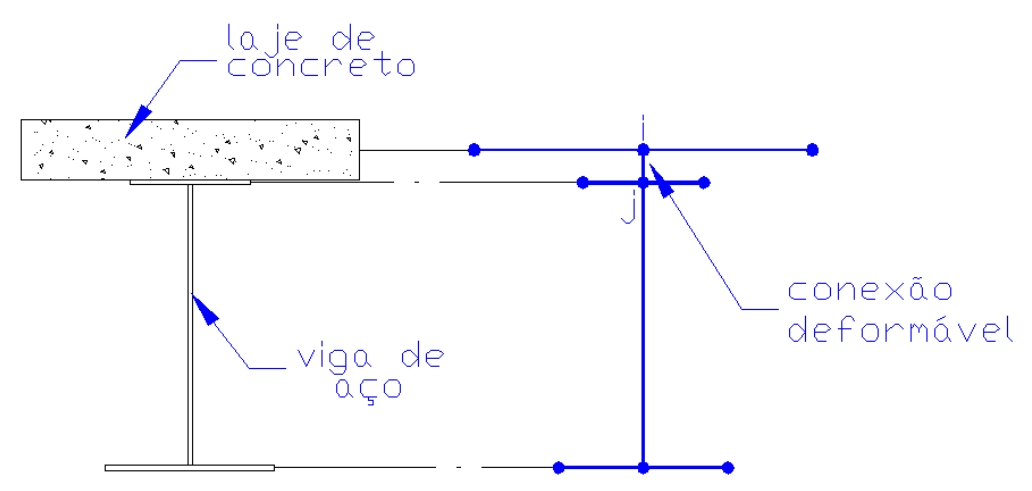

FIGURA 4.6 - Condições de compatibilidade de deslocamentos. KRISTEK \& STUDNICKA (1988)

\subsubsection{Análise proposta pela AASHTO}

Segundo a AASHTO (1989) o cálculo dos esforços, ocasionados nas vigas por ações móveis, pode ser realizado considerando que uma linha de rodas do veículo tipo atue diretamente sobre a viga em questão. A ação provocada por cada roda é então multiplicada pelo fator de carga $S / D$, onde $S$ é o espaçamento entre vigas longitudinais e $D$ um fator que depende das características da ponte. No caso de tabuleiros de concreto, apoiados sobre vigas de aço, a AASHTO considera dois casos (ver tabela 3.23.1 desta norma):

a) Pontes com uma via de circulação: adota-se um fator de distribuição de cargas de $S / 2,14$. Se $S$ for maior que $3 \mathrm{~m}$, adota-se como carga nas vigas a reação devida às cargas de roda considerando que a laje entre as vigas comporta-se como uma viga simplesmente apoiada.

b) Pontes com duas ou mais vias de circulação: adota-se um fator de distribuição de cargas de $S / 1,68$. Se $S$ for maior que $4,2 \mathrm{~m}$. adotase raciocínio similar ao descrito em a.

Tanto no item a) como no item b), considera-se $\mathrm{S}$ em metros.

No caso de tabuleiro de concreto suportado por 4 ou mais vigas de aço não deve ser tomado um fator de distribuição inferior a $S / 1,68$; onde $S$ 
deve ser menor ou igual a 1,80 m. Em casos em que $S$ for maior a 1,80 m e menor a 4,2 $\mathrm{m}$ ver item 3.23.2.3.1.5 da norma.

A norma ainda especifica que em caso nenhum uma viga interna deve possuir maior capacidade de carga do que uma viga externa (item 3.23.2.3.1.4).

As cargas assim obtidas são posicionadas na viga de maneira a provocar as solicitações máximas, podendo estas serem determinadas através das linhas de influência ou das tabelas fornecidas pela AASHTO (Apêndice A). Cabe ainda chamar a atenção para o fato de que este processo de cálculo considera o veículo tipo especificado pela AASHTO, não sendo apropriado para o cálculo de esforços provocados por cargas móveis diferentes.

A proposta descrita acima baseia-se no trabalho realizado por NEWMARK apud MARK et al (1993), este estudou a distribuição de carga de vários tipos de tabuleiros sobre vigas e obteve os fatores de distribuição $D$ calculando a média entre os fatores de distribuição obtidos nas análises para os diferentes tabuleiros. Devido a isto a proposta de análise da AASHTO leva a valores que às vezes são contra a segurança ou que levam a superdimensionar a estrutura.

A Segunda edição das especificações da AASHTO-LRFD (1998) ${ }^{1}$ para o projeto de pontes fornece no item 4.6.2 um método aproximado que fornece valores mais realistas que os obtidos pela AASHTO; no ANEXO B deste trabalho apresenta-se a formulação proposta pela AASHTO-LRFD (1998).

MARX et al (1993) estudaram através do método dos elementos finitos, o comportamento linear elástico de 108 pontes em viga reta. Os resultados obtidos na análise mostraram que o método de cálculo, proposto pela AASHTO, fornece valores que as vezes são inseguros e com frequência conservadores. Esta situação levou os autores do trabalho a proporem um método simplificado baseado nos resultados obtidos e que fornece valores mais próximos da realidade.

\footnotetext{
${ }^{1}$ BridgeSight Solutions for the AASHTO-LRFD Design Specifications http://www.bridgesight.com
} 
Este método baseia-se na formulação apresentada a continuação:

Para as vigas internas:

$$
D=\left(0,01538+\frac{S}{45,72}\right)\left[\frac{L}{\sqrt{H}}\right]+1,298+\frac{b}{30}
$$

Para as vigas externas com $H\left(\frac{S}{L}\right)^{3} \leq 0,0569$ :

$$
D=121,92 H\left(\frac{S}{L}\right)^{3}-145,69\left[H\left(\frac{S}{L}\right)^{3}\right]^{1,1}+2,042
$$

Para as vigas externas com $H\left(\frac{S}{L}\right)^{3} \geq 0,0569$ :

$$
D=1,597 H\left(\frac{S}{L}\right)^{3}+2.664
$$

Onde S e L são o espaçamento entre vigas e o vão da ponte em metros, respectivamente, e $\mathrm{H}$ é o fator de proporcionalidade entre a rigidez das vigas e da laje, conforme descrito no capítulo 6.

\subsubsection{Aspectos relacionados à redundância estrutural}

Julga-se importante reproduzir, nesta seção, as considerações que a AASHTO faz sobre a redundância estrutural de pontes. Em 1978 esta norma apresentou as primeiras especificações sobre o comportamento de elementos ou ligações de pontes não redundantes. Estas especificações determinaram condições especiais na consideração de fadiga de elementos e ligações submetidos às tensões de tração.

A AASHTO (1989) apresenta as seguintes definições para estruturas redundantes e não redundantes:

- Estrutura redundante ( com caminho alternativo de transmissão de carregamento): 
" São os tipos de estruturas que apresentam vários caminhos para transmissão de carga e a presença de uma única fratura em qualquer elemento não conduz ao colapso total".

\section{- Estrutura não redundante:}

"São tipos de estruturas onde a falha de um simples elemento pode causar o colapso da estrutura".

A norma americana classifica as pontes constituídas de duas vigas principais como "pontes não redundantes".

GHOSN \& MOSES (1994) estabeleceram que a redundância de um sistema estrutural pode ser definida como a capacidade que este possui para continuar suportando carregamento após a ruptura de um ou mais elementos. No caso de uma viga de aço, por exemplo, tensões ocasionadas por fadiga, corrosão, fogo, colisão de um caminhão ou navio, etc; podem ocasionar o colapso ou perda de um elemento estrutural.

Nestas condições, uma ponte deve possuir a capacidade de absorver o dano e continuar a operar sem oferecer riscos de utilização até a próxima inspeção, que pode acontecer em dias, semanas ou meses após o dano. Este período de tempo é relativamente curto em comparação ao tempo de vida útil da estrutura.

A utilização de modelos simplificados, em projetos de estruturas de pontes constituídas por duas vigas bi apoiadas, cria a falsa idéia de que o aparecimento de uma fratura localizada no meio do vão de uma das vigas ocasiona o colapso total da estrutura; na realidade neste tipo de tabuleiros as vigas, laje e sistemas de contraventamento vertical e horizontal constituem um entramado espacial, o qual, desde que esteja convenientemente contraventado e vinculado aos apoios, pode possuir vários caminhos alternativos para transferir as forças atuantes até os pilares e fundações.

Um exemplo de redundância pós-fratura de um tabuleiro em duas vigas é o da ponte I-40 sobre o Rio Grande. IDRISS et al (1995) provocaram 
uma fissura ao longo de quase toda a altura da alma de uma das vigas para investigar a influência que esta exerce na redistribuição das tensões atuantes nos elementos, na capacidade de carga e no risco de ocorrência de colapso. Na figura 4.7 é mostrada a seção transversal desta ponte.

\section{SEÇÃO TRANSVERSAL}

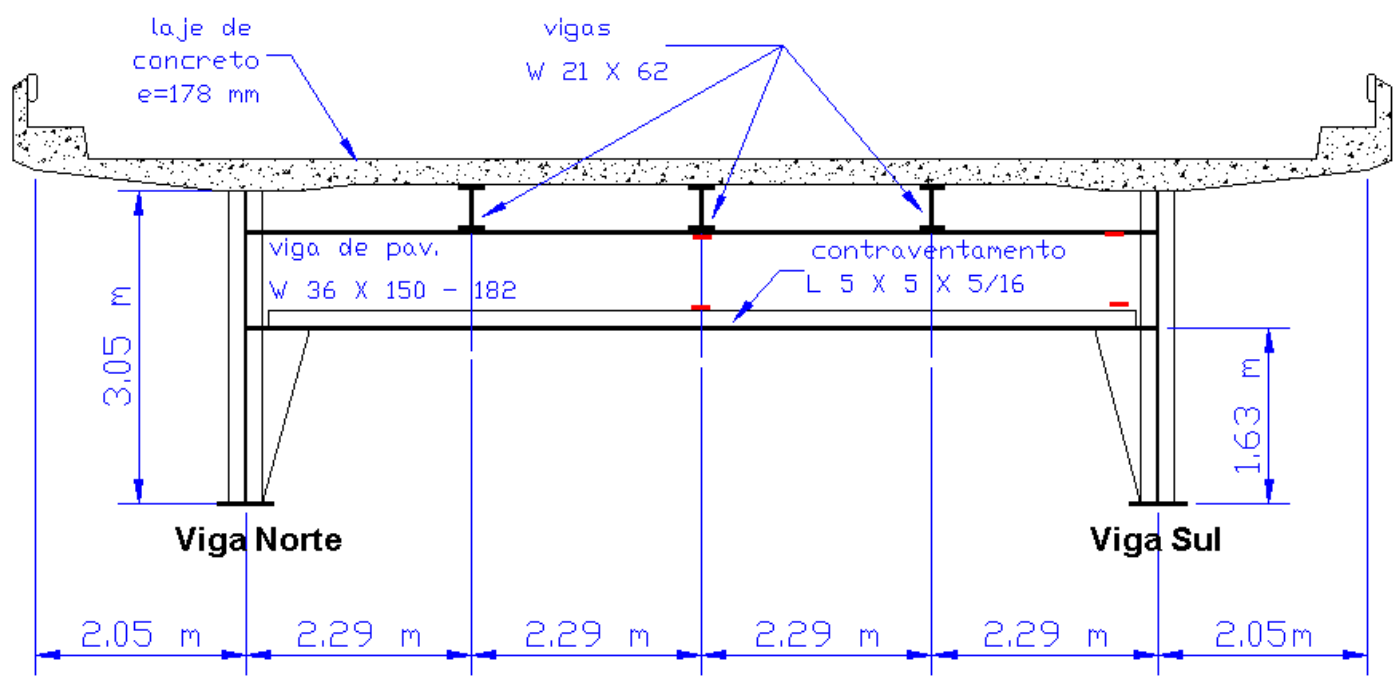

FIGURA 4.7 - Seção transversal da ponte I-40 sobre o Rio Grande. IDRISS et al (1995).

Na Figura 4.8 apresenta-se a disposição dos extensômetros nas vigas principais desta ponte. Os pesquisadores obtiveram no ensaio um deslocamento máximo no local da fissura de 30,2 mm sob ações de carga permanente e móvel (foi utilizado o caminhão tipo HS-18,35 como carga móvel), não foi verificada a ocorrência de plastificação nas vigas. A redistribuição de esforços foi observada nos elementos primários e secundários do tabuleiro .

Foi observado ainda que a viga fraturada teve um comportamento similar ao de uma viga em balanço, isto foi devido ao efeito da continuidade desta através dos apoios e ao sistema de contraventamentos horizontal e vertical. 

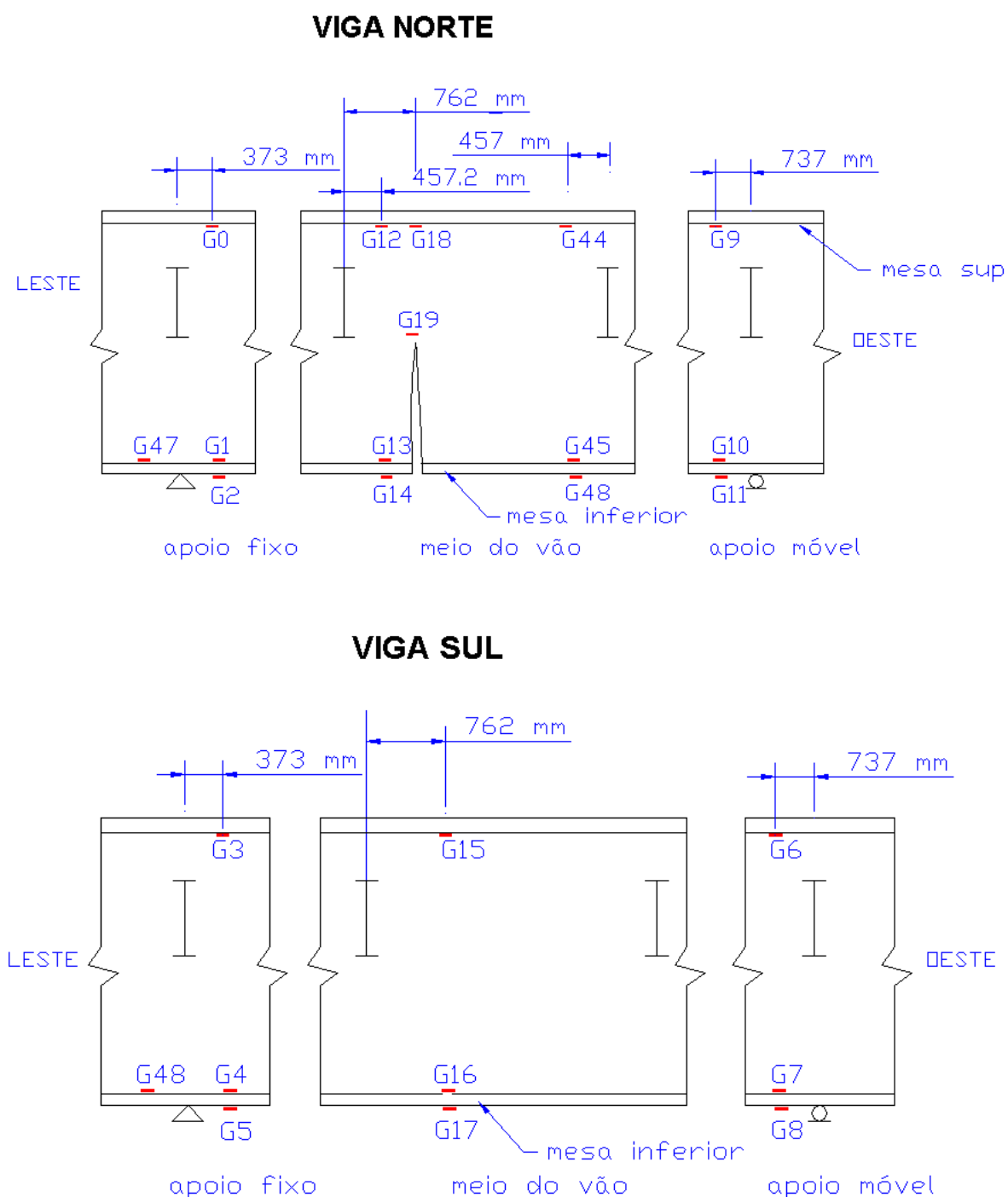

FIGURA 4.8 - Localização dos extensômetros nas vigas principais. IDRISS et al (1995).

Esta capacidade de carga que as pontes possuem após a ruptura de um elemento tem sido considerada por GHOSN \& MOSES (1992) como uma reserva de resistência, a qual varia em função da ductilidade dos elementos, geometria da ponte, número de vigas, elementos secundários e laje de concreto. NOWAK (1994) e GHOSN \& MOSES (1995) consideraram a reserva de resistência para determinar fatores de resistência que possam ser utilizados no projeto de maneira mais realista que os propostos pela AASHTO. 


\subsection{4 - Aplicação do método dos elementos finitos}

O método dos elementos finitos talvez constitui hoje em dia a mais poderosa ferramenta para a análise de estruturas. Foi inicialmente apresentado em um artigo por Turner, Clough, Martin e Topp (1959), os quais introduziram o conceito de subdividir uma estrutura de forma irregular em um grande número de elementos de formas mais simples, seguindo este raciocínio descobriram que se as equações que relacionam cargas e deslocamentos de um elemento simples são reproduzidas na forma matricial, seria possível utilizar a álgebra matricial para combinar os efeitos que interagem nos elementos. O advento do computador digital fez possível implementar este procedimento para resolver uma grande quantidade de problemas complexos que se apresentam na prática.

Não se pretende neste texto apresentar os fundamentos e formulação geral do método, estes podem ser encontrados nos excelentes textos que tratam sobre o assunto, como: ZIENKIEWICZ (1971), OÑATE (1995), BATHE (1996).

\subsubsection{Modelagens de tabuleiros de pontes encontradas na} literatura

A geometria da superestrutura de uma ponte pode ser idealizada de diferentes maneiras, sendo nesta fase e na escolha dos tipos de elementos finitos, que as maiores diferenças são encontradas nos trabalhos publicados sobre o assunto.

Vários pesquisadores tem estudado o comportamento estrutural de tabuleiros de pontes em vigas através do método dos elementos finitos. ZIENKIEWICZ (1971) apresentou a idealização do tabuleiro da ponte Castleton; o tabuleiro era composto por uma laje de dois vãos apoiada sobre vigas de concreto em todo o contorno. Foram utilizados elementos triangulares de placa para modelar a laje e elementos de barra para as 
vigas, neste modelo foi considerado o C.G. da laje coincidente com o das vigas.

HAYS et al. (1986) idealizaram a superestrutura de uma ponte usando elementos de placa e elementos espaciais e planos de barra, considerando o centroide das vigas coincidente com o da laje. BISHARA et al (1984) modelaram a superestrutura da ponte utilizando elementos de placa para a laje e alma das vigas e elementos de barra para as mesas (Figura 4.9).

\section{SEÇÃO TRANSVERSAL}

\section{ELEVAÇÃo}

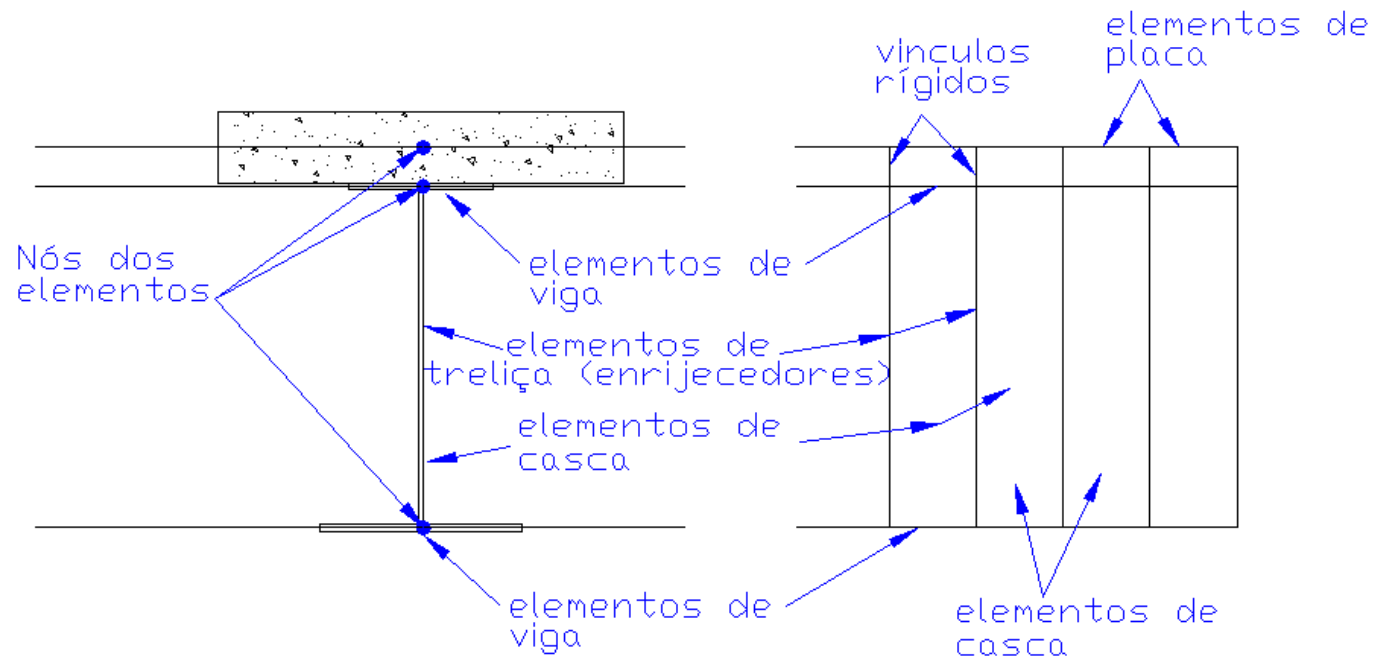

FIGURA 4.9 - Modelagem de viga mista de ponte. BISHARA et al (1993).

Os pesquisadores realizaram várias análises de tabuleiros apoiados sobre cinco vigas, estes possuíam diferentes vãos e ângulos de esconsidade; o programa utilizado na análise foi o ADINA (1984). Na tabela 4.2 apresenta-se uma comparação entre os resultados teóricos e experimentais obtidos pelos pesquisadores.

TABELA 4.2 - Comparação entre valores teóricos e experimentais. BISHARA et al (1993).

\begin{tabular}{|l|c|c|c|c|c|}
\cline { 2 - 6 } \multicolumn{1}{c|}{} & \multicolumn{5}{c|}{ Número da viga } \\
\cline { 2 - 6 } \multicolumn{1}{c|}{} & 1 & 2 & 3 & 4 & 5 \\
\hline $\begin{array}{l}\text { Distância do apoio ao local } \\
\text { da tensão medida }(\mathrm{m})\end{array}$ & 15,110 & 15,116 & 15,326 & 16,141 & 13,255 \\
\hline Tensão medida $(\mathrm{MPa})$ & 6,072 & 5,393 & 6,931 & 10,776 & 10,569 \\
\hline Tensão obtida pelo MEF $(\mathrm{MPa})$ & 4,410 & 5,994 & 5,429 & 10,590 & 11,713 \\
\hline
\end{tabular}


KENNEDY et al (1989) estudaram, mediante o método dos elementos finitos, o comportamento estrutural de pontes mistas com contraventamentos soldados e parafusados. Os resultados da análise, fornecidos pelos programas SAP IV e STRUDL, foram comparados com resultados experimentais. A comparação mostrou que diafragmas soldados contribuem de maneira mais efetiva na distribuição transversal de cargas. Na figura 4.10 apresenta-se uma comparação dos deslocamentos teóricos e experimentais, obtidos através da análise de tabuleiros com contraventamentos soldados e parafusados; observa-se nesta figura que os resultados teóricos obtidos a partir do modelo de grelha são muito próximos aos experimentais.
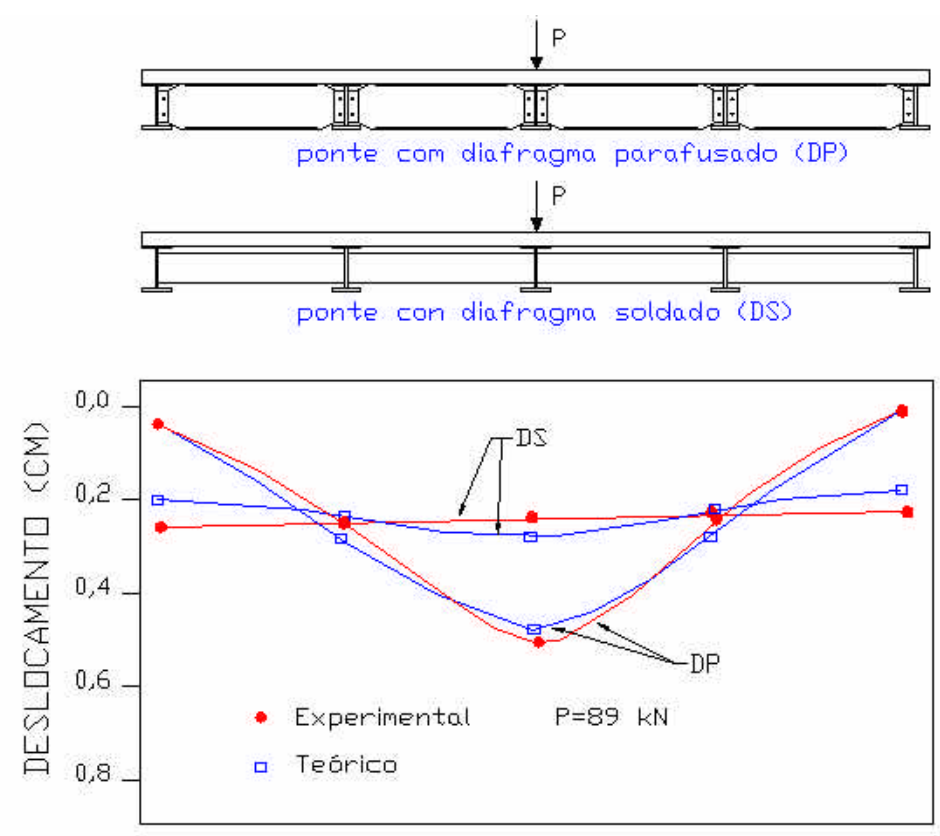

FIGURA 4.10 - Comparação entre deslocamentos teóricos e experimentais. KENNEDY et al (1989)

TARHINI \& FREDERICK (1992) utilizaram um modelo tridimensional de tabuleiro misto para estudar a distribuição de cargas sobre as vigas de aço. A laje de concreto foi representada por elementos tridimensionais isotrópicos de oito nós com três graus de liberdade por nó. A alma e mesas das vigas foram modeladas por elementos de casca quadrilaterais com cinco 
graus de liberdade por nó. Os contraventamentos tipo $X$ da ponte foram modelados através de elementos de treliça (Figura 4.11).
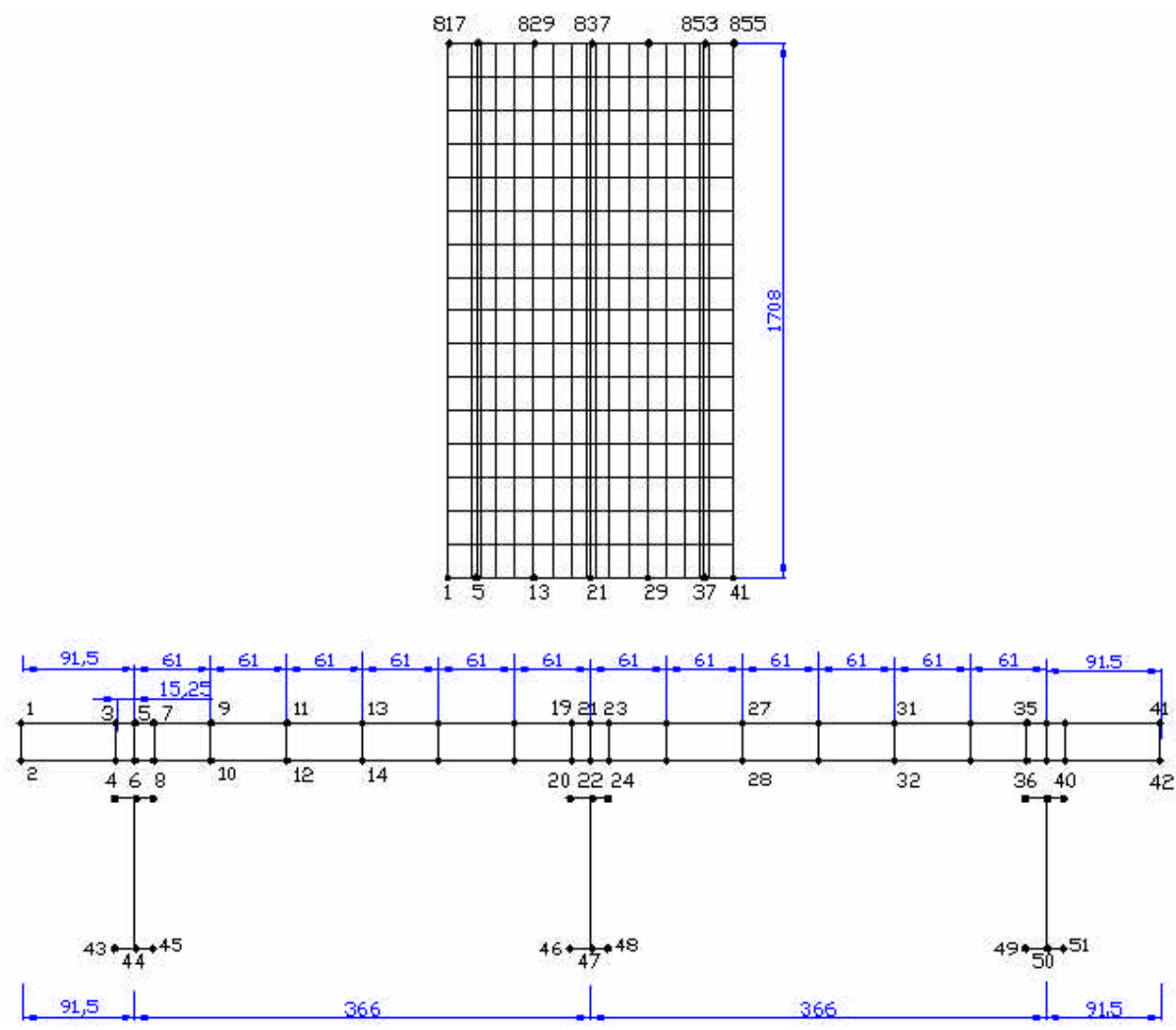

FIGURA 4.11 - Modelo tridimensional utilizado por TARHINI \& FREDERICK (1992).

A partir dos resultados obtidos, os pesquisadores propuseram uma formulação alternativa à proposta pela AASHTO para calcular os fatores de distribuição de carga. Esta proposta baseia-se na seguinte expressão (S e L em pés):

$$
D=0.00013 L^{2}-0,021 L+1,25 \sqrt{S}-\frac{S+7}{10}
$$

SFER et al (1995) realizaram a modelagem por elementos finitos de um tabuleiro de ponte constituído por uma laje apoiada sobre 7 vigas de concreto armado. A representação da laje e das vigas foi realizada através de elementos isoparamétricos lineares de oito nós. No trabalho foi estudada a distribuição transversal das forças aplicadas nas vigas do tabuleiro; para 
isto foi disposta uma carga concentrada por vez na metade do vão do tabuleiro e sobre cada uma das vigas.

Os resultados obtidos por esta análise foram comparados com os fornecidos através da técnica da analogia de grelha e da modelagem por estruturas prismáticas laminares. A comparação foi feita através dos coeficientes de distribuição obtidos para cada viga do tabuleiro.

Os autores da análise concluíram que o método dos elementos finitos se ajusta melhor à realidade devido a que neste são utilizadas menos idealizações e simplificações que nos outros dois.

ANSOURIAN \& RODERICK (1978) determinaram que um sistema misto de vigas e laje pode ser representado de diferentes maneiras pelo método dos elementos finitos, segundo estes, a laje pode ser idealizada por elementos sólidos tipo "brick" ou por elementos de placa delgada na superfície média desta. As vigas são representadas pelos elementos convencionais de viga utilizados na análise estrutural de pórticos. A excentricidade entre os centros de gravidade da viga e da laje é levada em consideração através da introdução de barras rígidas que vinculam os C.G. da viga e da laje nos pontos nodais destas (Figura 4.12).

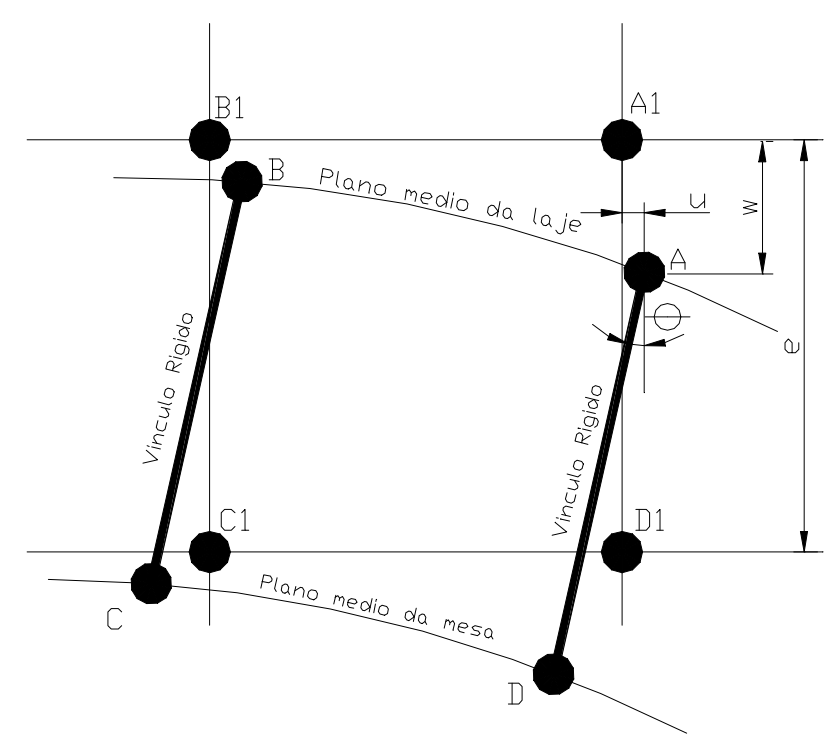

FIGURA 4.12 - Condições de compatibilidade na interface aço - concreto. ANSOURIAN \& RODERICK (1978). 
As condições de compatibilidade de deslocamentos representadas na figura 4.12 são:

$$
\begin{gathered}
\mathbf{u}_{\mathbf{D}}=\mathbf{u}_{\mathbf{A}}-\mathbf{e} \cdot \theta_{\mathbf{A}} \\
\mathbf{w}_{\mathbf{D}}=\mathbf{w}_{\mathbf{A}} \\
\theta_{\mathbf{D}}=\theta_{\mathbf{A}}
\end{gathered}
$$

onde u e w são os deslocamentos segundo as direções horizontal e vertical, $\theta$ é a rotação do nó e e a excentricidade entre os nós $A$ e $D$.

Na Figura 4.13 apresenta-se a distribuição de deformações, teórica e experimental, obtida por ANSOURIAN (1975) em uma viga mista em balanço. Os resultados teóricos foram obtidos através da modelagem da viga por elementos finitos, onde foram utilizados elementos sólidos de 16 nós para modelar a laje e elementos de viga para as vigas; a ação mista entre os dois materiais foi imposta através das condições apresentadas na figura 4.12.

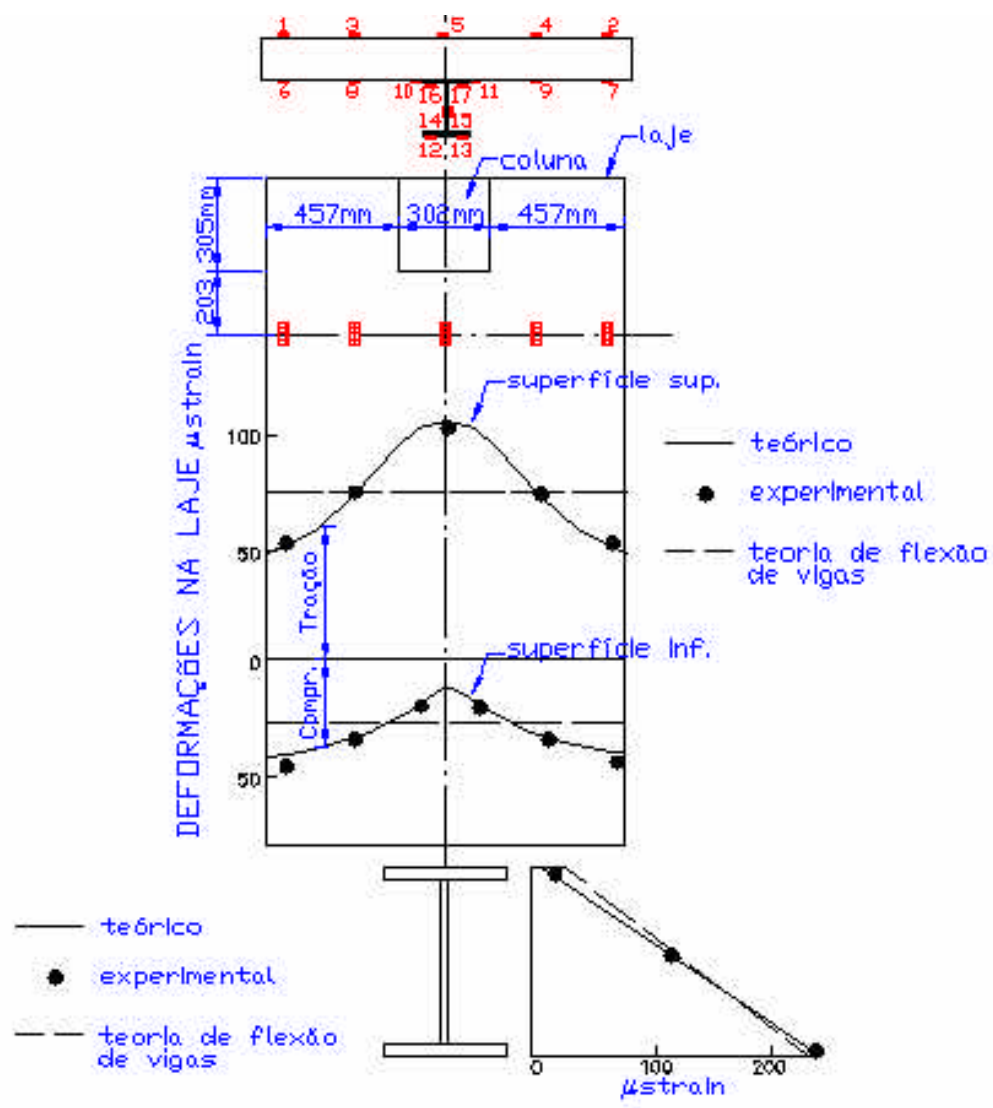

FIGURA 4.13 - Comparação entre resultados teóricos e experimentais.

ANSOURIAN (1975) 
O conceito de introdução de vínculos rígidos entre as vigas e a laje tem sido também utilizado por AKTAN et al (1993) para estudar os mecanismos de transferência de solicitações em tabuleiros contínuos.

O comportamento não linear de vigas mistas em tabuleiros de pontes tem sido estudado por RAZAQPUR \& NOFAL (1990), estes realizaram uma modelagem por elementos finitos para estudar o comportamento não linear de pontes em vigas mistas. Para isto foi desenvolvido o programa NONLACS no qual foram utilizados três tipos de elementos na modelagem de vigas, laje e conectores (Figura 4.14). Foram empregados elementos quadrilaterais de membrana RQUAD4 (Figura 4.14a) que combinados com elementos de placas quadrangulares de Kirchoff IDKQ (Figura 4.14b) deram origem ao elemento apresentado na figura 4.14c, formando assim um elemento de casca com seis graus de liberdade por nó: 3 rotações e 3 translações.

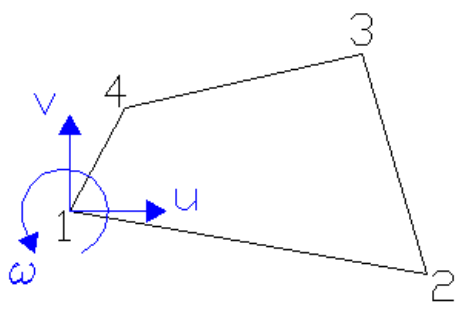

(a)

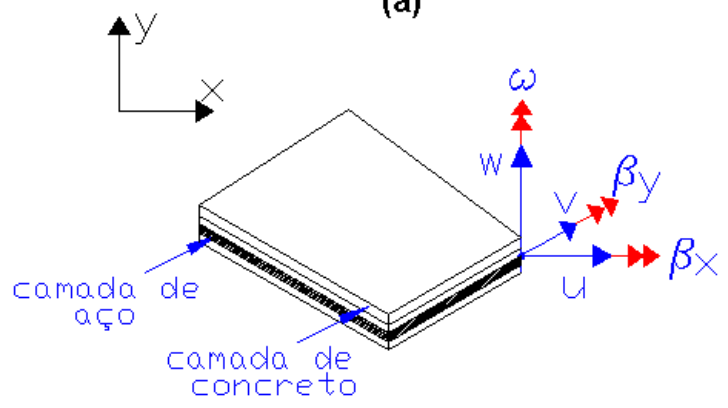

(c)

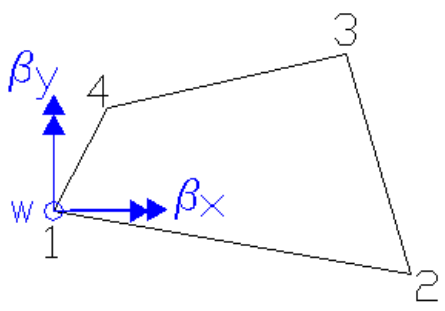

(b)

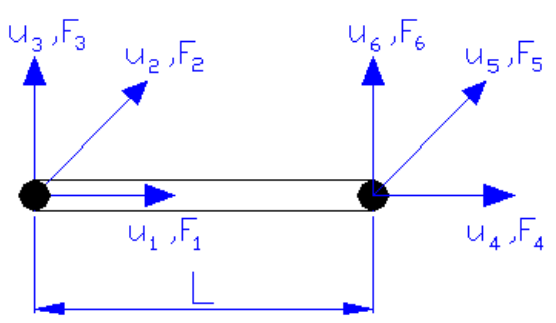

(d)

FIGURA 4.14 - Elementos finitos utilizados por RAZAQPUR \& NOFAL (1990)

A modelagem dos conectores de cisalhamento foi realizada através de elementos de barras ( figura 4.14d ) com três deslocamentos por nó. Os 
deslocamentos $u_{2}, u_{3}, u_{5}$ e $u_{6}$ foram obtidos a partir de relações empíricas de força - escorregamento ( Yam \& Chapman, 1968, 1972). Esta relação é apresentada da seguinte forma:

$$
F=a \cdot\left(1-e^{-b \lambda}\right)
$$

Onde F é a força de cisalhamento atuante no conector em uma dada direção, $\lambda$ é o escorregamento na direção de $F$ e a, b são constantes experimentais. Segundo Chapman e Yam a $=30 \mathrm{kN}, \mathrm{b}=5$ para conectores tipo "stud" de 19 mm diâmetro.

A matriz de rigidez deste elemento é obtida a partir de procedimentos básicos do método dos elementos finitos, onde as forças são relacionadas aos deslocamentos nodais $\mathrm{u}$ :

$$
\left\{\begin{array}{l}
F_{1} \\
F_{2} \\
F_{3} \\
F_{4} \\
F_{5} \\
F_{6}
\end{array}\right\}=\left[\begin{array}{cccccc}
k_{1} & 0 & 0 & -k_{1} & 0 & 0 \\
0 & k_{2} & 0 & 0 & -k_{2} & 0 \\
0 & 0 & k_{3} & 0 & 0 & -k_{3} \\
-k_{1} & 0 & 0 & k_{1} & 0 & 0 \\
0 & -k_{2} & 0 & 0 & k_{2} & 0 \\
0 & 0 & -k_{3} & 0 & 0 & k_{3}
\end{array}\right] \cdot\left\{\begin{array}{l}
u_{1} \\
u_{2} \\
u_{3} \\
u_{4} \\
u_{5} \\
u_{6}
\end{array}\right\}
$$

sendo $k_{1}=E A / L$ e $k_{i}=a b e^{-b \lambda_{i}}$.

Este elemento de barra permite a consideração de interação completa, parcial e nula entre o aço e concreto. Na figura 4.15 apresenta-se modelagem de uma viga mista de dois vãos e a comparação entre os valores teóricos e os experimentais obtidos a partir de ensaios. 


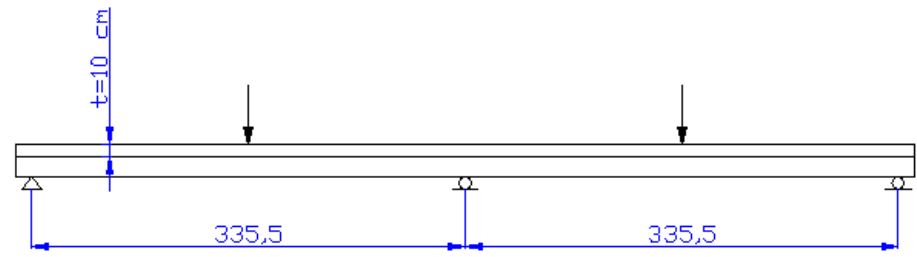

ELEVAÇã̃

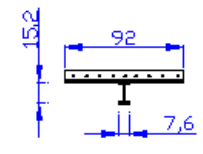

SEÇã̃ TRANSVERSAL

(a)

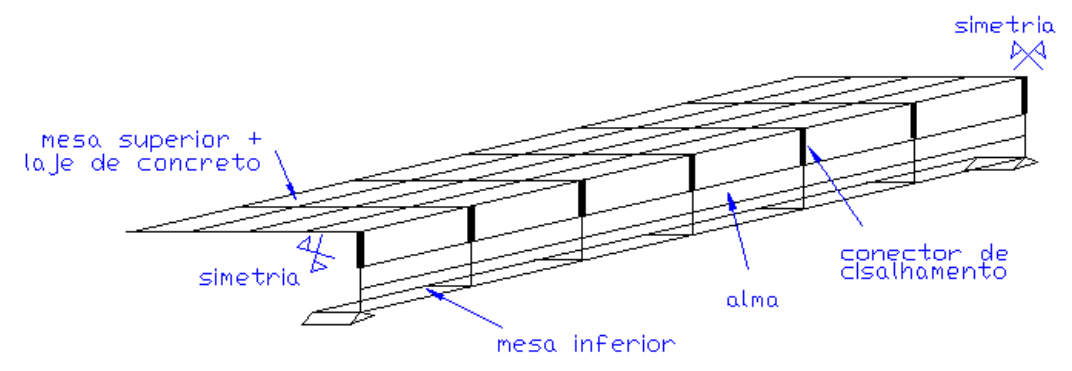

(b)

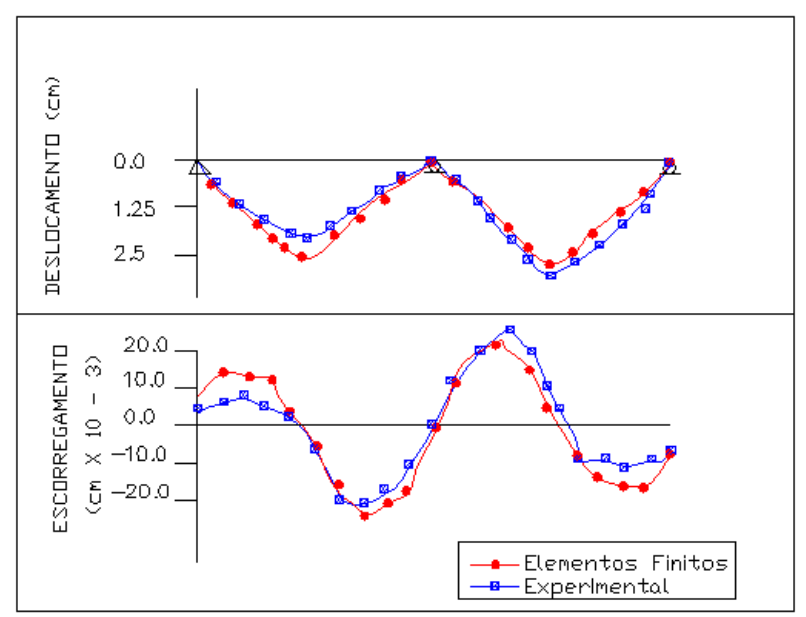

(c)

FIGURA 4.15 - a) Elevação e seção transversal da viga mista; b) modelagem por elementos finitos; c) comparação entre resultados teóricos e experimentais. RAZAQPUR \& NOFAL (1990)

HELWIG et al (1993) estudaram, via elementos finitos, a estabilidade lateral das vigas de aço antes da concretagem e cura da laje, e a maneira em que o posicionamento e quantidade de contraventamentos influencia na rigidez à torção do conjunto. O estudo foi realizado utilizando o programa ANSYS, sendo as vigas de aço modeladas por elementos de casca de oito 
nós e as barras dos contraventamentos por elementos de treliça conforme mostra a figura 4.16 .

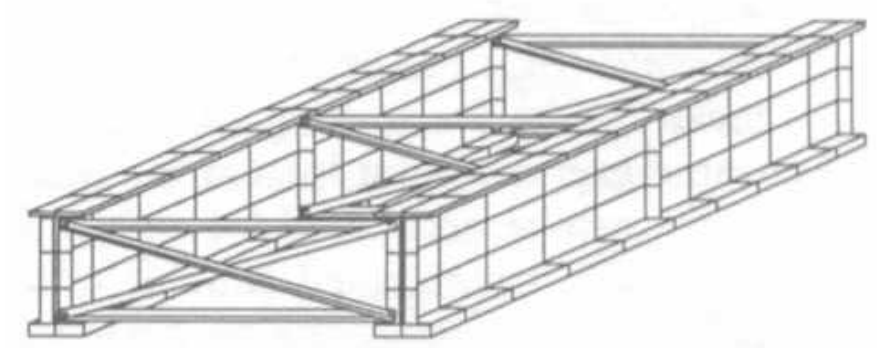

FIGURA 4.16 - Modelo analisado por HELWIG et al (1993).

AMADIO \& FRAGIACOMO (1993) apresentaram um tipo de elemento finito que permite a análise dos efeitos que a retração e fluência produzem em vigas mistas com conectores de cisalhamento deformáveis. Na figura 4.17 ilustra-se o modelo proposto, este é constituído por duas vigas paralelas, a primeira com comportamento visco - elástico e a segunda com comportamento linear elástico, assumindo que as duas vigas são associadas por um sistema de conectores elásticos de rigidez $\mathrm{k}(\mathrm{x})$.

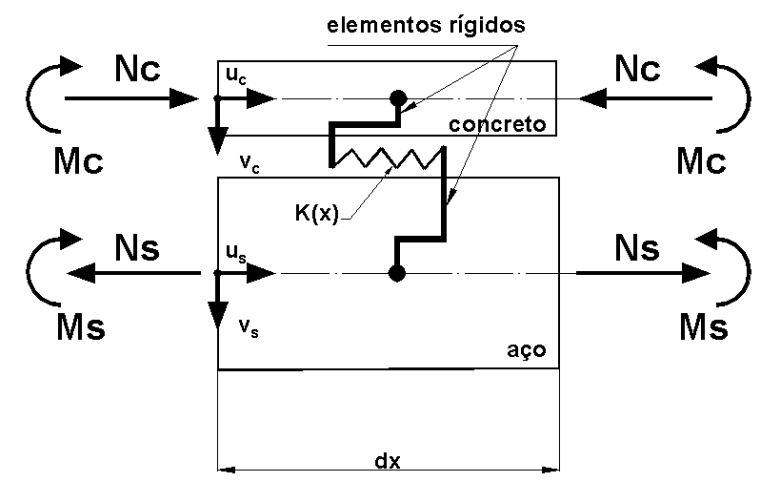

FIGURA 4.17 - Elemento finito proposto por AMADIO \& FRAGIACOMO (1993)

Tanto a matriz de rigidez deste elemento como as hipóteses consideradas para a obtenção desta podem ser encontradas no artigo publicado por AMADIO \& FRAGIACOMO (1993). 
A análise tridimensional de estruturas de pontes com transversinas intermediárias tem sido estudada por BATISTA \& EBECKEN (1980), estes utilizaram o processo semi-analítico, obtido através da combinação de elementos finitos com séries de Fourier. Neste método os deslocamentos, as cargas, forças de massa, expansão térmica, etc; são desenvolvidos em séries de Fourier e as forças nodais equivalentes são obtidas para o elemento isoparamétrico quadrilátero quadrático, de ampla divulgação na literatura. O problema tridimensional é reduzido a uma solução bidimensional, procedendo como se os elementos fossem planos, os deslocamentos são calculados e consequentemente são determinadas as tensões.

O estudo da distribuição transversal de cargas em tabuleiros mistos curvados tem sido abordado por BROCKENBROUGH (1986), o pesquisador utilizou o programa de elementos finitos MSC/NASTRAN.

$\mathrm{Na}$ análise a laje de concreto foi modelada com elementos de casca, as mesas das vigas por elementos de barra, a alma por elementos de casca (4 elementos ao longo da altura da viga) e os contraventamentos através de elementos de barra articulada (ver figura 4.18). A ligação entre aço e concreto foi modelada através de elementos rígidos de barra; na figura 4.19 apresenta-se as linhas de influência obtidas para um tabuleiro em curva, apoiado sobre quatro vigas.

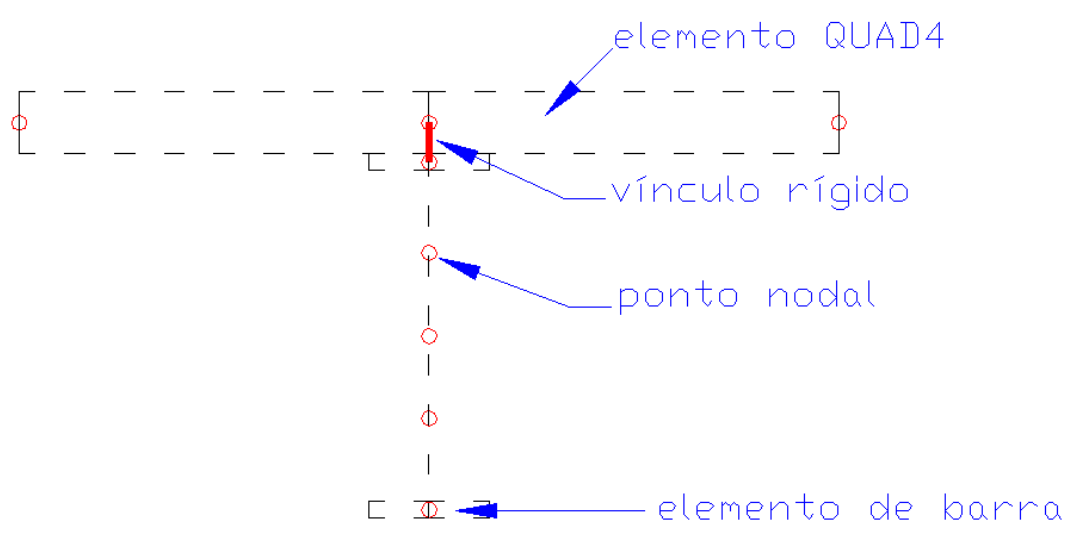

FIGURA 4.18 - Modelagem de uma seção de viga mista.

BROCKENBROUGH (1986) 


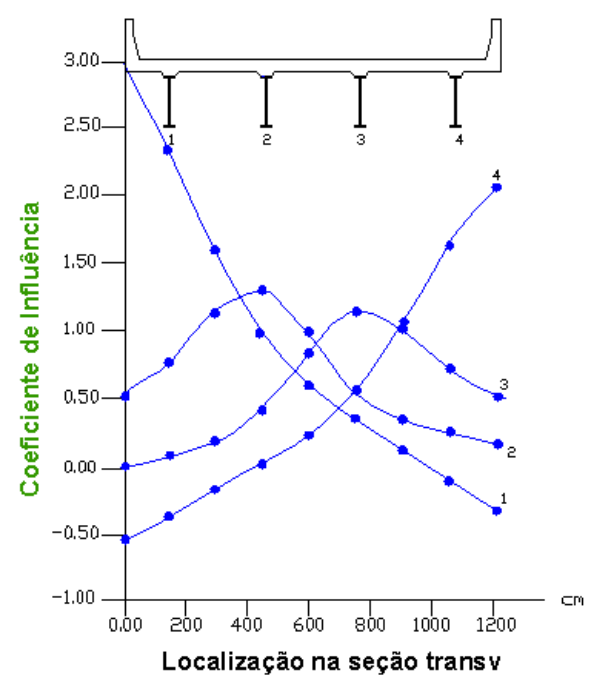

FIGURA 4.19 - Linhas de influência para tabuleiro curvo em planta.

BROCKENBROUGH (1986)

A aplicação da técnica de diferenças finitas na análise do comportamento de tabuleiros de pontes tem sido utilizada por ZHOU \& NOWAK (1987). Na aplicação foi considerado que o sistema de vigas, diafragmas e laje conformam uma placa ortotrópica.

AL AMERY e ROBERTS (1989), baseados no fato de que o escorregamento na interface aço - concreto é inevitável em pontes mistas, realizaram um estudo utilizando a técnica das diferenças finitas. A solução do problema requer o conhecimento dos módulos de elasticidade dos materiais envolvidos. Numa análise linear estes módulos são constantes, na análise não linear são funções de deformação ou deslocamento sendo necessário um processo iterativo para sua resolução.

OÑATE (1992), baseado na teoria de chapas grossas de ReissnerMindlin (seções planas se mantém planas após a deformação mas não necessariamente normais ao eixo neutro), apresentou a formulação para o estudo do comportamento não linear de cascas de concreto enrijecidas por elementos excêntricos de vigas.

Neste modelo as não linearidades físicas da casca e das vigas são modeladas através da representação dos elementos em várias camadas (ver figura 4.20) associadas a um modelo constitutivo para o aço e o 
concreto respectivamente; o modelo discretizado em camadas permite monitorar a evolução do dano acumulado em cada camada do aço e do concreto. Na figura 4.20 apresenta-se a discretização de uma viga mista de ponte.

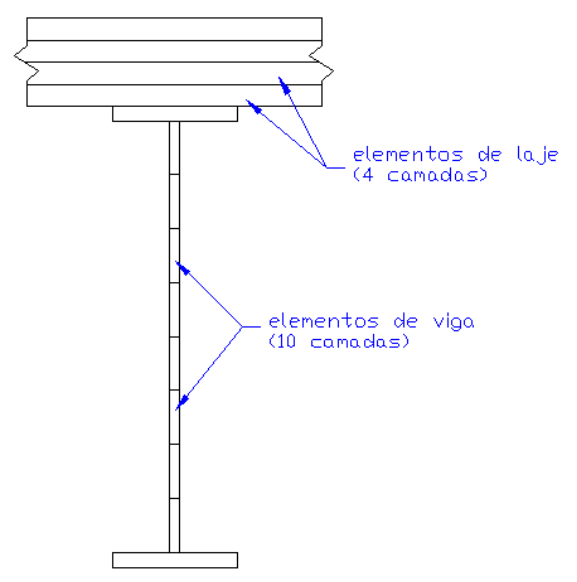

FIGURA 4.20 - Discretização de seção mista em várias camadas. OÑATE (1992).

De maneira geral, uma grande variedade de elementos de viga, placa, chapa, casca, sólidos, etc, tem sido propostos na literatura para realizar a modelagem e análise estrutural de tabuleiros mistos; os resultados obtidos em análises que incorporam estes elementos tem sido comparados com resultados obtidos através de métodos clássicos de análise e com resultados experimentais, de maneira a verificar se estes representam adequadamente o problema em questão.

Pelo exposto até aqui pode-se observar que, dependendo dos recursos disponíveis e objetivos que se pretende alcançar, uma análise estrutural pode ser realizada de diferentes maneiras.

$\mathrm{Na}$ análise estrutural por elementos finitos é fundamental determinar a natureza do problema em questão, ou seja, que tipo de elementos compõem a estrutura, quais as dimensões e geometria destes elementos, de que materiais a estrutura é constituída, qual o tipo de vinculação desta, qual a natureza do carregamento aplicado, que tipo de simplificações podem ser realizadas na idealização da estrutura sem comprometer a validade dos 
resultados, que parâmetros e variáveis se pretende estudar e que resultados devem ser fornecidos pela análise.

O estudo e discriminação de cada um destes aspectos é de vital importância pois auxilia na escolha do(s) tipo(s) de elemento(s) finito(s) a ser(em) utilizado(s) na análise, lembrando que podem existir várias formas alternativas de modelagem para representar uma mesma estrutura.

\subsection{3 - Análise experimental de tabuleiros de pontes}

A análise experimental de tabuleiros de pontes tem sido empregada extensamente para obter maiores conhecimentos sobre o comportamento estrutural destes. Ensaios realizados em pontes existentes geralmente visam obter informações sobre a distribuição de cargas nos elementos estruturais constituintes e verificar as condições de serviço sob as quais a estrutura opera (limites de utilização, limites últimos, grau de deterioração, etc).

Geralmente, a partir dos resultados experimentais é estabelecida uma correlação com os estabelecidos no projeto, de maneira a verificar se as hipóteses utilizadas são válidas ou aprimorar critérios de projeto.

Ensaios experimentais realizados por BAKHT \& JAEGER (1992) na ponte Stoney Creek, Canada, mostraram por exemplo que na interface entre a extremidade das vigas e os apoios surgem forças horizontais que são ocasionadas por atrito entre as duas superfícies; estas forças de atrito podem alterar o valor dos momentos esperados, no caso da ponte citada os momentos medidos foram inferiores em $11 \%$ aos valores esperados.

Na Figura 4.21 apresenta-se a seção transversal da ponte ensaiada pelos pesquisadores, as mesas superiores das vigas encontram-se parcialmente imersas na laje, o que ocasiona um certo comportamento misto da seção apesar de não existir conectores de cisalhamento. No ensaio foi observado que esta ação mista é perdida quando é aplicada uma carga de magnitude elevada. 

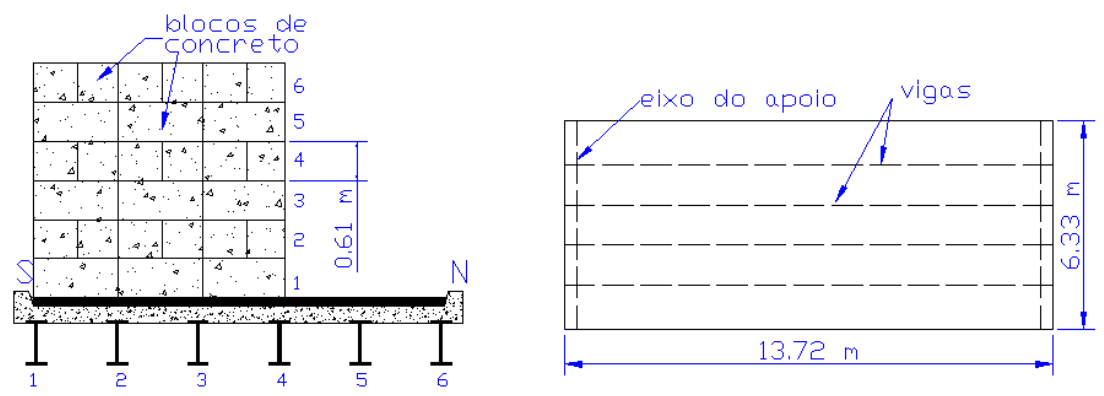

FIGURA 4.21 - Prova de carga na ponte Stoney Creek. BAKHT \& JAEGER (1992).

O tabuleiro da ponte foi carregado colocando blocos de concreto em diferentes níveis, cada bloco tinha um peso de 9,26 kN; na Figura 4.22 apresenta-se os fatores de distribuição correspondentes a cada viga, para cada nível de carregamento aplicado. Apresenta-se também nesta figura o gráfico de deslocamentos versus carga aplicada para a viga 2, observa-se que esta viga apresenta comportamento linear elástico durante a aplicação dos três primeiros níveis de carga.

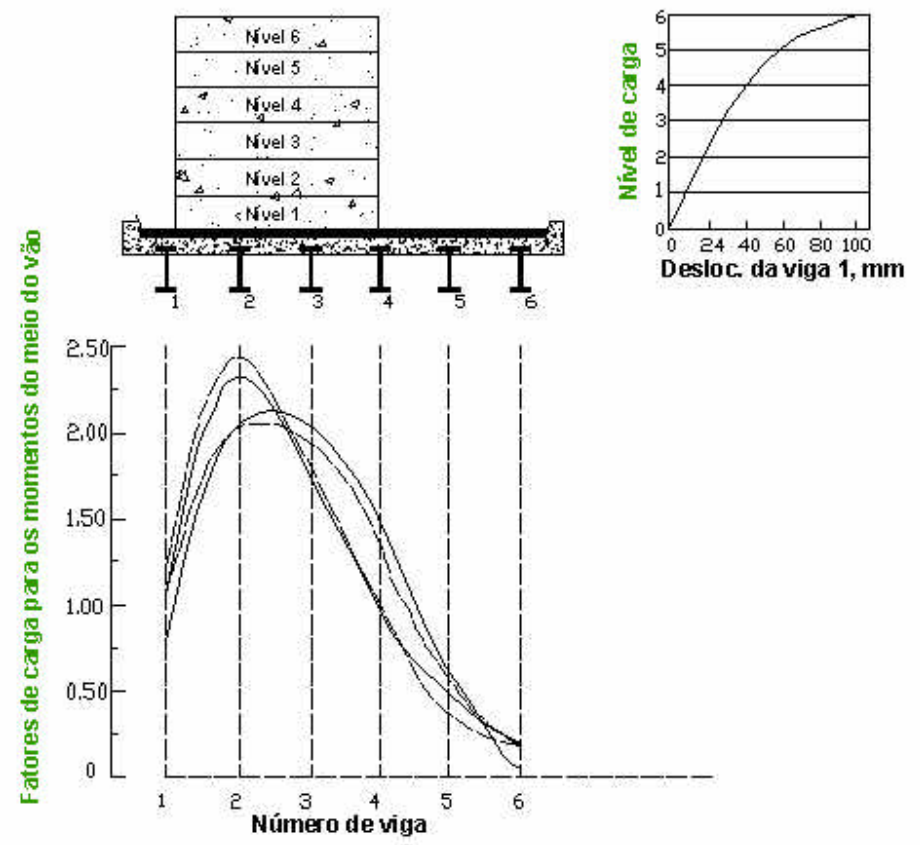

FIGURA 4.22 - Fatores de distribuição para cada nível de carregamento. BAKHT \& JAEGER (1992). 
NOWAK et al (1993) realizaram várias provas de carga sobre a ponte Woodrow Wilson Memorial Bridge, cuja seção transversal é ilustrada na Figura 4.23; foi observado no ensaio que as máximas tensões ocasionadas por carga móvel ocorreram nas vigas exteriores quando o veículo percorria o tabuleiro pela via direita, próximo às vigas de extremidade. Na Figura 4.23 apresentam-se também as tensões provocadas pela passagem do veículo na via direita.
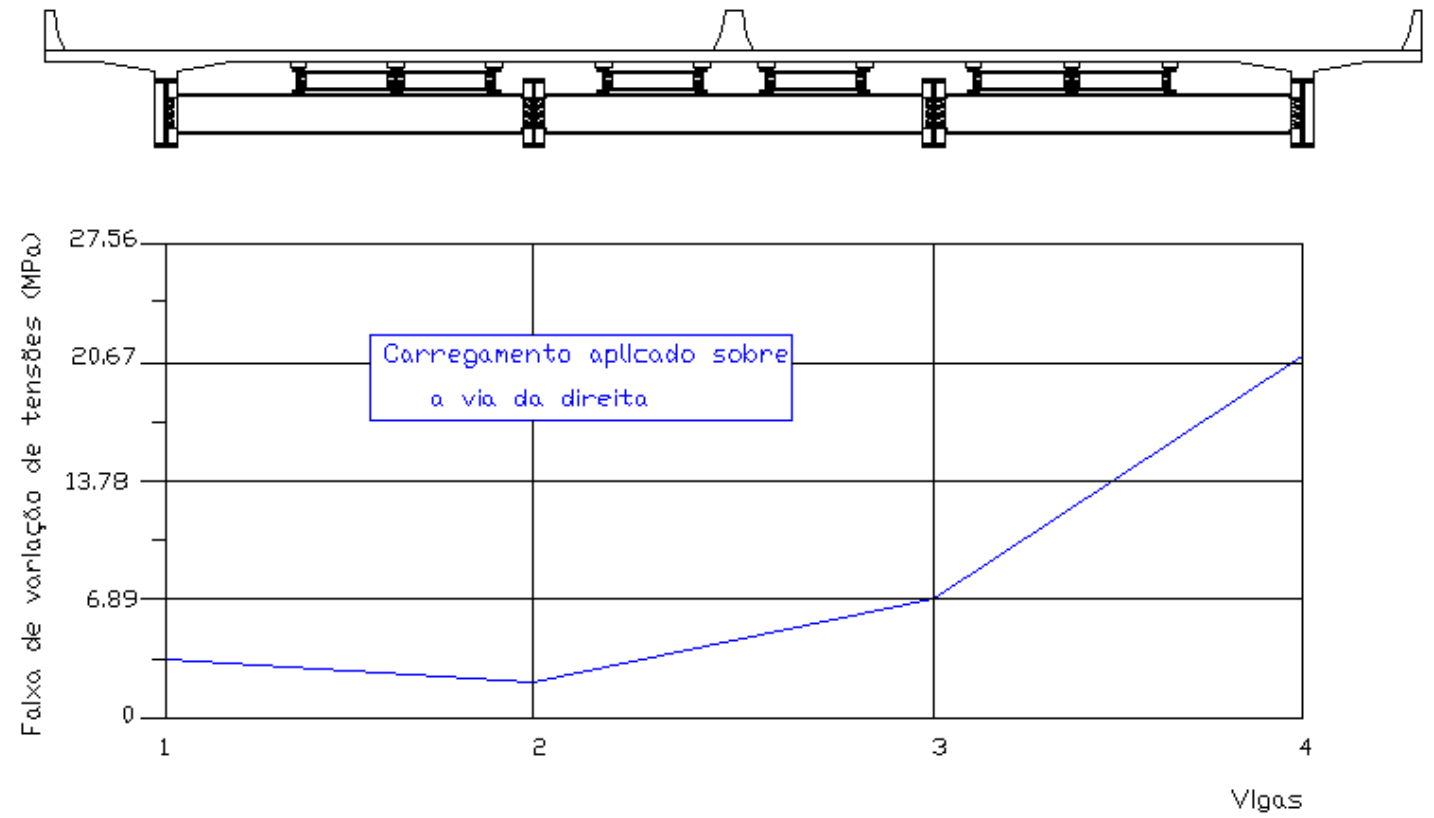

FIGURA 4.23 - a) Seção transversal da ponte Wilson Memorial Bridge; b) tensões atuantes nas vigas. NOWAK et al (1993).

DEATHERAGE et al (1995); obtiveram experimentalmente os coeficientes de distribuição de carga para a ponte Holston, para isto foram realizadas várias provas de carga com um veículo que tinha um peso total de 341,6 kN. Para caracterizar os fatores de distribuição da ponte ensaiada foram utilizados os parâmetros $\alpha$ e $\theta$, que são parâmetros de torção e de flexão respectivamente e que determinam os coeficientes de influência que devem ser utilizados para uma estrutura em particular ${ }^{1}$

\footnotetext{
${ }^{1}$ para maiores referências ver JAEGER \& BAKHT (1985)
} 
Um modelo reduzido de tabuleiro misto de dois vãos (escala 0,4 ) foi ensaiado por MOORE et al (1990) para estudar a forma em que a carga aplicada é distribuída, nas seções submetidas a momentos fletores positivos e negativos, os pesquisadores também estudaram a influência dos contraventamentos na distribuição transversal de cargas e concluíram que a influência destes é mínima. Na figura 4.24 apresenta-se a seção transversal do modelo ensaiado e a distribuição de forças axiais, nas mesas inferiores das vigas longitudinais, para a situação de carregamento.

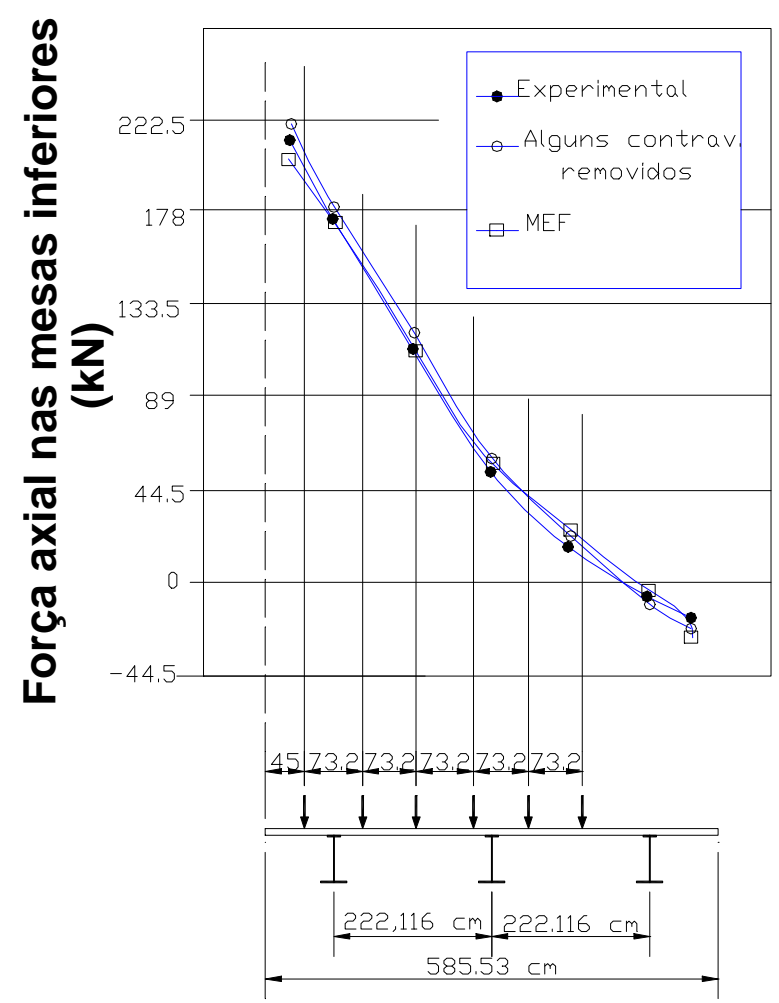

FIGURA 4.24 -a) seção transversal da ponte; b) distribuição de forças axiais. MOORE et al (1990).

Ensaios realizados por AZIZINAMINI et al (1994) em tabuleiros mistos simplesmente apoiados e constituídos por três vigas, mostraram que a presença de contraventamentos exerce pouca influência no comportamento estrutural da ponte, após a laje ter atingido uma resistência adequada e é capaz de transferir o carregamento aplicado para as vigas. 
Outras provas de carga realizadas por BAKHT \& MUFTI (1992) mostraram ainda que nem sempre é possível generalizar alguns aspectos para um mesmo tipo de ponte, ou seja, os resultados obtidos em uma prova de carga realizada em determinada ponte não são aplicáveis a uma outra do mesmo tipo.

Vários estudos experimentais tem sido apresentados neste item no intuito de mostrar que, de maneira geral, a análise rigorosa de um sistema estrutural composto pela associação de vigas e laje é complicada. Muitas vezes é necessário recorrer à experimentação para verificar a validade das técnicas teóricas utilizadas ou simplesmente porque não existem recursos de análise que permitam avaliar a resposta da estrutura em determinadas situações.

Questões como a deterioração do tabuleiro, vida útil restante, dano acumulado, perda de resistência da estrutura, etc, não podem ser analisadas por processos simplificados de análise, isto deve-se ao fato que envolvem uma série de variáveis complexas cuja influência no comportamento da estrutura somente pode ser conhecida através da pesquisa experimental ou de técnicas numéricas avançadas.

Em muitos casos a segunda alternativa resulta mais econômica. É obvio que a análise numérica deve fornecer resultados tão bons e confiáveis quanto os que se obteria através da experimentação. Isto pode ser conseguido pela representação das propriedades e geometria de todos os elementos estruturais e da interação entre estes da maneira mais realista possível. 


\section{TABULEIROS MISTOS MODELADOS PELO MEF}

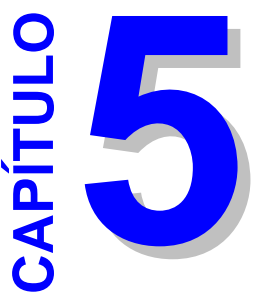

\subsection{Generalidades}

O estudo detalhado de tabuleiros de pontes através do MEF requer uma análise estrutural tridimensional. Se bem que existe a possibilidade de aproximar o comportamento estrutural da laje, alma e mesas das vigas ao de lâminas delgadas, estas devem ser asssociadas segundo diferentes planos ortogonais no espaço, dando ao problema um aspecto tridimensional conforme apresentado na figura 5.1.

Neste trabalho foram modelados vários tipos de tabuleiros mistos propostos pela SIDERBRÁS, estes possuíam vãos de 8, 10, 12, 14, 16, 18, 20, 22, 24 e $26 \mathrm{~m}$, sistemas de contraventamentos com diferentes espaçamentos e espessuras de laje de 25 e $30 \mathrm{~cm}$. Nos vãos de 8 a $16 \mathrm{~m}$ foram considerados apenas tabuleiros mistos sobre quatro vigas, enquanto que nos vãos de 18 a $26 \mathrm{~m}$ foram considerados tabuleiros sobre três vigas. O espaçamento entre vigas foi de $2,60 \mathrm{~m}$, para os tabuleiros de 8 a $16 \mathrm{~m}$ de vão, e de $3,50 \mathrm{~m}$ para os de 18 a $26 \mathrm{~m}$. 
A seção transversal, arranjo estrutural e características geométricas dos elementos estruturais dos tabuleiros modelados são apresentados no ANEXO A.

Para os tabuleiros sobre três vigas foi adotada uma espessura de laje de $30 \mathrm{~cm}$, enquanto que para os de quatro vigas foi adotado o valor de 25 $\mathrm{cm}$.

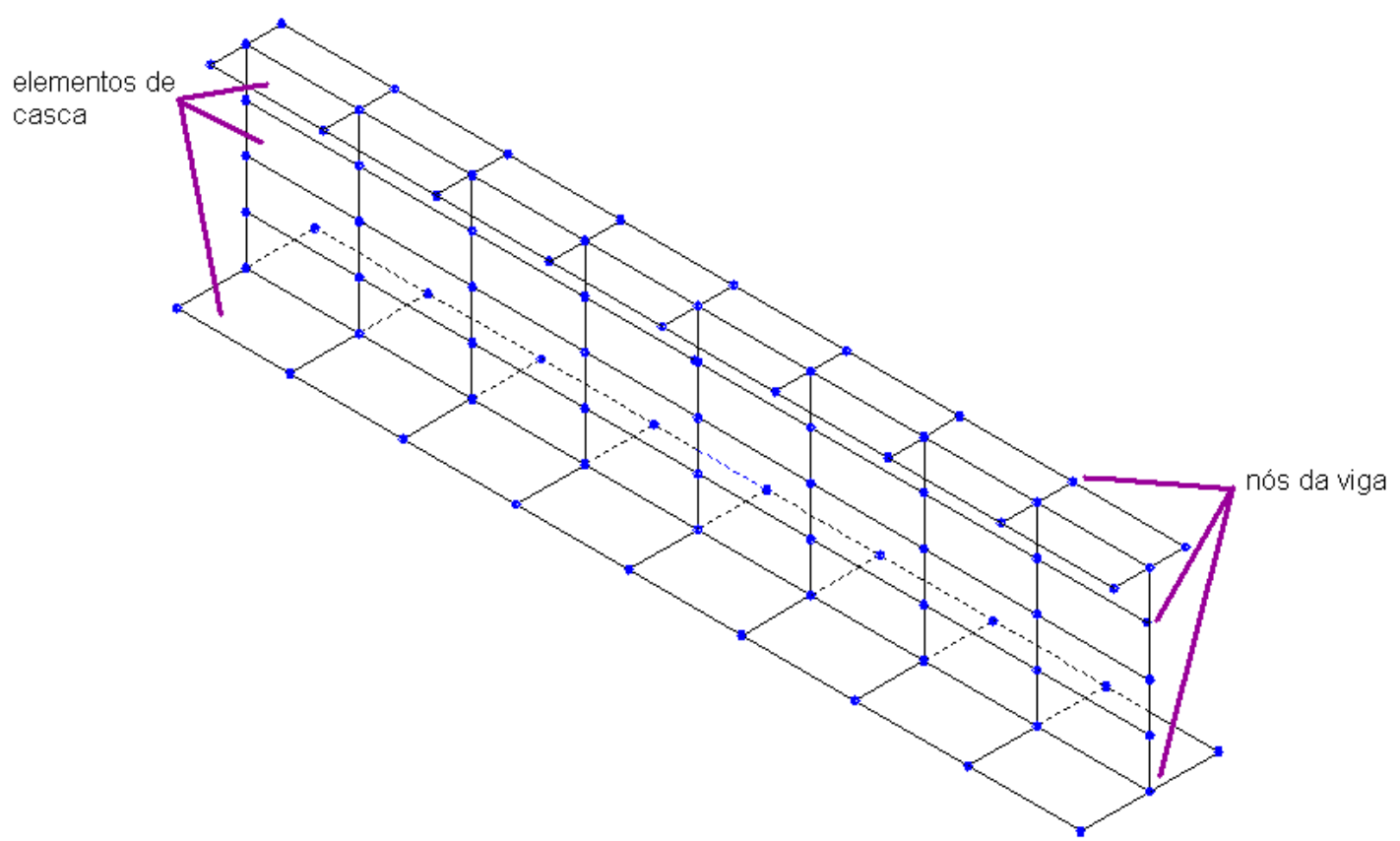

FIGURA 5.1 - Modelo tridimensional de uma viga de aço com seção I .

\subsection{Modelagem das vigas de aço}

Uma viga de aço de seção I pode ser considerada como sendo formada pela interseção ortogonal de chapas; na interseção da lâmina da alma com as lâminas das mesas existe uma interação entre as forças atuantes no plano da alma e as forças fora do plano desta, ocasionadas pela lâmina da mesa e vice versa (HAMBLY, 1991). Por este motivo é essencial utilizar na análise elementos que possuam a capacidade de sofrer deformações ocasionadas por estados planos de tensão e por flexão de placas. 
Para poder levar em consideração a interação descrita no parágrafo anterior, foram utilizados, na modelagem das vigas, elementos capazes de sofrer deformações ocasionadas tanto por efeitos de flexão como por tensão plana.

$\mathrm{Na}$ biblioteca de elementos do programa ANSYS, o elemento de casca elástica "SHELL63" pode ser utilizado em função de que este reúne as condições necessárias para representar bem os efeitos mencionados no parágrafo anterior. Como pode-se observar na figura 5.2, este elemento é definido por quatro nós, existindo ainda a possibilidade de utilizar a opção triangular; cada nó possui seis graus de liberdade: três translações e três rotações, as cargas aplicadas podem ser de superfície, distribuídas ao longo do perímetro ou concentradas nos nós.

Este elemento leva em consideração a espessura, a qual é introduzida em cada um dos nós do elemento, isto permite que a espessura possa variar linearmente entre os nós.

\section{ELEMENTO DE CASCA ELÁSTICA SHELL63}

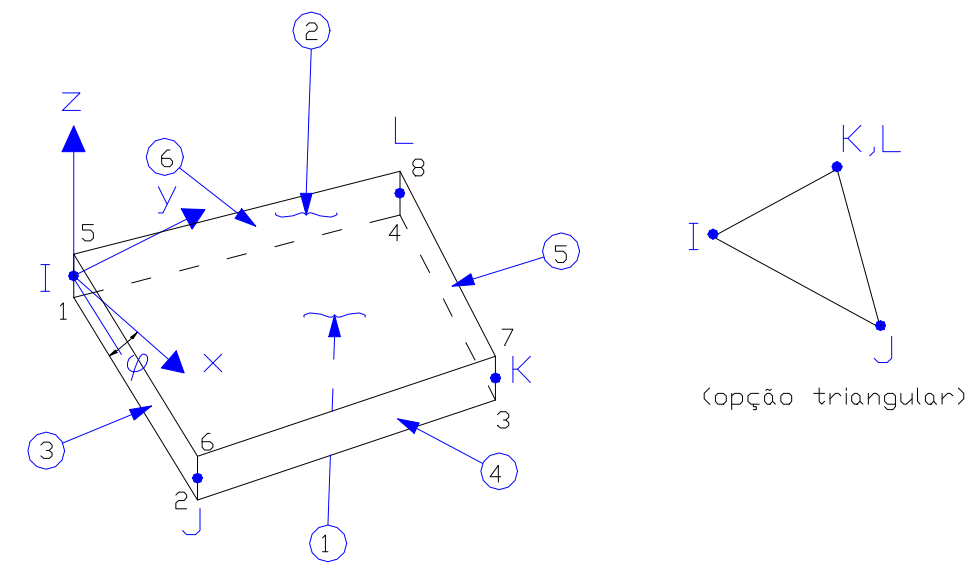

FIGURA 5.2 - Elemento de casca elástica "SHELL63". ANSYS

A modelagem das mesas e da alma das vigas foi realizada testando vários tipos de malha geradas com este elemento, de maneira a obter uma malha ótima que forneça resultados próximos dos obtidos através da teoria de vigas. Após realizar vários testes foram adotados 4 elementos ao longo da largura das mesas inferior e superior e entre 6 e 10 elementos ao longo 
da altura da alma; na figura 5.3 apresenta-se a seção transversal de uma das vigas utilizadas nos testes.

Tanto na modelagem das mesas como na modelagem da alma foram consideradas as diferentes espessuras destas.

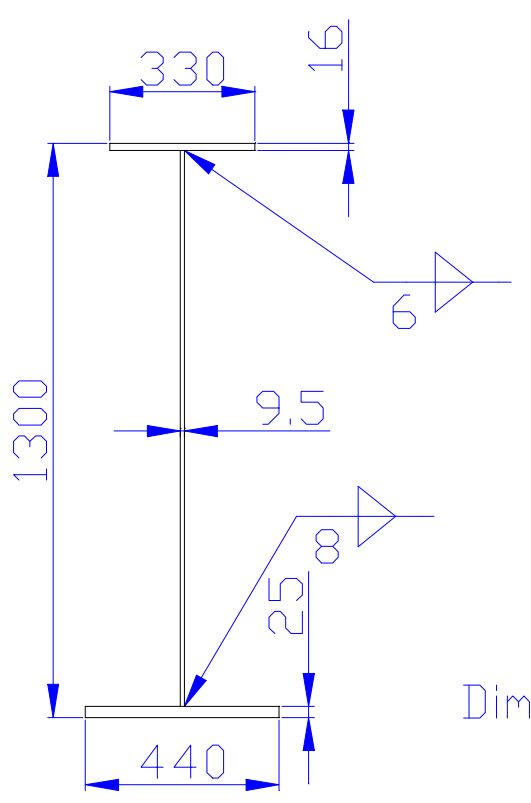

FIGURA 5.3 - Seção transversal da viga modelada.

Na tabela 5.1 apresenta-se os resultados obtidos para alguns tipos de malha e a comparação destes com resultados obtidos a partir da teoria de flexão de vigas; o carregamento aplicado sobre a viga foi o equivalente a uma linha de rodas do trem tipo Classe45 da norma NBR 7188, na posição mais desfavorável (meio do vão); a viga tinha um vão total de $20 \mathrm{~m}$ e foi considerada como simplesmente apoiada.

Observa-se nesta tabela que os valores obtidos para os momentos dos três modelos considerados, apresentaram diferenças inferiores ao 5\% em relação aos momentos calculados através da teoria de vigas. Este estudo mostrou que o tipo de elemento, o número e as dimensões adotadas representam bem o problema da flexão de uma viga. 
TABELA 5.1 - Comparação dos resultados obtidos para vários tipos de malha com os da teoria de flexão de vigas.

\begin{tabular}{|c|c|c|c|c|c|c|c|}
\hline \multirow{2}{*}{\multicolumn{4}{|c|}{ Número de elementos }} & \multicolumn{4}{|c|}{ Comparação de momentos (kN.m) } \\
\hline & & & & \multicolumn{2}{|c|}{ Momento Calculado } & \multicolumn{2}{|c|}{ Momento Exato } \\
\hline $\begin{array}{l}\text { Mesa } \\
\text { superior }\end{array}$ & \begin{tabular}{|l} 
Mesa \\
Inferior
\end{tabular} & $\begin{array}{l}\text { Alma } \\
\text { da viga }\end{array}$ & $\begin{array}{l}\text { Ao longo } \\
\text { do eixo long }\end{array}$ & $x=8,5 m$ & $x=10 m$ & $\mathrm{x}=8,5 \mathrm{~m}$ & $\mathrm{x}=10 \mathrm{~m}$ \\
\hline 4 & 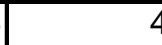 & 6 & 40 & 964,06 & 996,12 & 956,25 & 1012,5 \\
\hline 4 & 4 & 8 & 40 & 958,92 & 1003,25 & 956,25 & 1012,5 \\
\hline 4 & 4 & 10 & 40 & 959,9 & 1006,12 & 956,25 & 1012,5 \\
\hline & & & \multicolumn{5}{|c|}{$\stackrel{10 \mathrm{~m}}{\longrightarrow}$} \\
\hline & & & & $0 \mathrm{~m}$ & & \multicolumn{2}{|c|}{$\mathrm{p}=75 \mathrm{kN}$} \\
\hline
\end{tabular}

A obtenção dos momentos da tabela 5.1 foi realizada através da integração das tensões médias atuantes nos elementos da seção transversal (fornecidas pelo arquivo de resultados do programa), de maneira a obter as forças concentradas atuantes em cada elemento. Após isto foi realizada a somatória de momentos em relação ao centróide da seção, obtendo assim o momento fletor total atuante nesta; raciocínio similar tem sido utilizado por SFER \& CUDMANI (1997).

$\mathrm{Na}$ figura 5.4 ilustra-se $\mathrm{o}$ procedimento utilizado para calcular $\mathrm{O}$ momento fletor atuante na seção; o qual é obtido da seguinte maneira:

$$
\mathrm{M}=\sum_{\mathrm{i}=1}^{\mathrm{n}} \mathrm{F}_{\mathrm{i}} \cdot \mathrm{d}_{\mathrm{i}}
$$

Onde $F_{i}$ é obtido multiplicando a tensão média do elemento pela área deste e $d_{i}$ é a distância da força resultante ao centro de gravidade da seção. 


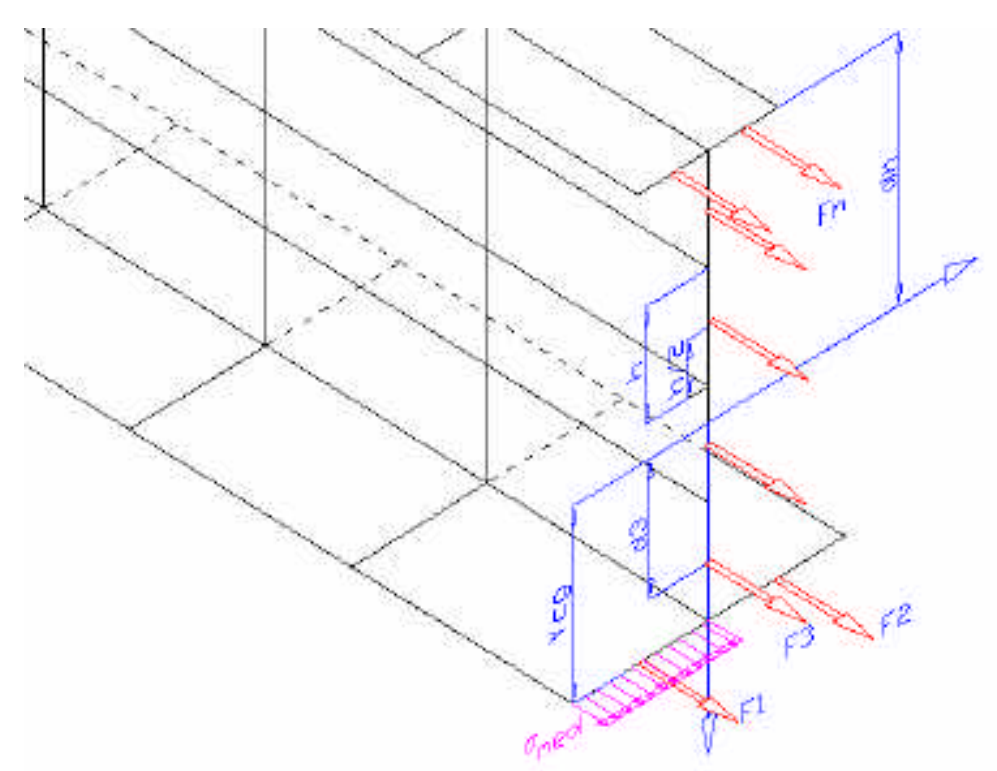

FIGURA 5.4 - Cálculo do momento fletor atuante na seção.

$\mathrm{Na}$ figura 5.5 ilustra-se a modelagem da viga por elementos de casca "SHELL63".

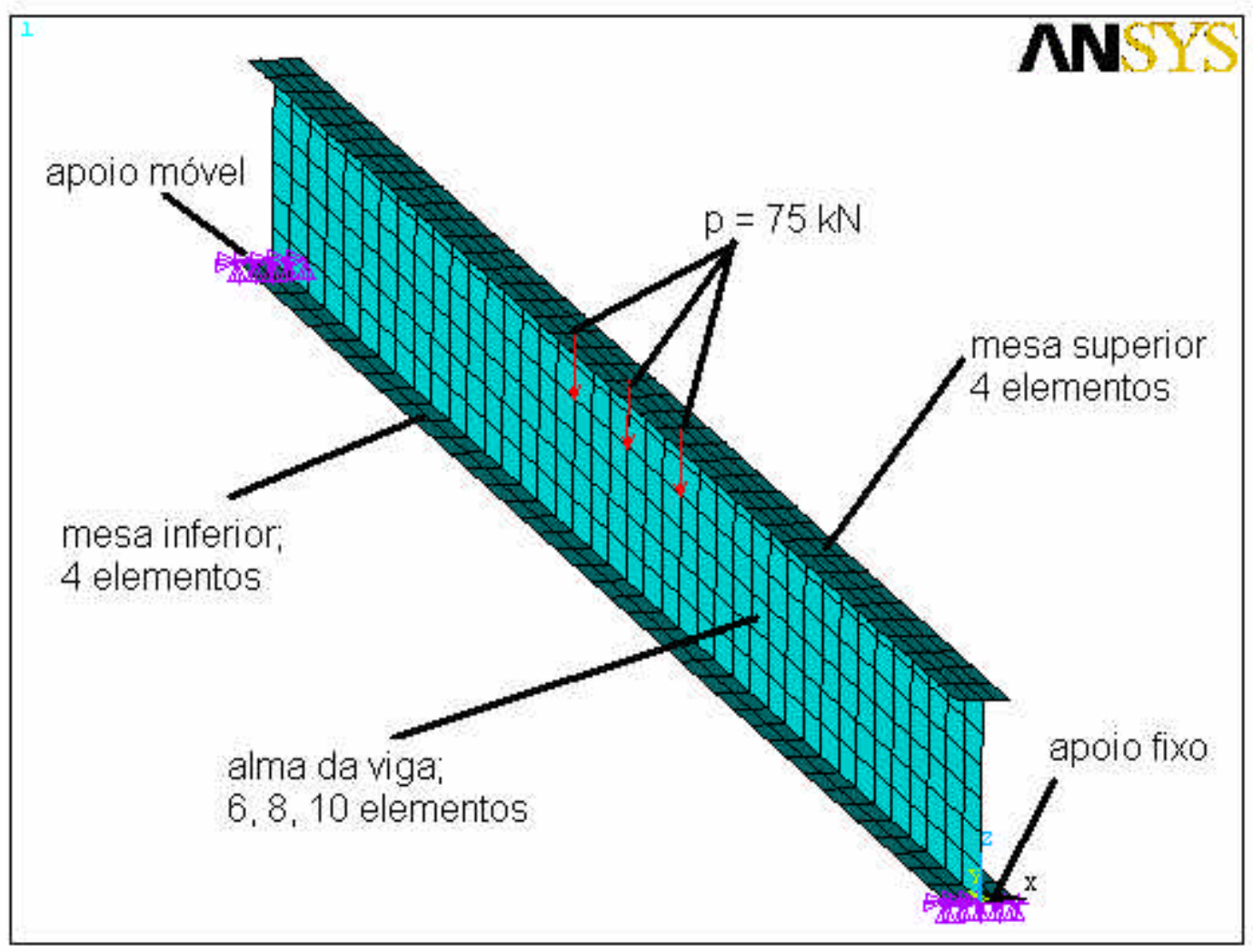

FIGURA 5.5 - Modelagem da viga de aço. 


\section{3 - Modelagem da Laje de concreto}

A laje de concreto foi modelada utilizando elementos de casca SHELL63, para isto foram também analisados vários tipos de malha de maneira a verificar se este elemento possibilita resultados compatíveis com os obtidos através de métodos simplificados.

A modelagem da laje utilizando o elemento "SHELL63" foi realizada levando em consideração a excentricidade existente entre o plano médio desta e o da mesa superior da viga de aço, o número de divisões ao longo do vão foi coincidente com o número de divisões das vigas de aço, de maneira a possibilitar a introdução de condições de compatibilidade de deslocamentos na interface aço - concreto, para representar a ligação entre laje e vigas.

As dimensões dos elementos utilizados na discretização da laje foram escolhidas levando em consideração dois critérios:

a) número de elementos necessários para que os esforços e tensões obtidos sejam compatíveis com os determinados através do cálculo clássico de esforços em lajes.

b) escolha da dimensão dos elementos de maneira a que estes sejam sub-módulos dos espaçamentos entre cargas de roda do trem tipo da NBR- 7188 facilitando assim a aplicação das cargas móveis.

Com base nestes dois critérios a modelagem da laje foi realizada com o elemento "SHELL63"; a largura adotada para cada elemento foi de 25 $\mathrm{cm}$ nos tabuleiros de quatro vigas e de $10 \mathrm{~cm}$ nos de três vigas. $O$ comprimento longitudinal adotado para todos os elementos foi de $50 \mathrm{~cm}$.

$\mathrm{Na}$ figura 5.6 apresenta-se as modelagens de lajes apoiadas sobre três e quatro vigas, em ambos os tabuleiros foi adotado o mesmo número de elementos na direção longitudinal tanto para a laje como para as vigas de aço; de maneira a facilitar a modelagem da ligação entre os dois materiais. 

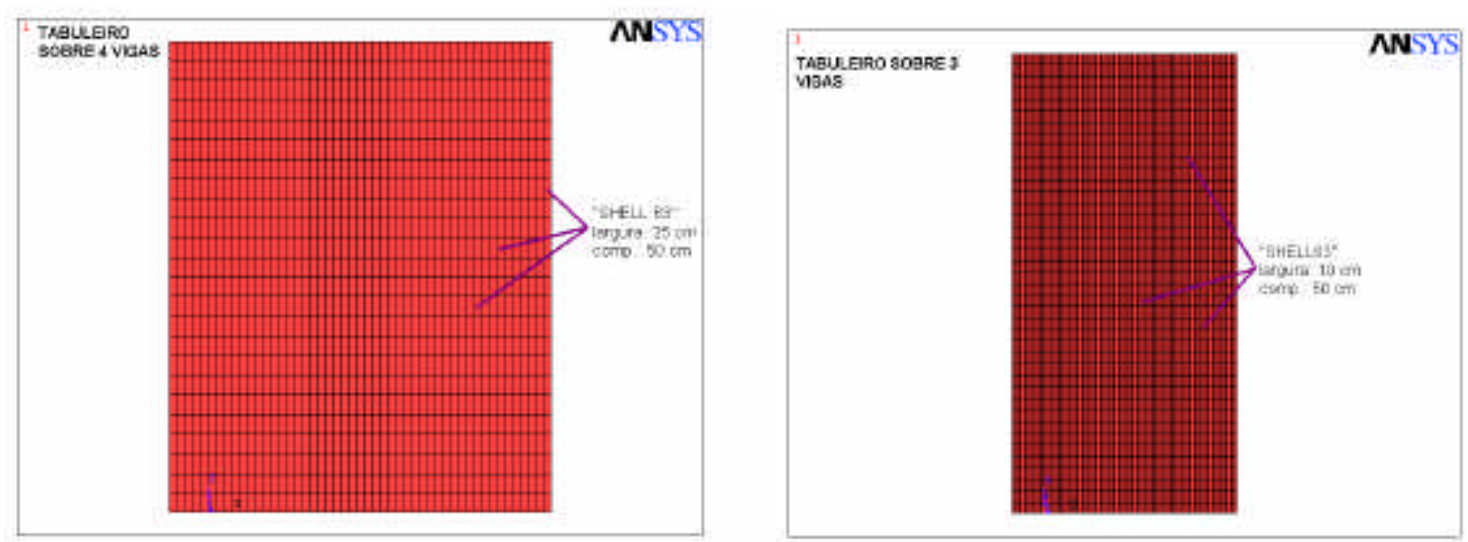

FIGURA 5.6 - Modelagem da laje por elementos de casca SHELL63.

\section{4 - Ligação entre elementos de viga e elementos de laje}

O problema mais complicado de resolver na representação de tabuleiros mistos é, sem dúvida, a modelagem da ligação entre vigas e laje. Autores como ANSOURIAN \& RODERICK (1978), AL AMERY \& ROBERTS (1990), RAZAQPUR \& NOFAL (1989); tem estabelecido que existe uma relação não linear entre carga aplicada e escorregamento experimentado na interface dos materiais.

A norma americana AASHTO considera válida a hipótese de conexão rígida no dimensionamento dos conectores, na realidade existe perda parcial da conexão ao longo do tempo e diminuição da resistência estática dos conectores quando submetidos a efeitos de carga cíclica.

Obviamente, é muito complicado considerar estes aspectos na análise global de tabuleiros mistos pois seria necessária a elaboração de rotinas adicionais no programa que considerassem estes efeitos.

Como o objetivo principal deste trabalho consiste no estudo do comportamento global do tabuleiro, foi considerada como válida a hipótese de conexão rígida entre os dois materiais. A aplicação desta hipótese no modelo pode ser realizada de duas maneiras diferentes:

a) introduzindo as equações de compatibilidade de deslocamentos entre as vigas e a laje.

b) através da introdução de elementos rígidos entre os nós da viga e da laje. 
Para a modelagem da ligação foi escolhida a segunda opção pois, no programa, a introdução de condições de compatibilidade em todos os nós da interface resulta muito mais laboriosa que a geração de vínculos rígidos.

A introdução de vínculos rígidos na interface foi realizada mediante a incorporação de elementos de viga tridimensional entre os nós da interface, para isto foi utilizado o elemento de viga elástica "BEAM4" do programa ANSYS.

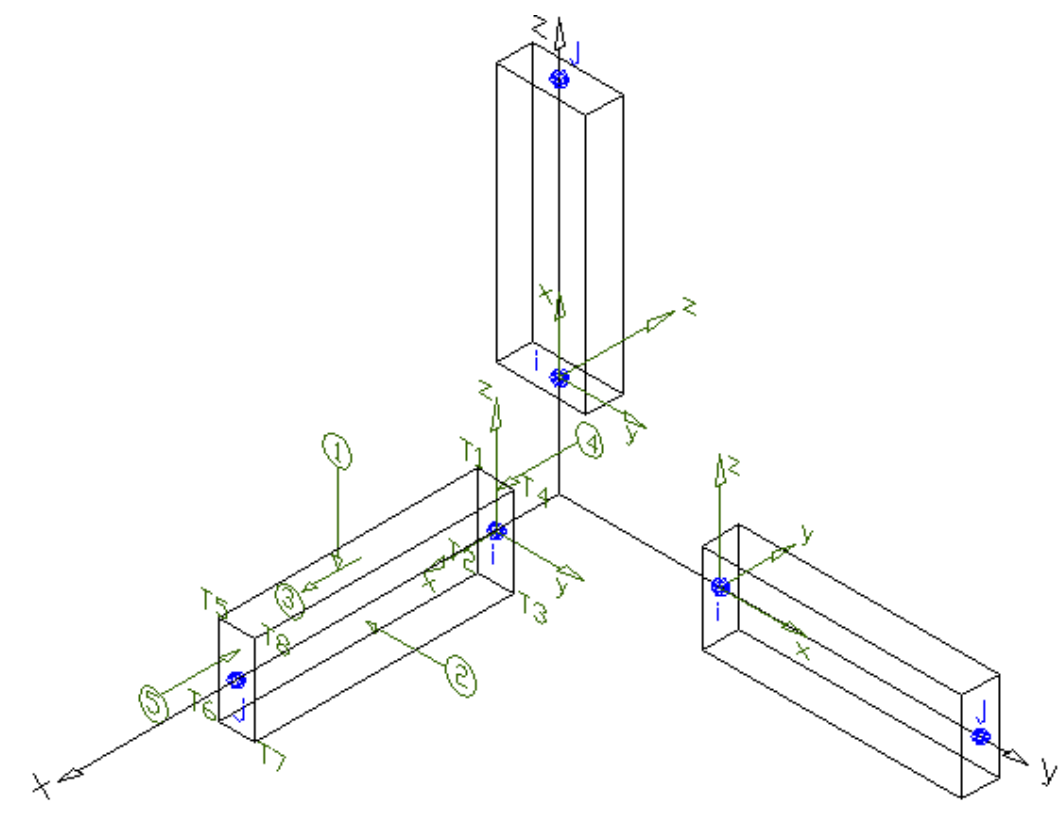

FIGURA 5.7 - Elemento de viga tridimensional. "BEAM4"; ANSYS

Pode-se observar, na figura 5.7, que o elemento de viga "BEAM4" é definido por dois nós I e J, tendo cada um destes seis graus de liberdade: três rotações e três translações. O elemento é capaz de sofrer tração, compressão, torção e flexão, podendo as cargas serem aplicadas nas diferentes faces deste conforme indicado na figura.

Para garantir que as condições de compatibilidade de deslocamentos sejam satisfeitas, foram adotados valores elevados para a inércia e a área destes elementos (1E5 e 1E6 respectivamente).

De maneira a verificar a validade das hipóteses apresentadas até aqui foi modelada uma viga mista com a seção transversal apresentada na figura 5.8. Nesta figura são também apresentadas as características 
geométricas da seção, as quais foram determinadas através do procedimento apresentado em detalhe no ANEXO B.
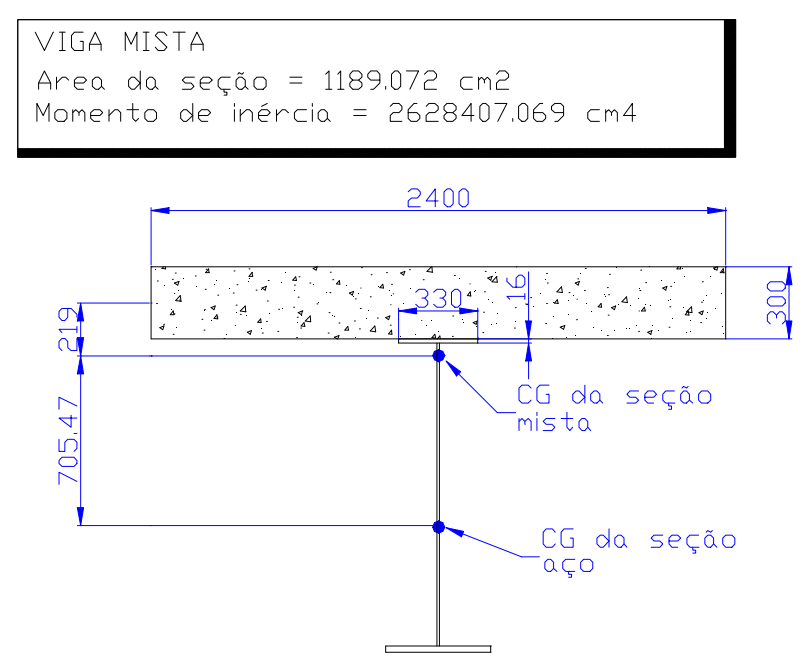

VIGA DE $A C_{\zeta} \square$

Area da seção $=282.405 \sqsubset m 2$

Momento de inércia $=777646.0784 \mathrm{~cm} 4$

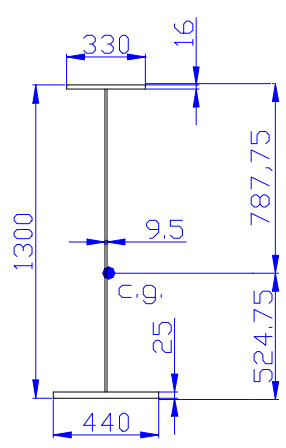

FIGURA 5.8 - Seção transversal e características geométricas da viga mista.

A modelagem das vigas mistas foi realizada utilizando elementos de casca "SHELL63", tanto para as vigas como para a parcela de laje equivalente, e por elementos de viga "BEAM4" para modelar os conectores de cisalhamento. A determinação das malhas da laje e da viga foi realizada conforme descrito nos itens 5.2 e 5.3 .

$\mathrm{Na}$ figura 5.9 apresenta-se a modelagem da viga analisada; nesta figura pode-se observar que foram consideradas tanto a espessura da laje como a das chapas que conformam a viga.
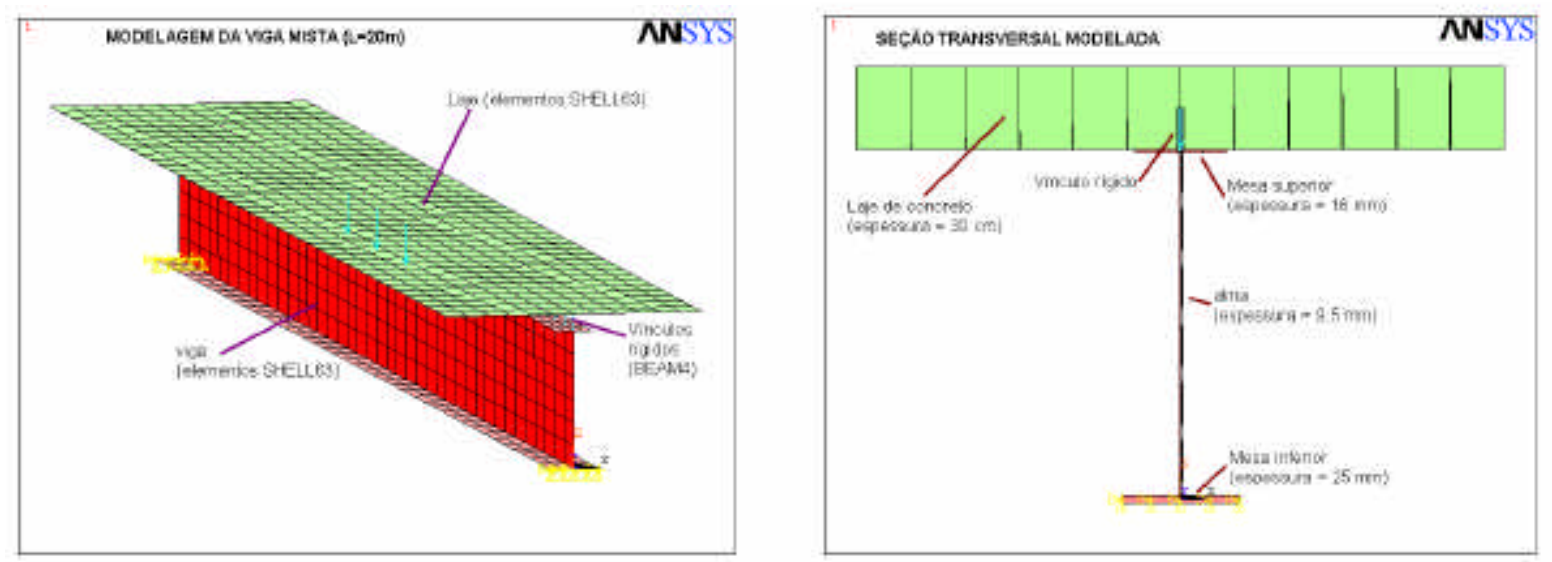

FIGURA 5.9 - Modelagem da viga mista. 
Na Tabela 5.2 apresenta-se a comparação das tensões obtidas pelo MEF com as obtidas através da formulação apresentada no APÊNDICE B, observa-se que a utilização de vínculos rígidos no modelo por elementos finitos fornece valores coerentes.

TABELA 5.2 - Comparação entre as tensões obtidas pelo MEF e pela teoria de vigas mistas.

\begin{tabular}{|l|c|c|c|c|c|}
\hline \multirow{3}{*}{ Método } & \multicolumn{3}{|c|}{ Distribuicão de tensões (kN/cm2) } & Flecha (cm) \\
\cline { 2 - 6 } & \multicolumn{2}{|c|}{ Viga de aço } & \multicolumn{2}{c|}{ Concreto } & meio do vão \\
\cline { 2 - 6 } & Mesa Superior & Mesa Inferior & Fibra inferior & Fibra superior & \\
\hline Teoria & $-0,269$ & 4,738 & $-0,030$ & $-0,158$ & 0,7 \\
MEF & $-0,274$ & 4,500 & $-0,018$ & $-0,200$ & 0,75 \\
\hline
\end{tabular}

\section{5 - Modelagem dos Contraventamentos}

Para realizar a modelagem dos contraventamentos foram utilizados elementos de barra "LINK8" (figura 5.10), sendo criados nós intermediários entre as vigas de aço para simular as ligações intermediárias da treliça. $O$ espaçamento entre contraventamentos varia segundo o tipo de tabuleiro considerado. 
O elemento "LINK8" é definido por dois nós de extremidade I e J, sendo que cada nó possui três graus de liberdade: deslocamentos nas direções x, y e z; podendo sofrer tração e compressão. Este elemento é capaz de plastificar e sofrer fluência.

$\mathrm{Na}$ ligação das barras da treliça às vigas foi considerado que as barras coincidem num mesmo nó, na realidade sempre existe uma pequena excentricidade que ocasiona o surgimento de tensões localizadas, esta influência sobre o comportamento global da estrutura foi considerada mínima e, portanto, desprezada neste trabalho. Na figura 5.11 apresenta-se a modelagem do sistema de contraventamentos mediante o elemento de barra "LINK8", o tabuleiro é constituído por três vigas e possui 20 m de vão, nesta figura foi excluída a laje de maneira a mostrar a disposição dos contraventamentos ao longo do vão.

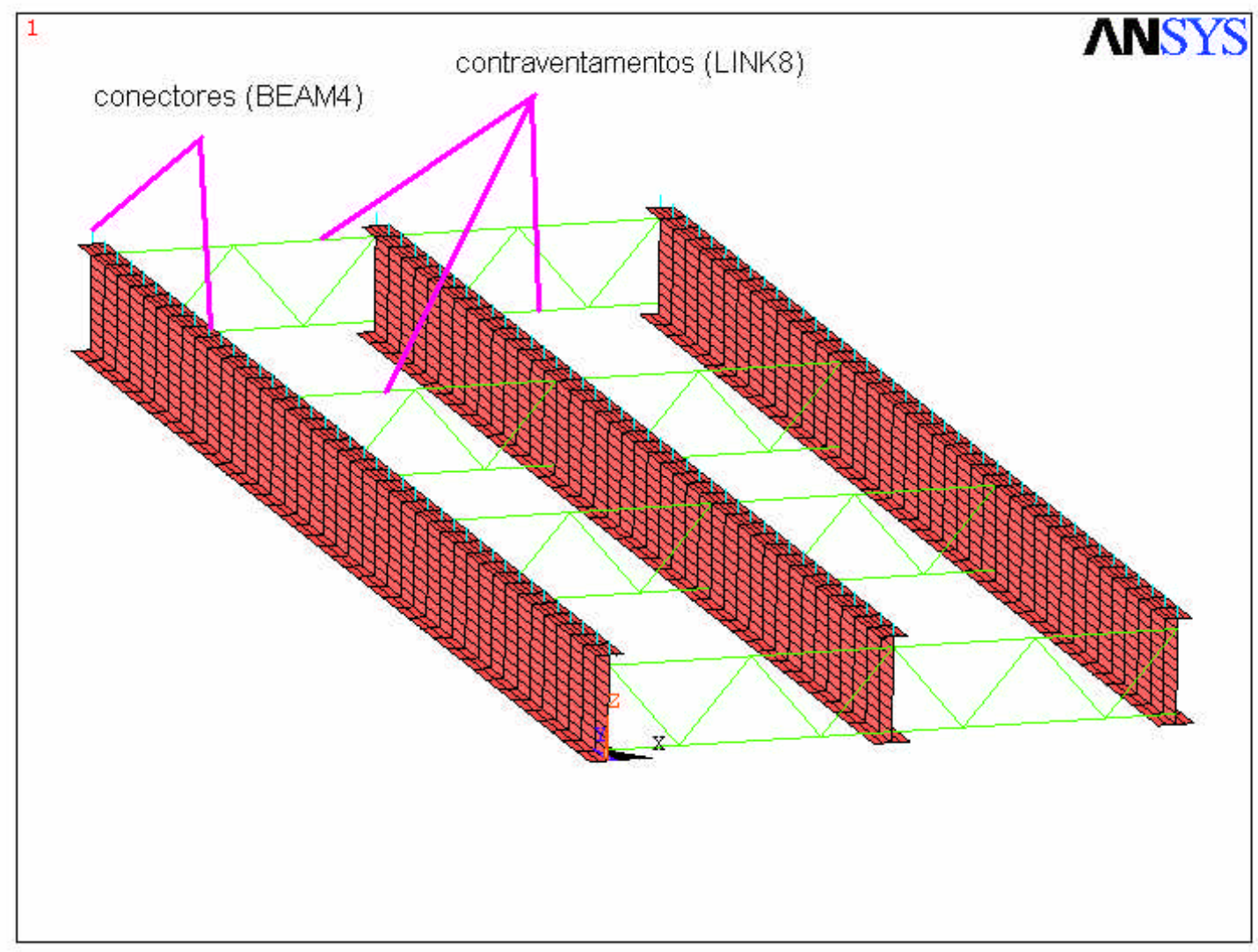

FIGURA 5.11 - Modelagem do sistema de contraventamentos por elementos de barra "LINK8". Tabuleiros de 20 m de vão. 


\section{6 - Condições de apoio}

A maioria dos tabuleiros simplesmente apoiados possuem apoios fixos e móveis; a representação rigorosa da interação entre viga e apoio fixo, ou móvel, constitui um problema complexo.

No caso do apoio ser fixo pode-se apresentar a situação em que o tipo de fixação executada proporciona à viga um certo grau de engastamento, ocasionando uma distribuição de tensões diferente da esperada, AKTAN et al (1993) tem estudado experimentalmente este efeito e proposto um modelo teórico baseado na introdução de molas elásticas na região do apoio.

O aparecimento de forças longitudinais ocasionadas pelo atrito na interface entre o apoio móvel e a viga pode também ocasionar redistribuição de esforços, neste caso o coeficiente de atrito entre os materiais constitui um importante parâmetro de projeto porque determina a magnitude das forças transferidas da super-estrutura para a infra-estrutura (CAMPBELL et al, 1990).

É obvio que resulta complicado considerar estes efeitos na análise global do tabuleiro, por este motivo a modelagem dos apoios foi realizada restringindo simplesmente os deslocamentos dos nós de extremidade das mesas inferiores das vigas (BISHARA et al, 1992). Numa das extremidades foram impedidos os deslocamentos nas direções longitudinal e transversal da ponte e na outra foram impedidos apenas na direção transversal, conforme ilustrado na figura 5.12. 

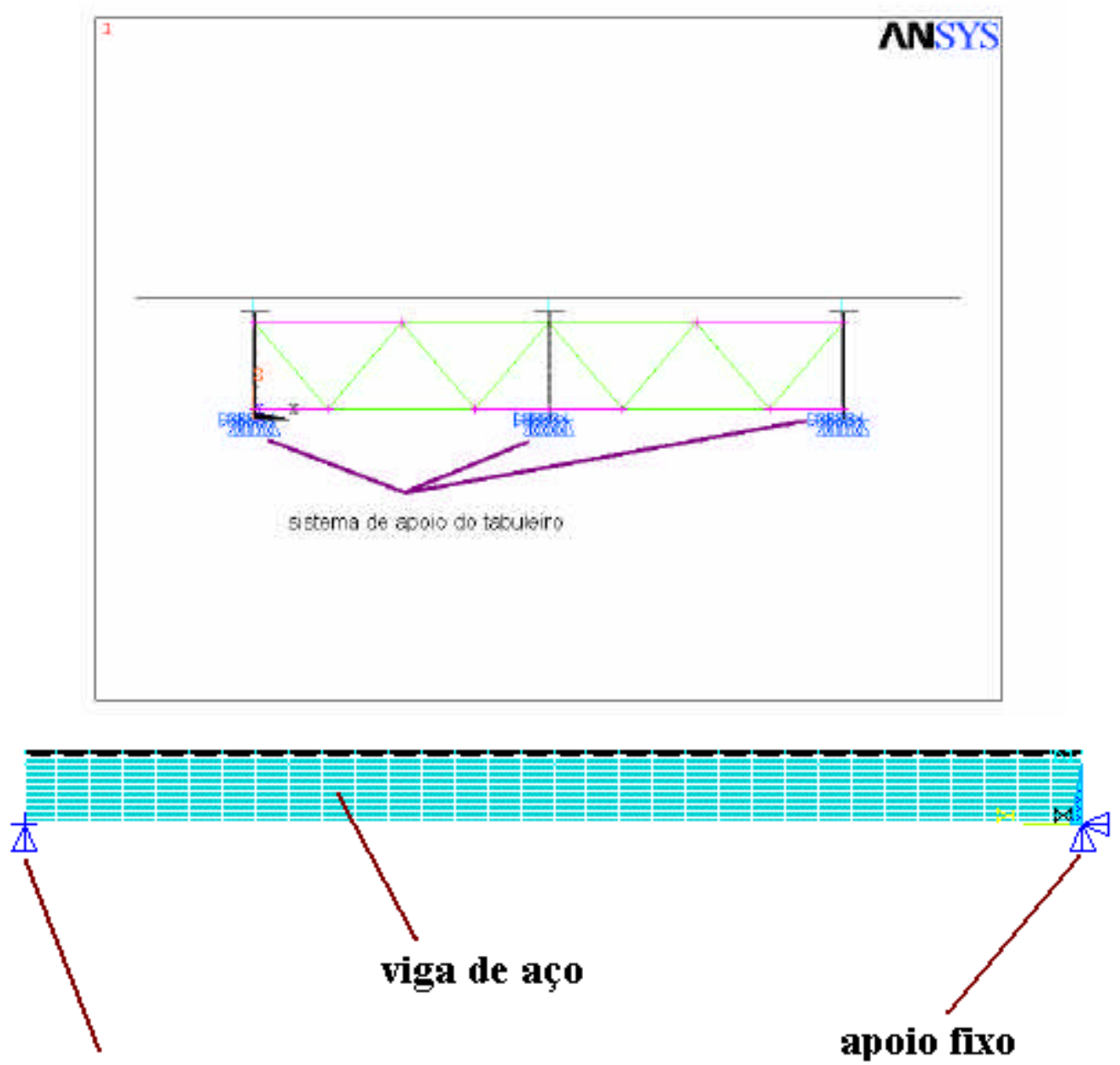

\section{apoio móvel}

FIGURA 5.12 - Condições de apoio da estrutura.

\section{7 - Propriedades dos materiais}

Foi adotado para as vigas de aço um módulo de elasticidade de $20.000 \mathrm{kN} / \mathrm{cm}^{2}$ e uma tensão de escoamento de $35 \mathrm{kN} / \mathrm{cm}^{2}$.

Para o concreto foi adotada uma resistência $f_{c k}=21 \mathrm{MPa}$, sendo 0 módulo de elasticidade calculado segundo as prescrições da NBR 6118:

$$
\mathrm{E}_{\mathrm{C}}=0,9 \cdot 6640,78 \cdot \sqrt{21+3,5}=29583,2 \mathrm{MPa}=2.958,32 \mathrm{kN} / \mathrm{cm}^{2}
$$

Segundo as prescrições da AASHTO, o módulo de elasticidade do concreto, para $\eta=9$ seria de $2.222 \mathrm{kN} / \mathrm{cm}^{2}$.

\section{8 - Exemplos de tabuleiros modelados}


Com todos os parâmetros e hipóteses definidos até aqui foi possível modelar os tabuleiros apresentados no ANEXO A como um conjunto único, no qual todos os elementos constituintes colaboram na transferência de solicitações para os apoios. Na figura 5.13 apresenta-se um tabuleiro sobre três vigas, modelado através do programa ANSYS.

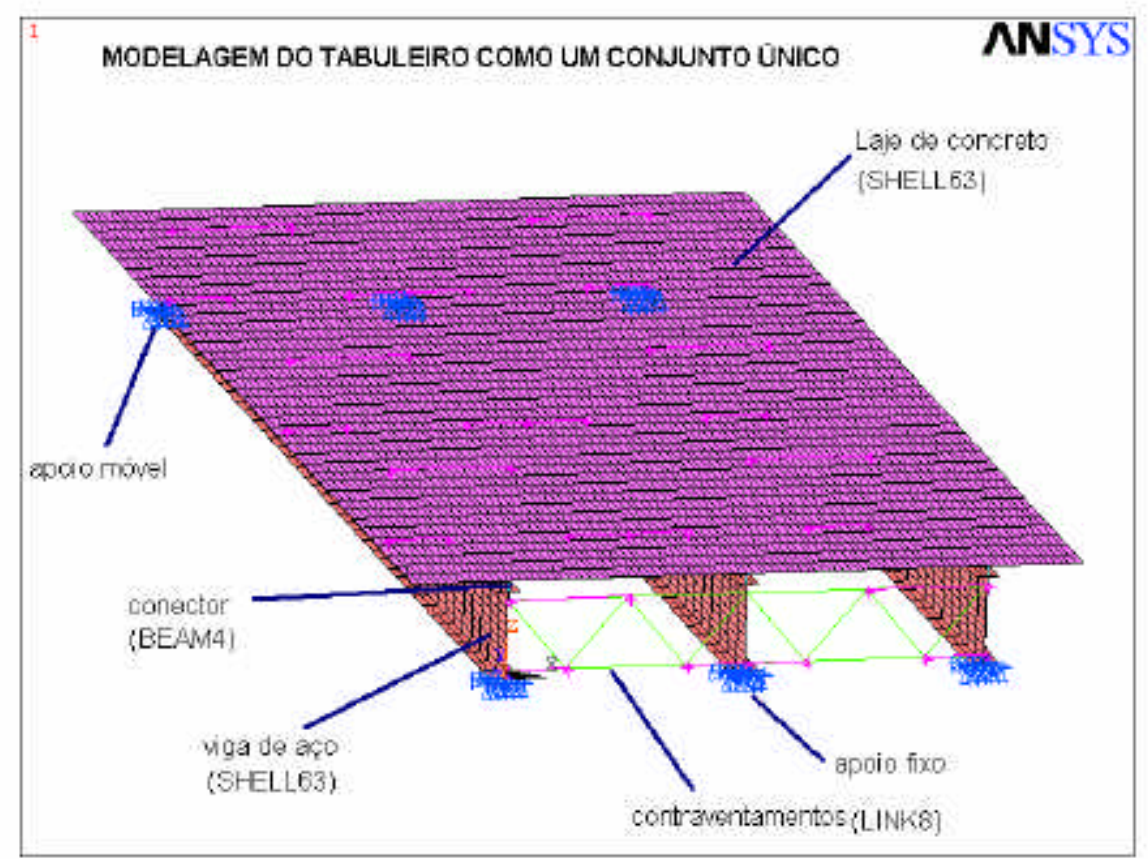

FIGURA 5.13 - Tabuleiro sobre três vigas. 


\section{ANÁLISES REALIZADAS E RESULTADOS OBTIDOS

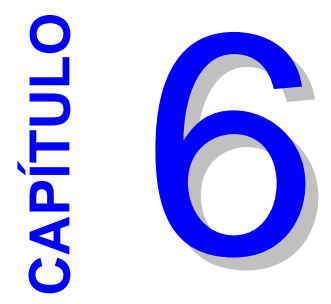

Neste capítulo foram realizadas várias análises com os tabuleiros modelados, basicamente o carregamento considerado foi equivalente ao veículo tipo referente à Classe 45 especificada pela NBR 7187, incluído o impacto.

Por se tratar de tabuleiros simplesmente apoiados, os veículos tipo foram aplicadas no meio do vão de maneira a estudar as tensões e deslocamentos máximos que estes ocasionam na estrutura.

Exceto as análises realizadas em tabuleiros com vigas fissuradas, foi assumido que a estrutura apresenta comportamento elástico-linear.

\section{1 - Estudo da influência dos contraventamentos}

Foram realizadas várias análises para estudar a forma em que a presença de contraventamentos no tabuleiro influencia na distribuição de tensões nas mesas inferiores das vigas. Para isto foram considerados tabuleiros com 3 e 4 vigas com vãos de 22 e 12 m respectivamente.

Nas análises realizadas neste item foi considerada apenas a ação do veículo tipo, incluído o impacto; isto deve-se à dificuldade de se comparar os resultados se fossem utilizados os trens tipo. Foram estudados dois casos de carregamento: assimétrico (consideração de apenas uma carga móvel) e 
simétrico (consideração de duas cargas móveis ${ }^{1}$ ). Inicialmente os tabuleiros citados foram analisados com a presença de contraventamentos, sendo realizada uma segunda análise na qual estes foram removidos.

Nos gráficos 6.1 e 6.2 apresenta-se uma comparação entre as tensões obtidas no meio do vão para as mesas inferiores das vigas, no caso de carregamento simétrico. Nestes gráficos apresenta-se também a localização das cargas móveis na seção transversal.

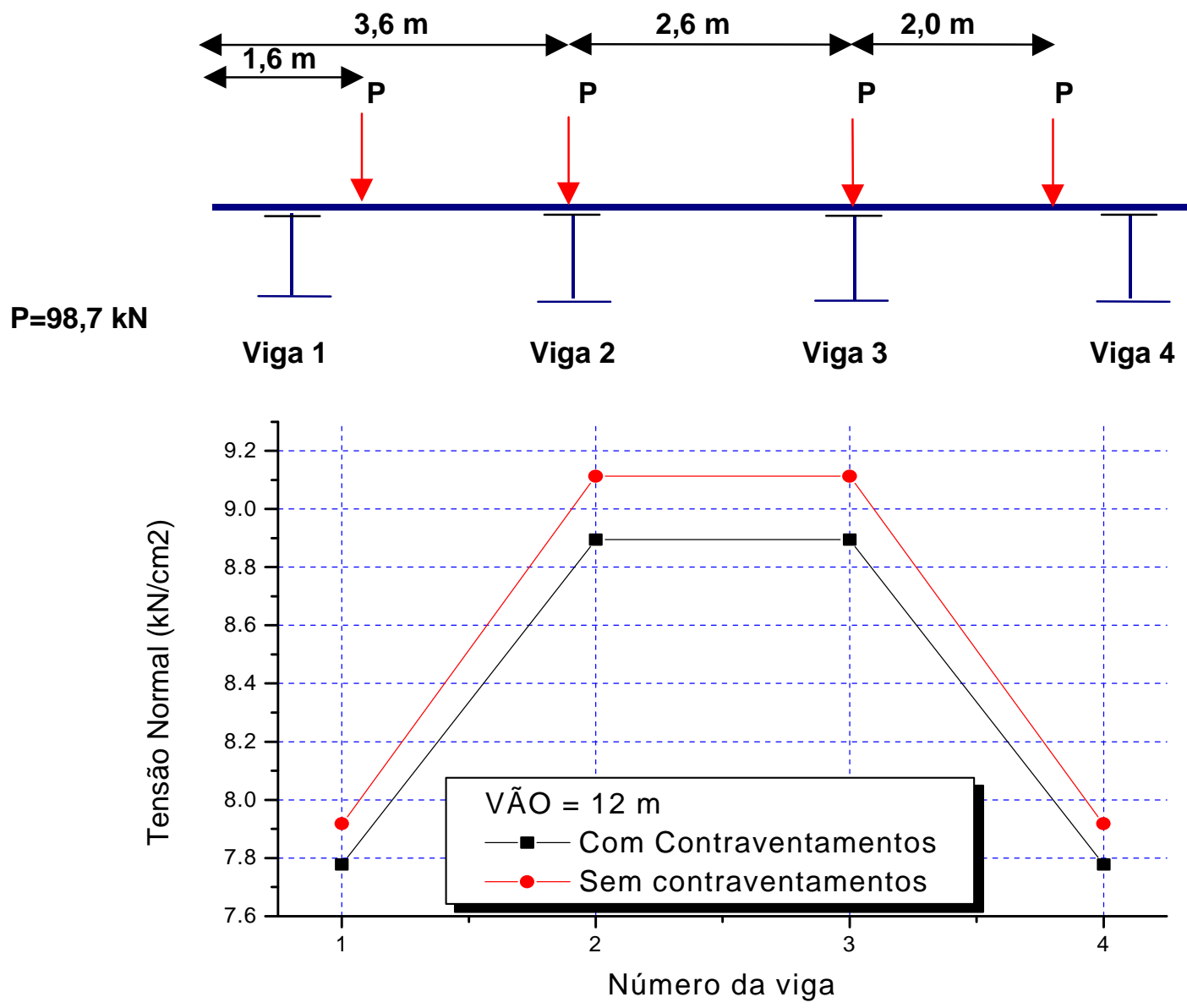

GRÁFICO 6.1 - Distribuição de tensões em tabuleiros sobre quatro vigas. Carregamento simétrico.

\footnotetext{
${ }^{1}$ Utilizar-se-á cargas móveis ou veículo tipo indistintamente
} 

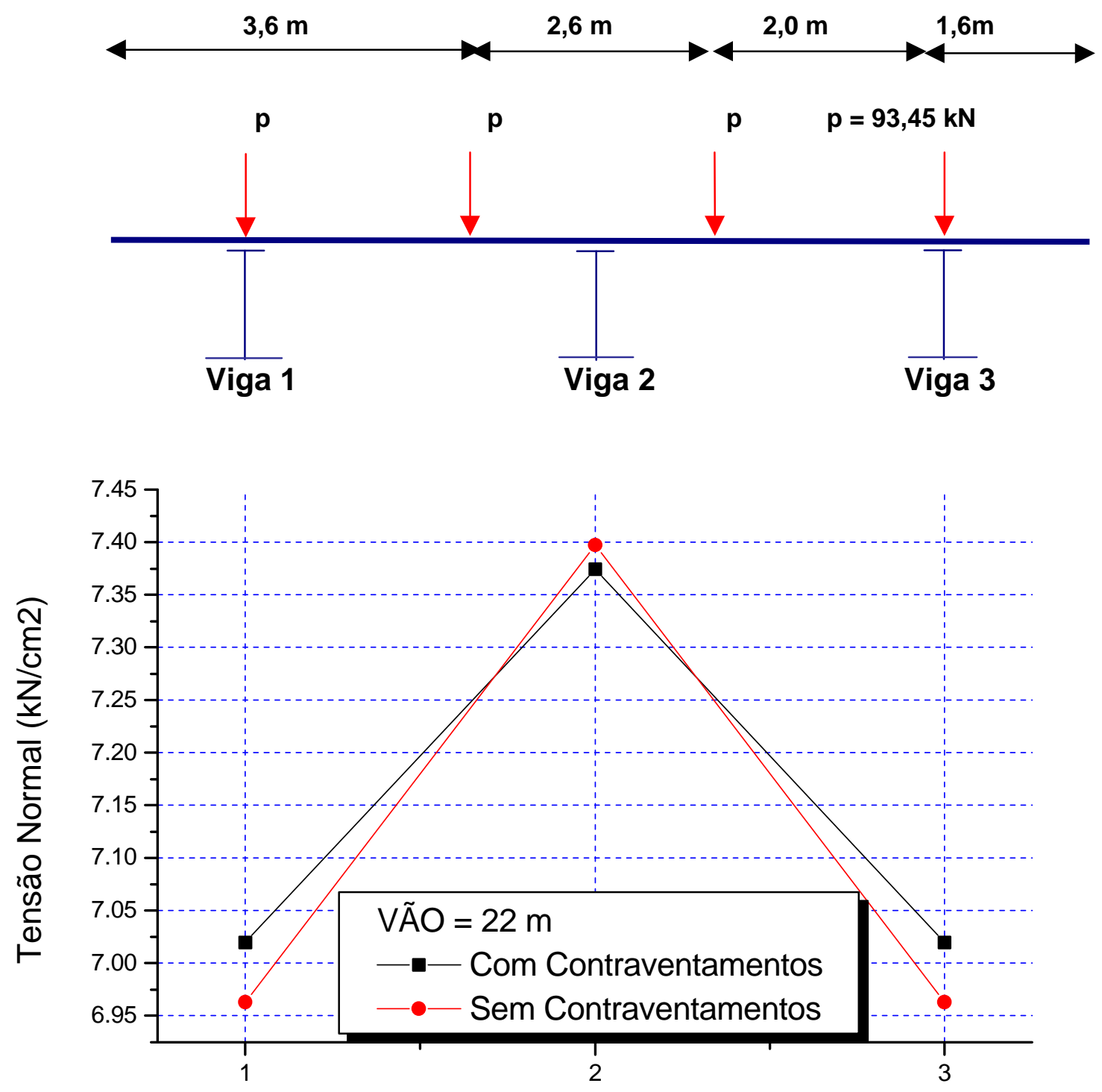

Número da viga

GRÁFICO 6.2 - Distribuição de tensões em tabuleiros sobre três vigas.

Carregamento simétrico.

No gráfico 6.1 observa-se que houve uma diminuição das tensões normais atuantes em todas as vigas, isto pode ser atribuído a que o sistema de contraventamento impede que uma viga desloque de maneira independente em relação à outra aumentando assim a distribuição dos esforços entre as vigas. 
No gráfico 6.1 observa-se ainda que não houve redistribuição das tensões atuantes nas vigas, como era esperado, quando o sistema de contraventamentos foi considerado. Foram comparadas as tensões e deslocamentos atuantes na laje de maneira a investigar se este fato era ocasionado por um possível efeito de arqueamento da laje, contudo foram obtidos valores muito próximos de tensão e deslocamento em ambos os casos.

Provavelmente o elemento de casca adotado para modelar a laje não seja o mais indicado para estudar a ocorrência deste efeito e sim elementos tridimensionais, esta questão merece estudos mais aprofundados que podem ser assunto de sumo interesse em trabalhos futuros.

No gráfico 6.2 observa-se que em tabuleiros sobre três vigas existe uma diminuição da diferença de tensões entre as vigas externas e a viga interna quando é considerado o contraventamento, ou seja, a presença deste melhora a capacidade de distribuição de carga do tabuleiro porque ocasiona uma diminuição de tensão na viga interna e um aumento nas vigas externas. A capacidade de distribuição de carga de um tabuleiro é maior quando a diferença de tensão entre vigas diminui, isto significa que todas as vigas são solicitadas e contribuem de maneira similar na absorção e transferência das solicitações até os apoios.

Nos gráficos 6.3 e 6.4 apresenta-se a distribuição de tensões normais nas mesas inferiores das vigas no caso de carregamento assimétrico, neste caso foi considerada apenas a ação ocasionada pela passagem de uma carga móvel na posição transversal indicada nos correspondentes gráficos.

Observa-se, no gráfico 6.3, que a consideração do sistema de contraventamento na análise ocasiona diferenças de tensões inferiores às observadas no caso em que é desconsiderado. Neste gráfico é possível verificar também que as tensões nas vigas 1 e 2 são de maior intensidade no caso em que o sistema de travamento é eliminado, esta situação não se reflete para as vigas 3 e 4 onde a tensão é maior quando o contraventamento é considerado. 

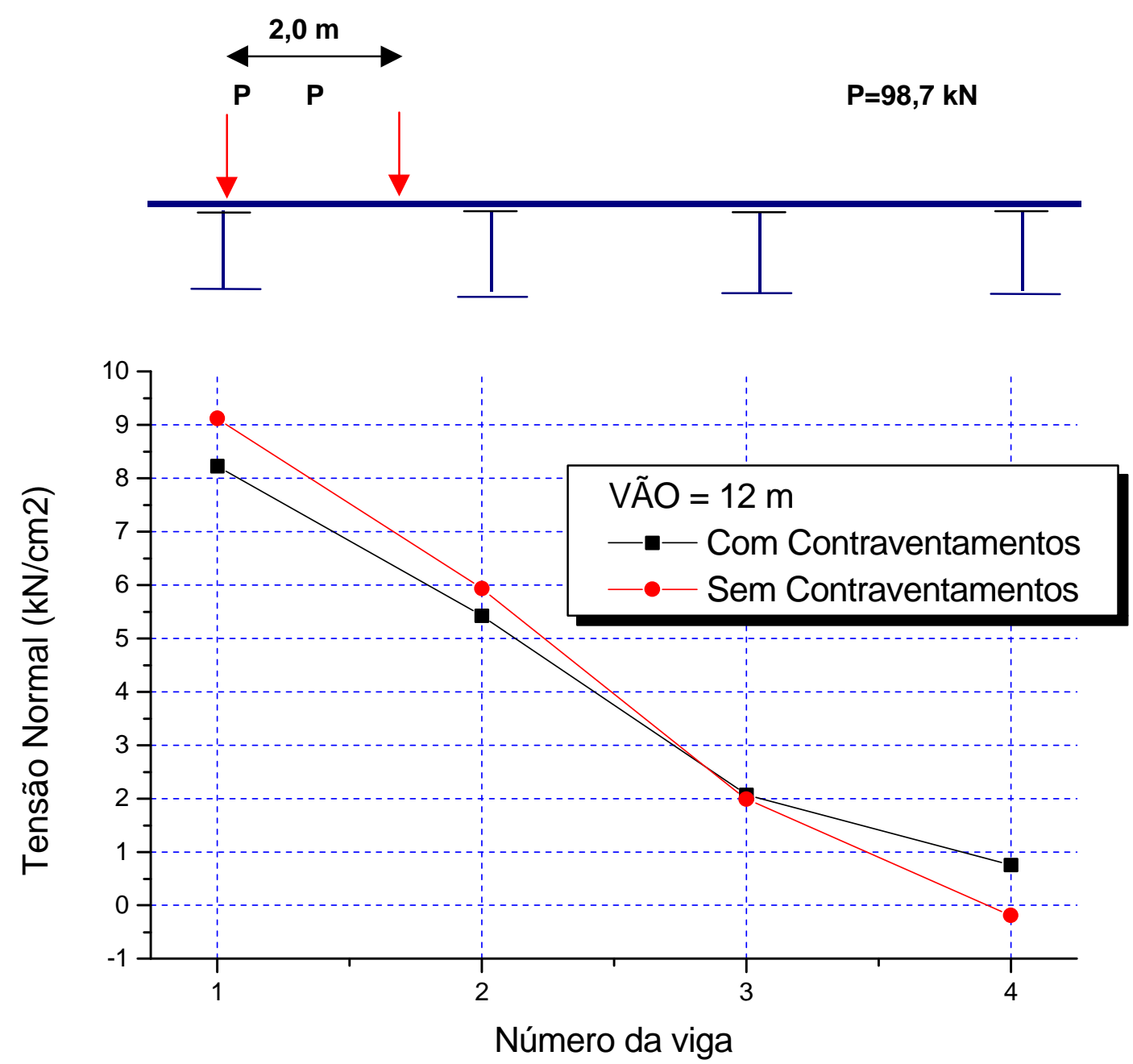

GRÁFICO 6.3 - Distribuição de tensões em pontes sobre quatro vigas.

Este fato pode ser explicado da seguinte maneira: no caso em que o sistema de contraventamento não é considerado as cargas de roda são transferidas de maneira quase direta para as vigas 1 e 2 por meio da laje, cujo comportamento poderia ser aproximado ao de uma viga simplesmente apoiada (AASHTO, 1989). Nestas condições, as vigas citadas deformam sem experimentar a restrição de deslocamento ocasionada pelas barras dos contraventamentos, sendo realizada a transferência de cargas para as vigas 3 e 4 através do efeito de flexão transversal da laje.

Pelo exposto até aqui pode-se deduzir que a maior parcela da carga aplicada é transferida para as vigas mais próximas, enquanto que a parcela 
da carga transferida para as vigas mais distantes depende da rigidez à flexão e fissuração da laje.

No caso em que o sistema de contraventamentos é considerado, as vigas 1 e 2 ao deslocarem experimentam uma restrição de deslocamento que ocasiona o surgimento de tensões nos contraventamentos, estes transferem para as vigas 3 e 4 uma parte das parcelas de carga distribuídas para as vigas 1 e 2, melhorando desta forma a capacidade de distribuição de carga do tabuleiro.

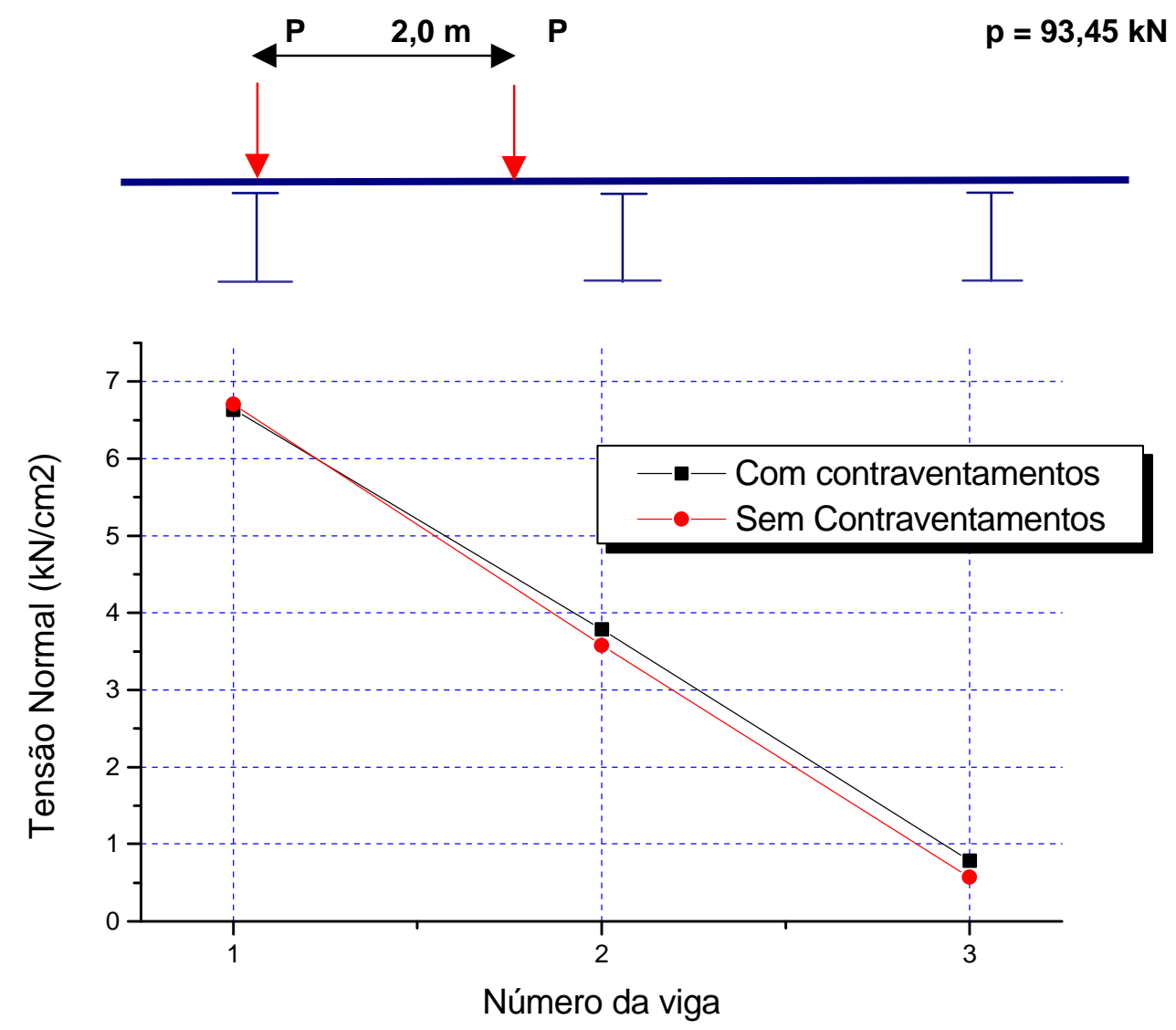

GRÁFICO 6.4 - Distribuição de tensões em tabuleiros sobre três vigas. Carregamento assimétrico.

No gráfico 6.4 observa-se que ocorre um fenômeno similar ao descrito para o tabuleiro sobre quatro vigas, há uma diminuição de tensão da viga mais solicitada e um acréscimo desta nas outras vigas. A diferença de tensões nestas vigas é mínima. 
Observou-se, de maneira geral, que em todos os casos analisados existe uma melhora da capacidade de distribuição de carga do tabuleiro quando o sistema de contraventamentos é considerado, embora as tensões atuantes nas mesas inferiores não variem de maneira sensível. Conclusões similares têm sido obtidas por AZIZINAMINI et al (1995) em ensaios experimentais realizados em tabuleiros de pontes sobre três vigas.

Nos gráficos 6.5 e 6.6 apresenta-se a comparação dos deslocamentos das vigas do tabuleiro de $12 \mathrm{~m}$ de vão, nos casos de aplicar carregamento assimétrico e simétrico, respectivamente.

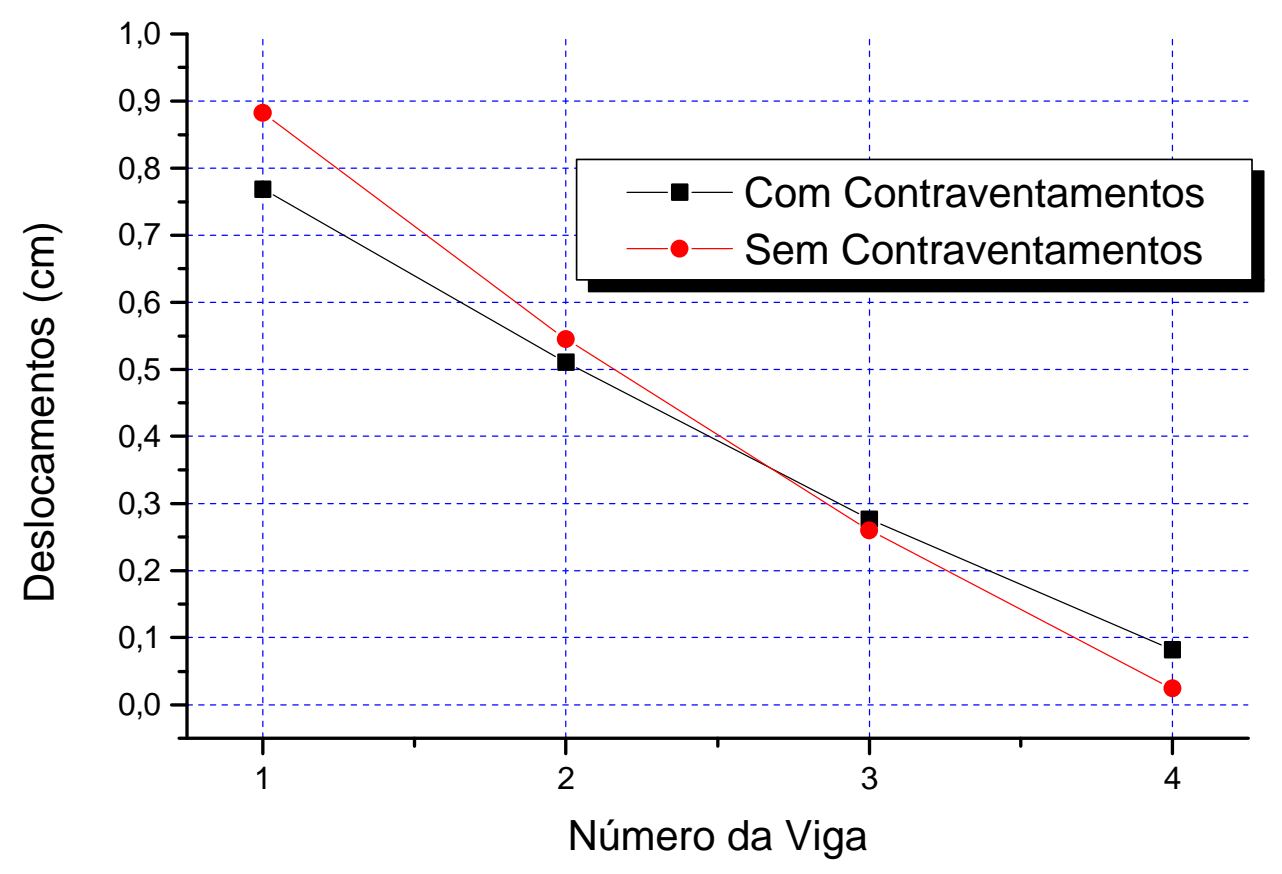

GRÁFICO 6.5 - Deslocamentos das vigas do tabuleiro de $12 \mathrm{~m}$. Carregamento assimétrico. 


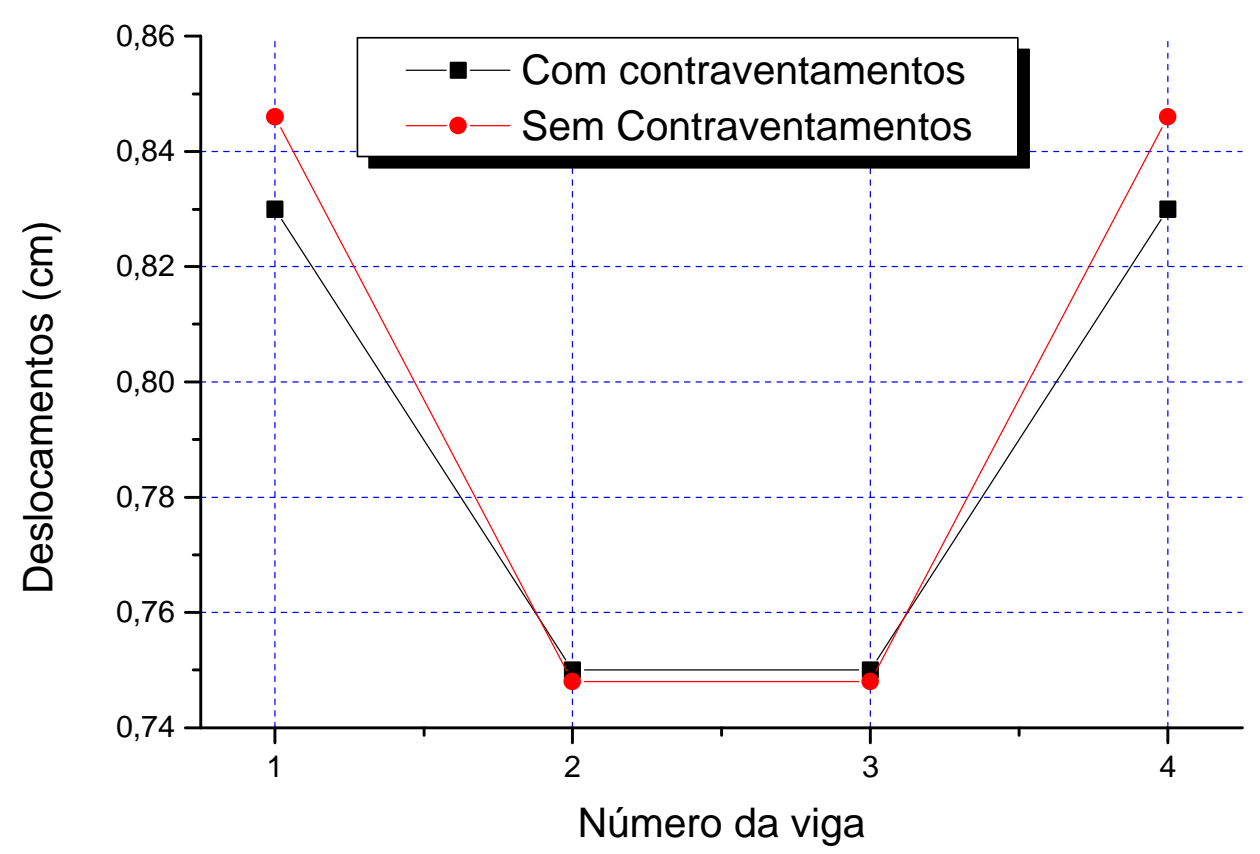

GRÁFICO 6.6 - Deslocamentos das vigas do tabuleiro de $12 \mathrm{~m}$. Carregamento simétrico.

Nos gráficos 6.5 e 6.6 é possível observar que, tanto no caso de carregamento simétrico como assimétrico, as vigas externas sofrem uma maior variação de deslocamentos quando o sistema de contraventamentos é removido; observa-se também no gráfico 6.5 que a presença dos contraventamentos ocasiona uma diminuição de deslocamento nas vigas 1 e 2 e um aumento nas vigas 3 e 4 .

De maneira similar ao ocorrido no gráfico 6.1, não houve redistribuição de deslocamentos no gráfico 6.6, este fato merece estudos mais aprofundados sobre $o$ comportamento da laje $e$ dos contraventamentos que podem ser assunto de interesse em trabalhos futuros.

Nos gráficos 6.7 e $\quad 6.8$ apresenta-se a comparação dos deslocamentos das vigas do tabuleiro de $22 \mathrm{~m}$ de vão, nos casos de aplicar carregamento simétrico e assimétrico. 


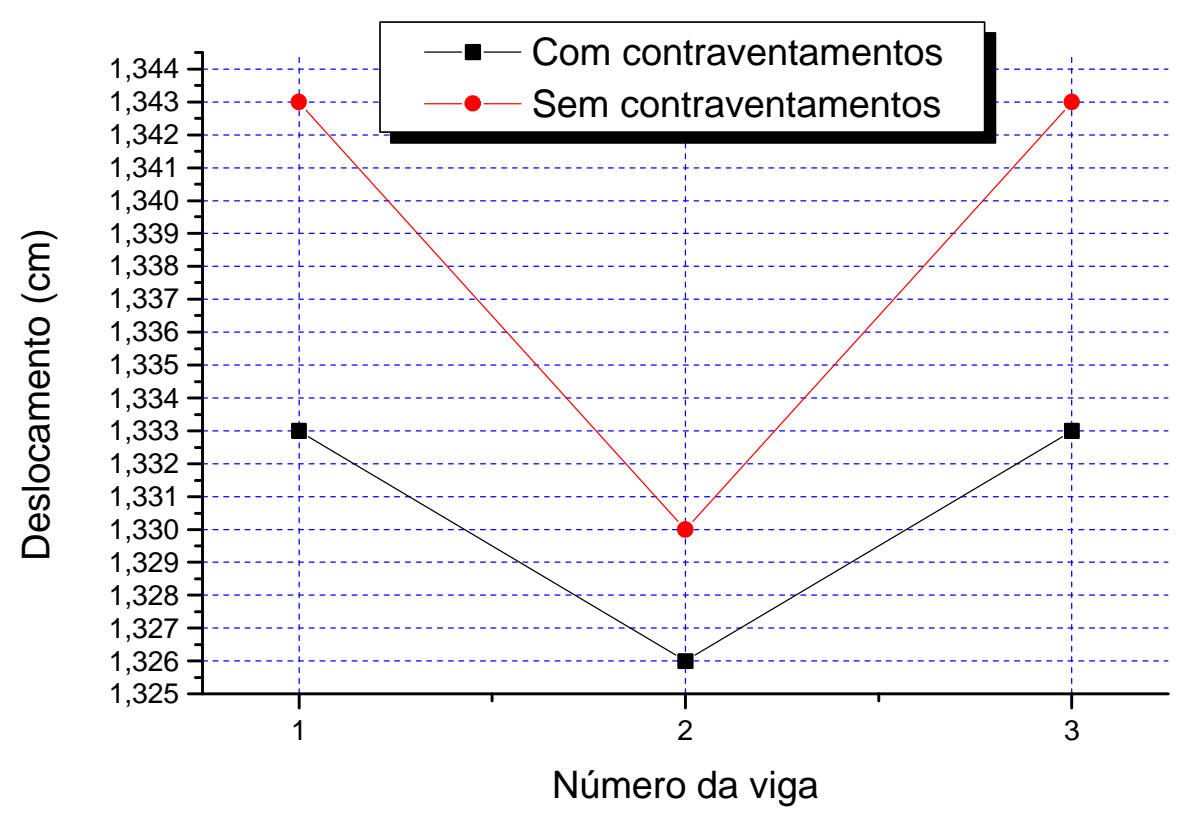

GRÁFICO 6.7 - Deslocamentos das vigas do tabuleiro de 22 m. Carregamento simétrico.

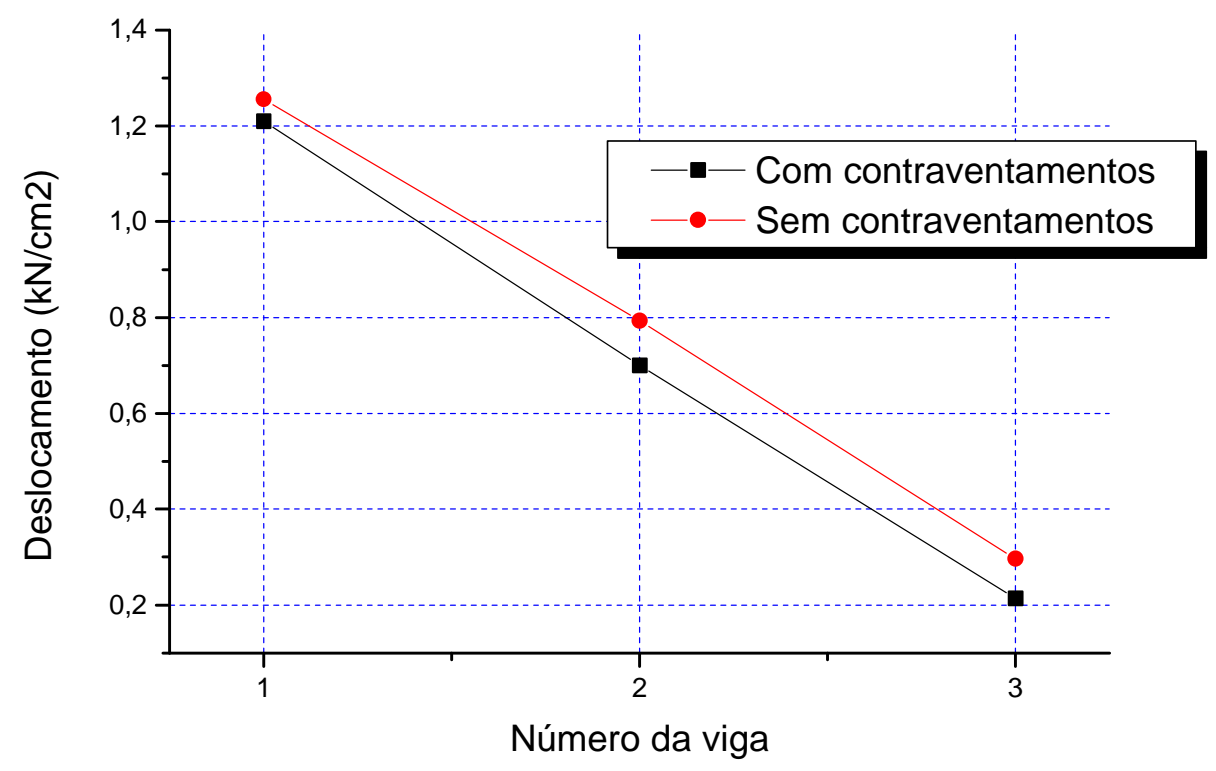

GRÁFICO 6.8 - Deslocamentos das vigas do tabuleiro de 22 m. Carregamento assimétrico.

Nestes gráficos é possível observar que os deslocamentos máximos ocorrem nas vigas externas, sendo menores na viga interna. 
Na figura 6.1 apresenta-se os deslocamentos das vigas e deformação destas, ao aplicar carregamento assimétrico quando existe contraventamento. $\mathrm{Na}$ figura 6.2 apresenta-se os deslocamentos experimentados pelas mesmas vigas quando 0 sistema de contraventamentos é removido.

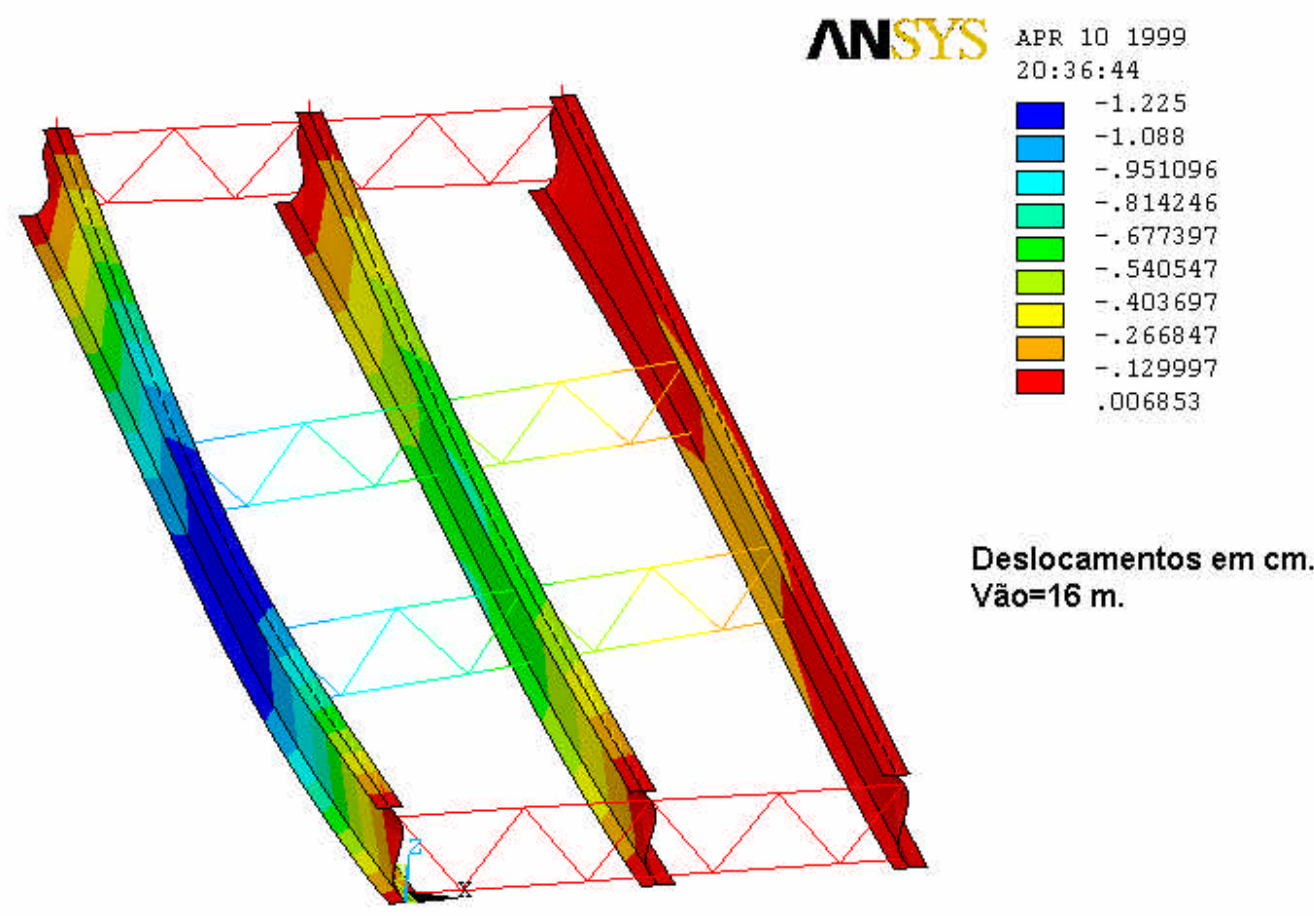

FIGURA 6.1 - Deslocamentos das vigas do tabuleiro de 22 m quando existe sistema de contraventamentos. Carregamento assimétrico. 


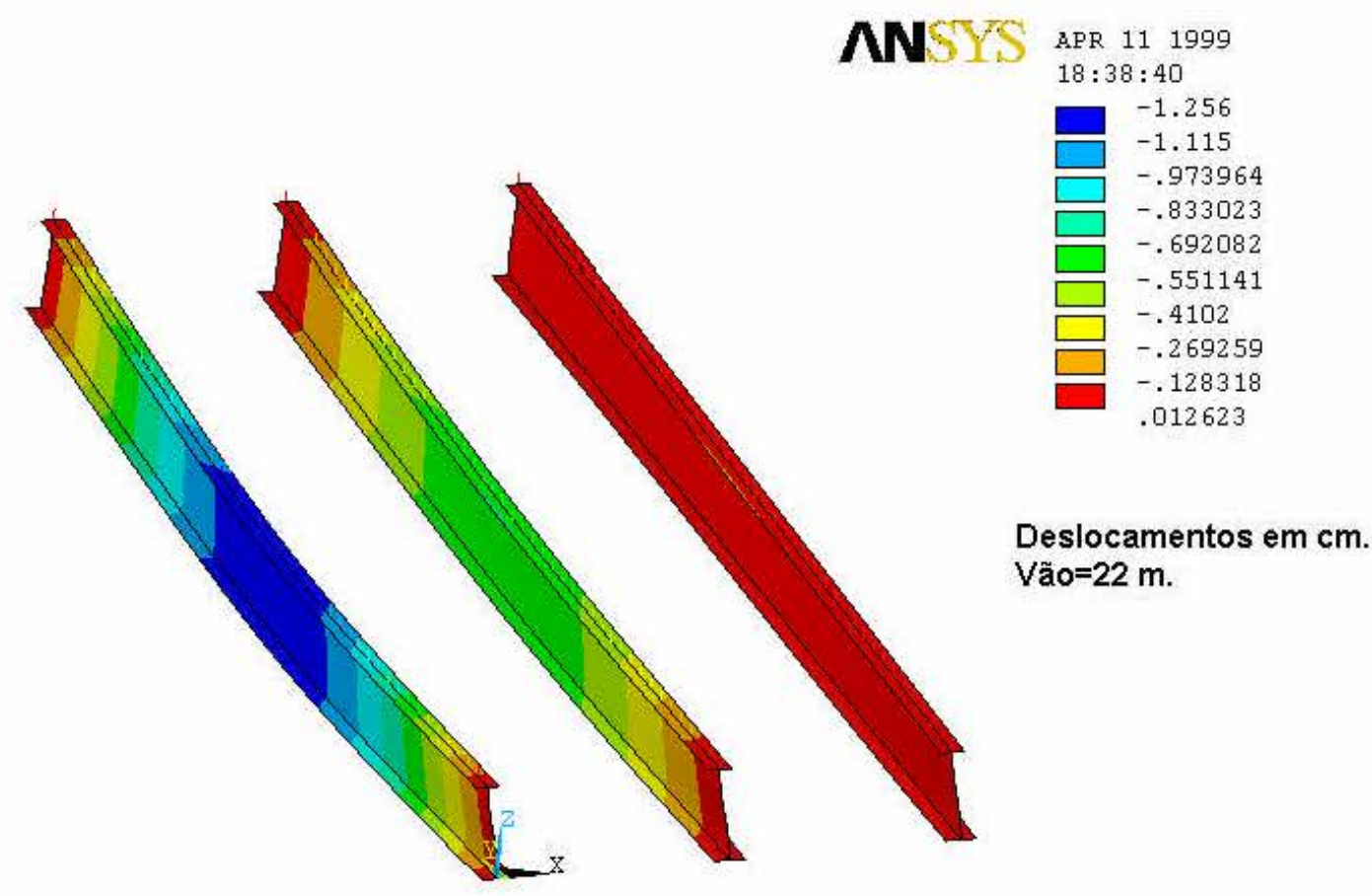

FIGURA 6.2 - Deslocamentos das vigas do tabuleiro de $22 \mathrm{~m}$ quando o sistema de contraventamentos é removido. Carregamento assimétrico. 


\section{2 - Estudo da influência da geometria do tabuleiro na} distribuição de cargas.

Neste item foram estudados os parâmetros geométricos que maior influência exercem no comportamento global de tabuleiros de pontes. Segundo MARX et al (1994) são três os parâmetros que determinam a geometria de uma ponte: ângulo de esconsidade $(\alpha)$, vão da ponte, (a), e espaçamento entre vigas, (b). Resulta também conveniente apresentar um quarto parâmetro adimensional obtido através da relação espaçamento entre vigas e vão. Neste trabalho foram consideradas apenas as variações do vão do tabuleiro e da espessura da laje.

\subsection{1 - Influência do vão.}

Para realizar o estudo da influência deste parâmetro foram consideradas duas seções transversais com as características e arranjo estrutural das pontes de 16 e 26 m que estão apresentadas no ANEXO A. Para a seção correspondente ao vão de $16 \mathrm{~m}$ foram considerados vãos de $8,10,12,14$ e $16 \mathrm{~m}$ e para a seção transversal de $26 \mathrm{~m}$, vãos de 18, 20, 22, 24 e $26 \mathrm{~m}$; sendo modelados no total 10 tabuleiros.

Foi considerada apenas a situação de carregamento assimétrico, para a qual foi utilizada a carga móvel da classe 45 da norma. $O$ espaçamento entre vigas foi mantido constante e o vão variável para todos os tabuleiros modelados.

Nos gráficos 6.9 e 6.10 apresenta-se a variação da tensão atuante nas mesas inferiores das vigas em função do vão, quando é aplicado um carregamento assimétrico, nestes gráficos esta esquematizada também a posição das cargas na seção transversal. Cabe citar que para cada variação de vão foi considerado o impacto. 

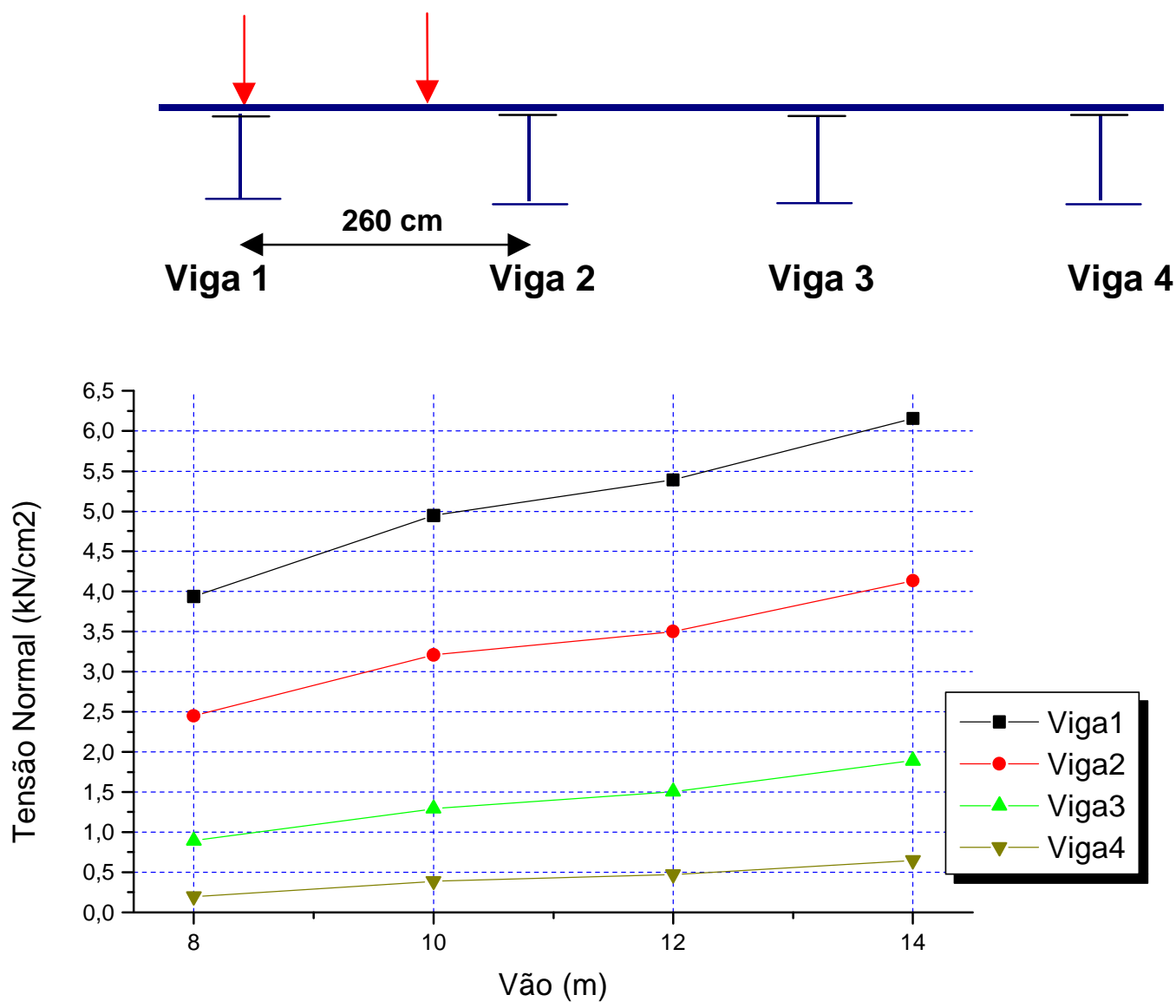

GRÁFICO 6.9 - Influência da variação do vão em tabuleiro sobre quatro vigas. Carregamento assimétrico. 


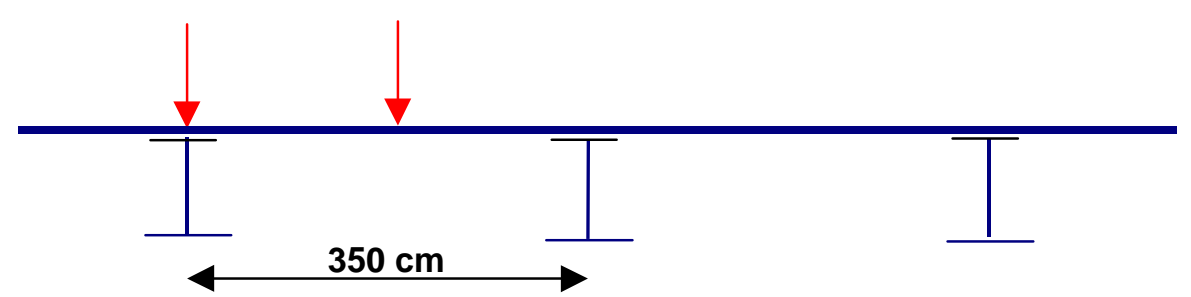

Viga $1 \quad$ Viga $2 \quad$ Viga 3

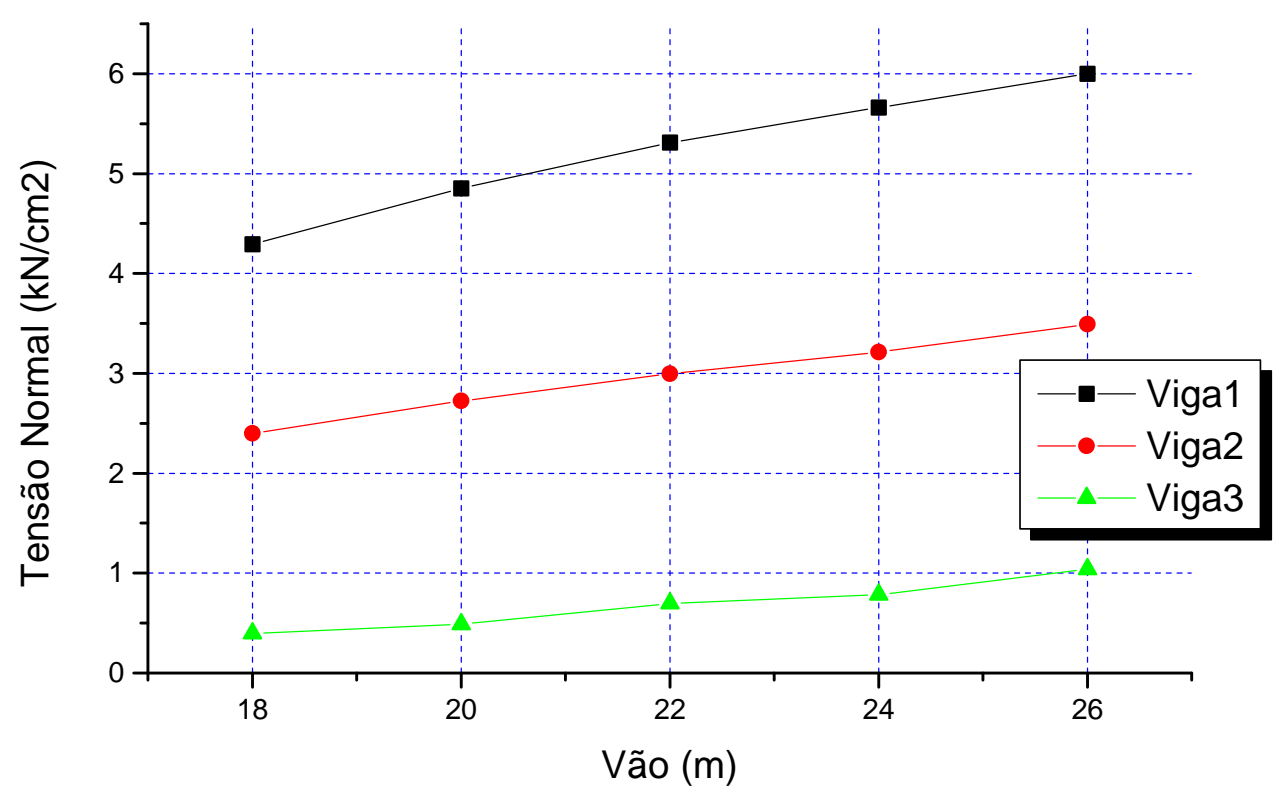

GRÁFICO 6.10 - Influência da variação do vão em tabuleiro sobre três vigas. Carregamento assimétrico.

No gráfico 6.9 pode ser observado que a variação de tensão nas vigas é não linear quando o vão varia linearmente, isto mostra que o método de cálculo proposto pela AASHTO pode levar ao cálculo de esforços que se afastam da realidade, pois esta norma apresenta critérios de cálculo baseados na extrapolação linear. No gráfico 6.10 as tensões obtidas para o tabuleiro sobre três vigas apresentaram uma variação mais próxima da linear. 


\subsection{2 - Influência da espessura da laje na distribuição de} tensões.

Sobre a laje são aplicadas diretamente as cargas móveis restando a esta distribuir as forças para as vigas. Para estudar a forma em que a espessura da laje influencia na distribuição de cargas foram modelados e analisados tabuleiros sobre três e quatro vigas com espessuras de 20, 25 e $30 \mathrm{~cm}$ respectivamente. As seções transversais adotadas para estes foram equivalentes às apresentadas no ANEXO A para os tabuleiros de 10 e 26 m de vão.

Neste estudo foi considerado apenas o carregamento assimétrico ocasionado pela carga móvel da Classe 45. A posição do carregamento na seção transversal foi a mesma do item anterior, tanto para o tabuleiro sobre quatro vigas como para o tabuleiro sobre três vigas.

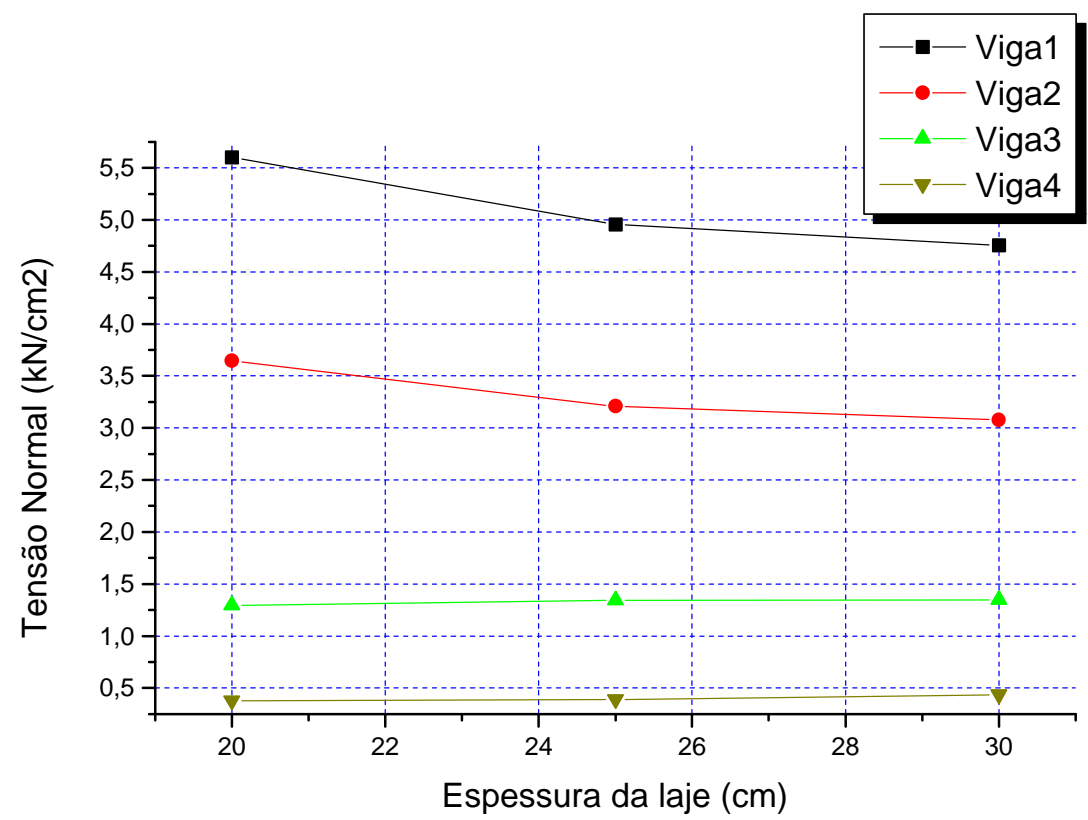

GRÁFICO 6.11 - Influência da variação da laje em tabuleiros sobre quatro vigas. Carregamento assimétrico.

No gráfico 6.11 foi observado que o aumento da espessura da laje ocasionou uma diminuição das tensões atuantes nas vigas 1 e 2 e um acréscimo destas nas vigas 3 e 4 . Isto pode ser atribuído a que o aumento 
de rigidez da laje melhora a capacidade desta para distribuir maiores parcelas de carga para as vigas mais afastadas, melhorando assim a distribuição de carga no conjunto. Outra possível causa da diminuição das tensões atuantes nas vigas 1 e 2 é o aumento da área de concreto das vigas mistas equivalentes, o que ocasiona um aumento de rigidez diminuindo por conseguinte as tensões nas vigas de aço.

No gráfico 6.12 podem ser realizadas observações similares às apresentadas no parágrafo anterior. Nos gráficos 6.11 e 6.12 observa-se que as vigas mais próximas do carregamento sofrem maiores variações de tensão que as mais afastadas quando a espessura da laje varia.

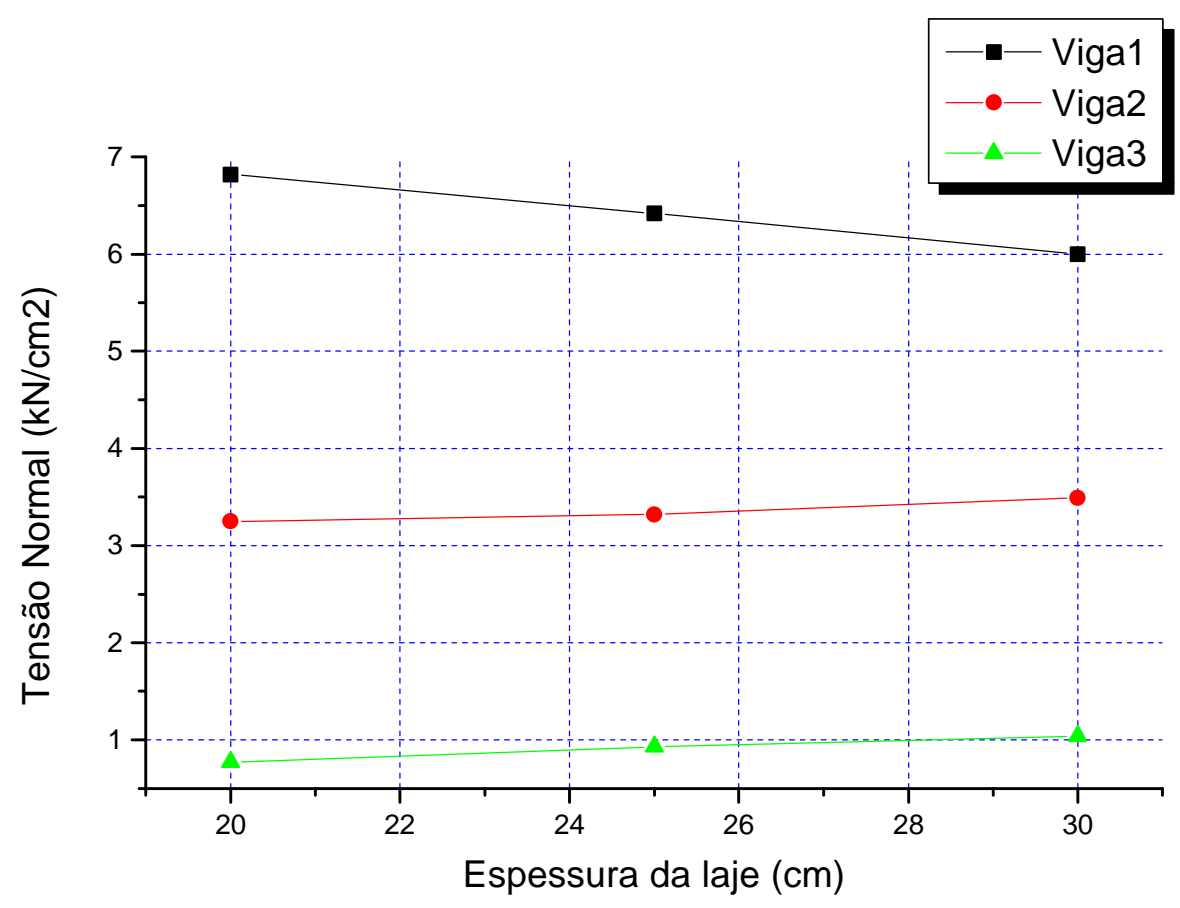

GRÁFICO 6.12 - Influência da variação da laje em tabuleiros sobre quatro vigas. Carregamento assimétrico.

\subsection{3 - Relação entre parâmetros geométricos e estruturais}

O comportamento estrutural de um tabuleiro de pontes em vigas mistas depende tanto da geometria como das propriedades estruturais dos 
elementos constituintes. NEWMARK apud MARX et al (1993), baseado em resultados de várias análises de pontes observou que a rigidez à flexão das vigas e a rigidez à flexão da laje não devem ser tratados como dois parâmetros separados. Estes devem ser combinados de maneira a formar um novo parâmetro adimensional. NEWMARK definiu o parâmetro $\mathrm{H}$ como a proporção entre a rigidez longitudinal das vigas e a rigidez transversal da laje em um sistema não misto, este parâmetro é calculado da seguinte maneira:

$$
\mathrm{H}=\frac{\mathrm{E}_{\mathrm{g}} \bullet \mathrm{I}_{\mathrm{g}}}{\mathrm{a} \bullet \mathrm{D}}
$$

$O$ parâmetro $D$ constitui a rigidez à flexão da laje por unidade de largura, sendo necessário multiplicar $\mathrm{D}$ por alguma unidade de comprimento de maneira a tornar o termo $\mathrm{H}$ adimensional. $\mathrm{O}$ vão do tabuleiro resulta conveniente para alcançar este objetivo, mesmo que este não seja a largura efetiva da laje na direção transversal.

Um alto valor de $\mathrm{H}$ significa, por exemplo, que a ponte possui vigas muito rígidas. NEWMARK determinou que pontes diferentes, sem ação mista, mas com os mesmos parâmetros $\mathrm{H}$ e b/a (vão/comprimento) sempre mantém superfícies de influência idênticas para os momentos fletores atuantes no tabuleiro.

No estudo realizado por MARX et al (1995), foram utilizadas as inércias das vigas mistas em lugar das pertencentes às vigas de aço, na seguinte maneira:

$$
H=\frac{E_{g} \bullet I_{c g}}{a \bullet D}
$$

$\mathrm{O}$ valor de $\mathrm{H}$ torna-se então uma função da largura da laje efetiva pois este depende do momento de inércia da viga mista. A largura efetiva da laje é uma aproximação realizada para levar em consideração o efeito de "shear lag" na laje, o qual depende, entre outros, da espessura da laje, espaçamento entre vigas, vão, excentricidade das vigas e condição de carregamento. 
Outras incertezas que afetam o parâmetro $\mathrm{H}$ são o valor real do módulo de elasticidade do concreto e a maneira em que a fissuração da laje influencia na rigidez do conjunto.

Julga-se importante citar que neste trabalho foi considerada válida a hipótese de que a laje é suficientemente armada nas duas direções, de maneira que a fissuração desta não afeta de maneira considerável a rigidez do tabuleiro. Atualmente tem sido formulados elementos finitos de concreto que são capazes de esmagar, fissurar e transferir tensões de cisalhamento após a fissuração; o elemento "SOLID65" da biblioteca do programa ANSYS possui estas opções mas não foi incorporado nas análises realizadas pois sua utilização implicaria a consideração de aspectos mais complexos como o da interação entre os conectores e o concreto circundante ${ }^{1}$.

$\mathrm{O}$ parâmetro $\mathrm{H}$ exerce o seguinte efeito no comportamento estrutural do tabuleiro: uma ponte que possui um elevado valor de $\mathrm{H}$ pode ter vigas rígidas e laje muito flexível. Seja por exemplo o caso dos tabuleiros com 25 $\mathrm{cm}$ de espessura; a carga concentrada aplicada diretamente sobre uma das vigas ocasiona que esta se desloque, enquanto que as outras vigas experimentam deslocamentos inferiores à primeira devido ao fato de que a laje é muito flexível para transferir quaisquer forças significativas. A maior parcela da carga é absorvida, então, pela viga mais próxima do ponto de aplicação do carregamento.

Se o valor de $\mathrm{H}$ diminui, pode-se considerar que a laje possui maior capacidade para distribuir uma determinada carga para todas as vigas longitudinais do tabuleiro. Um menor valor de $\mathrm{H}$ corresponde portanto a uma melhor distribuição de carga ao longo da largura da ponte.

\footnotetext{
${ }^{1}$ Os resultados obtidos utilizando este tipo de elemento se mostraram não confiáveis.
} 


\section{3 - Linhas de influência de distribuição de carga nas vigas}

Numa ponte rodoviária a carga móvel pode ocupar diferentes posições na seção transversal do tabuleiro, isto não ocorre no caso de pontes ferroviárias onde as cargas de roda atuam apenas sobre os trilhos. Neste item foi analisada a variação das tensões atuantes nas vigas de aço em função da localização da carga móvel na seção transversal.

Para isto foram modelados os dez tipos de tabuleiros apresentados no ANEXO A; conforme descrito no Capítulo 5, os elementos de casca da laje possuíam larguras de 20 e $10 \mathrm{~cm}$ para tabuleiros sobre quatro e três vigas, respectivamente. Estas dimensões permitiram considerar a carga móvel em diferentes pontos ao longo da seção transversal e introduzir as cargas de roda nos nós dos elementos.

Para todas as pontes analisadas foram traçadas as linhas de influência das tensões normais atuantes nas mesas inferiores das vigas de aço, em função da posição da carga móvel na seção transversal; foi considerada apenas a porção de seção pela qual a carga móvel pode trafegar livremente, isto é, a região onde não existem guarda-rodas. Em todos os tabuleiros foi considerada uma largura de $7,8 \mathrm{~m}$, conforme ilustrado na figura 6.3.

Na figura 6.3 apresenta-se também o esquema de posicionamento da carga móvel ao longo da seção transversal. Inicialmente a linha de rodas da esquerda foi posicionada na extremidade esquerda da faixa de circulação, sendo a linha de rodas da direita aplicada a 2,0 m de distância (NBR 7188); a seguir ambas as linhas de rodas foram deslocadas para a direita em acréscimos de $20 \mathrm{~cm}$, até a linha de rodas da direita alcançar a extremidade direita da faixa de circulação.

Para cada posição da carga móvel na seção transversal foi criado um arquivo de carregamento (LS FILE) de maneira a que, uma vez arquivadas todas as situações de carga (30 no total), fosse possível obter a solução para cada caso de maneira automática. 


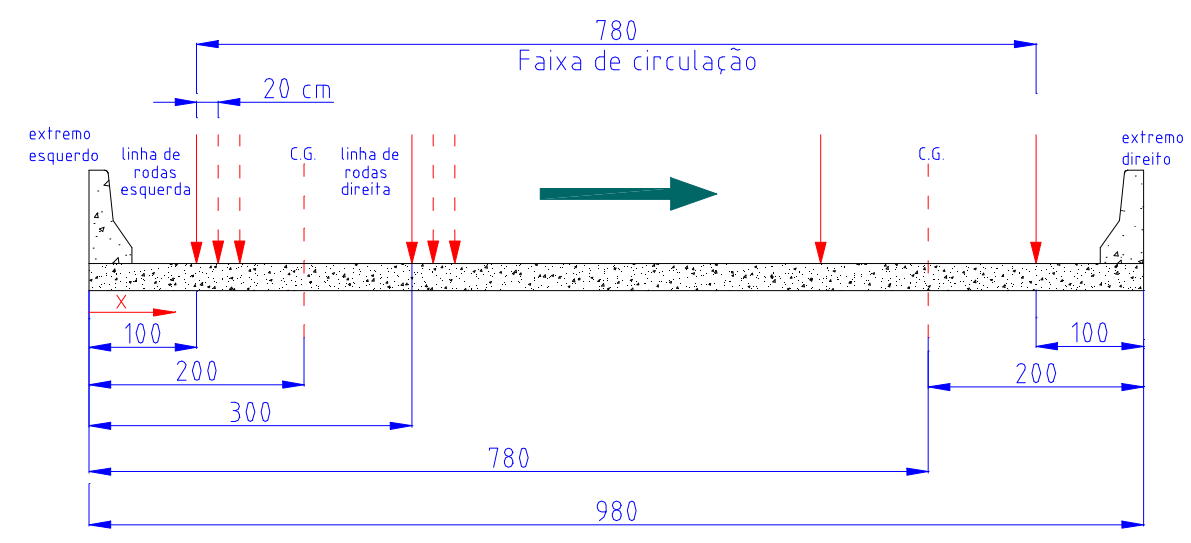

FIGURA 6.3 - Esquema de carregamento da estrutura para obtenção das linhas de influência.

A obtenção das tensões atuantes no meio do vão das mesas inferiores foi realizada através da leitura da história do carregamento da estrutura (time history). No ANEXO C apresenta-se as linhas de influência obtidas para as vigas dos tabuleiros analisados.

De maneira a realizar uma comparação da capacidade de distribuição de carga dos tabuleiros analisados, foram calculados fatores de distribuição de carga para cada linha de influência. A determinação destes fatores foi realizada dividindo as tensões, obtidas na análise, pelas tensões máximas obtidas através da consideração de vigas mistas equivalentes submetidas à ação de uma linha de rodas da carga móvel.

Nos gráficos 6.13 e 6.14 apresenta-se a variação dos fatores de distribuição de carga para as vigas interiores e exteriores, para tabuleiros sobre quatro vigas, em função da posição da carga móvel na seção transversal. Nestes gráficos o eixo de abscissas representa a distância da extremidade esquerda da laje ao C.G. da carga móvel, ou seja, as linhas de roda da carga móvel encontram-se a $1 \mathrm{~m}$ à direita e à esquerda desta distância (ver figura 6.3). 


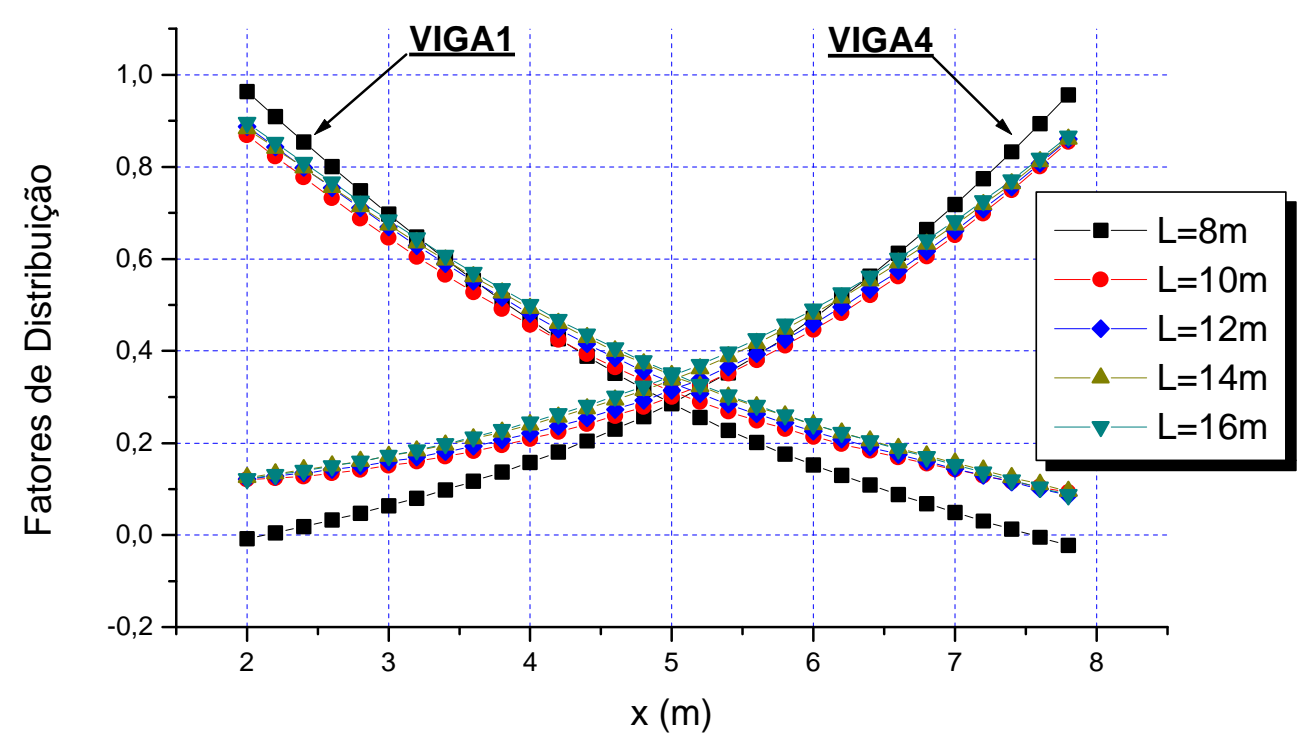

GRÁFICO 6.13 - Fatores de distribuição de carga para as vigas externas.

Tabuleiros sobre quatro vigas.

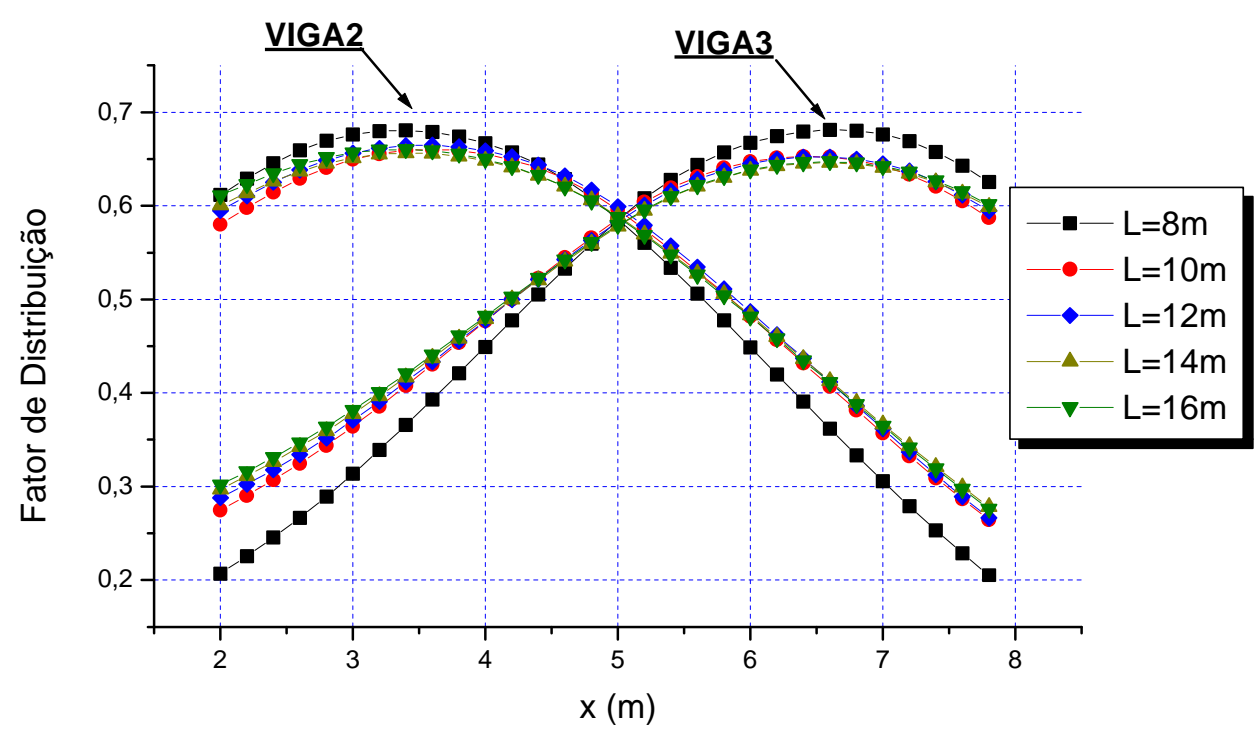

GRÁFICO 6.14 - Fatores de distribuição de carga para as vigas internas.

Tabuleiros sobre quatro vigas.

Através dos gráficos apresentados é possível observar que as máximas tensões atuantes nas vigas externas são superiores às das vigas internas. Nas vigas 1 e 4 as tensões máximas atingiram valores próximos 
aos calculados através da consideração de vigas mistas isoladas, já as vigas 2 e 3 atingiram valores inferiores em 70\%.

Foi observado também que as vigas do tabuleiro de $8 \mathrm{~m}$ de vão foram as mais sensíveis de sofrer variação de tensão em função da posição da carga móvel na seção. As vigas deste tabuleiro apresentaram as maiores faixas de variação de tensão, chegando inclusive as vigas externas a experimentar alternância de tensões; este comportamento pode ocasionar fadiga no tabuleiro diminuindo a vida útil da estrutura. As vigas dos tabuleiros de 10, 12, 14 e $16 \mathrm{~m}$ apresentaram curvas muito similares, com faixas de variação de tensão muito próximas.

Nos gráficos 6.15 e 6.16 apresenta-se a variação dos fatores de distribuição de carga, para tabuleiros sobre três vigas, em função da posição da carga móvel na seção transversal.

No gráfico 6.15 observa-se que as tensões máximas obtidas nas vigas ultrapassam em mais de $20 \%$ às tensões atuantes calculadas através da consideração de viga mista isolada. As curvas obtidas para descrever a variação dos fatores de distribuição em função da posição da carga móvel, apresentaram pouca variação de um tabuleiro para outro.

As tensões máximas obtidas na viga interna dos tabuleiros não ultrapassaram $80 \%$ das tensões máximas obtidas em vigas mistas isoladas, para o tabuleiro de $18 \mathrm{~m}$ de vão esta tensão não ultrapassou $75 \%$.

Nos tabuleiros de três e quatro vigas foi observado que as máximas tensões atuantes ocorreram nas vigas externas. 


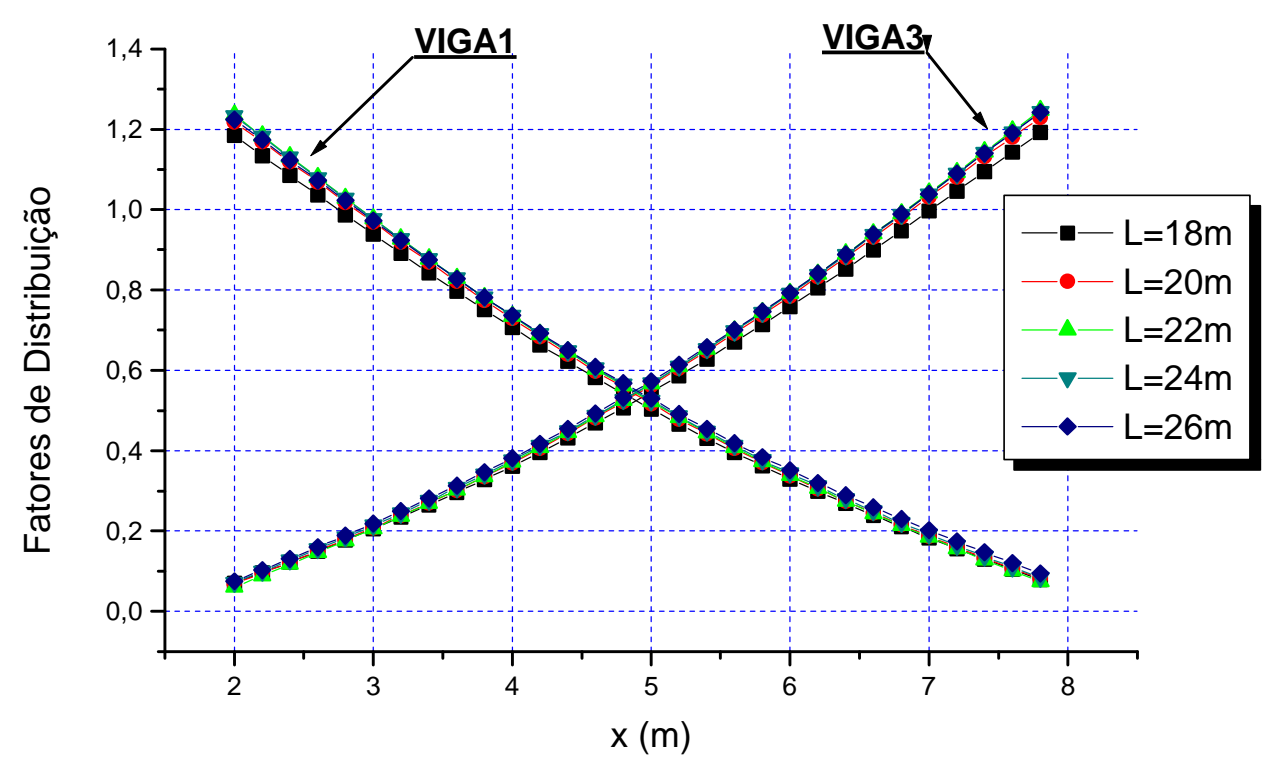

GRÁFICO 6.15 - Fatores de distribuição de carga para as vigas externas.

Tabuleiros sobre três vigas.

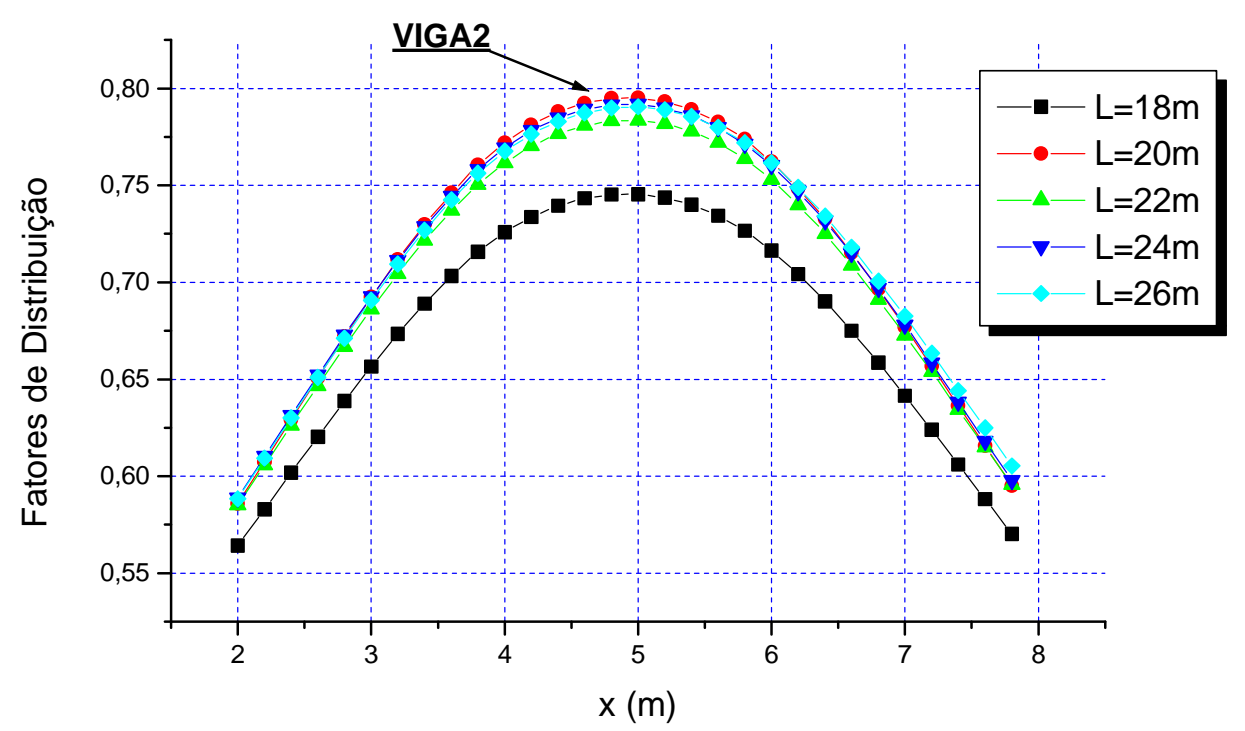

GRÁFICO 6.16 - Fatores de distribuição de carga para a viga interna. Tabuleiros sobre três vigas. 


\section{4 - Aplicação da técnica de Analogia de grelha.}

Para estudar a influência que o espaçamento e número de vigas transversais exercem no comportamento estrutural de uma grelha, foram inicialmente modelados nove tipos de grelha para representar o tabuleiro de $20 \mathrm{~m}$ de vão do ANEXO A. A única diferença entre um tipo e outro foi o número de vigas transversais de cada modelo, com a conseguinte variação do espaçamento entre estas.

Na região do tabuleiro onde foram aplicadas as cargas de roda, foram introduzidos nós vinculados ao resto dos elementos da grelha mediante elementos de viga. Quando a posição de uma carga de roda não coincide com um nó de grelha, é muito comum aplicar esta nos nós mais próximos, levando em consideração os momentos que transfere para estes (JAEGER \& BAKHT, 1982); a introdução de nós adicionais elimina esta dificuldade.

A inércia das vigas mistas foi calculada segundo as prescrições da AASHTO (ANEXO B), todas as vigas da grelha foram modeladas no programa ANSYS pelo elemento tridimensional de viga "BEAM4", a inércia à torção das vigas mistas foi desprezada.

A inércia das vigas transversais foi calculada considerando que estas possuem largura unitária, para os módulos de elasticidade do concreto e do aço foram adotados os valores estabelecidos no capítulo 5 .

Inicialmente foram consideradas apenas três transversinas: uma no meio do vão e as outras duas a $1,50 \mathrm{~m}$ desta, de maneira a que estas coincidam com as cargas de roda. A seguir o número de transversinas considerado foi de $5,7,9$ e 11, na sequência e posicionamento apresentados na figura 6.4. As vigas longitudinais foram posicionadas de maneira a coincidir com as vigas de aço.

Nesta figura apresenta-se também o posicionamento das cargas de roda para os casos de carregamento simétrico e assimétrico, a grelha foi considerada como simplesmente apoiada. 


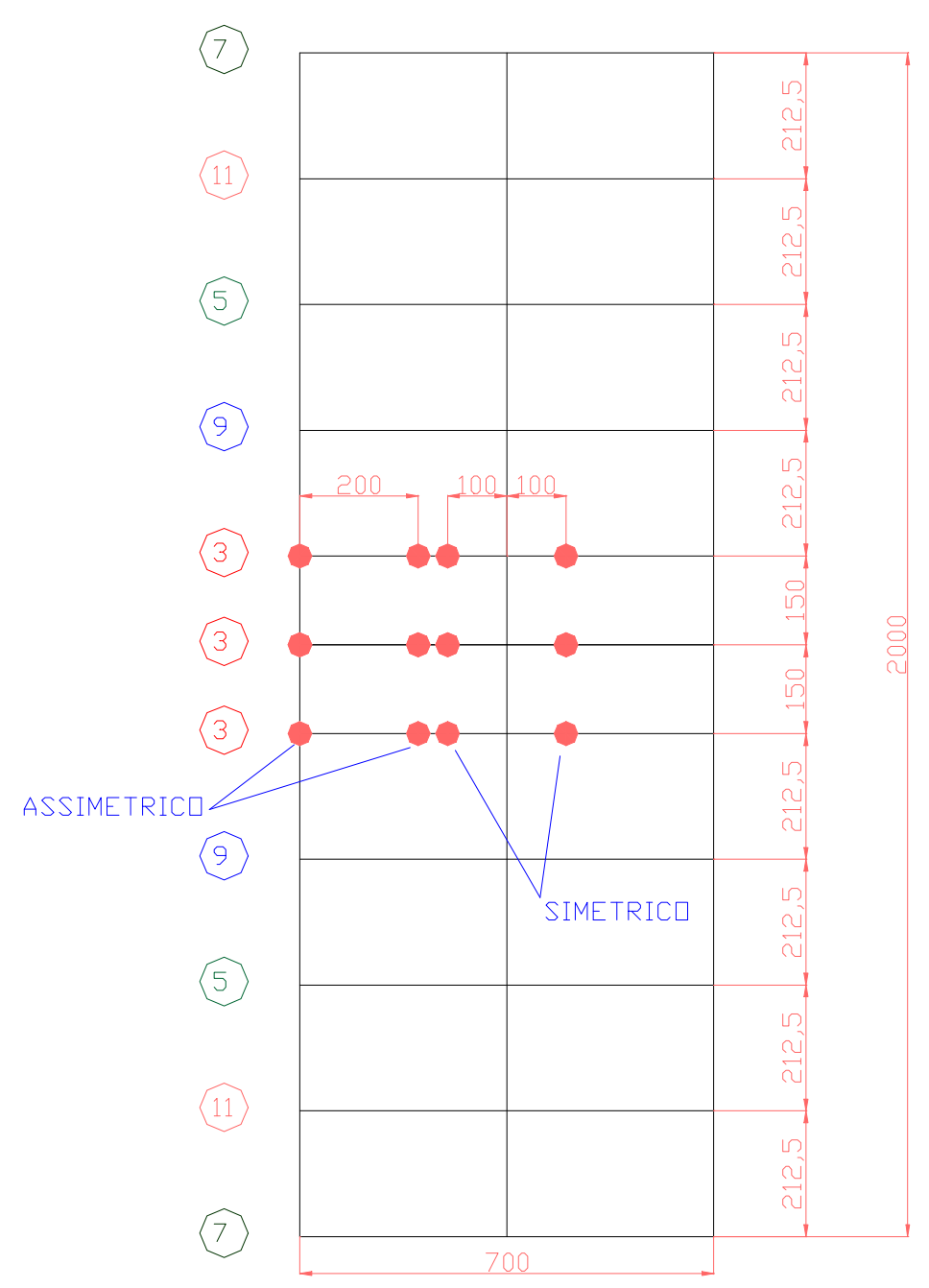

FIGURA 6.4 - Modelos de grelha analisados. Dim. em cm.

Na figura 6.5 apresenta-se a grelha modelada no programa ANSYS, versão 5.4 por elementos de viga, observa-se que os centros de gravidade entre as vigas transversais e longitudinais foram considerados coincidentes. 


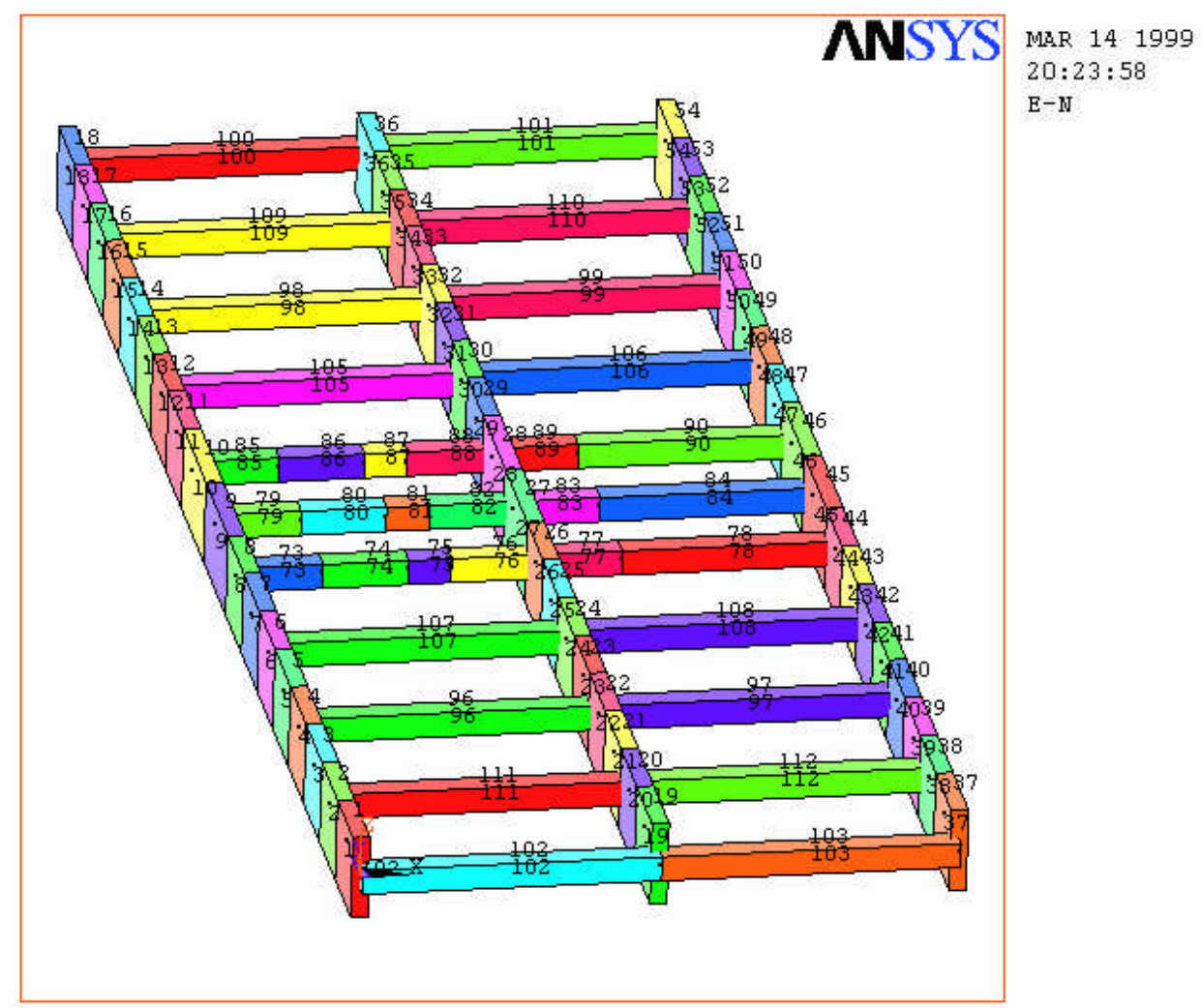

FIGURA 6.5 - Grelha modelada por elementos de viga "BEAM4".

Nos gráficos 6.17 e 6.18 apresentam-se as tensões obtidas nas vigas para os casos de carregamento simétrico e assimétrico. Em ambos os casos observa-se que um aumento do número de vigas transversais ocasiona um alívio de solicitação da viga mais carregada e um aumento desta nas vigas adjacentes.

Em ambos gráficos observa-se também que a introdução de mais de sete vigas transversais na grelha não ocasiona alterações sensíveis nos valores das tensões atuantes nas vigas longitudinais, estes resultados coincidem com a afirmação de WEST apud QUIROGA (1986) de que espaçamentos entre vigas transversais inferiores ao das vigas longitudinais não melhoram sensivelmente os resultados obtidos através da análise de uma grelha com menor número de elementos transversais. 


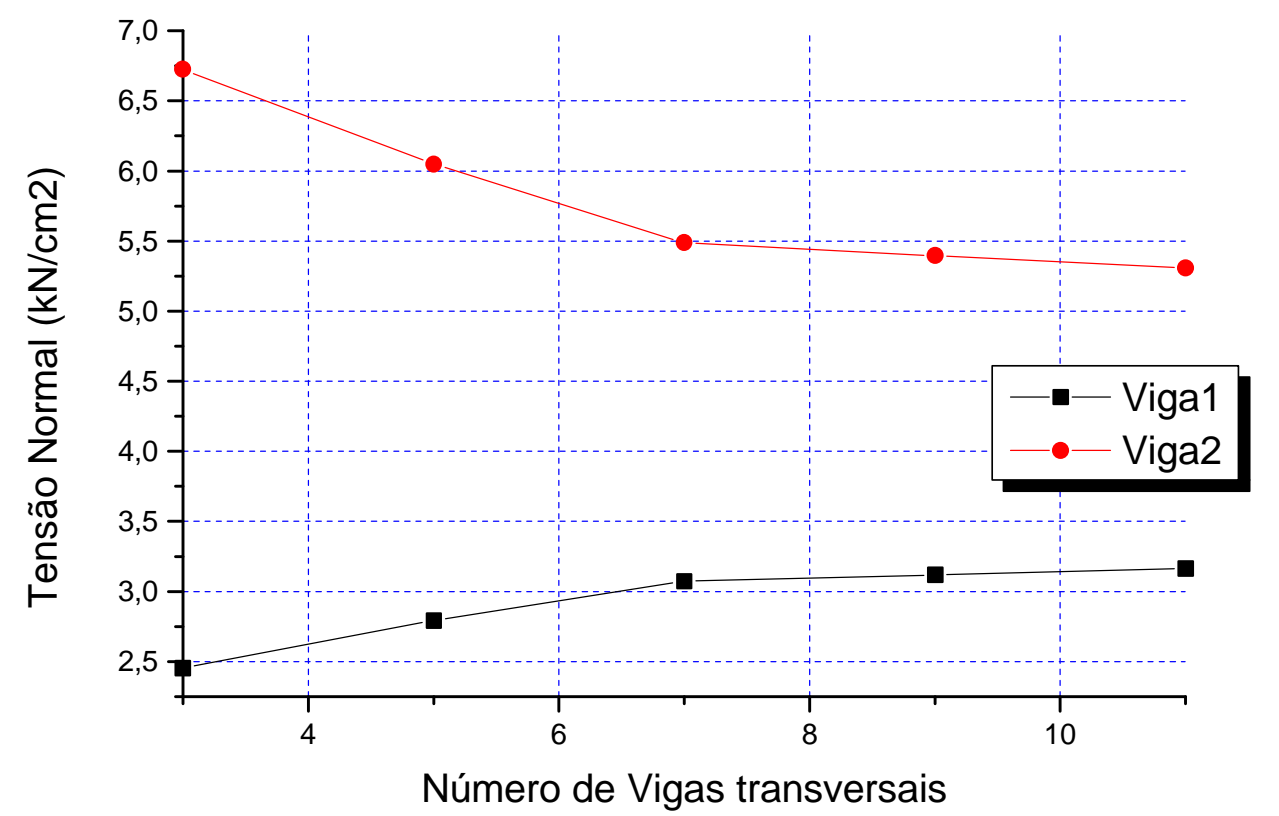

GRÁFICO 6.17 - Tensões normais no caso de carregamento simétrico.

Tabuleiro sobre três vigas, $L=20 \mathrm{~m}$.

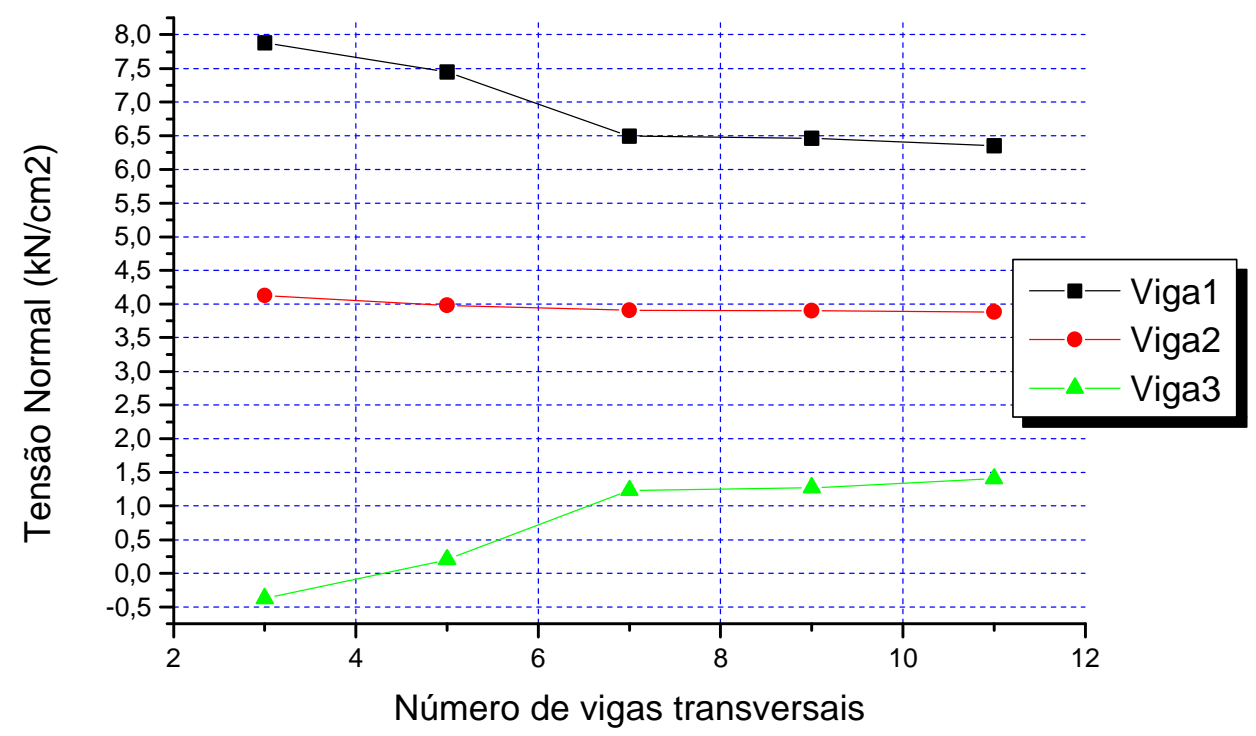

GRÁFICO 6.18 - Tensões normais no caso de carregamento assimétrico.

Tabuleiro sobre três vigas, $\mathrm{L}=20 \mathrm{~m}$.

Nos gráficos 6.19 e 6.20 apresenta-se uma comparação destes resultados com os obtidos através da modelagem tridimensional por elementos finitos. 


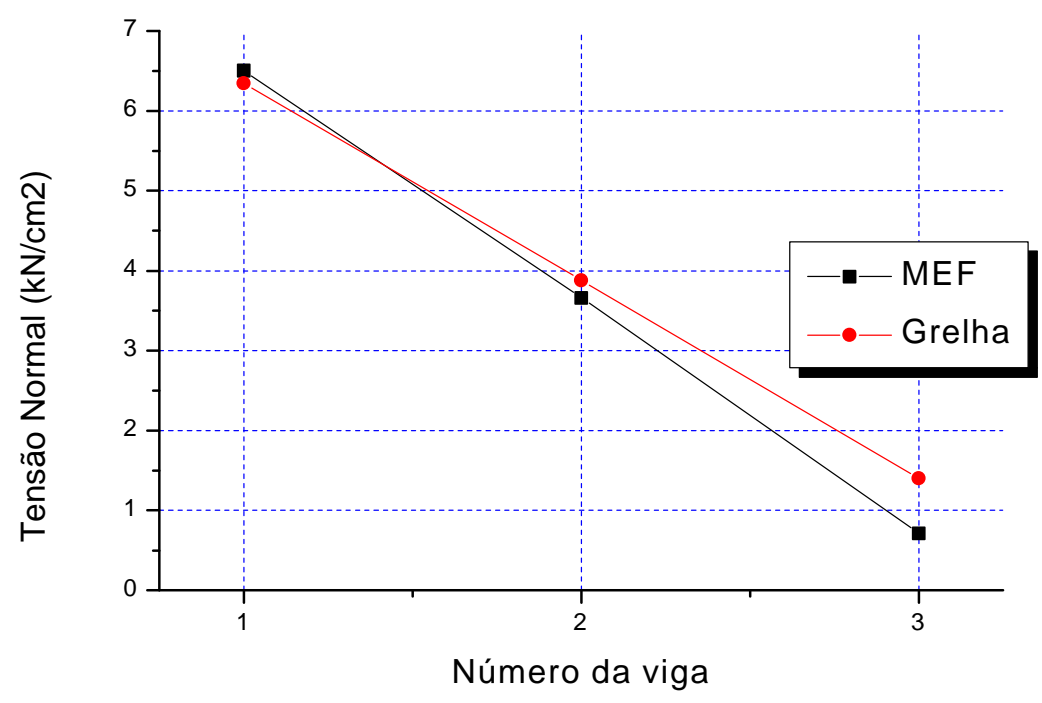

GRÁFICO 6.19 - Tensões normais no caso de carregamento assimétrico. Tabuleiro sobre três vigas, $\mathrm{L}=20 \mathrm{~m}$.

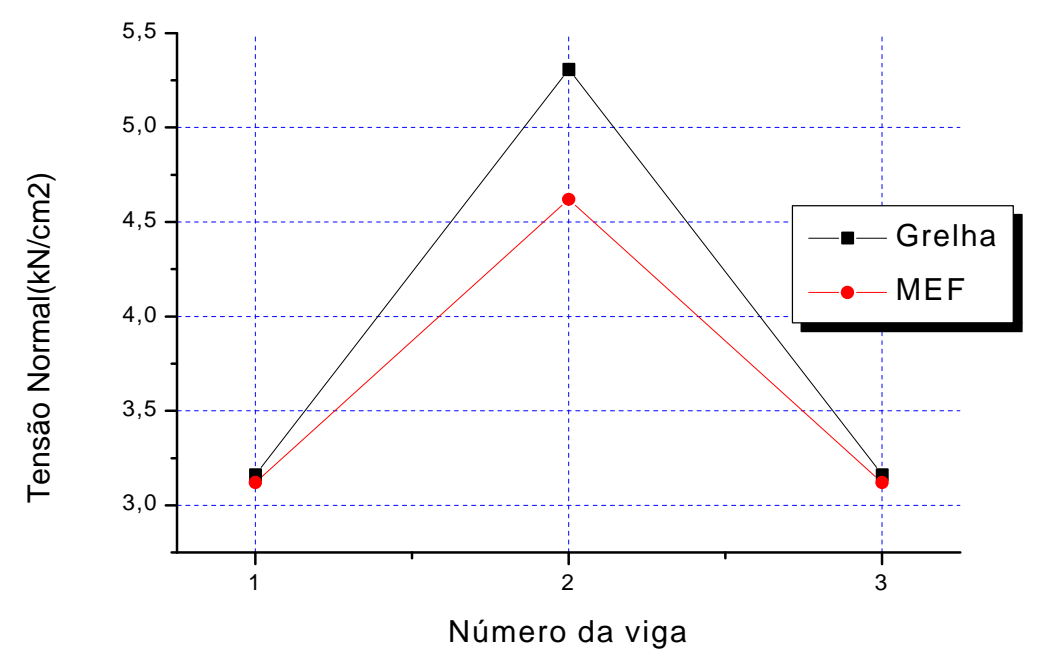

GRÁFICO 6.20 - Tensões normais no caso de carregamento simétrico.

Tabuleiro sobre três vigas, $\mathrm{L}=20 \mathrm{~m}$.

Exceto a viga 1 no caso de carregamento assimétrico observa-se que, de maneira geral, através do MEF obtem-se valores de tensões normais inferiores aos obtidos através da técnica de analogia de grelha. 


\section{5 - Estudo da redundância estrutural}

Para avaliar a redundância estrutural de uma determinada ponte é necessário quantificar da maneira mais precisa possível os esforços atuantes em todos os elementos da estrutura.

A fratura por fadiga em vigas de pontes surge através do desenvolvimento de uma trinca sob a influência de aplicações repetidas de tensões que são inferiores à tensão capaz de ocasionar a fratura por solicitação estática.

A norma AASHTO no item 10.3 estabelece os limites que devem ser respeitados no cálculo de estruturas redundantes e não redundantes. $\mathrm{Na}$ tabela 10.3.1.B desta norma são especificadas as tensões admissíveis de fadiga, em função da categoria, do detalhe e do número de ciclos.

$\mathrm{Na}$ tabela 6.1 apresenta-se os valores das tensões admissíveis de fadiga para estruturas redundantes e não redundantes. Observa-se nesta tabela que as tensões admissíveis de fadiga em estruturas não redundantes são inferiores às tensões admissíveis em estruturas redundantes.

TABELA 6.1 - Tensões admissíveis de fadiga em estruturas redundantes e não redundantes.

\begin{tabular}{|c|c|c|c|c|c|c|c|c|}
\cline { 2 - 9 } \multicolumn{1}{c|}{} & \multicolumn{4}{c|}{$\begin{array}{c}\text { Estruturas Redundantes } \\
\text { (MPa) }\end{array}$} & \multicolumn{4}{c|}{$\begin{array}{c}\text { Estruturas não Redundantes } \\
\text { (MPa) }\end{array}$} \\
\hline Categoria & $\begin{array}{c}100.000 \\
\text { ciclos }\end{array}$ & $\begin{array}{c}500.000 \\
\text { ciclos }\end{array}$ & $\begin{array}{c}2.000 .000 \\
\text { ciclos }\end{array}$ & $\begin{array}{c}\text { acima de } \\
2.000 .000\end{array}$ & $\begin{array}{c}100.000 \\
\text { ciclos }\end{array}$ & $\begin{array}{c}500.000 \\
\text { ciclos }\end{array}$ & $\begin{array}{c}2.000 .000 \\
\text { ciclos }\end{array}$ & $\begin{array}{c}\text { acima de } \\
2.000 .000 \\
\end{array}$ \\
\hline A & 435 & 256 & 166 & 166 & 345 & 200 & 166 & 166 \\
B & 338 & 200 & 124 & 111 & 269 & 159 & 110 & 110 \\
B' & 269 & 159 & 100 & 83 & 214 & 124 & 76 & 76 \\
C & 245 & 145 & 90 & 69 & 193 & 110 & 69 & 62 \\
D & 193 & 110 & 69 & 48 & 152 & 90 & 55 & 35 \\
E & 152 & 90 & 55 & 31 & 117 & 69 & 41 & 16 \\
E' & 110 & 64 & 40 & 18 & 83 & 48 & 28 & 9 \\
F & 104 & 83 & 62 & 55 & 83 & 62 & 48 & 41 \\
\hline
\end{tabular}

No intuito de estudar a capacidade que um tabuleiro em viga mista possui para continuar oferecendo segurança e estabilidade após a fratura de uma viga de aço, foram modeladas fraturas em pontes de 16 e 24 m de vão, 
a modelagem destas fraturas foi realizada através da introdução de uma descontinuidade ao longo de toda a largura da mesa inferior, conforme apresentado na figura 6.6.

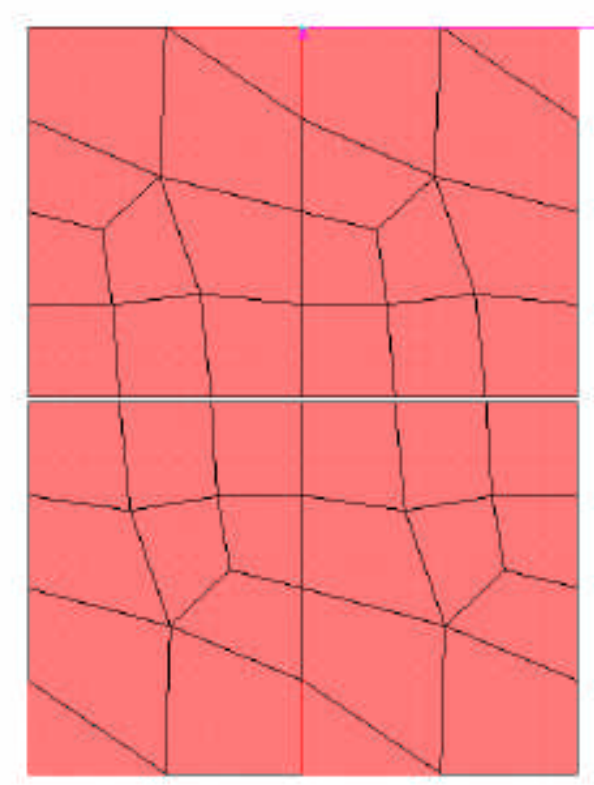

ANSYS

FIGURA 6.6 - Modelagem da fratura na mesa inferior.

A malha apresentada na figura 6.6 foi gerada de maneira automática pelo pré-processador do programa.

Foi também introduzida uma descontinuidade ao longo de quase toda a altura da alma da viga, deixando apenas $10 \mathrm{~cm}$ sem fissurar na região superior desta.

Na figura 6.7 apresenta-se a modelagem da fratura da alma. Cabe citar que o elemento utilizado na modelagem das vigas e da laje foi 0 "SHELL43", este elemento é similar ao de casca elástica "SHELL63" com a diferença de que o primeiro possui a capacidade de plastificar. 


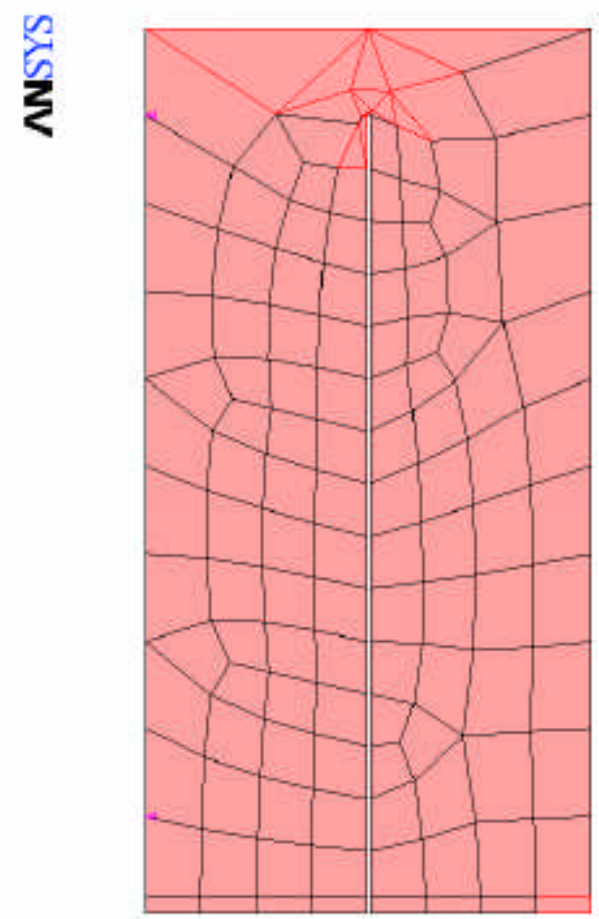

FIGURA 6.7 - Modelagem da fratura na alma.

O local onde a fissura foi modelada foi na região adjacente à metade do vão, onde ocorrem as máximas solicitações de momento fletor nas vigas, a abertura da fissura modelada foi de $2 \mathrm{~mm}$. Nos tabuleiros considerados foi introduzida apenas uma fissura, localizada numa das vigas exteriores.

$\mathrm{Na}$ figura 6.8 apresenta-se a fissura modelada, sendo esta localizada no meio do vão de uma das vigas exteriores, tanto para o tabuleiro de $16 \mathrm{~m}$ como para o de $24 \mathrm{~m}$. O arranjo estrutural e seção transversal destes tabuleiros encontram-se no ANEXO A. 


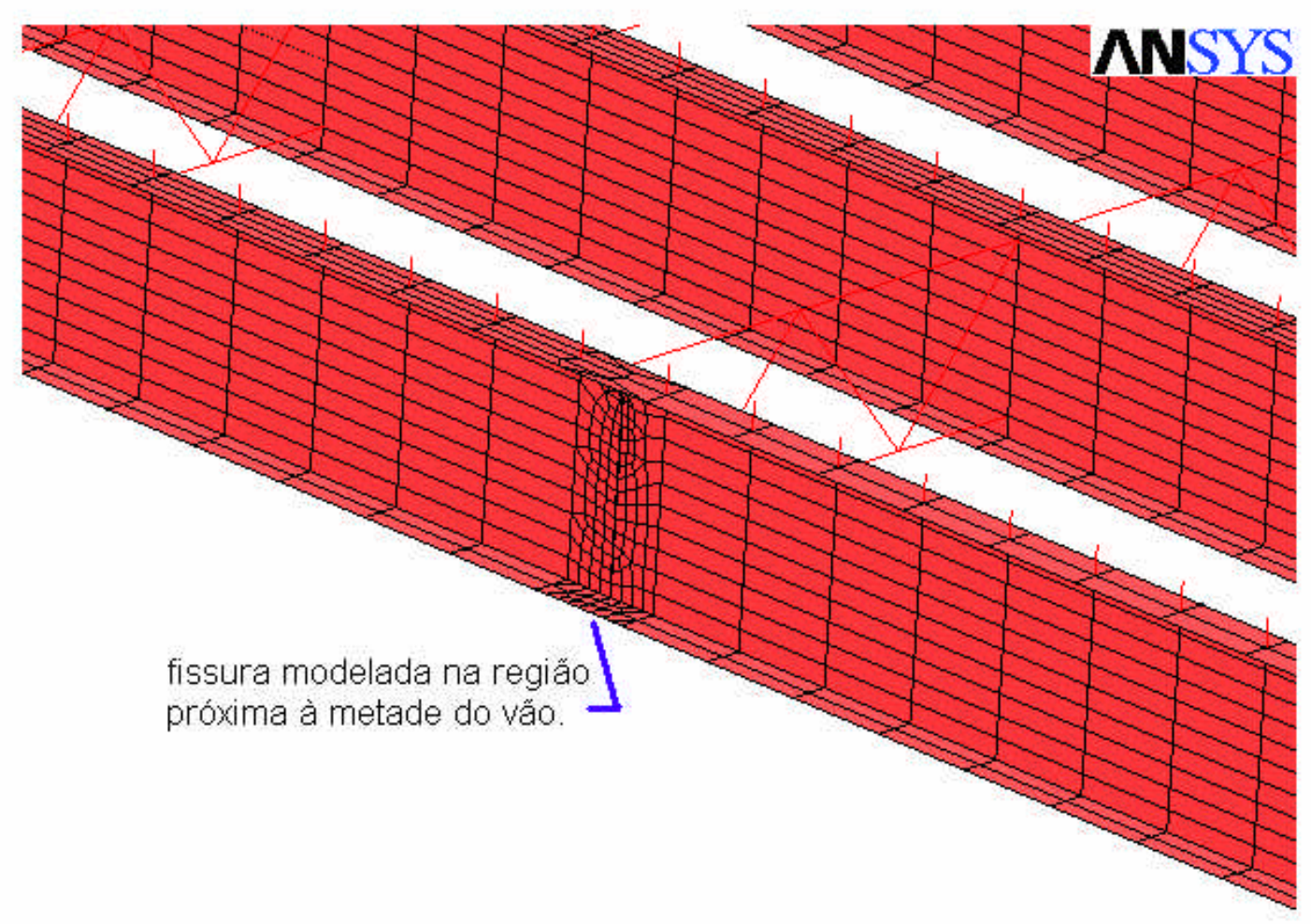

FIGURA 6.8 - Localização da fratura na viga.

Para estudar a redundância dos tabuleiros foram consideradas duas cargas móveis da classe 45, posicionadas conforme mostrado na figura $6.9^{1}$.

Nas análises realizadas foi considerada a não linearidade geométrica da estrutura e a não linearidade física das vigas de aço, sendo adotada a opção bi-linear do programa para representar a curva de tensão deformação destas. Na figura 6.10 apresenta-se esta curva.

O método de solução escolhido foi o de Newton - Raphson, sendo adotado o critério de convergência por forças; este critério foi adotado devido à rapidez de convergência que apresenta.

\footnotetext{
${ }^{1}$ Sendo esta hipótese correspondente a uma possível condição de carregamento à que a ponte poderia estar submetida.
} 


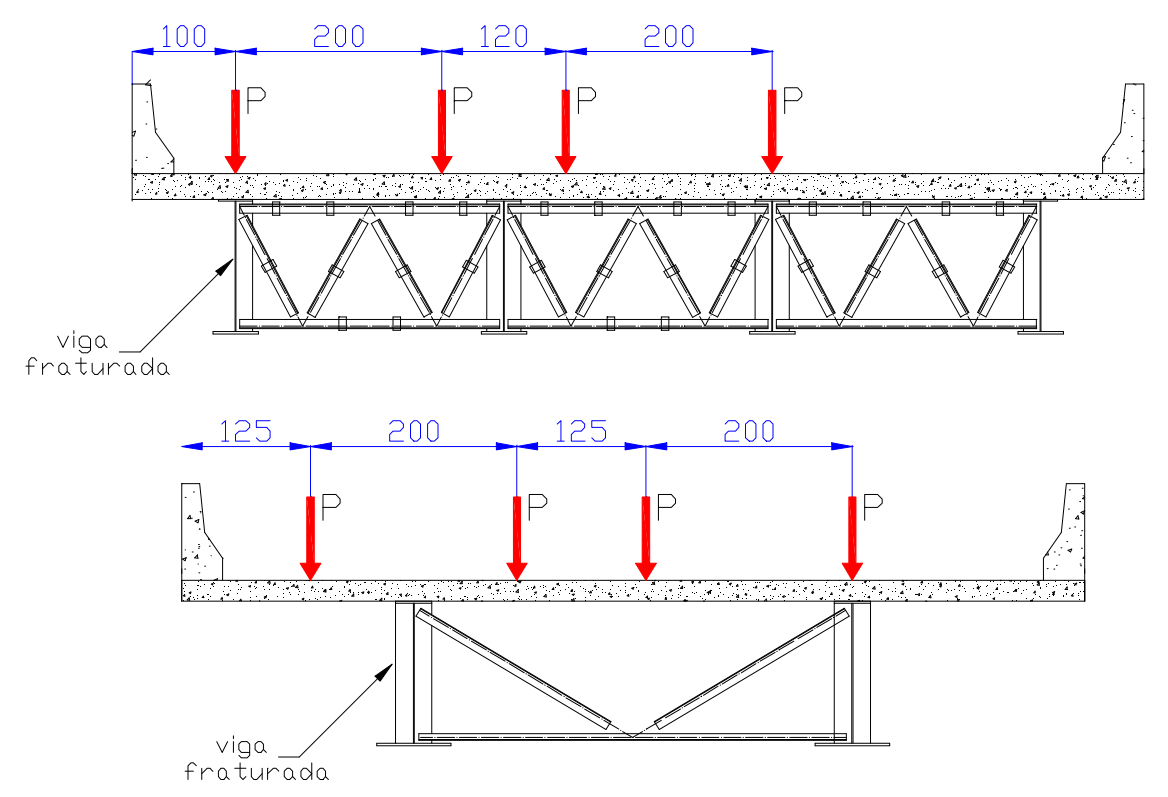

FIGURA 6.9 - Posição das cargas móveis na seção transversal. Dimensões $\mathrm{em} \mathrm{cm}$.

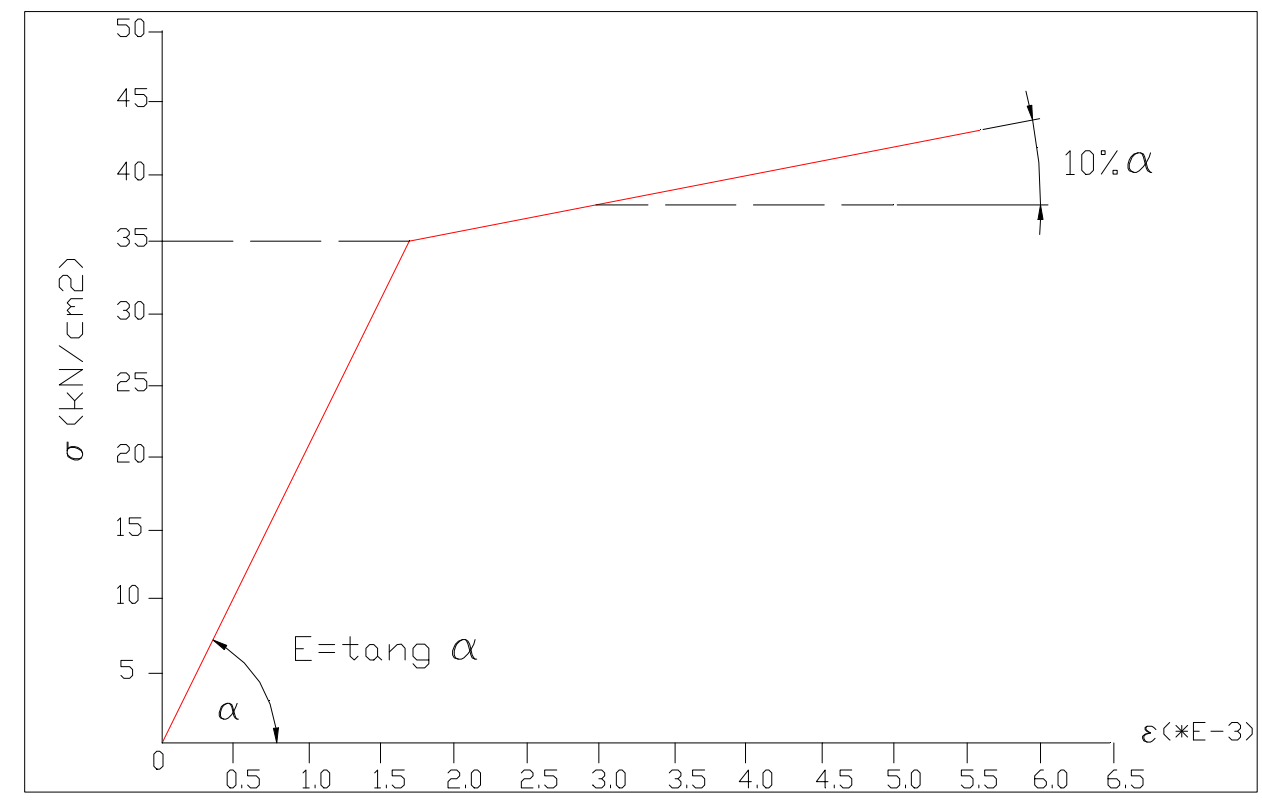

FIGURA 6.10 - Curva de tensão - deformação adotada para as vigas de aço. Comportamento bi-linear 
Nos tabuleiros analisados foram consideradas duas cargas móveis situadas lado a lado e próximas da viga fraturada. A norma AASHTO (1989) não considera nenhum fator de redução para as cargas de roda para o caso de considerar duas cargas móveis lado a lado.

\subsection{1 - Redundância do tabuleiro sobre quatro vigas}

Nas análises realizadas foi possível observar que este tipo de tabuleiro possui estabilidade após a fratura de uma das vigas exteriores, foi verificado também que existe uma redistribuição de esforços e que os contraventamentos contribuem na transferência de esforços para as vigas restantes após a fratura.

$\mathrm{Na}$ figura 6.11 apresenta-se a deformação das vigas e as tensões atuantes ao longo da altura destas, a tensão máxima observada foi de 18,75 $\mathrm{kN} / \mathrm{cm}^{2}$ na mesa inferior da viga mais próxima à viga fraturada, isto significa que não houve plastificação nas vigas sem fratura.

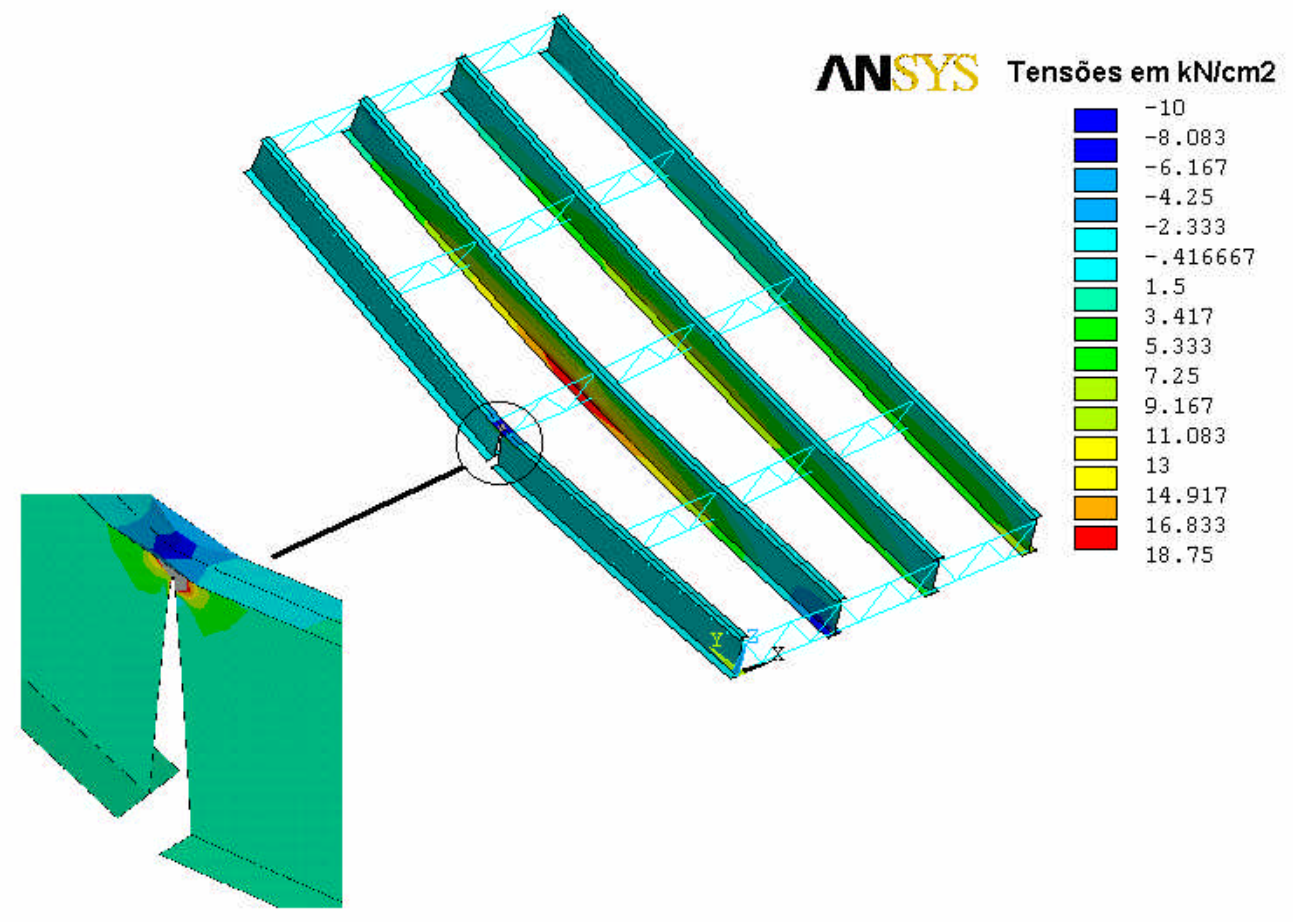

FIGURA 6.11 - Redistribuição das tensões atuantes. 
Observa-se também nesta figura que, a exceção da concentração de tensões observada na região próxima à fissura da alma, não ocorrem tensões importantes na viga fraturada.

$\mathrm{Na}$ figura 6.12 apresenta-se as tensões atuantes nas vigas antes da ocorrência de fratura na viga.

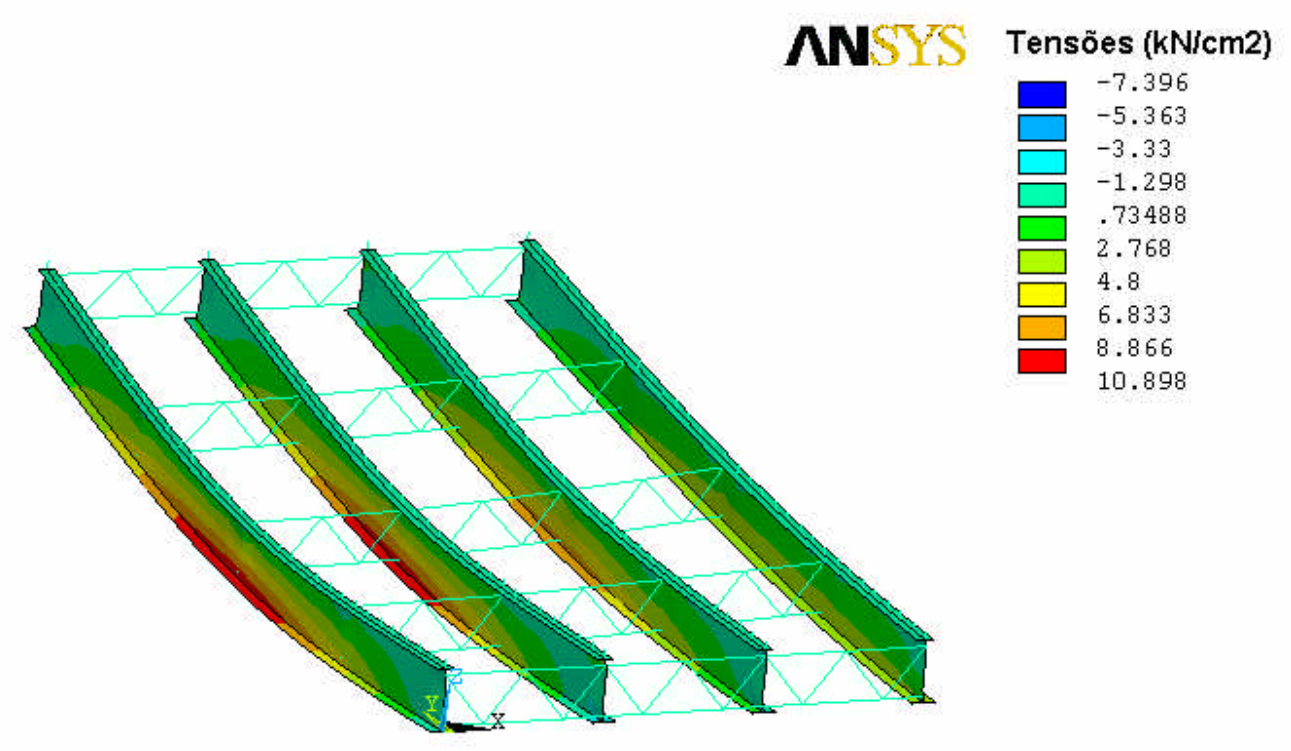

FIGURA 6.12 - Tensões atuantes nas vigas antes da fratura.

No gráfico 6.21 apresenta-se uma comparação entre as tensões obtidas nas vigas 2, 3 e 4 com a viga 1 fissurada e sem fissurar. Observa-se neste gráfico que a viga mais próxima da viga fraturada é a que sofre maior variação de tensão, enquanto que a tensão atuante na viga mais distante é pouco alterada. 


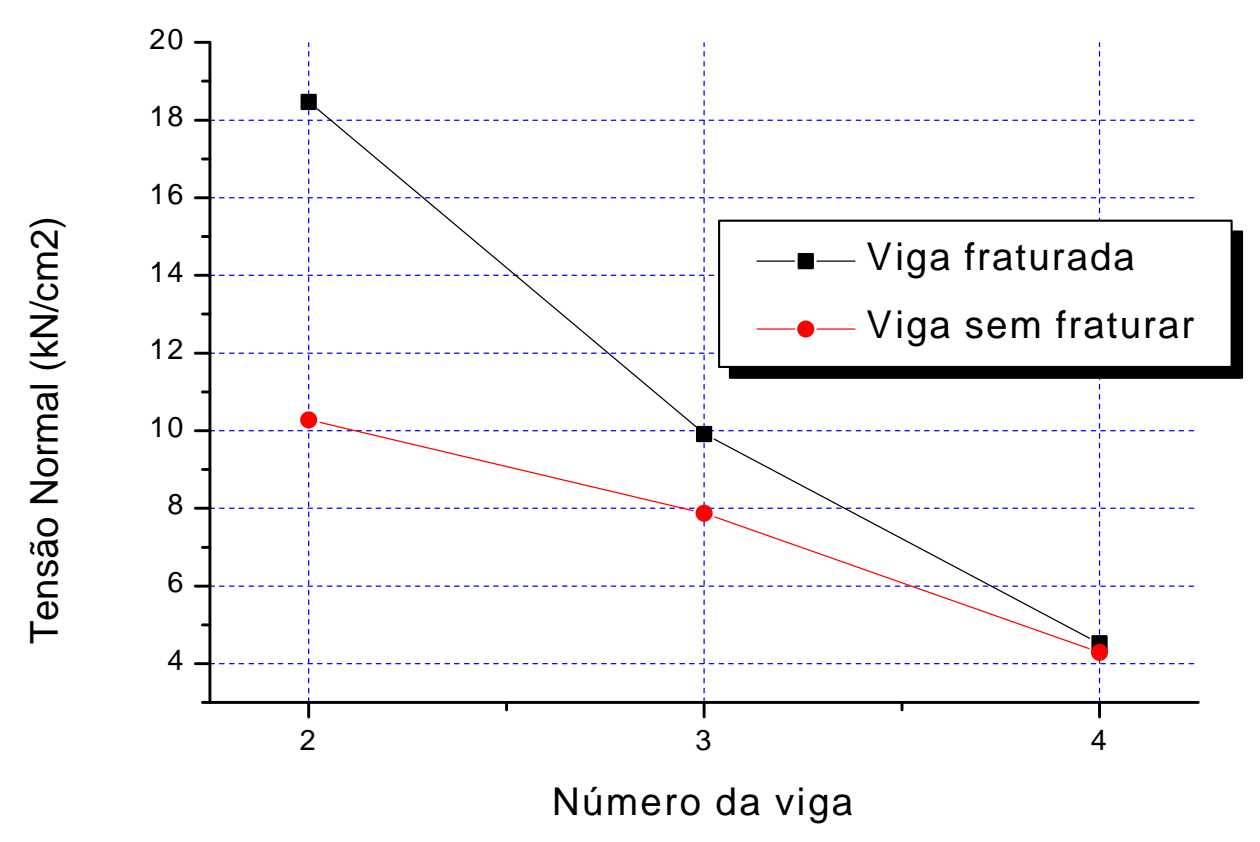

GRÁFICO 6.21 - Comparação de tensões antes e depois da fratura.

Na figura 6.13 apresenta-se os deslocamentos experimentados pelas vigas, observa-se que o deslocamento máximo, o qual ocorre no meio do vão da viga fissurada, é de $3,655 \mathrm{~cm}$; este deslocamento ultrapassa o limite de utilização de L/500 que para o vão de $16 \mathrm{~m}$ é de $3,2 \mathrm{~cm}$. As vigas 2,3 e 4 experimentaram deslocamentos inferiores a este limite.

Os deslocamentos ocasionados pelas cargas móveis nas vigas, no caso de não existir fratura na viga, são apresentados na figura 6.14. 


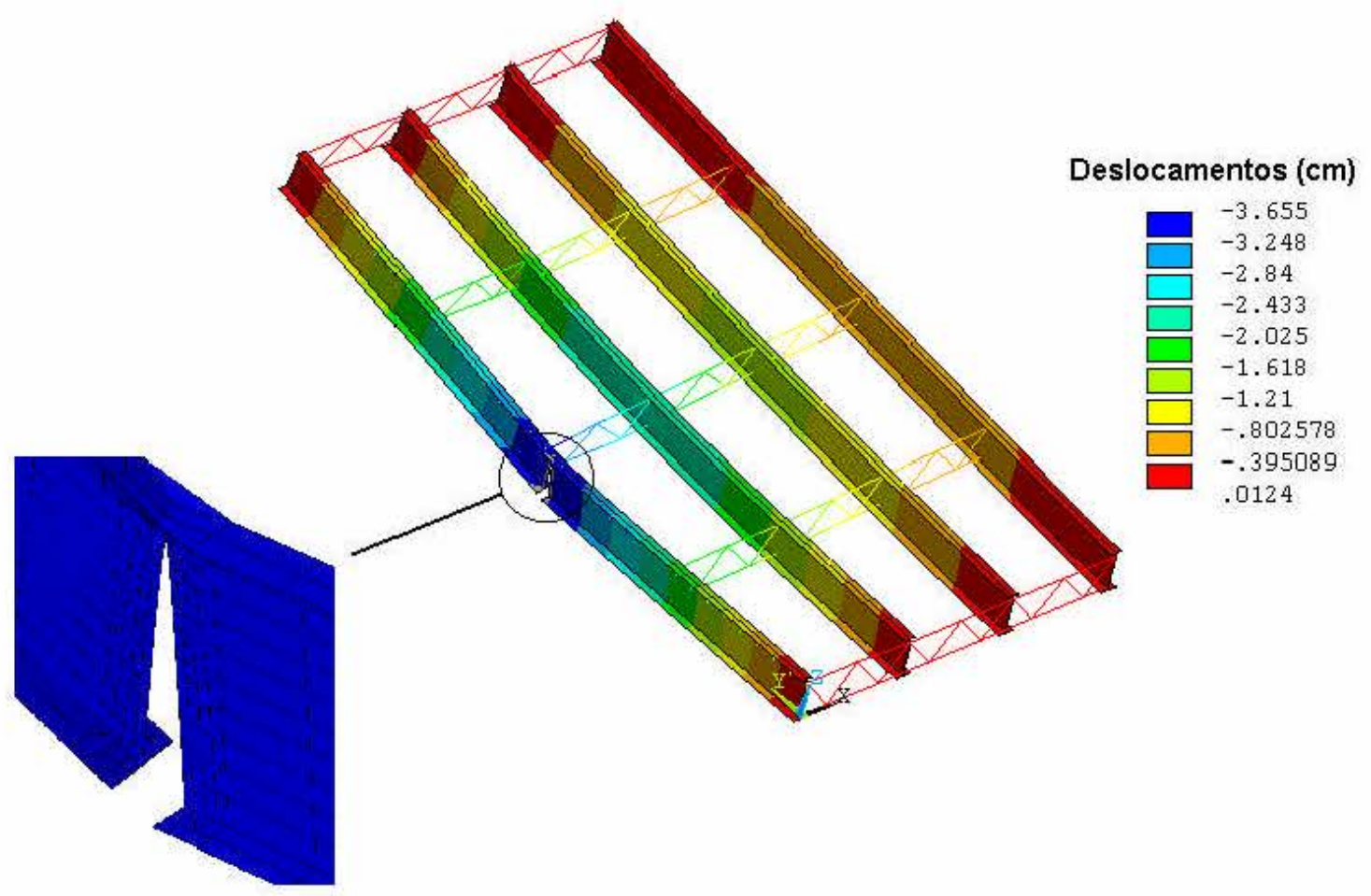

FIGURA 6.13 - Deslocamentos obtidos nas vigas com a viga 1 fraturada.

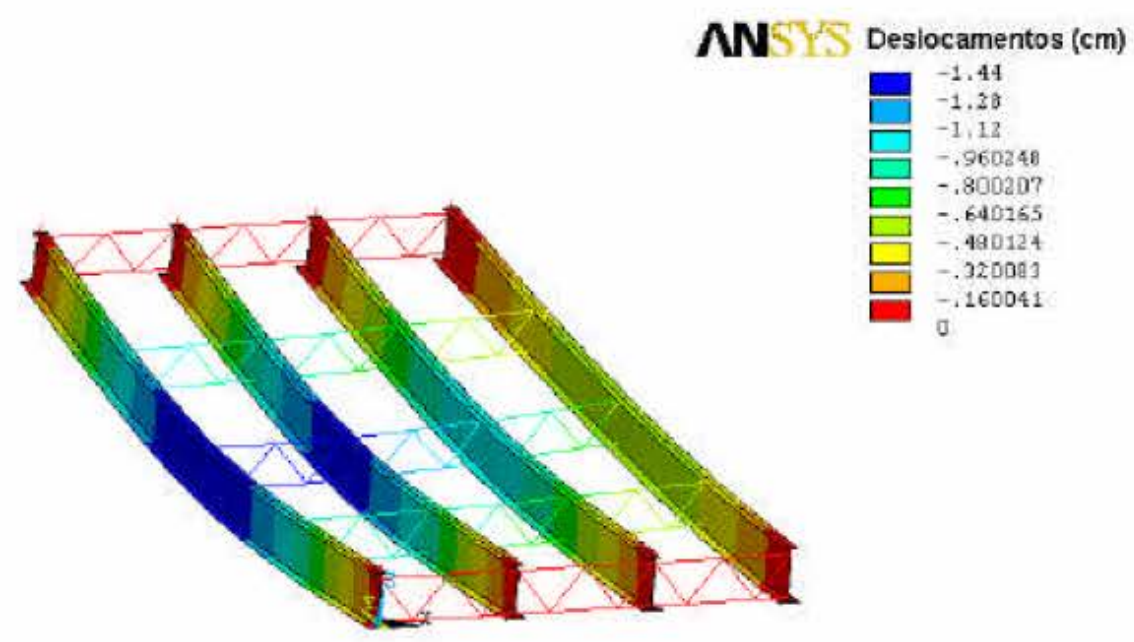

Figura 6.14 - Deslocamentos obtidos com a viga 1 sem fratura. 


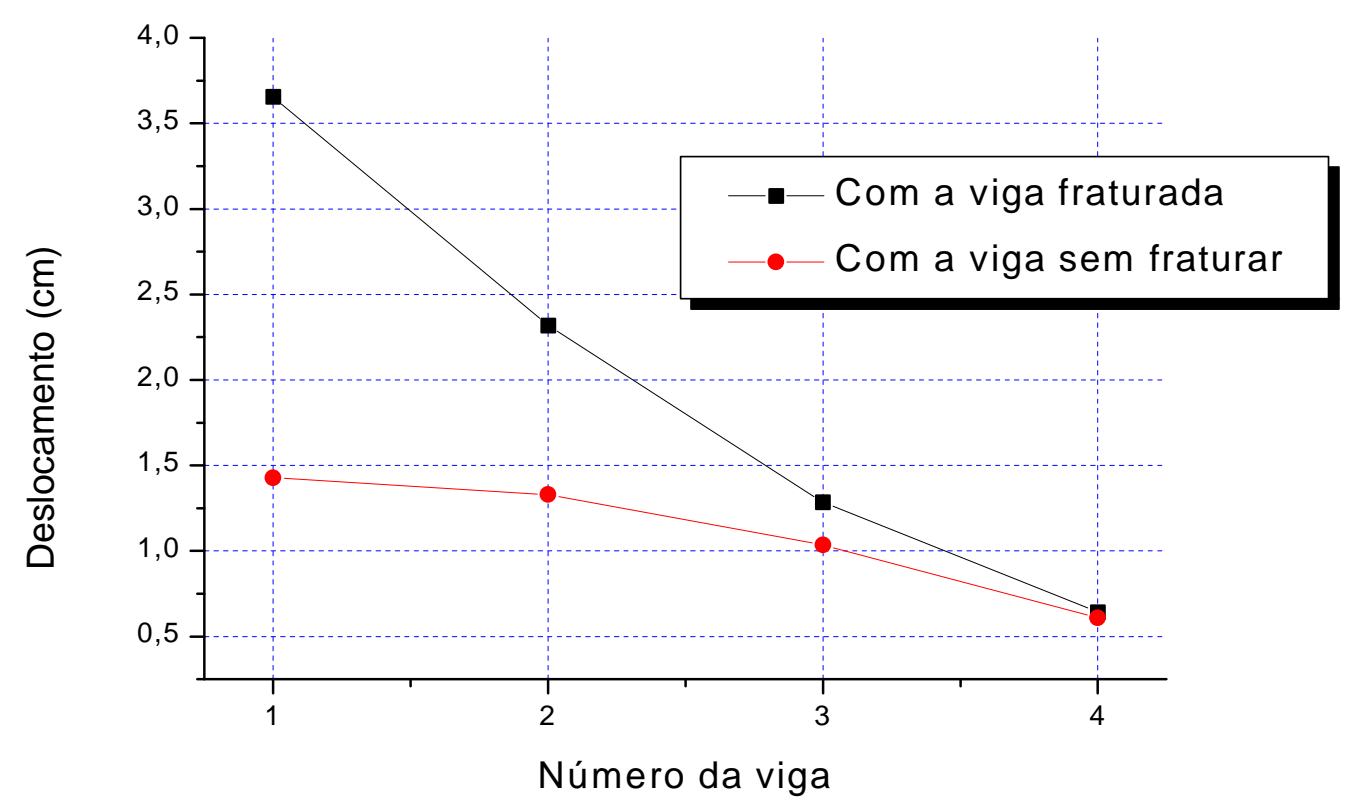

GRÁFICO 6.22 - Comparação de deslocamentos antes e depois da fratura.

Uma comparação dos deslocamentos das vigas antes e depois da viga externa fraturar é apresentada no gráfico 6.22, observa-se que a viga fraturada experimentou o maior acréscimo de deslocamento, sendo este mínimo para a viga mais distante.

$\mathrm{Na}$ figura 6.15 apresenta-se os esforços normais que surgem nas barras do contraventamento mais próximo da fratura (região central), apresenta-se também entre parênteses os esforços normais no caso de não existir fratura. Observa-se nesta figura que há uma inversão de esforços quando ocorre fratura: as barras do banzo superior são tracionadas e as barras do banzo inferior são comprimidas, o mesmo acontece com as diagonais. Isto sugere que o sistema de contraventamentos na região central passa a apresentar comportamento de treliça em balanço quando ocorre fratura na viga. 


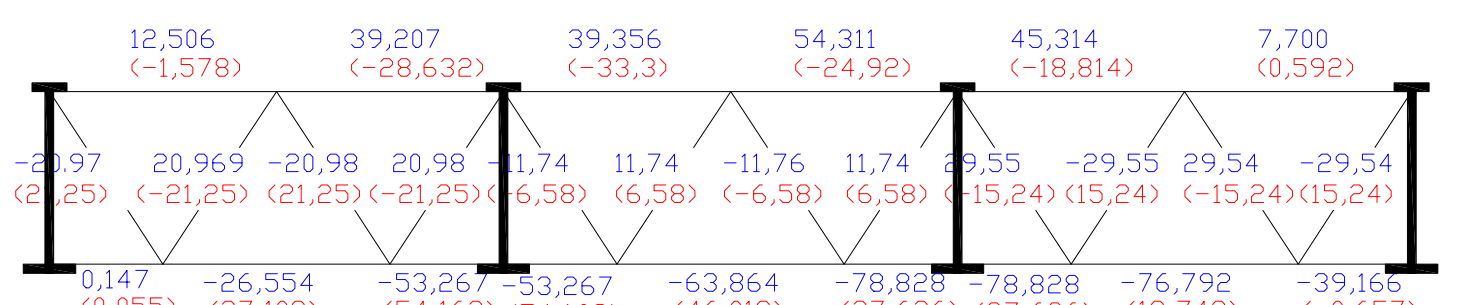

(+) Tração

Esforço normal 〈kN〉

(-) Compressão

FIGURA 6.15 - Esforços normais nas barras do contraventamento mais próximo da fratura (região central).

$\mathrm{Na}$ figura 6.16 apresenta-se a comparação entre as reações nos apoios das vigas com a viga externa fraturada e sem fraturar (valores entre parênteses).

\section{REACrú}
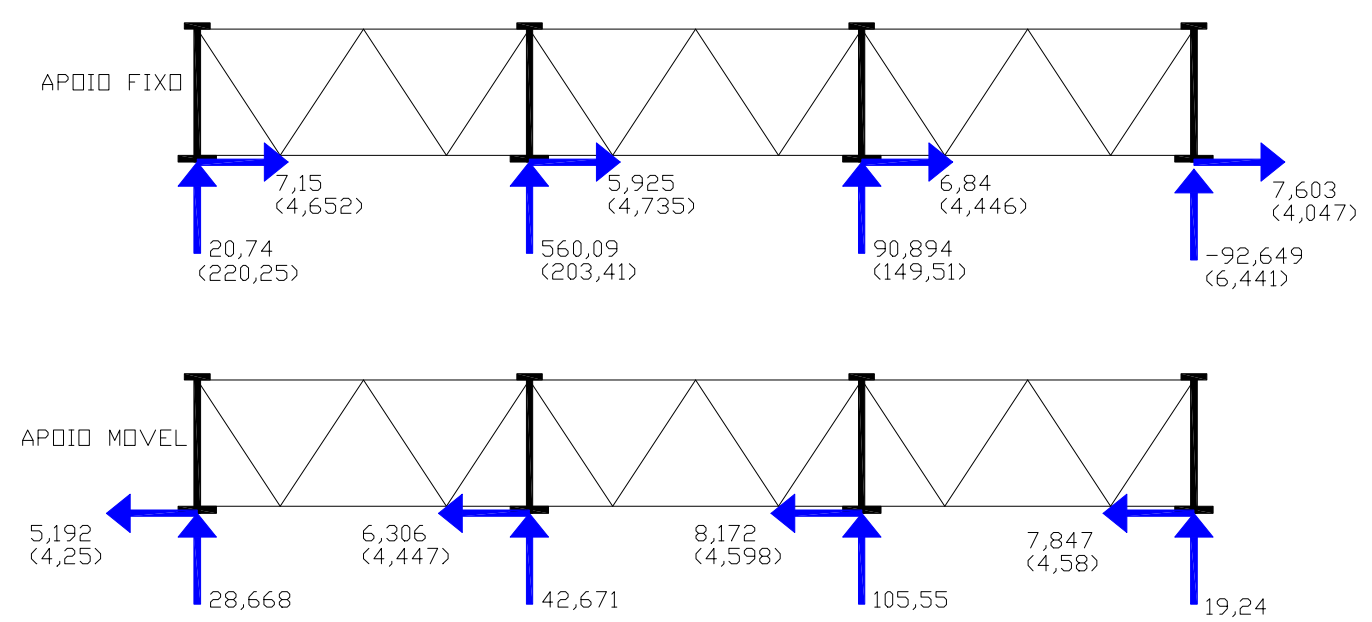

FIGURA 6.16 - Reações nos apoios antes e depois da fratura. 
Como o carregamento foi aplicado em 10 acréscimos de carga na análise não linear, foi investigada a forma em que as tensões e deslocamentos variaram a cada acréscimo de carga. Nos gráficos $6.23 \mathrm{e}$ 6.24 apresentam-se estas variações, observa-se que as vigas apresentam comportamento elástico-linear, estes resultados coincidem com as observações realizadas por AZIZINAMINI et al (1995) a partir de estudos experimentais.

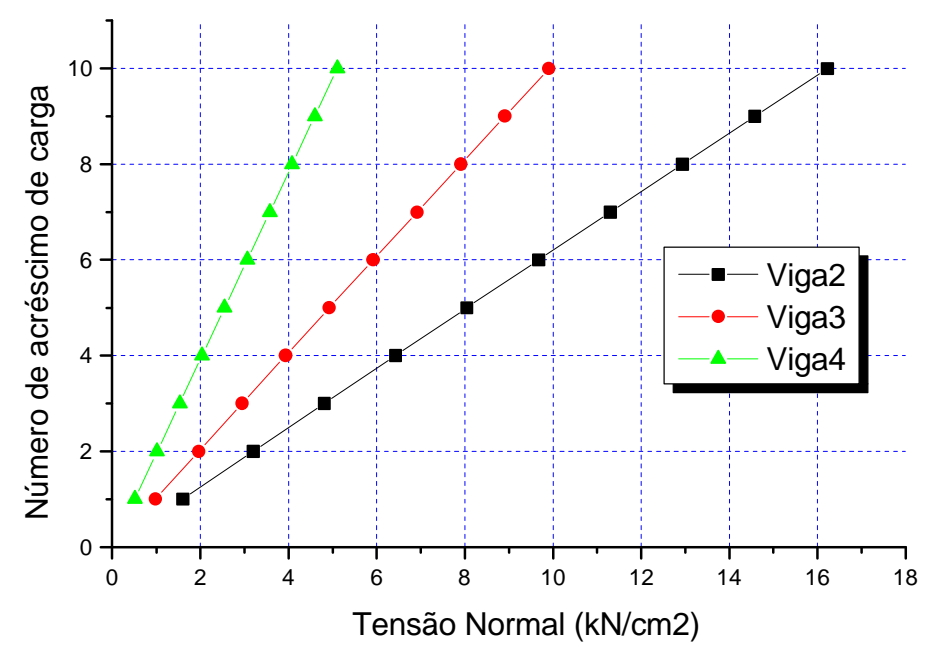

GRÁFICO 6.23 - Variação das tensões nas vigas a cada acréscimo de carga.

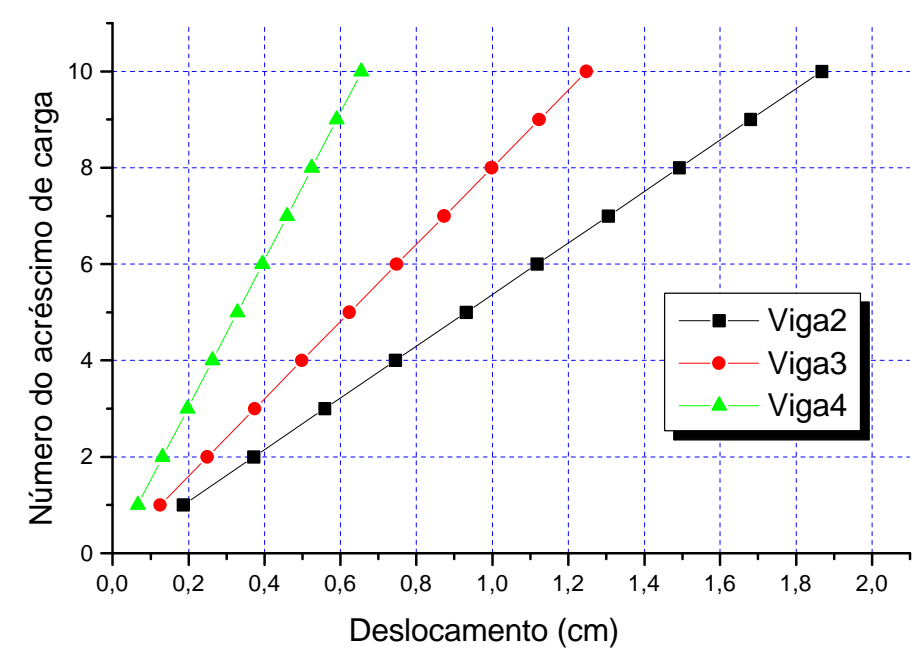

GRÁFICO 6.24 - Variação dos deslocamentos das vigas a cada acréscimo de carga. 


\subsection{2 - Redundância do tabuleiro sobre duas vigas}

$\mathrm{Na}$ análise realizada no tabuleiro sobre duas vigas foi possível observar que o sistema de contraventamentos fornece estabilidade ao tabuleiro após a fratura de uma das vigas. Através da análise dos resultados obtidos foi observado que a tensão atuante no meio do vão da viga sem fraturar foi de $19,26 \mathrm{kN} / \mathrm{cm}^{2}$, enquanto que na região adjacente à ligação da barra do contraventamento a esta viga foi de $26,389 \mathrm{kN} / \mathrm{cm}^{2}$, não sendo verificada a existência de plastificação na viga. Esta concentração de tensões pode ser atribuída a que o contraventamento aplica uma força concentrada de magnitude considerável ocasionando uma região de concentração de tensões na viga.

$\mathrm{Na}$ figura 6.17 apresenta-se a distribuição de tensões nas vigas fornecida pelo programa.

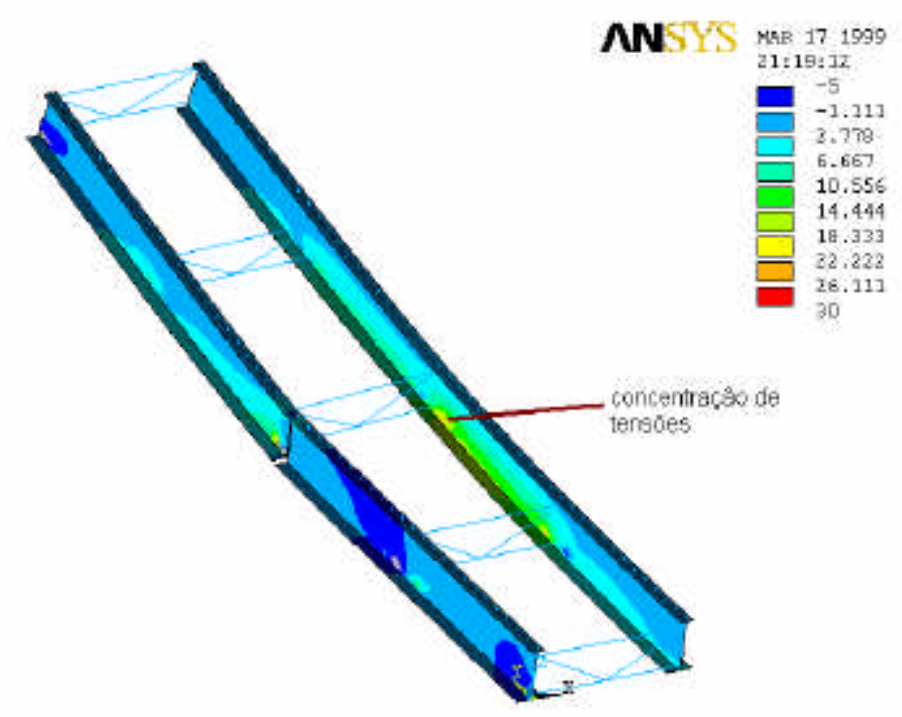

FIGURA 6.17 - Tensões atuantes nas vigas de aço após a fratura.

No caso em que a viga 1 foi considerada sem fraturar foi obtida uma tensão de $8,533 \mathrm{kN} / \mathrm{cm}^{2}$ na viga 2 ; a maior tensão foi de $9,809 \mathrm{kN} / \mathrm{cm}^{2}$ na viga 1. Na figura 6.18 apresenta-se as tensões obtidas com a viga sem fratura. 


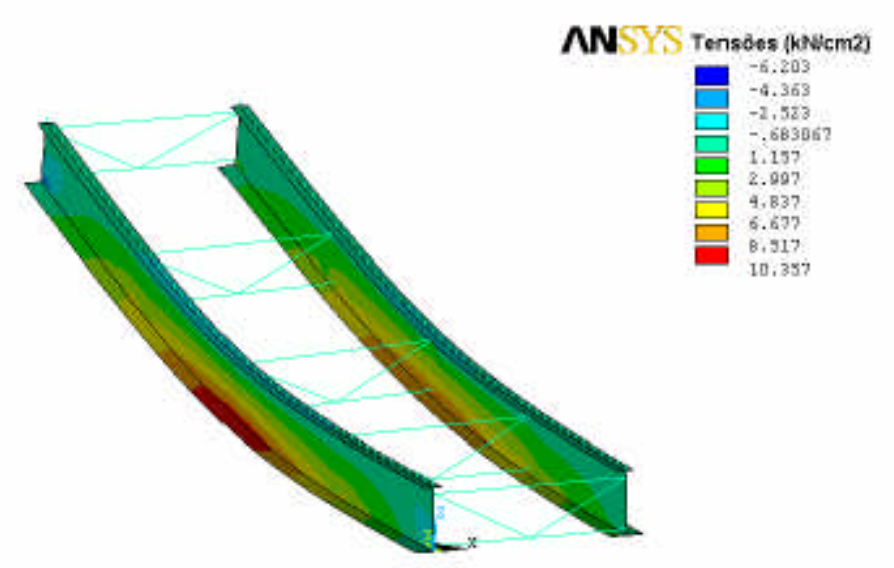

FIGURA 6.18 - Tensões obtidas nas vigas de aço antes da ocorrência da fratura.

Os deslocamentos da viga fraturada e sem fraturar são apresentados nas figuras 6.19 e 6.20 respectivamente, o máximo deslocamento de 4,324 $\mathrm{cm}$ ocorreu na viga fraturada, enquanto que a viga sem fraturar apresentou um deslocamento máximo de 2,916 cm no meio do vão. Observa-se ainda que o máximo deslocamento da viga foi inferior ao limite de L/500, que para o vão de $24 \mathrm{~m}$ assume um valor de $4,8 \mathrm{~cm}$.

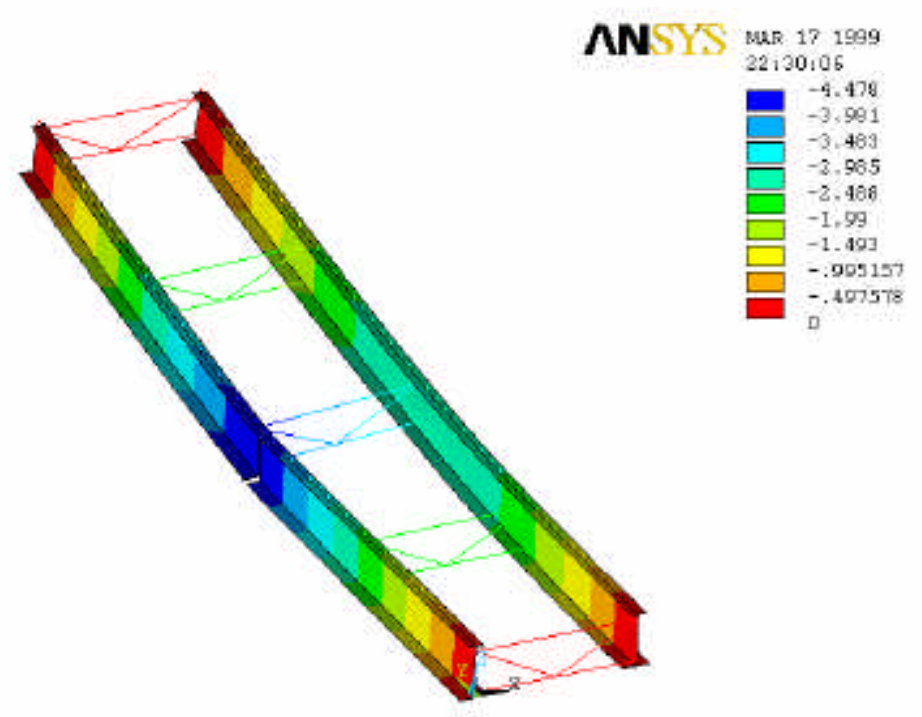

FIGURA 6.19 - Deslocamentos das vigas após a fratura. 


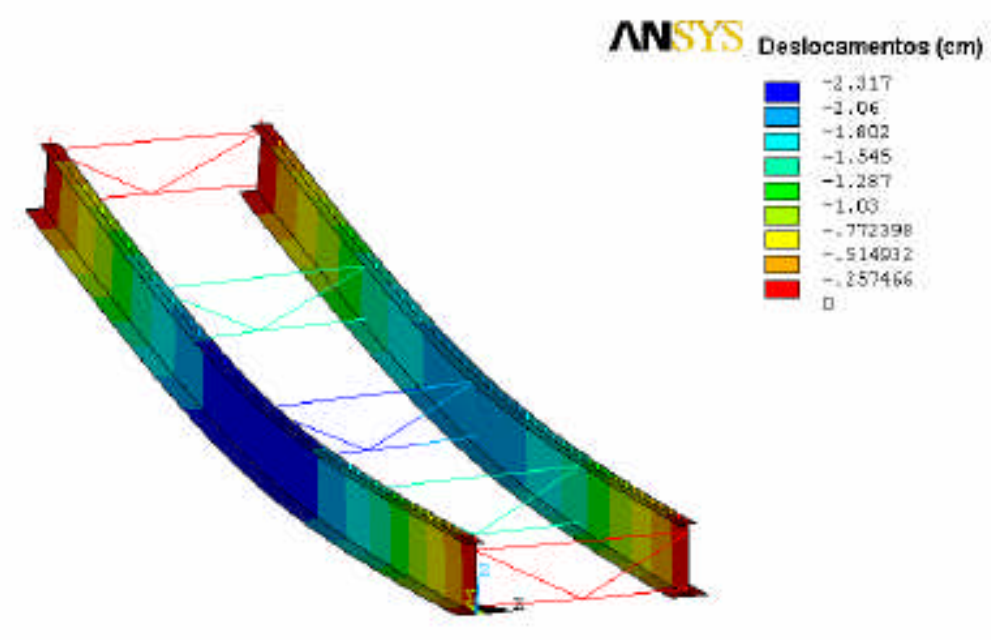

FIGURA 6.20 - Deslocamentos das vigas antes da fratura.

No gráfico 6.25 apresenta-se uma comparação entre os deslocamentos obtidos nas vigas antes e depois da fratura, pode-se observar que, de maneira similar ao tabuleiro sobre quatro vigas, a viga fraturada é a que sofre o maior acréscimo de deslocamento.

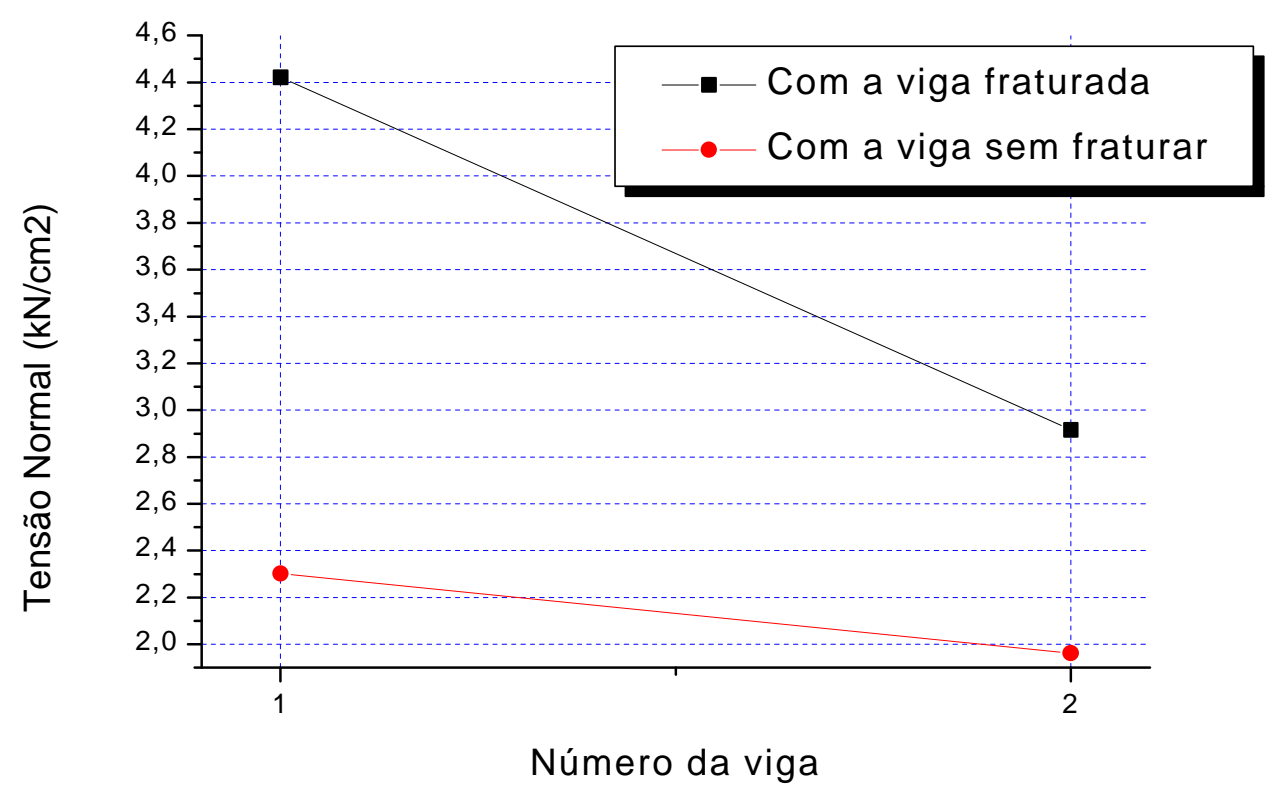

GRÁFICO 6.25 - Comparação de deslocamentos antes e depois da fratura. 
Os esforços normais atuantes nas barras do sistema de contraventamento no meio do vão antes e depois da viga sofrer fratura apresentam-se na figura 6.21; observa-se nesta figura que as barras que maior incremento de esforço normal sofreram foram as diagonais e a barra direita do banzo inferior, não houve inversão de esforços normais.

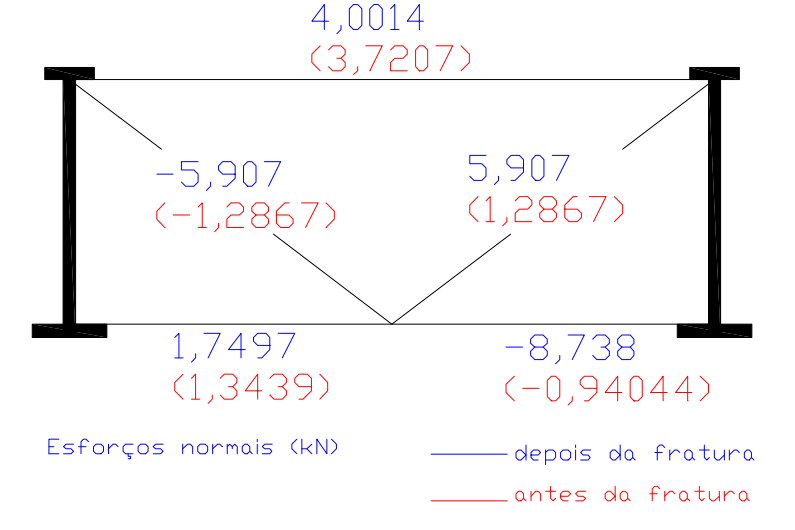

FIGURA 6.21 - Esforços normais antes e depois da fratura.

As reações obtidas nos sistemas de apoios móveis e fixos apresentam-se na figura 6.22.

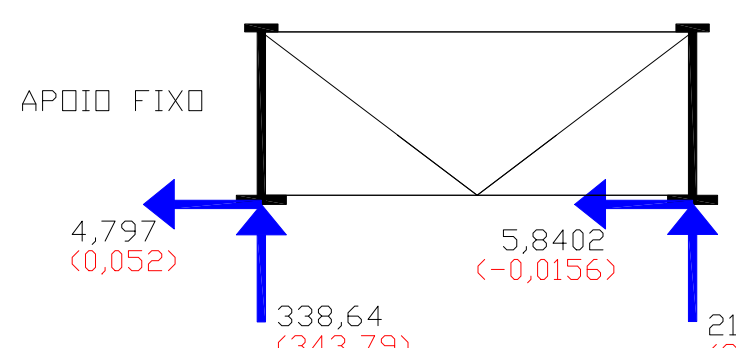

REAÇũES 〈KN〉

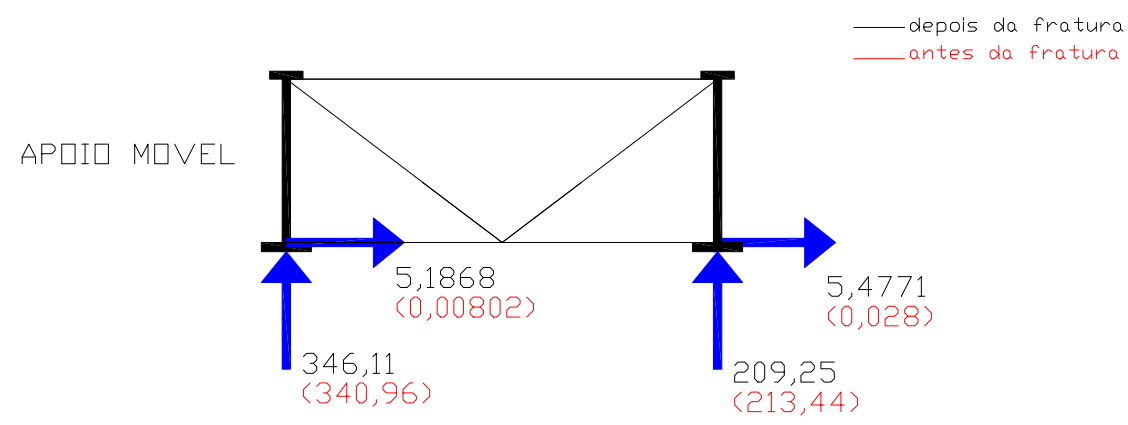

FIGURA 6.22 - Reações nos apoios antes e depois da fratura. 
De maneira similar ao tabuleiro sobre quatro vigas, o carregamento foi aplicado em 10 acréscimos de carga, sendo investigada a forma em que as tensões e deslocamentos variaram a cada acréscimo de carga. Nos gráficos 6.26 e 6.27 observa-se que as variações de tensão e deslocamento, na viga 2, seguem um comportamento elástico-linear a cada acréscimo de carga até que o carregamento total ser alcançado.

Estes resultados mostram que tabuleiros de pontes em duas vigas, desde que contraventados convenientemente, apresentam um certo grau de redundância que, se considerado no projeto com os devidos cuidados, pode levar a estruturas mais econômicas. Isto não significa classificar tabuleiros em duas vigas como estruturas redundantes no dimensionamento segundo a AASHTO, mas considerar talvez uma classe intermediária entre estruturas redundantes e não redundantes que considere esta reserva de resistência.

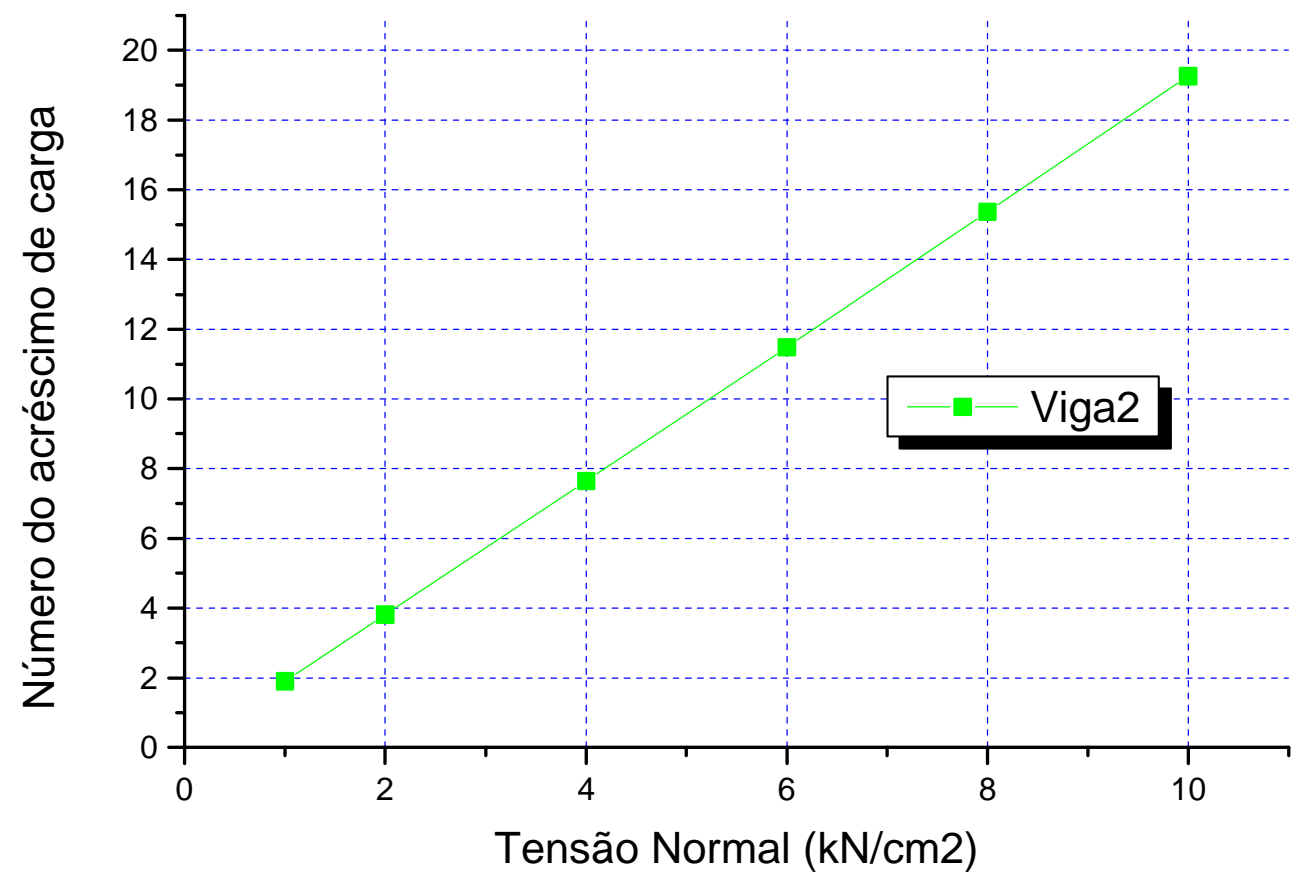

GRÁFICO 6.26 - Variação da tensão na viga 2 a cada acréscimo de carga. 


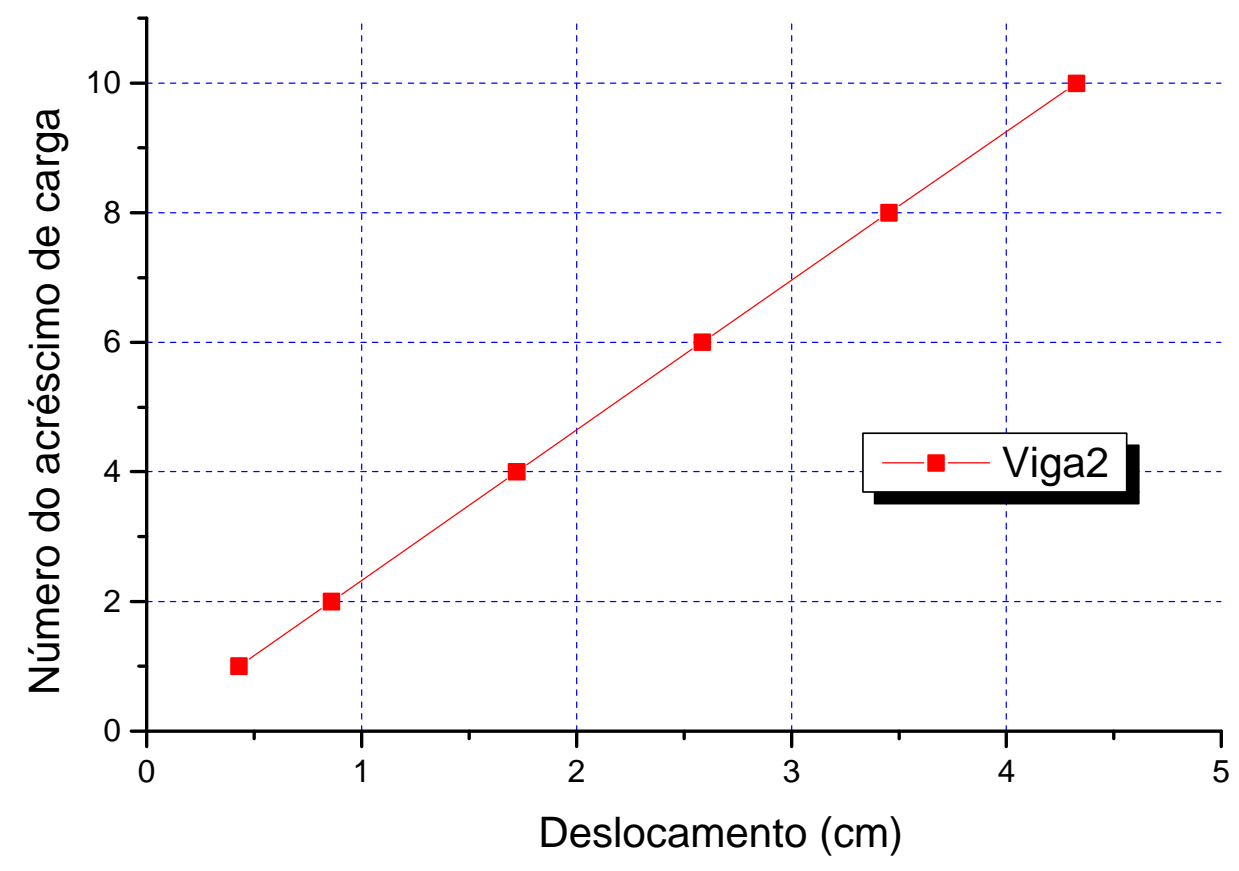

GRÁFICO 6.27 - Variação do deslocamento da viga 2 a cada acréscimo de carga.

Nas figuras 6.23 e 6.24 apresenta-se a abertura da fissura após que a viga deforma.

De maneira geral, os modelos de tabuleiros apresentados neste trabalho podem ser utilizados como um ponto de partida para realizar estudos mais detalhados sobre a taxa de propagação de fissuras sob a ação de carga cíclica, identificação de pontos de concentração de tensões ocasionados pela fratura de uma das vigas e reserva de resistência do tabuleiro após a fratura de um elemento principal.

O programa ANSYS possui a capacidade de realizar análises de fadiga, baseadas na quantificação do dano acumulado mediante a lei de Miner e de conceitos de Mecânica de Fratura (MF) que podem facilitar o estudo teórico das interrogações apresentadas no parágrafo anterior. 


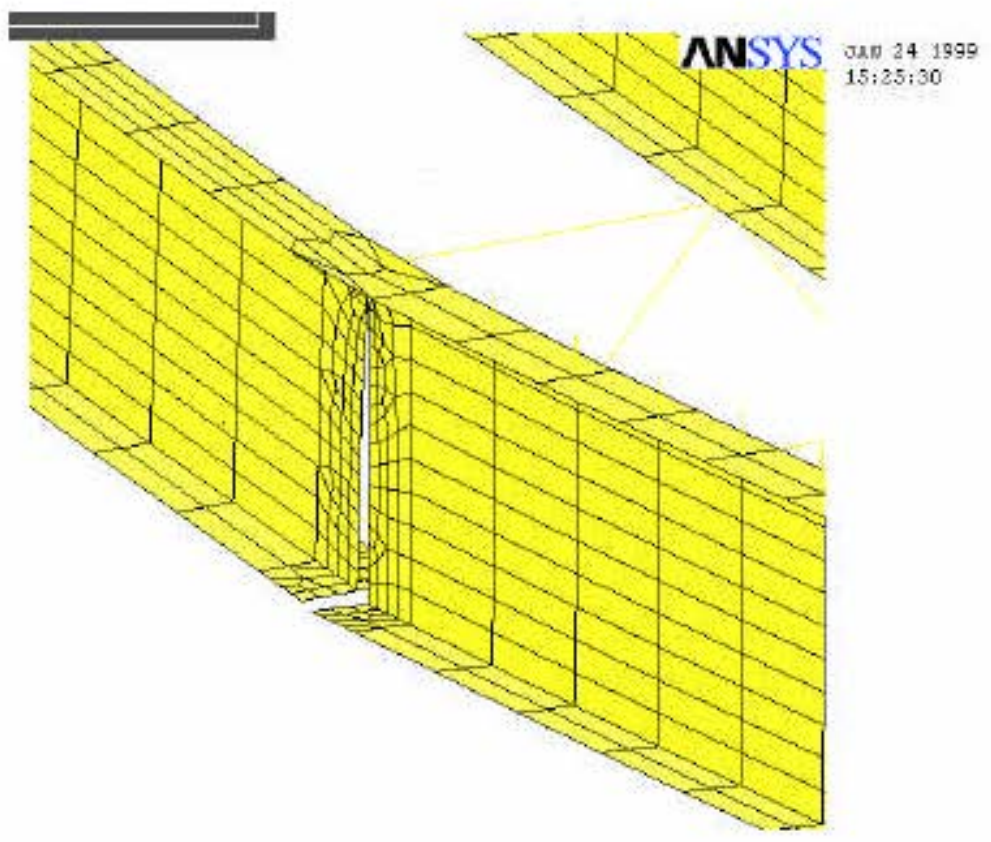

FIGURA 6.23 - Abertura da fissura por flexão da viga.

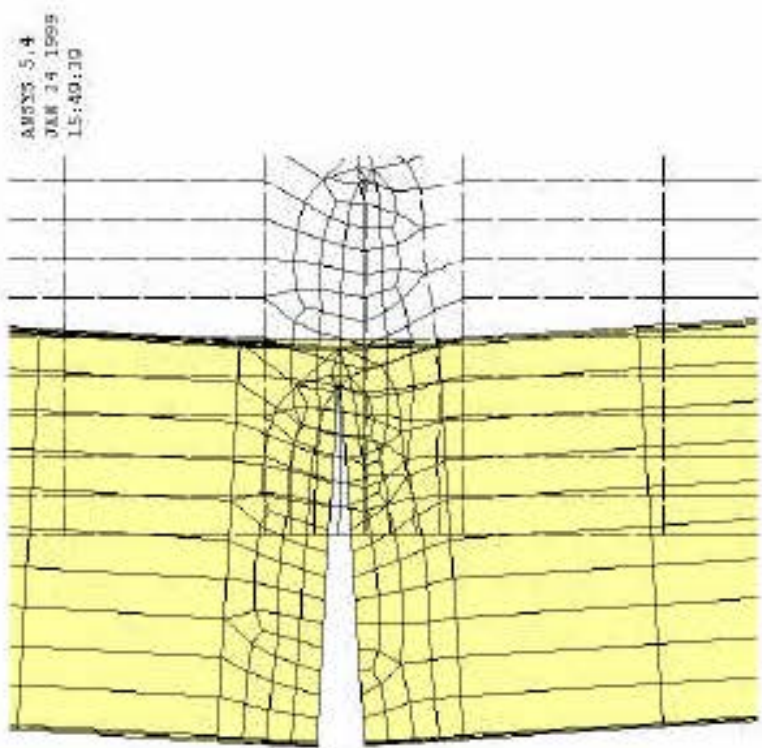

FIGURA 6.24 - Fissura antes e depois que a viga deforma.

Esta análise não foi objeto de continuidade deste trabalho, para o qual é uma proposta de estudo a ser realizada. 


\section{CONCLUSÕES E COMENTÁRIOS FINAIS}

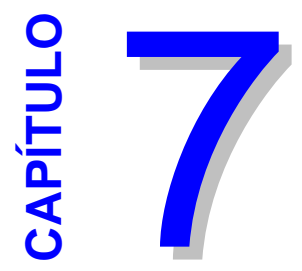

O contexto deste trabalho baseia-se no estudo de tabuleiros de pontes em vigas mistas.

Entre os objetivos deste trabalho pode-se destacar o estudo do estado da arte de pontes em vigas mistas para pequenos vãos; conceituação e técnicas de análise estrutural utilizadas para o cálculo estático, proposição de utilização dos elementos finitos e modelos tridimensionais e um estudo preliminar da redundância estrutural.

A utilização de painéis pré-moldados de laje, pré-lajes e fôrmas de aço incorporadas destacam, entre as técnicas de execução apresentadas no Capítulo 2, como as mais empregadas no Brasil para a construção de pontes e edifícios em estrutura mista.

O comportamento estrutural de pontes em vigas mistas é sensivelmente afetado por efeitos de temperatura, retração e fluência do concreto e efeitos de fadiga. Dos tópicos abordados no capítulo 3 , foi observado que, na literatura consultada, existem divergências sobre a determinação dos gradientes de temperatura ao longo da altura das vigas mistas.

Foi verificado também que algumas recomendações da AASHTO, em relação ao projeto de vigas mistas de pontes, se baseiam em hipóteses que não representam bem o comportamento real da estrutura. As simplificações encontradas nesta norma são: a) consideração de que a resistência estática 
dos conectores de cisalhamento permanece invariável sob a aplicação de carga cíclica; b) desconsideração da perda parcial de conexão entre aço e concreto ao longo do tempo; c) possibilidade dos conectores sofrerem deformações inelásticas.

Das técnicas de análise estrutural apresentadas no capítulo 4, a técnica de analogia de grelha talvez seja a mais utilizada e de maior divulgação no meio técnico para a análise de tabuleiros de pontes; o MEF tem sido utilizado principalmente para estudar efeitos localizados e o comportamento tridimensional deste tipo de estrutura.

$\mathrm{Na}$ literatura consultada foi observado que a maneira mais comum de representação de tabuleiros mistos é realizada através da montagem tridimensional de elementos de viga e casca, considerando a ligação entre aço e concreto como rígida.

Os elementos de casca "SHELL63" e "SHELL43" (ANSYS), utilizados para a modelagem numérica via MEF, se apresentaram satisfatórios para as vigas de aço, uma vez que os resultados obtidos com estes elementos mostraram variações inferiores ao $5 \%$ em relação aos obtidos através da teoria de flexão de vigas. A modelagem da conexão rígida através de elementos de viga "BEAM4" com elevados valores de área e inércia mostrou que pode representar de maneira adequada a ligação entre vigas e laje, pois os resultados obtidos nas vigas mistas analisadas se apresentaram coerentes com os obtidos através da formulação apresentada no ANEXO B.

Foi mostrado inicialmente, no capítulo 6 , que a presença de sistema de contraventamentos, em tabuleiros de 3 e 4 vigas, não altera significativamente a capacidade de distribuição de esforços no tabuleiro, as mesas inferiores das vigas de aço não sofrem alterações importantes de tensão. Em todos os casos analisados não foram verificadas alterações de tensão superiores a $1 \mathrm{kN} / \mathrm{cm}^{2}$.

As variações de deslocamentos ocasionadas pela remoção do sistema de contraventamentos foram inferiores a $2 \mathrm{~mm}$ em todos os casos considerados, isto mostra que a influência dos contraventamentos nos deslocamentos das vigas é mínima. 
Ressalta-se, porém, que o sistema de contraventamentos é de suma importância na fase construtiva, principalmente para o sistema de lajes não escoradas; garantir o comportamento conjunto das vigas para carregamentos assimétricos e, principalmente, garantir a redundância estrutural.

De maneira qualitativa, os resultados obtidos nestas análises se apresentaram compatíveis com os obtidos por AZIZINAMINI et al (1995) em estudos experimentais.

Foi observado também, no item 6.2.1 que a variação linear do vão, mantendo a seção transversal constante, pode ocasionar uma variação não linear das tensões atuantes nas vigas, isto significa que o método de cálculo proposto pela AASHTO pode levar à determinação de esforços que se afastam da realidade em função de que esta norma apresenta critérios de cálculo baseados na extrapolação linear, este fato aponta para simplificações que podem conduzir a resultados contra a segurança.

Nos gráficos, apresentados no item 6.2.2, ficou demonstrado que um aumento da espessura da laje ocasiona uma diminuição das tensões atuantes nas vigas próximas à carga móvel e um acréscimo destas, nas vigas mais afastadas. Isto é atribuído ao fato de que o aumento da espessura aumenta a capacidade de distribuição de carga da laje, aumentando a parcela de carga para as vigas mais afastadas.

Pode-se verificar que, em tabuleiros sobre quatro vigas, as tensões atuantes nas vigas internas não ultrapassaram $70 \%$ das tensões obtidas através da consideração de viga mista isolada submetida à ação de uma linha de rodas da carga móvel; nas vigas externas foram obtidos valores aproximadamente inferiores em $10 \%$ aos das vigas mistas isoladas.

Nos tabuleiros sobre três vigas foram obtidas, nas vigas internas, tensões máximas equivalentes a $80 \%$ das obtidas através da consideração de viga mista isolada, enquanto que nas vigas externas foram obtidas tensões superiores em cerca de $20 \%$.

Uma comparação entre os resultados obtidos através do MEF e da técnica de analogia de grelha foi realizada no item 6.4 ; foi observado que as 
tensões obtidas na vigas através do MEF foram inferiores às obtidas por analogia de grelha, embora esta diferença, em termos de tensão, tenha sido inferior a $1 \mathrm{kN} / \mathrm{cm}^{2}$, tanto no caso de carregamento assimétrico como simétrico.

A afirmação acima permite concluir que a analogia de grelha é uma técnica adequada para o cálculo estático de pontes de pequenos vãos.

As análises realizadas nos tabuleiros com vigas fraturadas consideraram as não linearidades física e geométrica do conjunto, sendo observado que a estrutura, além de apresentar estabilidade, apresentou valores de deslocamentos relativamente pequenos sem alterar as condições de equilíbrio estático.

Ficou também demonstrado que o tabuleiro sobre quatro vigas apresenta comportamento perfeitamente linear a cada acréscimo de carga, não sendo verificada a ocorrência de plastificação nas vigas sem fratura. A máxima tensão de tração observada foi na viga adjacente à viga fraturada, alcançando um valor de $18,75 \mathrm{kN} / \mathrm{cm} 2$.

No tabuleiro sobre duas vigas foi também observado que as tensões e deslocamentos apresentaram comportamento linear sob a ação do carregamento aplicado.

$\mathrm{Na}$ viga sem fratura do tabuleiro sobre duas vigas foi observada uma pequena região de concentração de tensões próxima ao contraventamento disposto no meio do vão, a tensão máxima nesta região foi de 26,389 $\mathrm{kN} / \mathrm{cm}^{2}$, enquanto que a máxima tensão observada na mesa inferior foi de $19,26 \mathrm{kN} / \mathrm{cm}^{2}$.

Finalmente, os máximos deslocamentos obtidos nas vigas fraturadas foram de 3,655 cm (tabuleiro sobre quatro vigas) e 4,325 cm (tabuleiro sobre duas vigas), estes deslocamentos podem ser considerados pequenos se comparados ao limite de utilização L/500, que para os vãos considerados assume valores de 3,2 e 4,8 cm respectivamente.

As observações acima devem ser analisadas com cautela, tendo em vista que trata-se de observações obtidas para um projeto de ponte particular, porém é possível afirmar que mesmo as pontes em duas vigas 
apresentam reservas de resistência que podem conduzi-las a um comportamento de redundância estrutural, contrariando assim as proposições da AASHTO que considera pontes em duas vigas não redundantes.

Para estudar o carregamento que ocasiona o início de plastificação em uma das vigas do tabuleiro foram incrementadas, por tentativa e erro, as cargas de roda das cargas móveis. No tabuleiro sobre quatro vigas foi observado o início de plastificação da mesa inferior da viga 2 aplicando duas cargas móveis com cargas de roda duas vezes superior à carga de roda do trem tipo Classe 45. Já no tabuleiro sobre duas vigas, a plastificação da viga sem fratura ocorreu sob a aplicação de duas cargas móveis com carga de roda equivalente a 1,5 vezes a carga de roda do trem tipo Classe 45.

Estes resultados devem ser tomados apenas como referência pois não foram comparados com dados experimentais. A plastificação da laje de concreto por compressão, fissuração do concreto tracionado, taxas de armadura da laje, efeitos de fluência e retração do concreto e deformabilidade da conexão, são fatores que podem alterar, de forma sensível, os resultados aqui apresentados; estes fatores encontram-se sempre presentes neste tipo de estrutura, podendo modificar os resultados esperados na análise teórica.

Embora tenham sido realizados alguns testes incorporando 0 elemento de concreto "SOLID65" para representar a laje, os resultados obtidos se apresentaram não confiáveis.

Para ser rigorosamente científicos, os resultados apresentados neste trabalho são baseados em modelos teóricos obtidos a partir de hipóteses e simplificações propostas na literatura, por tal motivo estes devem ser comparados com valores experimentais que possibilitem a determinação do maior ou menor grau de precisão do método utilizado e validade das hipóteses consideradas.

Este trabalho pretende ser apenas um estudo inicial que proporcione um ponto de partida a estudos mais aprofundados sobre o comportamento e redundância estrutural deste tipo de tabuleiros. 


\section{REFERÊNCIAS BIBLIOGRÁFICAS}

AKTAN, A. E.; CHUNTAVAN, C.; LEE, K-L, TOKSOY, T. (1993). Structural identification of a steel stringer bridge. Transportation Research Record, ASCE, n.1393, p.175-185.

AL-AMERY, R. I. M.; ROBERTS, T. M. (1990). Nonlinear finite difference analysis of composite beams with partial interaction. Computers \& Structures, v.35, n. 1, p. 81-87.

AMERICAN ASSOCIATION OF STATE HIGHWAY AND TRANSPORTATION OFFICIALS (1989). AASHTO. Standard specifications for highway bridges. Washington, D. C.

AMADIO, C. (1993). Simplified evaluation of creep and shrinkage effects in steel-concrete composite beams with rigid or deformable connections by means of the AAEM method. Costruzioni Metalliche, n. 5, p. 265-284.

AMADIO, C.; FRAGIACOMO, M. (1993). A finite element model for the study of creep and shrinkage effects in composite beams with deformable shear connections. Costruzioni Metalliche, n. 4, p. 213-228. 
AMADIO, C.; FRAGIACOMO, M. (1997). Simplified approach to evaluate creep and shrinkage effects in steel-concrete composite beams. Journal of Structural Engineering, ASCE, v. 123, n. 9, p. 1153-1162.

AN, L.; CEDERWALL, K. (1996). Push-out tests on studs in high strength and normal strength concrete. Journal of Constructional Steel Research, v. 36, n.1, p. 15-29.

ANDERSON, C. A. (1988). Numerical creep analysis of structures. In: BAZANT \& WITTMANN. Creep and shrinkage in concrete structures. New York, John Wiley \& Sons. Parte III, cap. 8, p. 259-303.

ANSYS (1991). Introduction to ANSYS.for release 5.3. USA, SAS IP.

(1996). Expanded ANSYS workbook.revision 5.2. USA, SAS IP. 2 pt.

(1996). Structural nonlinearities user's guide. USA, SAS IP. V.2.

(1996). Structural nonlinearities user's guide for revision 5.1. SAS IP. V.1.

ANSOURIAN, P. (1975). An application of the method of finite elements to the analysis of composite floor systems. Proceedings of the Institution of Civil Engineers. Parte 2, v.59, p. 699-726.

ANSOURIAN, P.; RODERICK, J. W. (1978). Analysis of composite beams. Journal of the Structural Division, ASCE, v. 104, n. ST10, p. 1631-1645.

ASSOCIAÇÃO BRASILEIRA DE NORMAS TÉCNICAS (1982). NBR 6118 Projeto e execução de estruturas de concreto armado. 
ASSOCIAÇÃO BRASILEIRA DE NORMAS TÉCNICAS (1987). NBR 7187 Projeto e execução de pontes de concreto armado e protendido.

ASSOCIAÇÃO BRASILEIRA DE NORMAS TÉCNICAS (1989). NBR 7188 Carga móvel em ponte rodoviária e passarela de pedestre.

ASSOCIAÇÃO BRASILEIRA DE NORMAS TÉCNICAS (1989). NBR 7197 Projeto de estruturas de concreto protendido.

ASSOCIAÇÃO BRASILEIRA DE NORMAS TÉCNICAS (1986). NBR 8800 Projeto e execução de estruturas de aço de edifícios: método dos estados limites. Rio de Janeiro.

AZIZINAMINI, A; ATOROD, K.; BEACHAM, M. (1995). Effect of cross frames on behavior of steel bridges. INTERNATIONAL BRIDGE CONFERENCE, 4th, TRB, San Francisco, USA, v. 1, p. 117-124.

BANGASH, M. Y. H. (1989). Concrete and concrete structures: Numerical modelling and applications. N. Y. Elsevier.

BAKHT, B.; JAEGER, L. G. (1985). Bridge analysis simplified. McGraw-Hill.

BAKHT, B.; MOSES, F. (1988). Lateral distribution factors for highway bridges. Journal of Structural Engineering, ASCE, v.114, n.8, p. 17851804.

BAKHT, B.; JAEGER, L. G. (1992). Ultimate load test of slab - on - girder bridge. Journal of Structural Engineering, ASCE, v. 118, n. 6, p. 1608 1624. 
BAKHT, B.; MUFTI, A. A. (1992). Proof load test on a short - span bridge. In: PROCEEDINGS OF THE 3RD INTERNATIONAL WORKSHOP ON BRIDGE REHABILITATION. Darmstadt, 14 - 17 junho. P. 715 - 726.

BATHE, K. J. (1996). Finite element procedures. New Jersey, Prentice - Hall.

BATISTA, R. C.; EBECKEN, N. F. F. (1990). Análise tridimensional de pontes com transversinas intermediárias. COPPE-UFRJ.

BISHARA, A. G.; LIU, M. C.; EL-ALI, N. D. (1993). Wheel load distribution on simple suported skew I-beam composite bridges. Journal of Structural Engineering, ASCE, v.119, n. 2, p. 399-419.

BRADFORD, M. A.; GILBERT, R. I. (1989). Non-linear behaviour of composite beams at service loads. The Structural Engineer, v. 67, n. 14, p. 263-268.

BRITISH STANDARDS INSTITUTION. BS5400. Steel, Concrete and composite bridges. Part 5: Code of practice for design of composite bridges.

BRITISH STANDARDS INSTITUTION. BS5400. Steel, Concrete and composite bridges. Part 3: Code of practice for design of steel bridges.

BROCKENBROUGH, R. L. (1986). Distribution Factors for curved I - girder bridges. Journal of Structural Engineering, ASCE, v.112, n. 10, p. 22002215.

COOPER, S. E.; ANDREW, C. C. (1985). Designing steel structures: methods and cases. USA. Prentice-Hall. 
CHANG, D.; LEE, H. (1994). Impact factors for simple-span highway girder bridges. Journal of Structural Engineering, ASCE, v.120, n.3, p. 704-715.

COMITÉ EUROPEO DE NORMALIZACIÓN. Eurocódigo 4. Proyecto de estructuras mixtas de hormigón y acero. Parte 1: reglas generales y reglas para edificación. Madrid, AENOR.

COMITÉ EUROPEO DE NORMALIZACIÓN. Eurocódigo 3. Proyecto de estructuras de acero. Parte 1: reglas generales y reglas para edificación. Madrid, AENOR.

CSAGOLY, P. F.; LYBAS, J. M. (1989). Advanced design method for concrete bridge deck slabs. Concrete International, p. 53-63.

CUSSENS, A R.; PAMA, R. P.; (1975). Bridge deck analysis. New York. John Wiley \& Sons.

DANIELS, J. H.; KIM, W.; WILSON, J. L. (1989). Recommended guidelines for redundancy design and rating of two-girder steel bridges. National Cooperative Highway Research Program Report, TRB, n. 319.

DANIELS, B. J.; BREKELMANS, J. W. P. M.; STARK, J. W. B. (1993). Stateof-the-art report for composite bridge research. Journal of Constructional Steel Research, v. 27, p. 123-141.

DEATHERAGE, J. H.; SANDERS, M. D.; GOODPASTURE, D. W.; BURDETTE, E.G. (1995). Controlled load tests on a four-girder steel bridge. Transportation Research Record, TRB, n. 1476, p. 106-116.

DEZI, L. (1994). Shrinkage effects in composite beams with flexible connection. Journal of Constructional Steel Research, v. 28, p. 295-320. 
DOWLING, r.; BURGAN, P. (1988). Shear lag in composite structures. In NARAYANAN, R. Composite Structures: advances in construction and design. London, Elsevier. Cap. 1.

DUBAS, P. (1986). Some remarks concerning the design of composite bridges. Journal of Constructional Steel Research, v. 7, p. 233-251.

DUBAS, P.; GEHRI, E. (1986). Behavior and design of steel plated structures. Brussels, eds. ECCS-CECM-EKS. (publication n. 44).

EL DEBS, M. K.; TAKEYA, T. (1995). Pontes de concreto: fascículos 1 a 7. São Carlos, EESC.

FISHER, J. W. (1981). Inspecting steel bridges for fatigue damage. Fritz Engineering Laboratory Report, n. 386-15. Lehigh University.

FISHER, j. W.; YEN, T. B.; WAGNER, D. C. (1987). Review of field measurements for distortion - induced fatigue cracking in steel bridges. Transportation Research Record, TRB, n. 1118, p. 49-55.

FISHER, J.W.; MENZEMER, C.C. (1991). Case studies and repair of fatiguedamaged bridge structures. In: NARAYANAN, R. et al. Structures subjected to repeated loading: stability and strength. London, Elsevier. Cap. 7, p. 177-204.

FU, H. C.; NG, S. F.; CHEUNG, M. S. (1990). Thermal behavior of composite bridges. Journal of Structural Engineering, ASCE, v. 116, n. 12, p. 33023323.

GATTESCO, N.; GIURIANI, E.; GUBANA, A . (1997). Low-cycle fatigue test on stud shear connectors. Journal of Structural Engineering, ASCE, v. 123, n. 2 , p. $145-150$. 
GATTESCO, N.; GIURIANI, E. (1996). Experimental study on stud shear connectors subjected to cyclic loading. Journal of Constructional Steel Research, v. 138, n. 1, p. 1-21.

GHALI, A.; FAVRE, R. (1986). Concrete Structures: stresses and deformations. London, Chapman and Hall.

GHOSN, M.; MOSES, F.; XU, J. M. (1994). Reliability and redundancy of highway bridges. In: PROCEEDINGS OF ICOSSAR 93' - THE 6TH INTERNATIONAL CONFERENCE ON STRUCTURAL SAFETY AND RELIABILITY. Innsbruck, Austria, 9 - 13 agosto, 1993. V.2, p. 887-894.

GHOSN, M.; MOSES, F. (1995). Redundancy in highway bridge superstructures. INTERNATIONAL BRIDGE CONFERENCE, 4th, TRB, San Francisco, USA, v.2, p. 338-348.

GHOSN, M.; MOSES, F. (1992). Evaluation of the redundancy of highway bridges. In: PROCEEDINGS OF THE 3RD INTERNATIONAL WORKSHOP ON BRIDGE REHABILITATION. Darmstadt, 14 - 17 junho, 1992. P. $581-590$.

GILBERT, R. I. (1989). Time-dependent analysis of composite steel-concrete sections. Journal of Structural Engineering, ASCE, v. 115, n. 11, p. 2687-2705.

HAMBLY, E. C. (1976). Bridge deck behaviour. New York. John Wiley \& Sons.

HAYS, C. O; SESSIONS, L. M.; BERRY, A J. (1986). Further studies on lateral load distribution using a finite element model. Transportation Research Record, TRB, n. 1072, p. 6-14. 
HELWIG, T. A.; YURA, J. A.; FRANK, K. H. (1993). Bracing forces in diaphragms and cross frames. In: IS YOUR STRUCTURE SUITABLY BRACED? CONFERENCE, Milwaukee, Wisconsin, USA, April.

HUANG, D.; WANG, T-L.; SHAHAWY, M. (1992). Impact analysis of continuous multigirder bridges due to moving vehicles. Journal of Structural Engineering, ASCE, v.118, n.12, p.3427-3443.

IDRISS, R. L.; WHITE, K. R.; WOODWARD, C. B.; MINOR, J.; JAUREGUI, D. V. (1993). In: IS YOUR STRUCTURE SUITABLY BRACED?, CONFERENCE, Milwaukee, Wisconsin, USA, April.

IDRISS, R. L.; WHITE, K. R.; WOODWARD, C. B.; JAUREGUI, D. V. (1995). After fracture redundancy of two girder bridge: testing I - 40 bridges over Rio Grande. INTERNATIONAL BRIDGE CONFERENCE, 4th, TRB, San Francisco, USA, v.2, p. 316 -326.

JAEGER, L. G.; BAKHT, B. (1982). The grillage analogy in bridge analysis. Canadian Journal of Civil Engineering, v. 9, p. 224-235.

JAEGER, L. G.; BAKHT, B. (1989). Bridge analysis by microcomputer. New York, Mc Graw Hill.

JOHNSON, R. P.; BUCKBY, R. J. (1986). Composite structures of steel and concrete: Bridges. Collins. v.2.

KALFAS, C.; PAVLIDIS, P.; GALOUSSIS, E. (1997). Inelastic behaviour of shear connection by a method based on FEM. Journal of Constructional Steel Research, v. 44, n. 1-2, p. 107-114. 
KENNEDY, J. B.; GRACE, N. F.; SOLIMAN M. (1989). Welded versus bolted I-diaphragms in composite bridges. Journal of Structural Engineering, ASCE. v. 115, n. 2, p. 417-432.

KNOWLES, P. R. (1973). Composite steel and concrete construction. New York, John Wiley \& Sons.

KRÍSTEK, V.; STUDNICKA, J. (1988). Composite girders with deformable connection between steel and concrete. In: NARAYANAN, R. Steelconcrete composite structures: stability and strength. London. Elsevier.

MAEDA, Y.; KAWAY, Y.; OKURA, I. (1991). Fatigue cracking in plate and box girders. In: NARAYANAN, R. et al. Structures subjected to repeated loading: stability and strength. London, Elsevier. Cap. 4, p. 73 - 102.

MADUGULA, M. K. S. (1991). Design against fatigue and fracture in steel structures: an overview. In: FATIGUE AND FRACTURE IN STEEL AND CONCRETE STRUCTURES, ISFF PROCEEDINGS. Ed: RAO, M. A. G.; RAO, T. V. S. R. december, Madras, India. p. 1261 - 1276.

MALITE, M. (1993). Vigas mistas aço concreto: ênfase em edifícios. São Carlos, EESC.

MARX, H. J.; KHACHATURIAN, N.; GAMBLE, W. L. (1993). Design criteria for right and skew slab-and-girder bridges. Tranportation Research Record, TRB. n. 1319, p. 72-85.

MASON, J.; GHAVAMI, K. (1994). Development in brazilian steel bridge construction. Journal of Steel Constructional Research, v. 28, p. 81-100. 
MIRAMBELL, E.; COSTA, J. (1997). Thermal stresses in composite bridges according to BS 5400 and EC 1. Proceedings of the Institution of Civil Engineers: Structures \& Buildings, v. 122, p. 281-292.

MOORE, M.; STRAND, K. A.; GRUBB, M. A.; CAYES, L. R. (1990). Wheel load distribution results from AISI-FHWA model bridge study. Transportation Research Record, TRB, v.1275, p. 34-44.

MOREIRA, D. (1977). Análise matricial das estruturas. Rio de Janeiro, EDUSP.

NAGAI, M.; FUJINO, Y.; KURODA, M.; YAMAZAKY, S. E.; TAJIMA, H.; KAWAI, Y. (1996). Possibility of fatigue - free steel bridges with simple transverse - stiffening systems based on large 3-d finite element analysis. In: HARDING et al. Bridge management: inspection maintenance, assessment and repair. London, E \& FN SPON. p. 352 360.

NEWHOOK, J. P.; AFTAB, MUFTI, A.A.; MACDONELL, R. E. (1997). Steel free concrete bridge deck innovation and application. In: XIIIth IRF WORLD MEETING, Toronto, Canada.

NOWAK, A . S.; NASSIF, H.; FRANK, K, H. (1993). Fatigue load spectra for a steel girder bridge. Transportation Research Record, TRB, n. 1393, p. 154-161.

NOWAK, A. S. (1994). Calibration of LRFD bridge design code. In: PROCEEDINGS OF ICOSSAR 93' - THE 6TH INTERNATIONAL CONFERENCE ON STRUCTURAL SAFETY AND RELIABILITY. Innsbruck, Austria, 9 - 13 agosto, 1993. V.2, p. 887-894. 
OEHLERS, D. J.; COUGHLAN, C. G. (1986). The shear stiffness of stud shear connectors in composite beams. Journal of Constructional Steel Research, v. 6, p. 273-284.

OEHLERS, D. J. (1990). Deterioration in strength of stud connectors in composite bridge beams. Journal of Structural Engineering, ASCE, v. 116, n. 12 , p. $3417-3431$.

OEHLERS, D. J.; SVED, G. (1995). Composite beams with limited-slipcapacity shear connectors. Journal of Structural Engineering, ASCE, v. 121 , n. 6 , p. $932-938$.

OEHLERS, D. J.; GHOSH, A .; WAHAB, M. (1995). Residual strength approach to fatigue design and analysis. Journal of Structural Engineering, ASCE, v. 121, n. 9, p. 1271-1279.

OEHLERS, D. J.; NGUYEN, N. T.; AHMED, M.; BRADFORD, M. (1997). Partial interaction in composite steel and concrete beams with full shear connection. Journal of Constructional Steel Research, v. 41, n. 2/3, p. 235-248.

OÑATE, E. (1992). Lectures on nonlinear finite element analysis of concrete shells. Monografía no. 7, fev. Barcelona. CIMNE.

OÑATE, E. (1995). Cálculo de estructuras por el método de elementos finitos: análisis estático lineal. Barcelona. CIMNE.

OWENS, G. W.; KNOWLES, P. R. (1992). Steel designer's manual. Blackwell.

PASTOUKHOV, V. A.; VOORWALD, H. J. C. (1995). Introdução à mecânica da integridade estrutural. São Paulo. UNESP. 
PETROU, M. F.; PERDIKARIS, P. C. (1996). Punching shear failure in concrete decks as snap-through instability. Journal of Structural Engineering, ASCE, v. 122, n. 9, p. 998-1005.

PODOLNY, W. (1998). New materials, techniques impact future bridges. TR News, TRB, n. 194, p. 23-31.

QUIROGA, A. S. (1983). Cálculo de estructuras de puentes de hormigón. Madrid, Rueda.

RANGANATHAN, R.; RAVI, G. (1992). Critical study of fatigue design of bridges as per BS 5400 - Part 10. In: FATIGUE AND FRACTURE IN STEEL AND CONCRETE STRUCTURES, ISFF PROCEEDINGS. Ed: RAO, M. A. G..; RAO, T. V. S. R. december, Madras, India, p. 1319 1336.

RAZAQPUR, A. G.; NOFAL, M. (1990). Analytical modeling of nonlinear behavior of composite bridges. Journal of Structural Engineering, ASCE. v. 116, n. 6, p. $1715-1733$.

ROCKEY, K. C. (1971). An ultimate load method of design for plate girders. In: ROCKEY, K. C. et al. Developments in bridge design and construction. London, Crosby Lockwood \& Son. p. 487 - 504.

SFER, D.; CUDMANI, R. O .; DANESI, R. F. (1995). Distribución transversal de cargas en puentes de vigas. In: JORNADAS SUDAMERICANAS DE INGENIERIA ESTRUCTURAL, 27., Tucumán, Argentina, 18-22 Septiembre 1995. Memórias. v. 4, p. 253-264.

SFER, D.; CUDMANI, R. O .; DANESI, R. F. (1997). Estudio de la distribución transversal de cargas en puentes de vigas bajo las reglamentaciones del reglamento argentino. In: JORNADAS 
SULAMERICANAS DE ENGENHARIA ESTRUTURAL, 28., São Carlos, Brasil, 1-5 setembro, 1997. Memórias. Estruturas e fundações, v.3, p. 905-914.

SIDERBRAS. Siderurgia Brasileira (1989). Pontes rodoviárias metálicas. Brasília. (Publicações técnicas para o desenvolvimento da construção metálica, 8).

SMITH, J. W. (1988). Vibration of structures: applications in civil engineering design. Chapman and Hall.

SMITH, I. F. C. (1991). Fatigue assessment and fracture mechanics in structural engineering. In: NARAYANAN, R. et al. Structures Subjected to repeated loading: Stability and strength. London, Elesevier. Cap 1, p. 124.

SOLIMAN, M.; KENNEDY, J. B. (1986). Simplified method for estimating thermal stresses in composite bridges. Transportation Research Record, TRB, n. 1072, p. 23-31.

SOTIROPOULOS, S. N., GANGARAO H. V. S. (1992). Design anomalies in highway bridge decks. Morgantown, West Virginia University, Constructed Facilities Center. interim report

SOTIROPOULOS, S. N.; GANGARAO, H. V. S. (1993). Design anomalies in concrete deck-steel stringer bridges. Transportation Research Record, TRB, n. 1393, p. 31-37.

TARANTINO, A. M.; DEZI, L. (1992). Creep effects in composite beams with flexible shear connectors. Journal of Structural Engineering, ASCE, v. 118, n. 8 , p. 2063-2081. 
TARHINI, K. M.; FREDERICK, G. R. (1992). Wheel load distribution in Igirder highway bridges. Journal of Structural Engineering, ASCE. v. 118, n. 5, p. 1285-1294.

TROITSKI, M. S. (1994). Planning and design of bridges. New York, John Wiley \& Sons.

TROITSKY, M. S. (1990). Prestressed steel bridges: theory and design. New York, Van Nostrand Reynhold Company.

VASCONCELOS, A C. (1993). Pontes brasileiras: viadutos e passarelas notáveis. São Paulo, Pini.

VIEST, I. M.; FOUNTAIN, R. S.; SINGLETON, R. C. (1958). Composite construction in steel and concrete: for bridges and buildings. New York. McGraw-Hill.

WANG, T-L.; HUANG, D.; SAHAWY, M. (1993). Vibration and impact in multigirder steel bridges. Transportation Research Record, TRB, n. 1393, p. 96-103.

XANTHAKOS, P. P. (1994). Theory and design of bridges. New York, John Wiley \& Sons.

YEN, J. Y. R.; LIN, Y.; LAI, M. T. (1997). Composite beams subjected to static and fatigue loads. Journal of Structural Engineering, ASCE, v. 123, n. 6, p. $765-771$.

ZIENKIEWICZ, O C.; (1971). The finite element method in engineering science. London. McGraw-Hill.

ZHOU, J.; NOWAK, A. S. (1987). Nonlinear analysis of highway bridges. Transportation Research Record. TRB. n.1118, p. 25 - 28. 
ZWERNEMAN, F. J. (1991). Fatigue damage accumulation under varyingamplitude loads. In: NARAYANAN, R. et al. Structures subjected to repeated loading: stability and strength. London, Elsevier. Cap. 2, p. 2554. 


\section{BIBLIOGRAFIA COMPLEMENTAR}

BAKHT, B.; MUFTI, A. A. (1998). Five steel-free bridge deck slabs in Canada. Structural Engineering International, IABSE, n. 3, p. 196-200.

BALLIO, G.; CASTIGLIONI, C. A . (1995). A unified approach for the design of steel structures under low and/or high cycle fatigue. Journal of Constructional Steel Research, v. 34, p. 75-101.

CAO, I. C.; SHING, P. B.(1999) Simplified analysis method for slab-on-girder highway bridge decks. Journal of Structural Engineering, ASCE, v. 125, n. 1 , p. $49-58$.

CSAGOLY, P. F. (1997). Testing of a composite steel-concrete bridge deck. Concrete International, p. 47-53.

DUBAS, P. (1975). Pontes em viga mista. Rio de Janeiro. Pontifícia Universidade Católica do Rio de Janeiro / Usiminas Mecânica (fascículo 11).

FALKNER, H.; HUANG, Z.; TEUTSCH, M. (1995). 3-D Nonlinear analysis of segmental box girders and steel fiber ground slabs under combined actions. In: COLÓQUIO ESTRUTURAS DE CONCRETO. U.F.J.F., Juiz de Fora, p. 11-18, agosto. 
GONÇALVES, R. M. Alguns aspectos relativos à inspeção e recuperação de pontes de aço - ênfase em pontes ferroviárias. São Carlos, 1992. Tese de Doutorado, EESC- USP.

HARDING, J. E.; PARKE, G.A.R.; RYALL, M.J. (1990). Bridge management: inspection, maintenance, assessment and repair. London, Elsevier. 2 v.

JASIM, N. A . (1997). Computation of deflections for continuous composite beams with partial interaction. Proceedings of the Institution of Civil Engineers: Structures \& Buildings, v. 122, p. 347-354.

JEFFERS, E. (1990). U-frame restraint against instability of steel beams in bridges. The Structural Engineer, v. 68, n. 18, p. 359-366.

JOHNSON, R. P.; OEHLERS, D. J. (1996). Integrated static and fatigue design or assessment of stud shear connections in composite bridges. The Structural Engineer, v. 74, n. 14, p. 236-240.

KALFAS, C.; PAVLIDIS, P.; GALOUSSIS, E. (1997). Inelastic behaviour of shear connection by a method based on FEM. Journal of Constructional Steel Research, v. 44, n. 1-2, p. 107-114.

LAWTHER, R.; GILBERT, R. I. (1992). Deflection analysis of composite structures using the rate-of-creep method. The Structural Engineer, v. 70, n. 12 , p. $220-223$.

LEE, S. L.; SHANMUGAN, N. E. (1991). Composite steel structures: recent research and developments. London. Elsevier. 
LEONHARDT, F.; ANDRA, W.; ANDRA, H.-P.; HARRE, W. (1987). Neues, vorteilhaftes verbundmittel fur stahlverbund-Tragwerke mit hoher Dauerfestigkeit. Beton und Stahlbetonbau, v. 12, p. 325-331.

MARREY, B. (1990). Les ponts modernes. Picard.

MASON, J. (1976). Pontes metálicas e mistas em viga reta: projeto e calculo. Rio de Janeiro, Mc Graw-Hill.

MERRITT, F. S. (1972). Structural steel designer's handbook. New York, McGraw-Hill.

NAITHANI, K. C.; GUPTA, V. K.; BHAL, N. S. (1992). Modified approach to design of shear connectors in composite beams for fatigue loading. In: FATIGUE AND FRACTURE IN STEEL AND CONCRETE STRUCTURES, ISFF PROCEEDINGS. Ed: RAO, M. A G.; RAO, T. V. S. R. december, Madras, India, p. 1361-1368.

OGUEJIOFOR, E. C.; HOSAIN, M. U. (1992). Behaviour of perfobond rib shear connectors in composite beams: full-size tests. Canadian Journal of Civil Engineering, v. 19, p. 224-235.

OGUEJIOFOR, E. C.; HOSAIN, M. U. (1995). Tests of full-size composite beams with perfobond rib connectors. Canadian Journal of Civil Engineering, v. 22, p. 80-92.

OGUEJIOFOR, E. C.; HOSAIN, M. U. (1997). Numerical analysis of push-out specimens with perfobond rib connectors. Computers \& Structures, v. 62 , n. 4 , p. $617-624$. 
PENTAS, H. A .; AVENT, R. R.; GOPU, V. K. A .; REBELLO, K. J. (1995). Field Study of longitudinal movements in composite bridges. Transportation Research Record, TRB. n. 1476, p. 117-128.

ROBERTS, W. S.; HEYWOOD R. J. (1994). Development and Testing of a New Shear Connector for Steel Concrete Composite Bridges. In: INTERNATIONAL BRIDGE ENGINEERING CONFERENCE, 4th, TRB, San Francisco, USA, v.2, p. 137-145.

STEINHAM, D. B.; WATSON, S. R. (1957). Bridges and their builders. New York, Dover.

TABSH, S. W.; MARCHESE, D. (1995). Span capability of noncompact composite steel bridge beams. Transportation Research Record, TRB, n. 1476 , p. $8-13$.

TADROS, M. K.; BAISHYA, M. C. (1998). Rapid replacement of bridge decks. National Cooperative Highway Research Program, TRB, report n. 407.

VELDANDA, M. R.; HOSAIN, M. U. (1992). Behaviour of perfobond rib shear connectors: push-out tests. Canadian Journal of Civil Engineering, v. 19, p. 1-10.

ZHAO, Z.; HALDAR, A .; BREEN JR. F. L. (1994). Fatigue-reliability evaluation of steel bridges. Journal of Structural Engineering, ASCE, v. 120 , n. 5 , p. $1608-1623$. 


\section{CARACTERÍSTICAS DOS TABULEIROS MODELADOS}

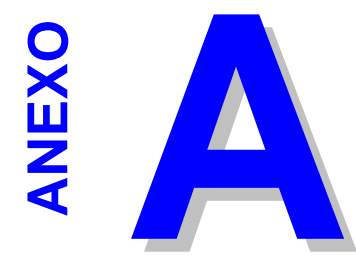

Nesta seção apresenta-se os tabuleiros analisados no trabalho, estes são baseados nos modelos propostos pela SIDERBRÁS, sendo classificados segundo o número de vigas que possuem.

O sistema estrutural adotado é o de estrutura mista baiapoiada, com os seguintes vãos: 8, 10, 12, 14, 16, 18, 20, 22, 24 e 26 m.

As pontes possuem pista de rolamento de $9,0 \mathrm{~m}$ e guarda-rodas laterais de 0,40 m, perfazendo largura de $9,80 \mathrm{~m}$.

A superestrutura de aço é constituída por vigas I unidas por transversinas intermediárias treliçadas.

A união entre o concreto armado e as vigas de aço é garantida por conectores de cisalhamento do tipo "stud".

As vigas internas e externas das pontes consideradas possuem perfis com dimensões idênticas, a razão para tal procedimento é obter vantagens no processo de fabricação, com a consequente redução de custos.

$\mathrm{Na}$ figura A.1 apresenta-se as seções transversais das vigas adotadas para cada vão de tabuleiro. 


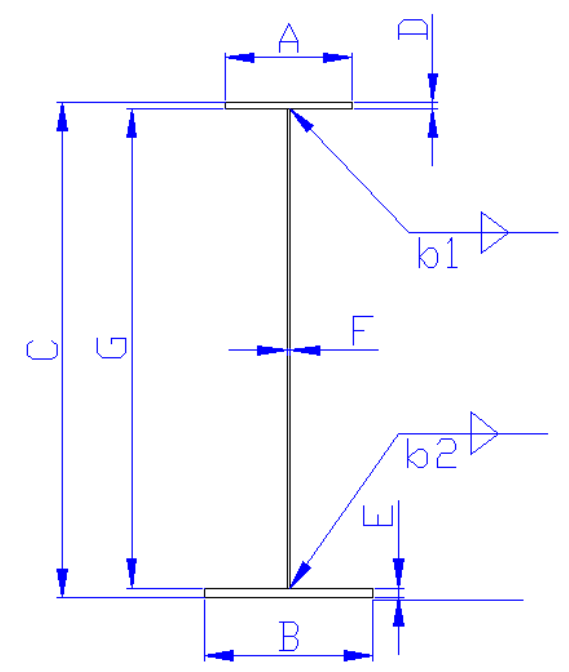

\begin{tabular}{|c|c|c|c|c|c|c|c|c|c|c|c|}
\hline Vão $(\mathrm{m})$ & No. Vigas & Perfil & A & B & C & D & E & F & G & b1 & b2 \\
\hline 8 & 4 & VI 700/76 & 160 & 230 & 700 & 8 & 12.5 & 8 & 679.5 & 6 & 6 \\
10 & 4 & VI 800/91 & 160 & 250 & 800 & 8 & 16 & 8 & 776 & 6 & 6 \\
12 & 4 & VI 800/115 & 160 & 370 & 800 & 8 & 16 & 9.5 & 776 & 6 & 6 \\
14 & 4 & VI 900/126 & 190 & 370 & 900 & 9.5 & 16 & 9.5 & 874.5 & 6 & 6 \\
16 & 4 & VI 1000/153 & 250 & 370 & 1000 & 12.5 & 19 & 9.5 & 968.5 & 6 & 7 \\
18 & 3 & VI 1200/197 & 280 & 450 & 1200 & 16 & 25 & 8 & 1159 & 6 & 8 \\
20 & 3 & VI 1300/222 & 330 & 440 & 1300 & 16 & 25 & 9.5 & 1259 & 6 & 8 \\
22 & 3 & VI 1400/244 & 350 & 460 & 1400 & 19 & 25 & 9.5 & 1356 & 7 & 8 \\
24 & 3 & VI 1500/266 & 380 & 510 & 1500 & 19 & 25 & 9.5 & 1456 & 7 & 8 \\
26 & 3 & VI 1600/292 & 400 & 540 & 1600 & 22 & 25 & 9.5 & 1553 & 8 & 8 \\
\hline
\end{tabular}

FIGURA A.1 - Características da seção transversal das vigas para os tabuleiros considerados.

Nas figuras A.2 e A.3 apresentam-se a seção transversal dos tabuleiros sobre três vigas, sistema de contraventamentos e espaçamentos entre estes.

Nas figuras A.4 e A.5 apresentam-se os mesmos aspectos para tabuleiros sobre quatro vigas.

Nas figuras A.6 e A.7 apresentam-se a seção transversal e arranjo estrutural do tabuleiro sobre duas vigas, finalmente na figura A.8 apresenta-se a seção transversal das vigas para tabuleiro de 24 m de vão sobre duas vigas. 


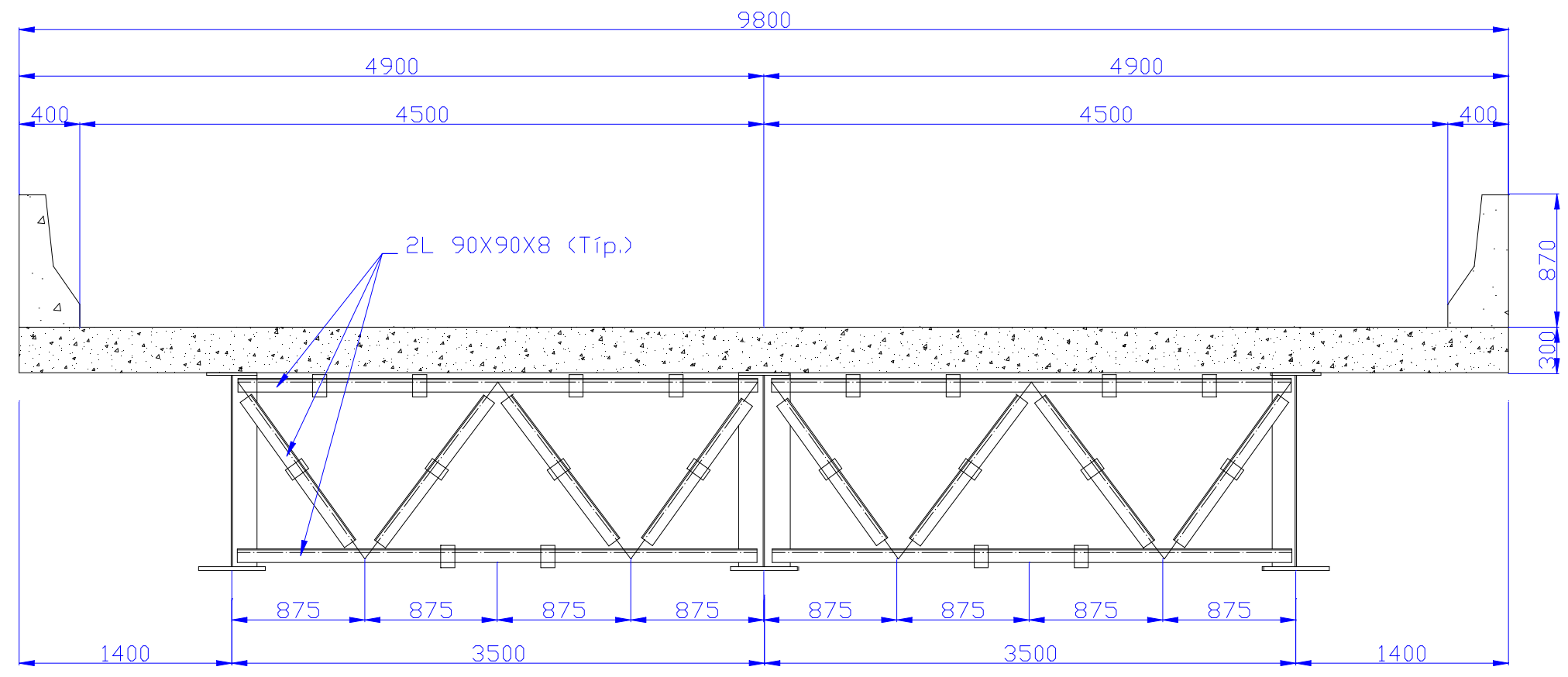

Dim. em mm.

FIGURA A.2 - Seção transversal para pontes com vãos de 18, 20, 22, 24, 26 m. 


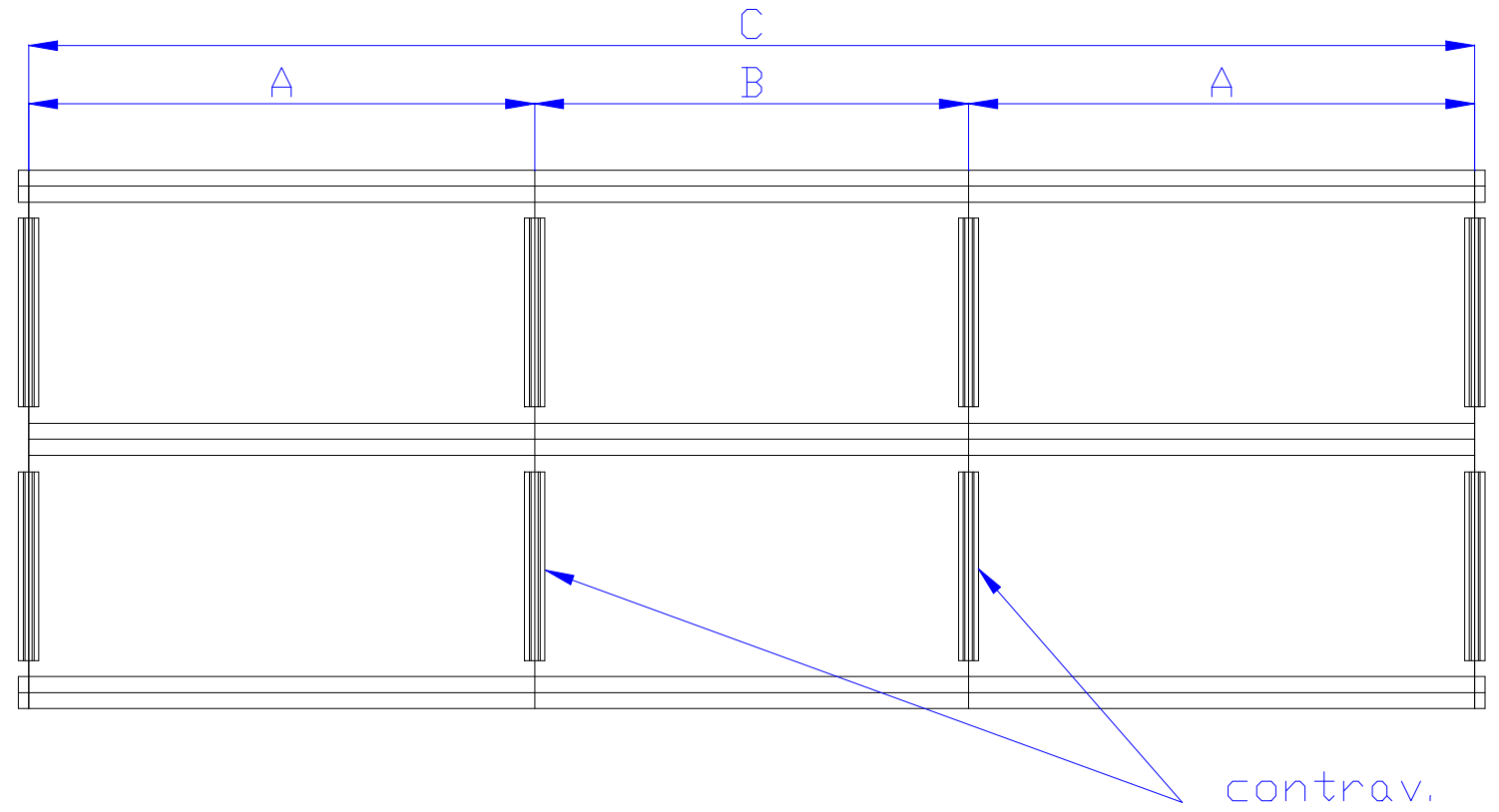

\begin{tabular}{|c|c|c|}
\hline $\mathrm{C}(\mathrm{cm})$ & $\mathrm{A}(\mathrm{cm})$ & $\mathrm{B}(\mathrm{cm})$ \\
\hline 1800 & 600 & 600 \\
2000 & 700 & 600 \\
2200 & 800 & 600 \\
2400 & 800 & 800 \\
2600 & 900 & 800 \\
\hline
\end{tabular}

FIGURA A.3 - Espaçamento entre contraventamentos. 


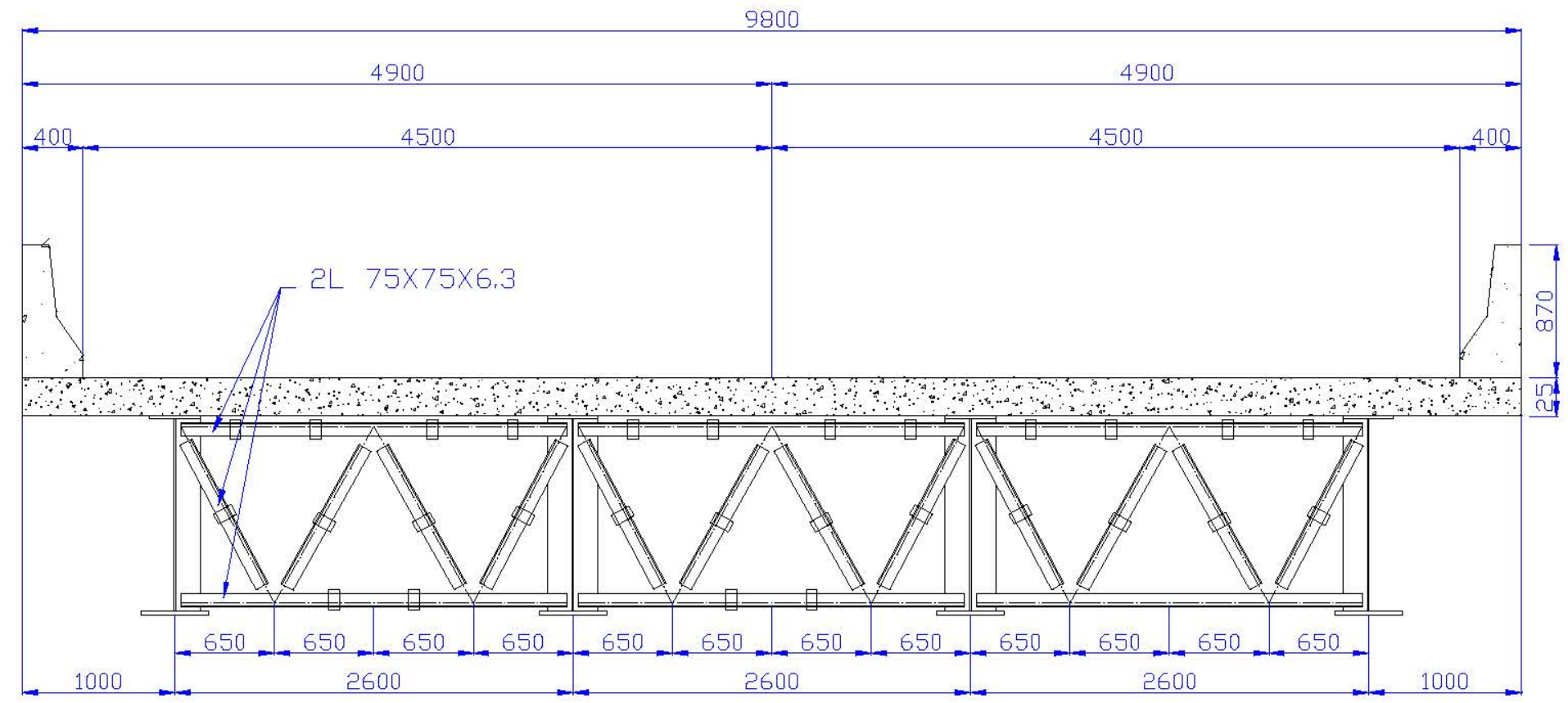

FIGURA A.4 - Seção transversal para pontes com vãos de 8, 10, 12, 14, 16 m. 


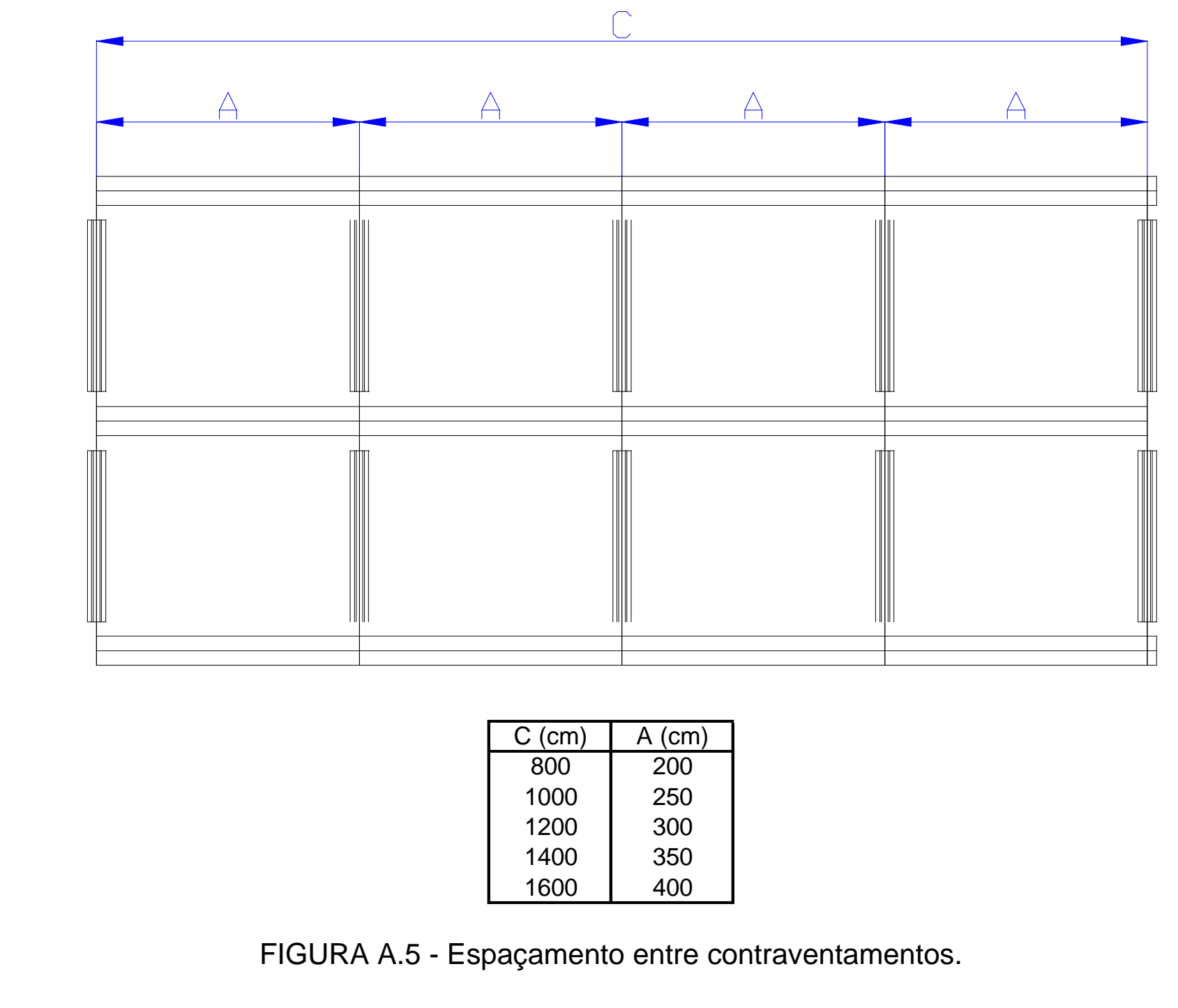




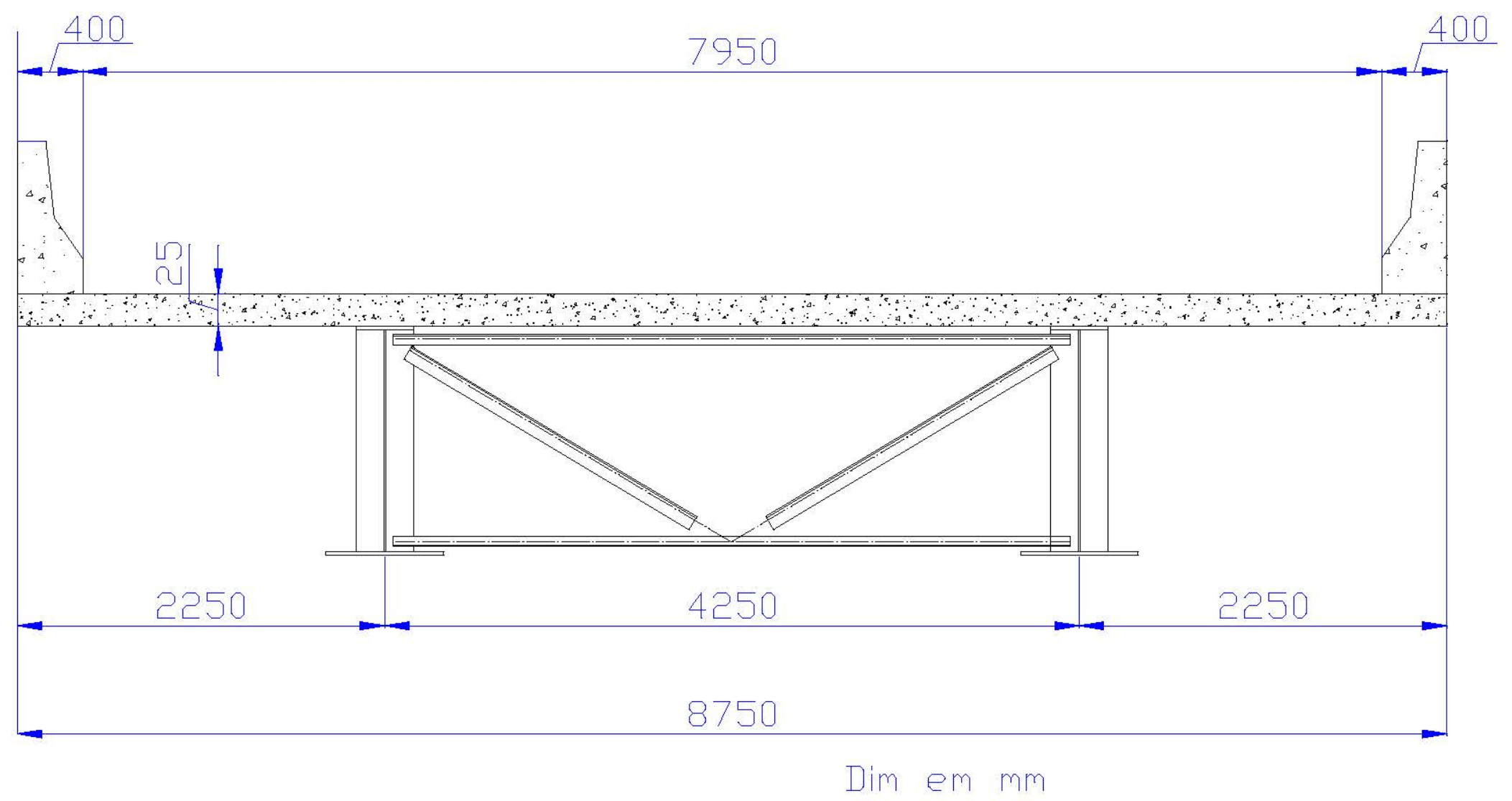

FIGURA A.6 - Seção transversal para ponte em duas vigas com vão de 24 m. 


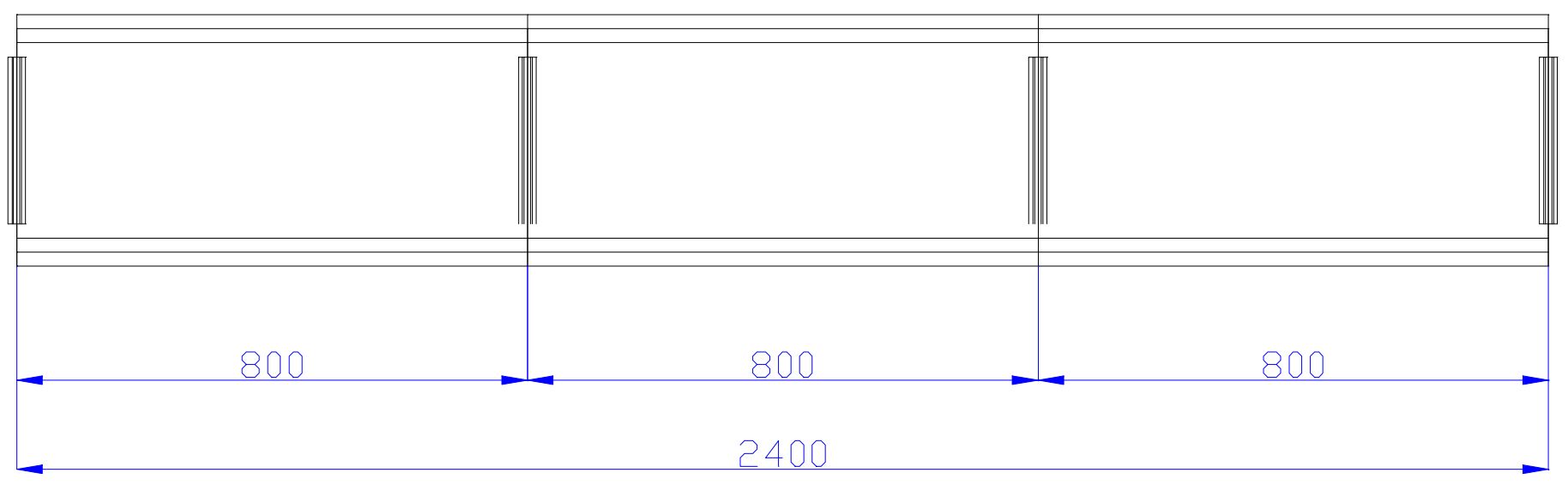

FIGURA A.7 - Espaçamento entre contraventamentos (dim em cm). 


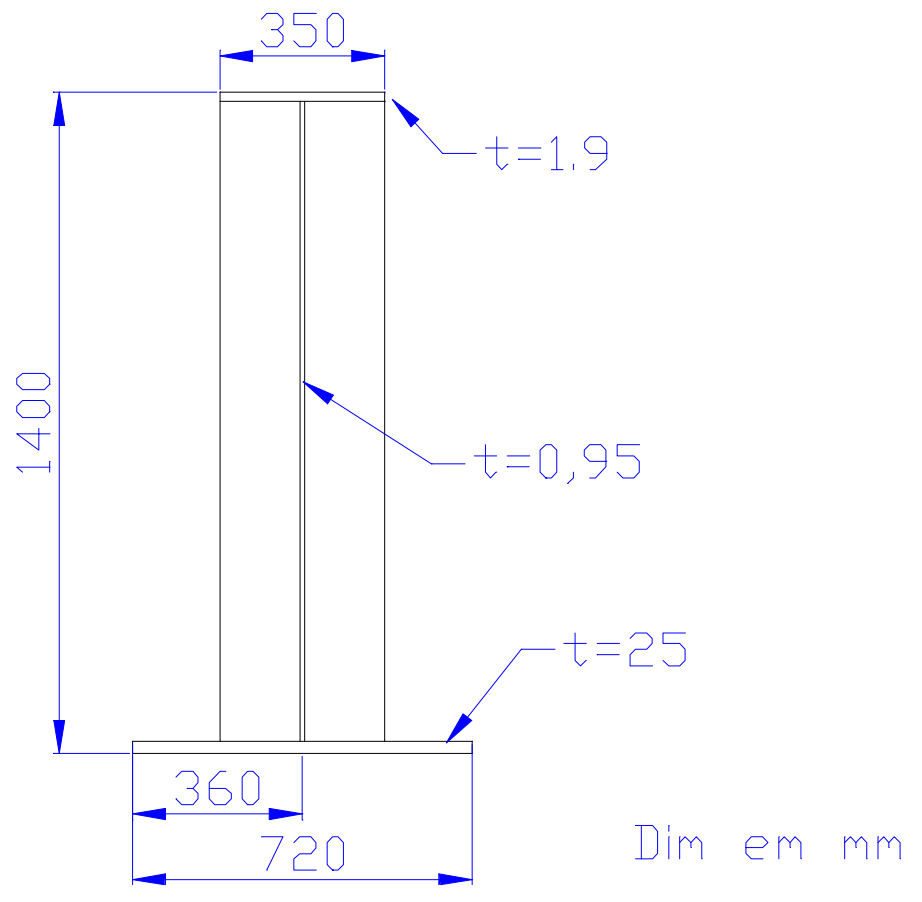

FIGURA A.8 - Seção transversal das vigas. 


\section{CARACTERÍSTICAS}

GEOMÉTRICAS DAS VIGAS

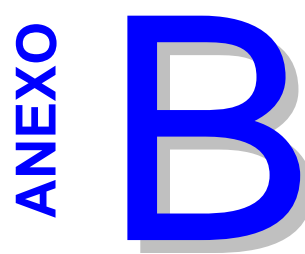
MISTAS

Apresenta-se aqui o roteiro de cálculo para a determinação das características geométricas de uma viga mista. Este roteiro foi obtido dos fascículos apresentados pela SIDERBRÁS.

$\mathrm{Na}$ figura B.1 apresenta-se parte da nomenclatura utilizada para um melhor entendimento do roteiro apresentado.

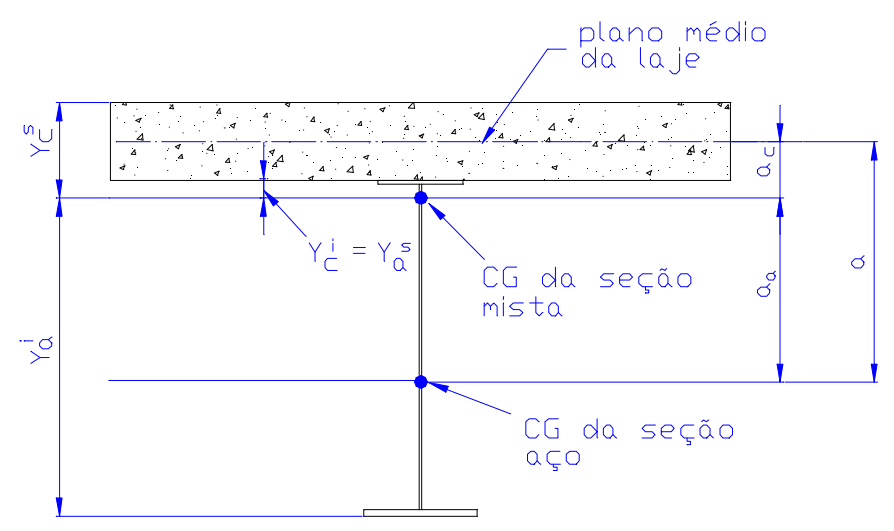

FIGURA B.1 - Nomenclatura utilizada para o cálculo das características geométricas. 


\section{Nomenclatura:}

$A_{a}=$ área da viga metálica.

$A_{c}=$ área da seção de concreto.

$A_{m}=A_{a}+\frac{A_{c}}{\eta_{o, f, r}}=$ área da seção mista.

$\mathrm{a}=$ distância entre os centros de gravidade da seção de aço e concreto.

$a_{c}=\frac{A_{a}}{\frac{A_{c}}{\eta_{o, f, r}}+A_{a}} a=$ distância entre os C.G. da seção de concreto e da viga mista.

$a_{a}=\frac{\frac{A_{c}}{\eta_{o, f, r}}}{\frac{A_{c}}{\eta_{o, f, r}}+A_{a}} a=$ distância entre os C.G. da viga de aço e da viga mista.

$\mathrm{I}_{\mathrm{a}}=$ momento de inércia da seção de aço.

$\mathrm{I}_{\mathrm{c}}=$ momento de inércia da seção de concreto.

$I_{m}=J_{a}+A_{a} a_{a}{ }^{2}+\frac{1}{\eta_{o, f, r}}\left(J_{c}+A_{c} a_{c}{ }^{2}\right)=$ momento de inércia da viga mista.

$W_{a a}{ }^{s}=$ módulo de resistência superior da viga de aço.

$W_{a a}{ }^{i}=$ módulo de resistência inferior da viga de aço.

$W_{c}^{s}=\frac{I_{m}}{Y_{c}^{s}}=$ módulo de resistência superior do concreto na viga mista.

$W_{c}^{i}=\frac{I_{m}}{Y_{c}^{i}}=$ módulo de resistência inferior do concreto na viga mista.

$W_{a}^{s}=\frac{I_{m}}{Y_{a}^{s}}=$ módulo de resistência superior da viga metálica na viga mista. 
$W_{a}^{i}=\frac{I_{m}}{Y_{a}^{i}}=$ módulo de resistência inferior da viga metálica na viga mista.

Para a ação de carga móvel, a relação entre módulos de elasticidade do aço e do concreto foi adotada como sendo igual a 9 (para concreto com $\mathrm{f}_{\mathrm{ck}}=21 \mathrm{MPa}, \frac{\mathrm{E}_{\mathrm{a}}}{\mathrm{E}_{\mathrm{c}}}=9$; AASHTO, 1989).

A seguir apresenta-se um exemplo de aplicação para determinar 0 momento de inércia da viga mista apresentada na figura B.2.

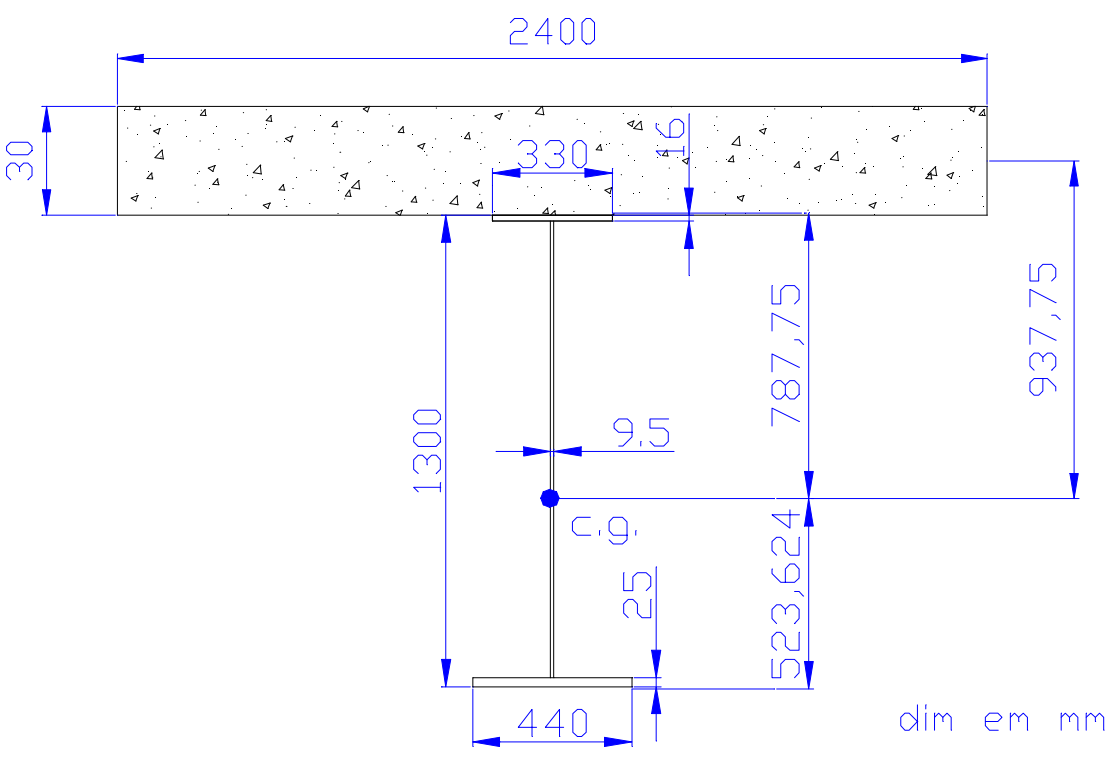

FIGURA B.2 - Seção transversal da viga mista.

$$
\begin{aligned}
& A_{a}=282,405 \mathrm{~cm}^{2} ; \\
& A_{c}=7200 \mathrm{~cm}^{2} ; \\
& \mathrm{I}_{\mathrm{a}}=777646,0784 \mathrm{~cm}^{4} ; \\
& \mathrm{I}_{\mathrm{c}}=540000 \mathrm{~cm}^{4} ;
\end{aligned}
$$

Cálculo da seção mista:

$$
A_{m}=282,405+\frac{7200}{9}=1082,405 \mathrm{~cm}^{2}
$$


Cálculo da posição do C.G. na viga mista:

$$
a_{c}=\frac{282,405}{\frac{7200}{9}+282,405} \bullet 93,775=24,466 \mathrm{~cm}
$$

$$
a_{a}=\frac{\frac{7200}{9}}{\frac{7200}{9}+282,405} \bullet 93,775=69,3086 \mathrm{~cm}
$$

Cálculo da inércia da viga mista:

$$
\begin{aligned}
& I_{m}=777646,0784+282,405 \cdot 69,3086^{2}+\frac{1}{9} \cdot\left(540000+7200 \cdot 24,466^{2}\right) \\
& I_{m}=2.673 .098,0282 \mathrm{~cm}^{4}
\end{aligned}
$$

Cálculo da altura das fibras:

$$
\begin{aligned}
& y_{a}^{i}=69,3086+52,3624=121,671 \mathrm{~cm} \\
& y_{a}^{s}=Y_{c}^{i}=24,466-15=9,466 \mathrm{~cm} \\
& y_{c}^{s}=24,466+15=39,466 \mathrm{~cm}
\end{aligned}
$$

Cálculo dos módulos de resistência:

$$
\begin{aligned}
& W_{a a}^{i}=\frac{2673098,0282}{121,671}=21.969,89 \mathrm{~cm}^{3} \\
& W_{a a}^{s}=W_{c}^{i}=\frac{2673098,0282}{9,466}=282.389,397 \mathrm{~cm}^{3} \\
& W_{c}^{s}=\frac{2673098,0282}{39,466}=67.731,6685 \mathrm{~cm}^{3}
\end{aligned}
$$


Na figura B.3 apresenta-se as características geométricas calculadas para a viga mista.

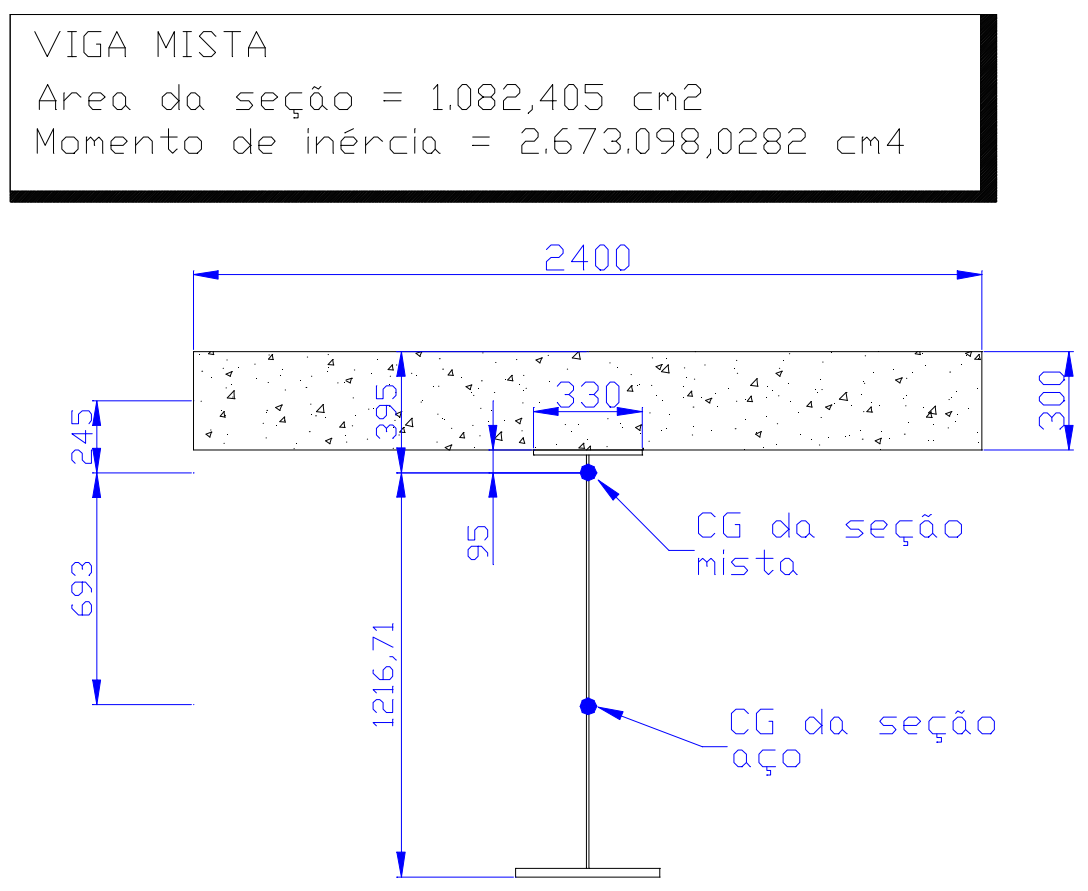

Dim. em $m m$

FIGURA B.3 - Características geométricas da viga mista.

O mesmo procedimento de calculo foi utilizado para determinar as características geométricas dos tabuleiros apresentados no ANEXO A, estas são apresentadas nas tabelas B.1 e B.2.

TABELA B.1 - Características geométricas das vigas de aço.

\begin{tabular}{|c|c|c|}
\hline Perfil & Area (cm2) & Ix (cm4) \\
\hline VI 700/76 & 95.91 & 67254.992 \\
VI 800/91 & 114.88 & 103361.82 \\
VI 800/115 & 145.72 & 126212.76 \\
VI 900/126 & 158.4275 & 178553.9 \\
VI 1000/153 & 193.5575 & 299102.7 \\
VI 1200/197 & 250.02 & 587867.05 \\
VI 1300/222 & 282.405 & 777646.08 \\
VI 1400/244 & 310.32 & 1023520.5 \\
VI 1500/266 & 338.02 & 1286145.3 \\
VI 1600/292 & 370.535 & 1645391.3 \\
\hline
\end{tabular}


TABELA B.2 - Características geométricas das vigas mistas.

\begin{tabular}{|c|c|c|c|c|c|c|}
\cline { 5 - 6 } & \multicolumn{9}{|l|}{ Características da seção } & mista \\
\hline Vão & Material & Area & Inércia & ac $(\mathrm{cm})$ & as $(\mathrm{cm})$ & Im (cm4) \\
\hline $10 \mathrm{~m}$ & Concreto & 5000 & 260416.6667 & 10.54163442 & 50.97896558 & 492590.1533 \\
& Aço & 114.88 & 103361.8157 & & & \\
\hline $12 \mathrm{~m}$ & Concreto & 5000 & 260416.6667 & 13.4534399 & 51.2910601 & 639056.9685 \\
& Aço & 145.72 & 126212.7613 & & & \\
\hline $14 \mathrm{~m}$ & Concreto & 5000 & 260416.6667 & 15.37872713 & 53.92837287 & 799630.7404 \\
& Aço & 158.4275 & 178553.9003 & & & \\
\hline $16 \mathrm{~m}$ & Concreto & 5000 & 260416.6667 & 18.65230295 & 53.53649705 & 1076086.419 \\
& Aço & 193.5575 & 299102.6963 & & & \\
\hline $18 \mathrm{~m}$ & Concreto & 8400 & 630000 & 19.15494095 & 71.50605905 & 2278699.413 \\
& Aço & 250.02 & 587867.0519 & & & \\
\hline $20 \mathrm{~m}$ & Concreto & 8400 & 630000 & 21.51896808 & 71.11903192 & 2708221.966 \\
& Aço & 282.405 & 777646.0784 & & & \\
\hline $22 \mathrm{~m}$ & Concreto & 8400 & 630000 & 23.84341128 & 71.71258872 & 3220009.393 \\
& Aço & 310.32 & 1023520.452 & & & \\
\hline $24 \mathrm{~m}$ & Concreto & 8400 & 630000 & 27.08699358 & 74.79200642 & 3931768.071 \\
& Aço & 338.02 & 1286145.307 & & & \\
\hline $26 \mathrm{~m}$ & Concreto & 8400 & 630000 & 29.80777672 & 75.08222328 & 4633493.173 \\
& Aço & 370.535 & 1645391.319 & & & \\
\hline
\end{tabular}

Com as características geométricas das vigas mistas e a distribuição de carga obtida segundo as especificações da AASHTO é possível determinar as tensões atuantes em determinada seção através da aplicação direta das equações de resistência dos materiais.

As especificações propostas pela AASHTO-LRFD variam notavelmente do método $S / D$ sobre o qual a AASHTO se baseia. $O$ item 4.6.2 desta norma propõe um método diferente descrito a continuação:

No item 4.6.2.2 da AASHTO-LRFD é apresentado o parâmetro de rigidez longitudinal denominado $K_{g}$, o qual é definido pela seguinte expressão:

$$
K_{g}=n\left(I+A e_{g}^{2}\right)
$$

onde:

n: módulo de homogeneização entre o material da laje e das vigas 
I: momento de inércia das vigas

A: área da viga

$e_{g}$ : distância entre os centróides das vigas e da laje. 


\section{LINHAS DE INFLUÊNCIA DE DISTRIBUIÇÃO DE CARGA}

Apresenta-se neste anexo as linhas de influência das tensões normais atuantes nas vigas de aço, em função da posição da carga móvel na seção transversal; foi considerada apenas a porção de seção pela qual o trem tipo pode trafegar livremente, isto é, a região onde não existem guarda-rodas. Em todos os tabuleiros foi considerada uma largura de $7,8 \mathrm{~m}$, conforme descrito no capítulo 6.

Nos gráficos apresentados a continuação o eixo de abscissas representa a distância existente entre o extremo esquerdo da laje e o centro de gravidade do veículo tipo, encontrando-se as linhas de rodas deste a $1 \mathrm{~m}$ para a esquerda e $1 \mathrm{~m}$ para a direita. De maneira a apresentar as linhas de influência de distribuição de carga com maior clareza, as vigas externas e internas foram apresentadas em gráficos diferentes, tanto para os tabuleiros sobre quatro vigas como para os tabuleiros sobre três vigas.

\section{C.1 - TABULEIROS SOBRE QUATRO VIGAS}




\section{C.1.1 - VIGAS EXTERNAS}

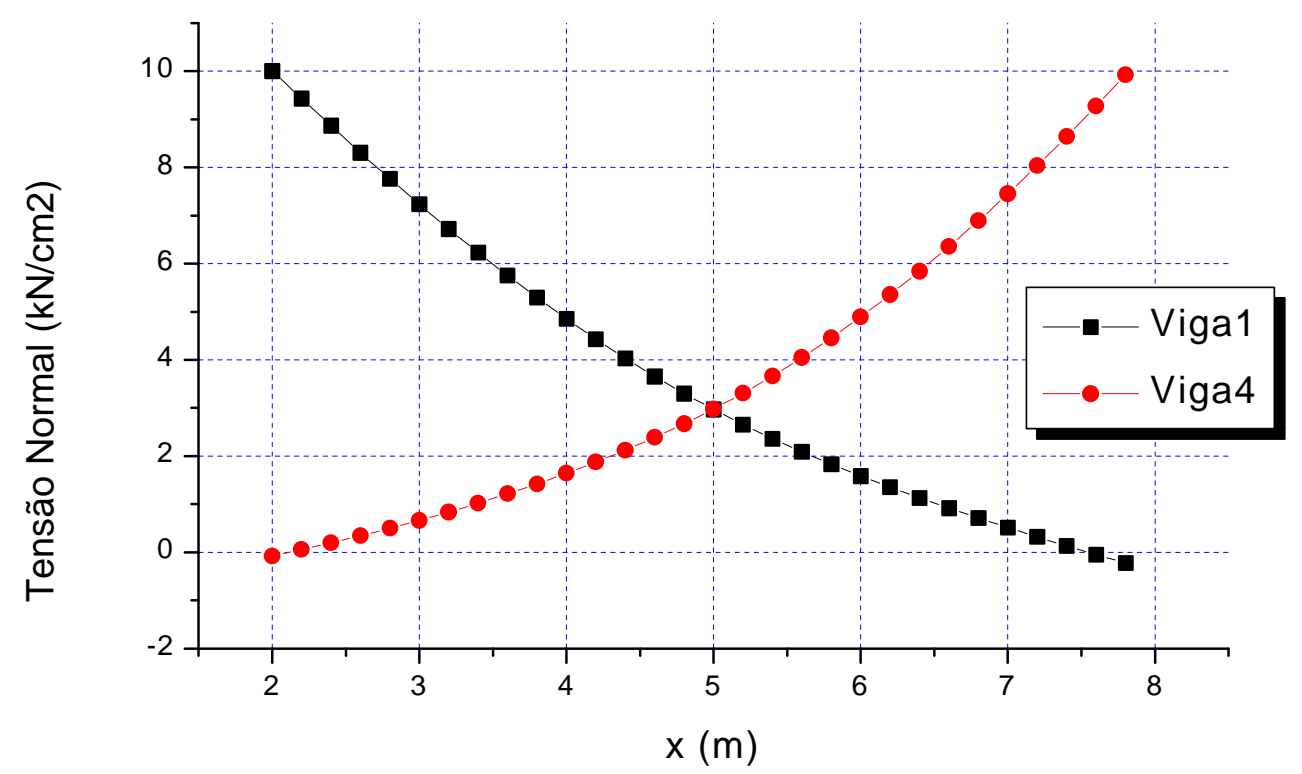

FIGURA C.1 - Linhas de influência para vão de 8 m.

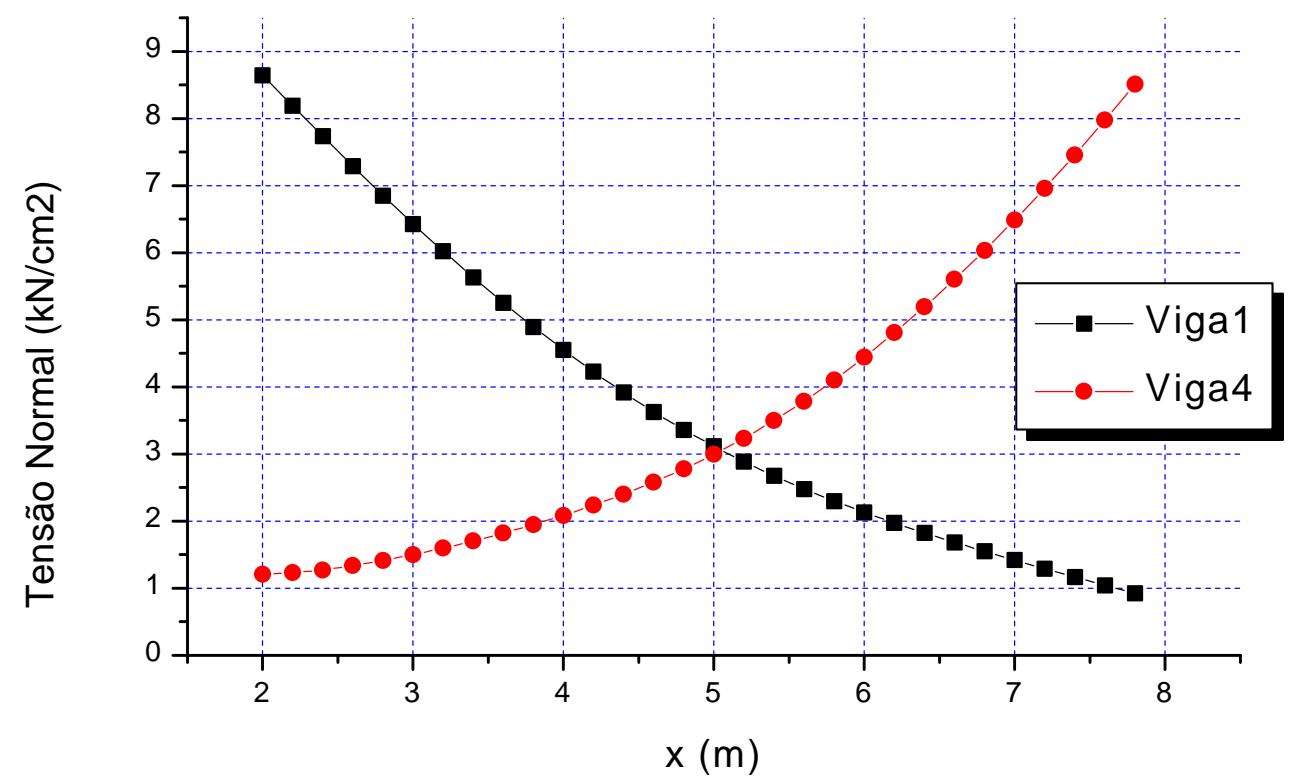

FIGURA C.2 - Linhas de influência para vão de 10 m. 


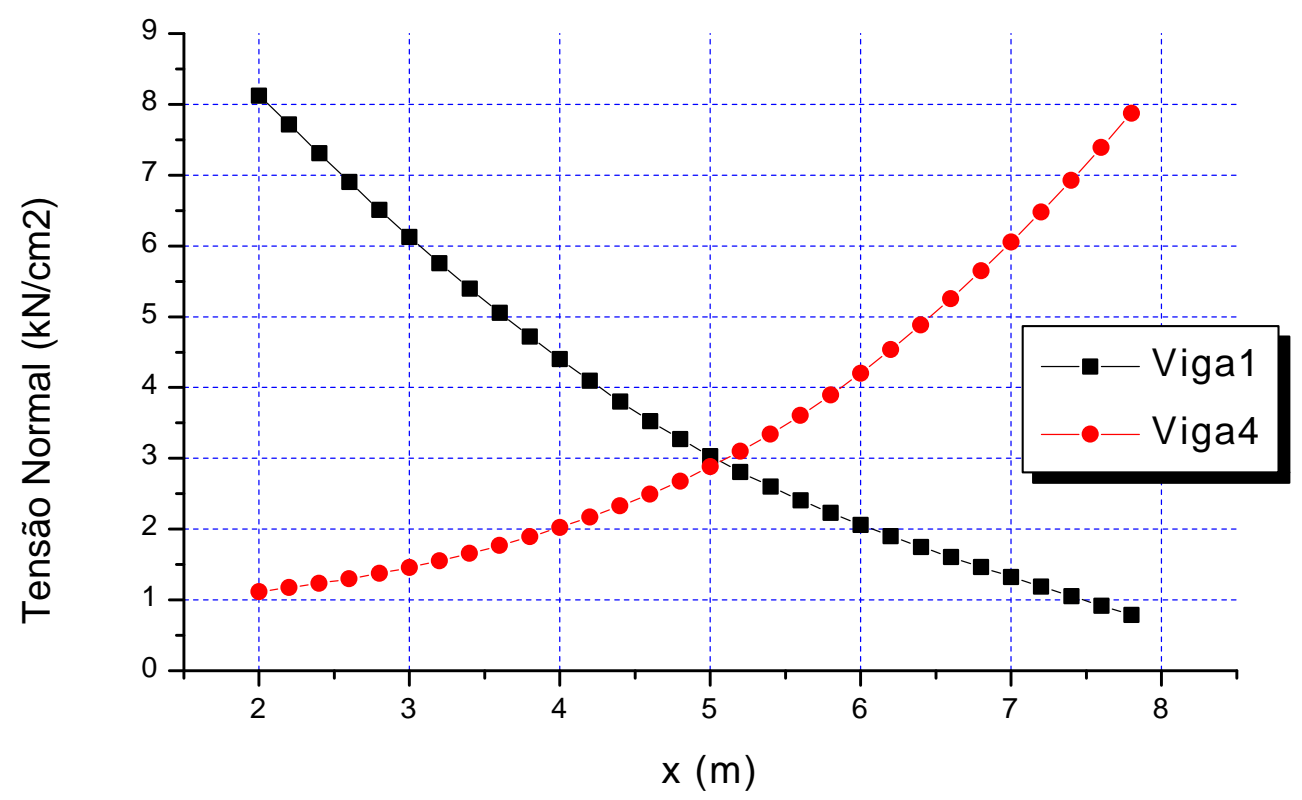

FIGURA C.3 - Linhas de influência para vão de 12 m.

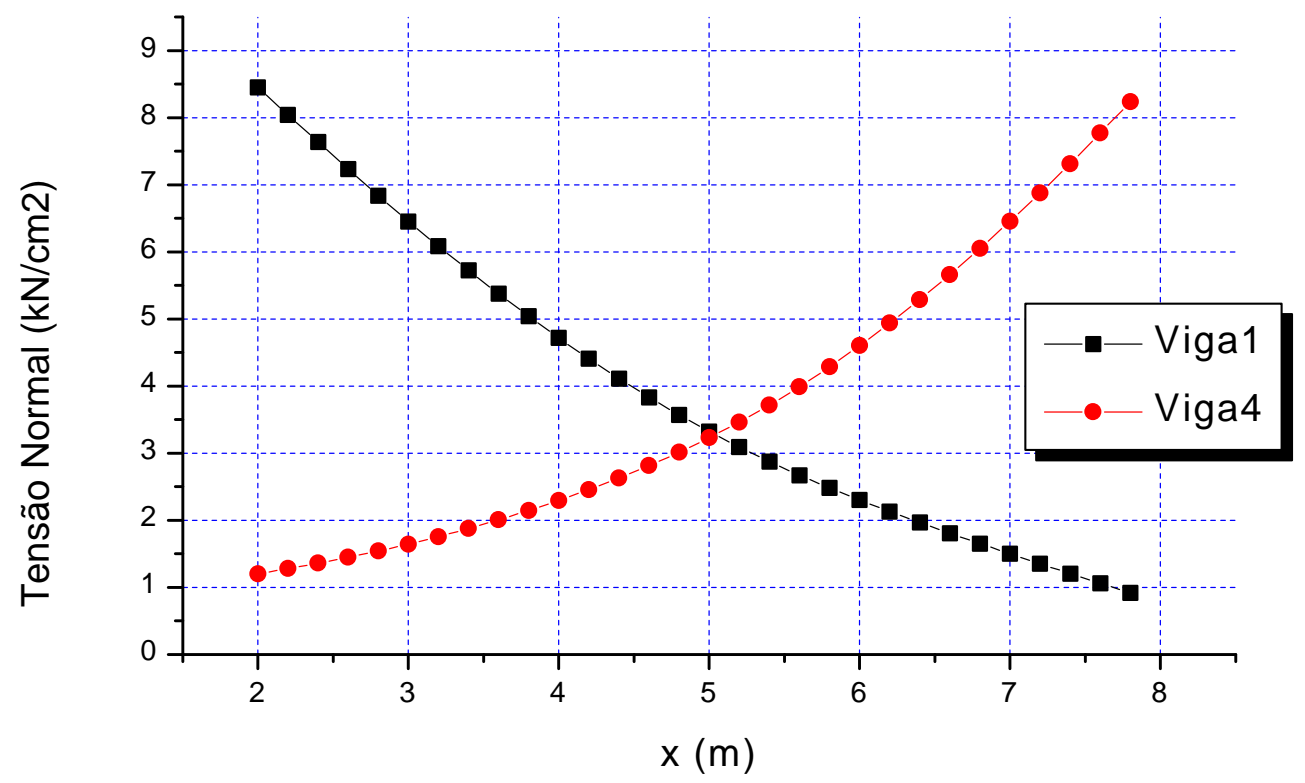

FIGURA C.4 - Linhas de influência para vão de 14 m. 


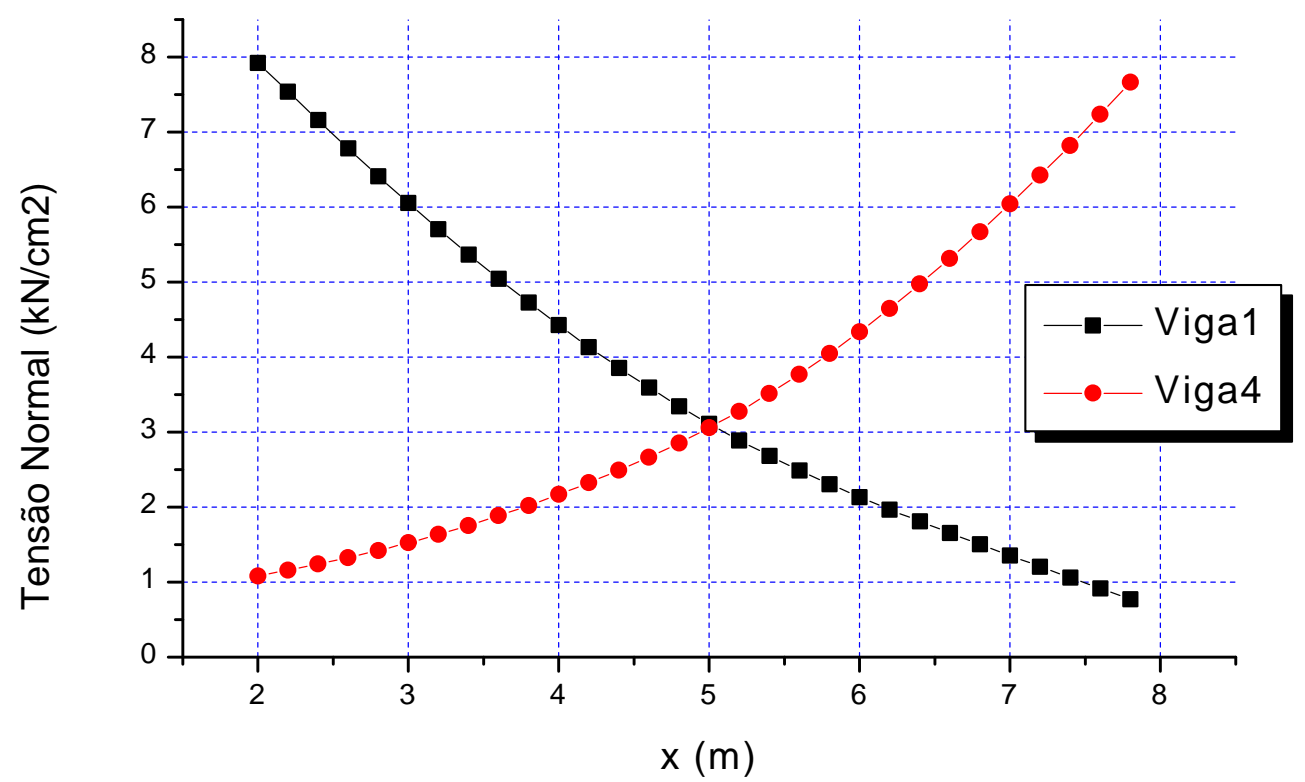

FIGURA C.5 - Linhas de influência para vão de 16 m.

C.1.2 - VIGAS INTERNAS

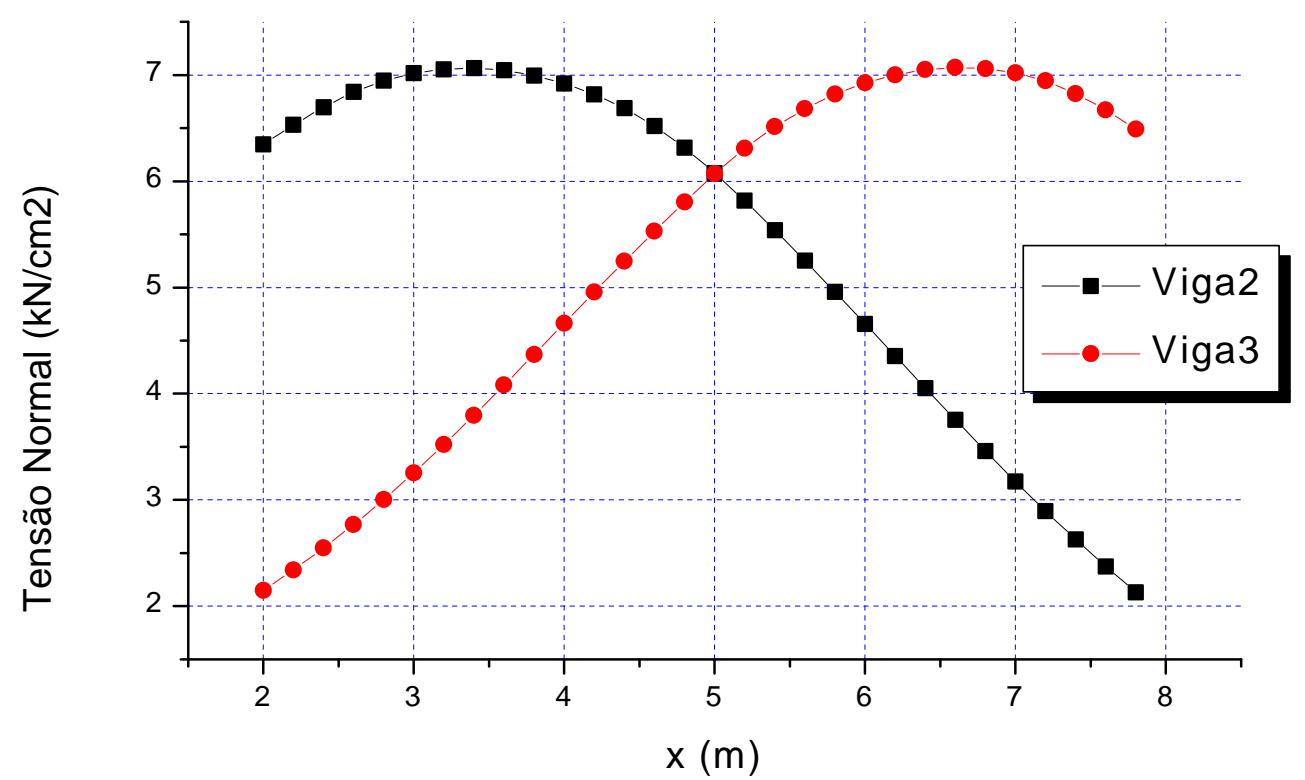

FIGURA C.6 - Linhas de influência para vão de 8 m. 


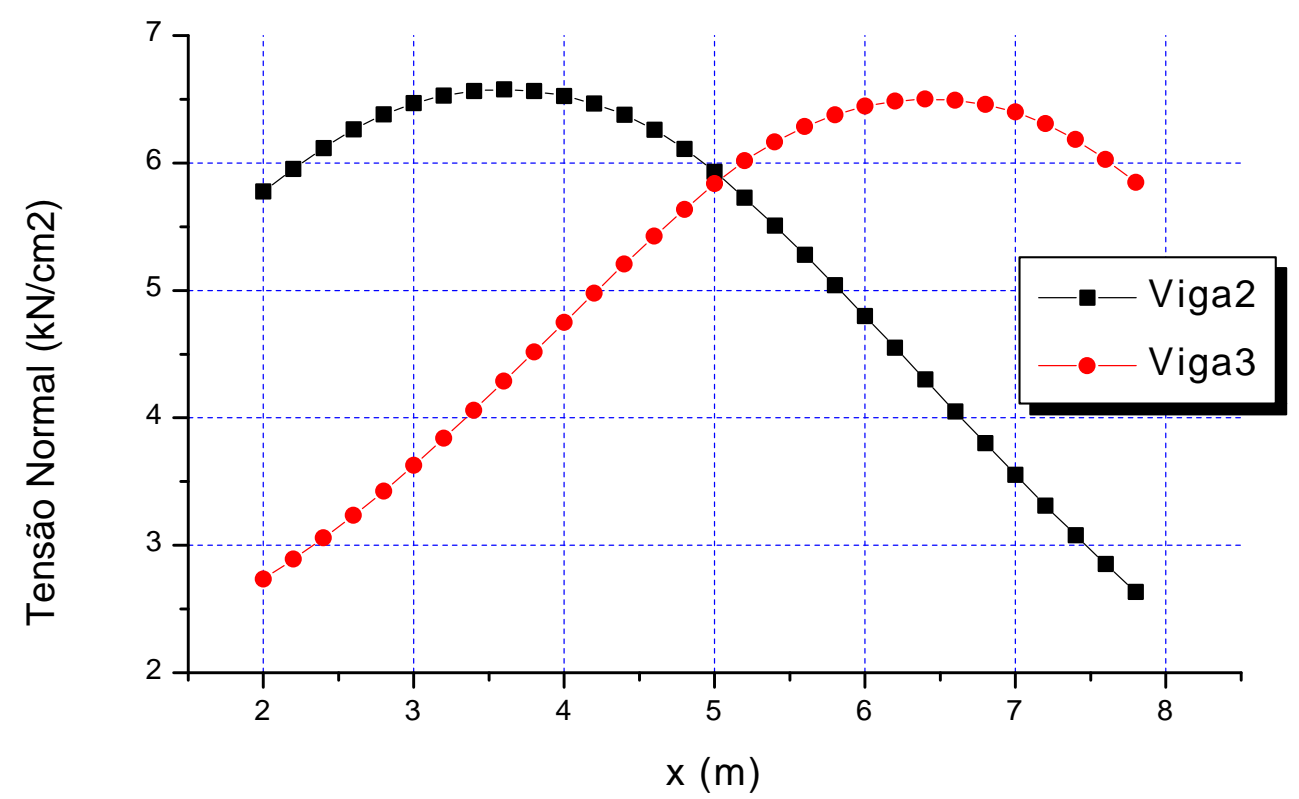

FIGURA C.7 - Linhas de influência para vãos de $10 \mathrm{~m}$.

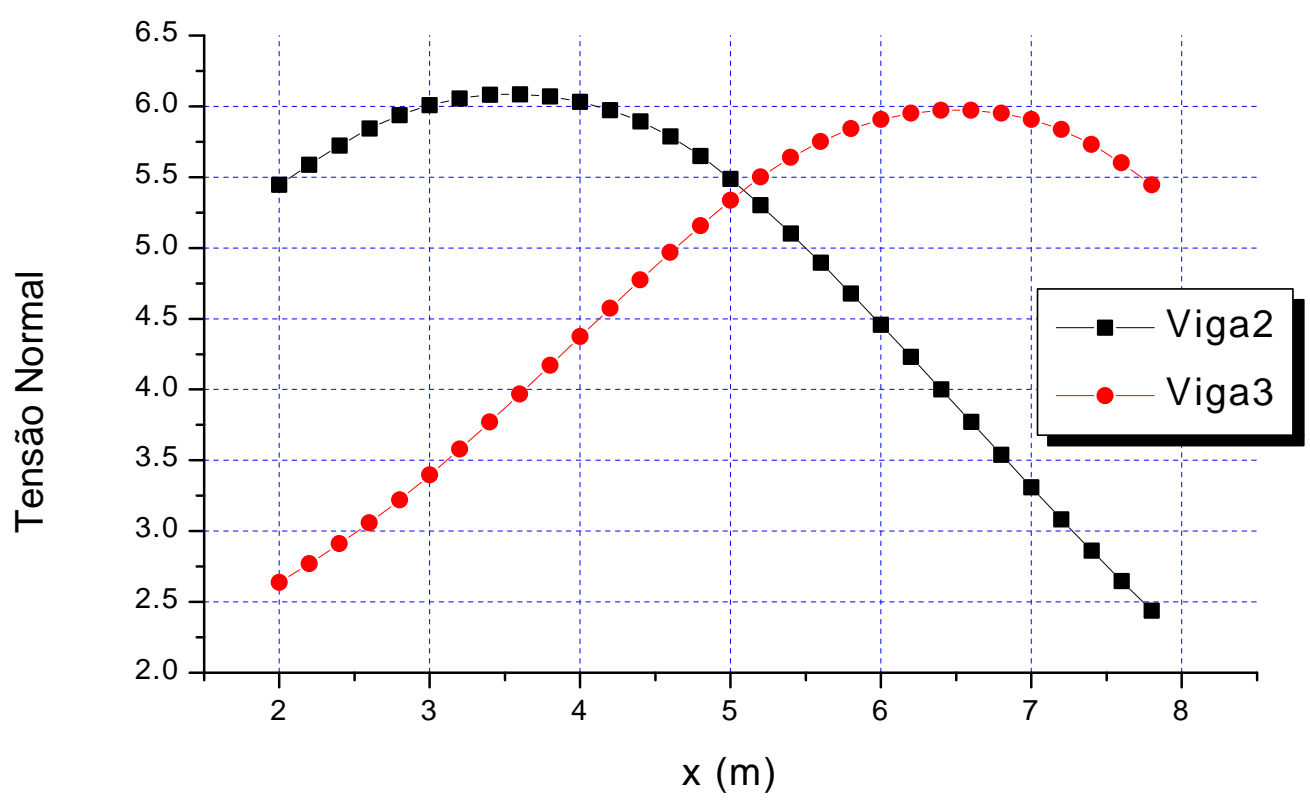

FIGURA C.8 - Linhas de influência para vão de 12 m. 


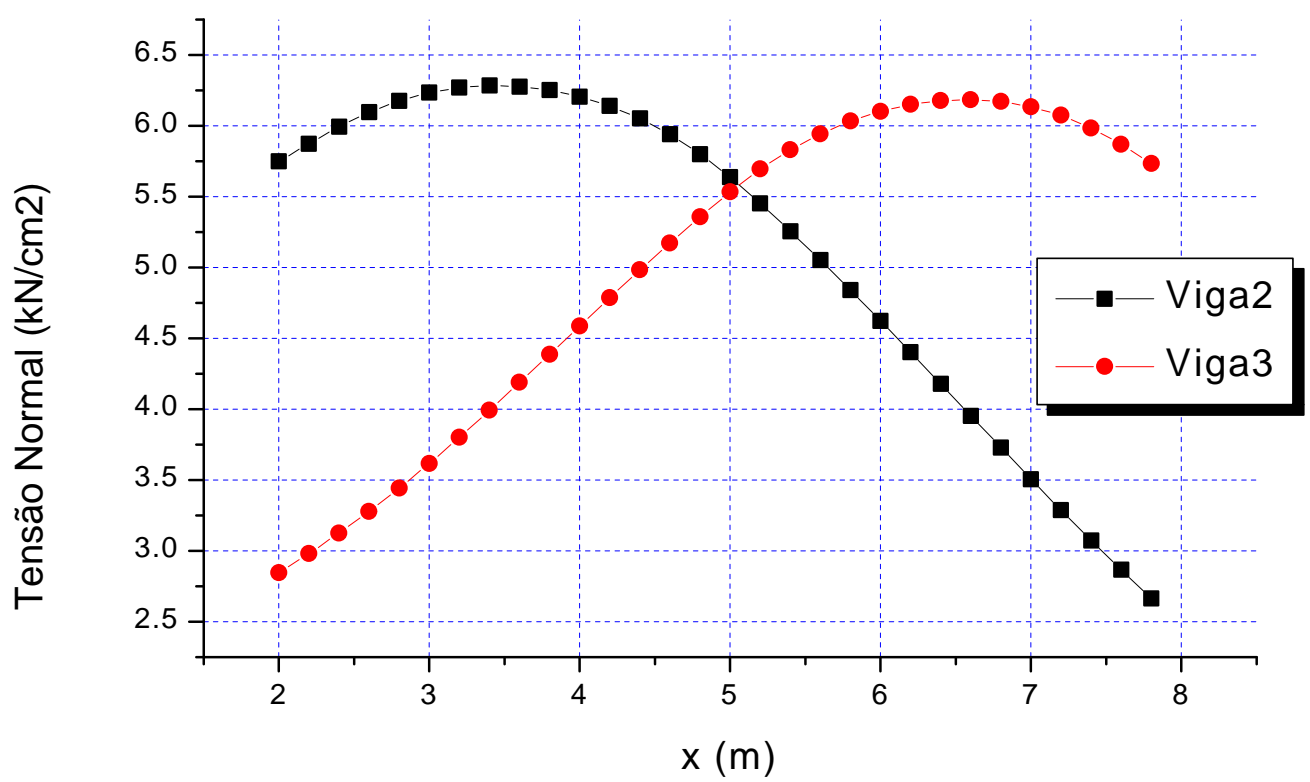

FIGURA C.9 - Linhas de influência para vão de 14 m.

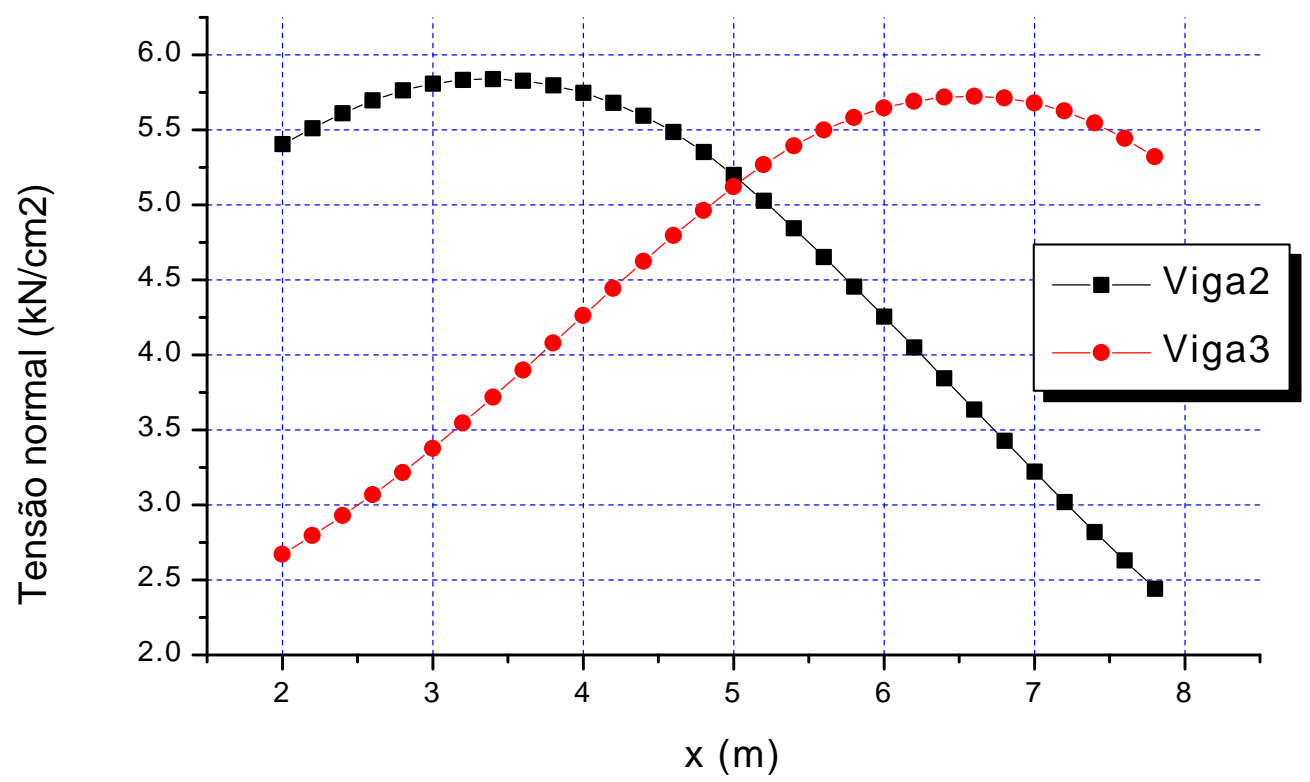

FIGURA C.10 - Linhas de influência para vão de 16 m. 


\section{C.2 - TABULEIROS SOBRE TRÊS VIGAS}

\section{C.2.1 - VIGAS EXTERNAS}

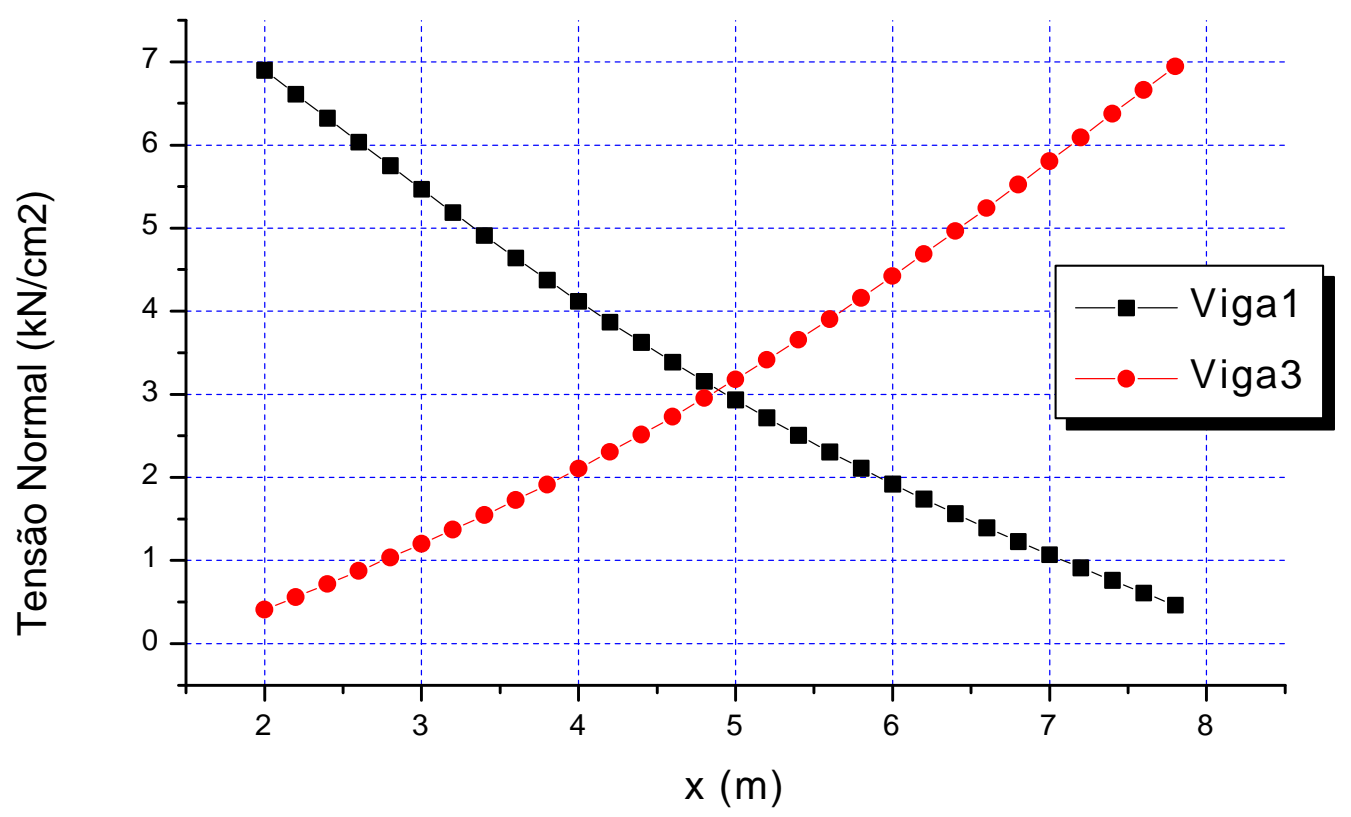

FIGURA 6.11 - Linhas de influência para vão de 18 m.

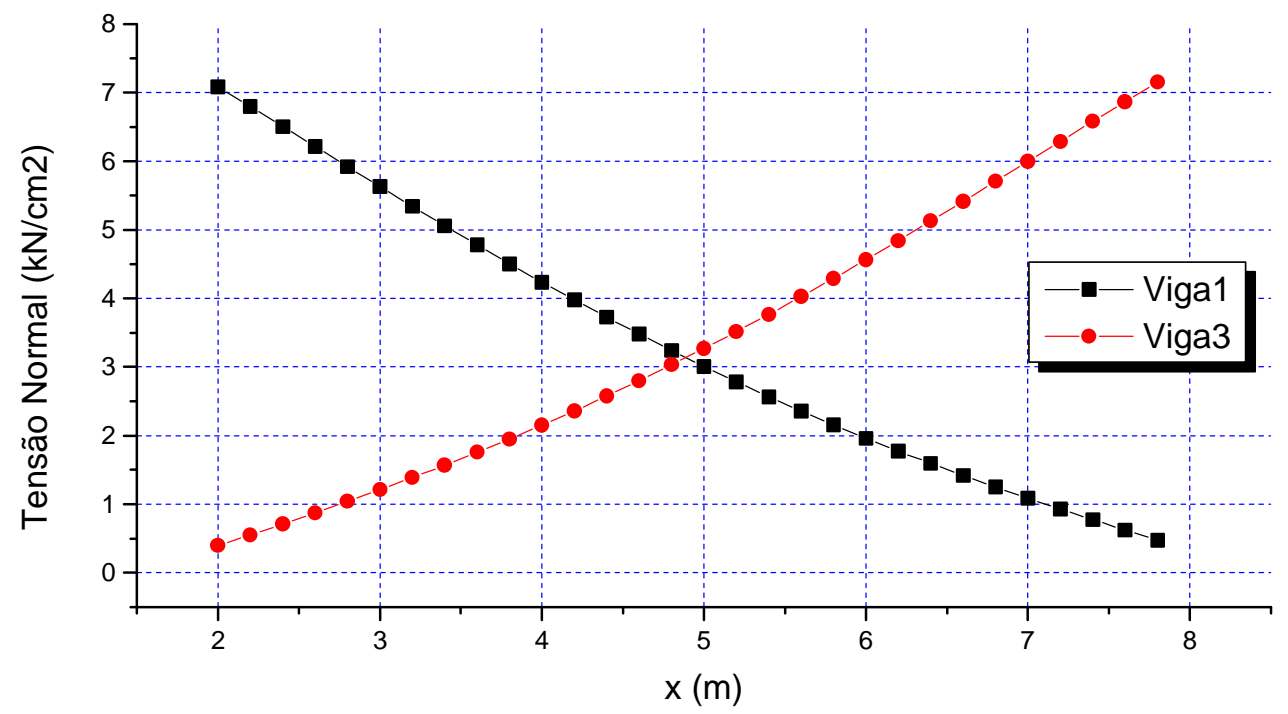

FIGURA C.12 - Linhas de influência para vão de 20 m. 


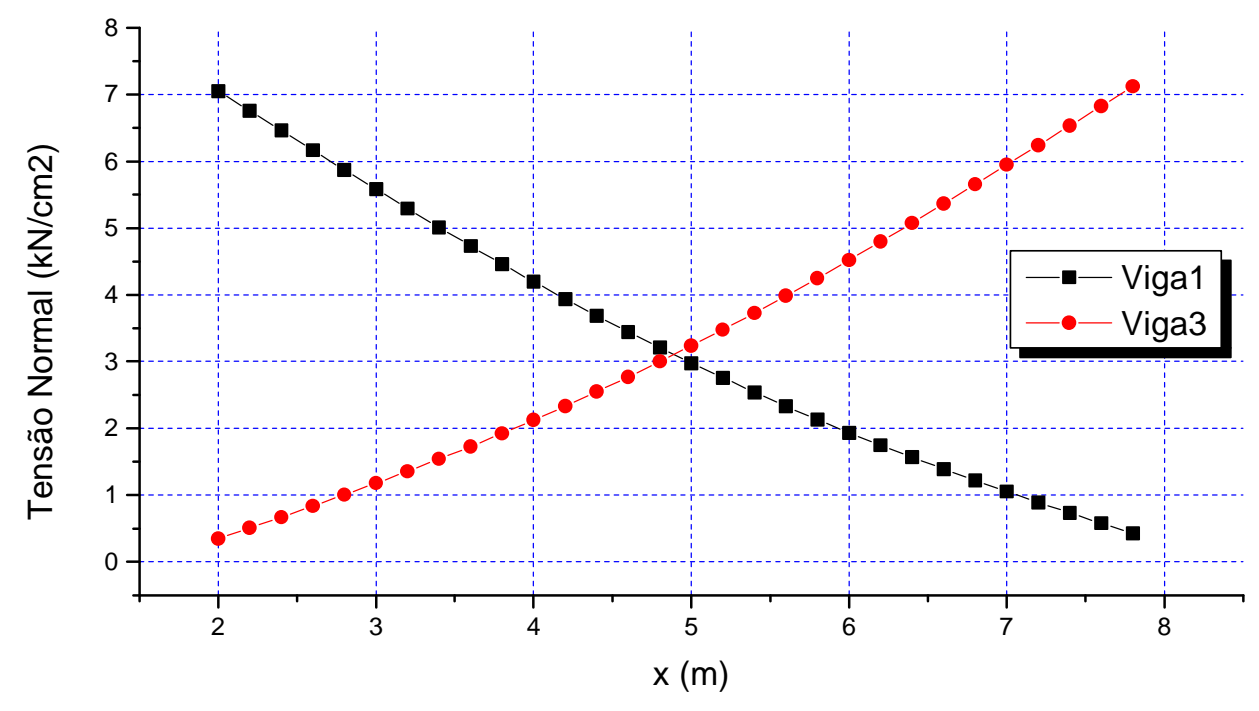

FIGURA C.13 - Linhas de influência para vão de 22 m.

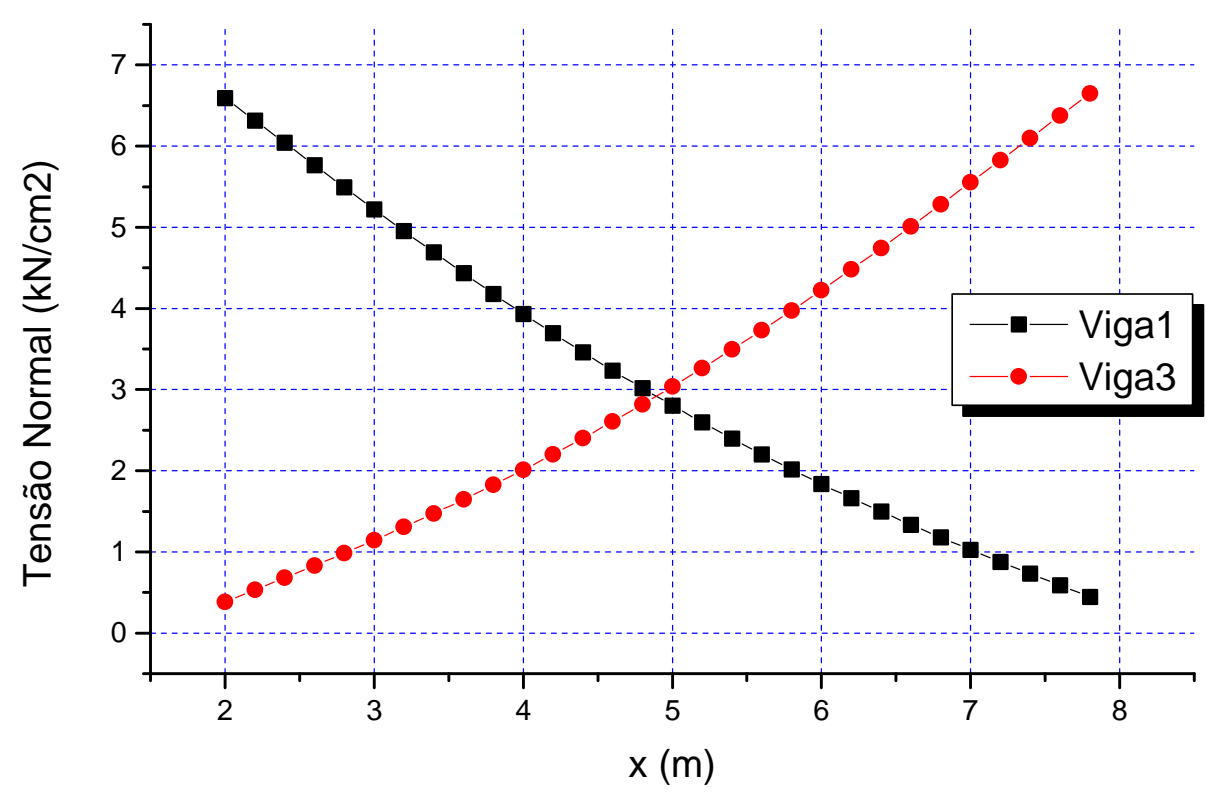

FIGURA C.14 - Linhas de influência para vão de 24 m. 


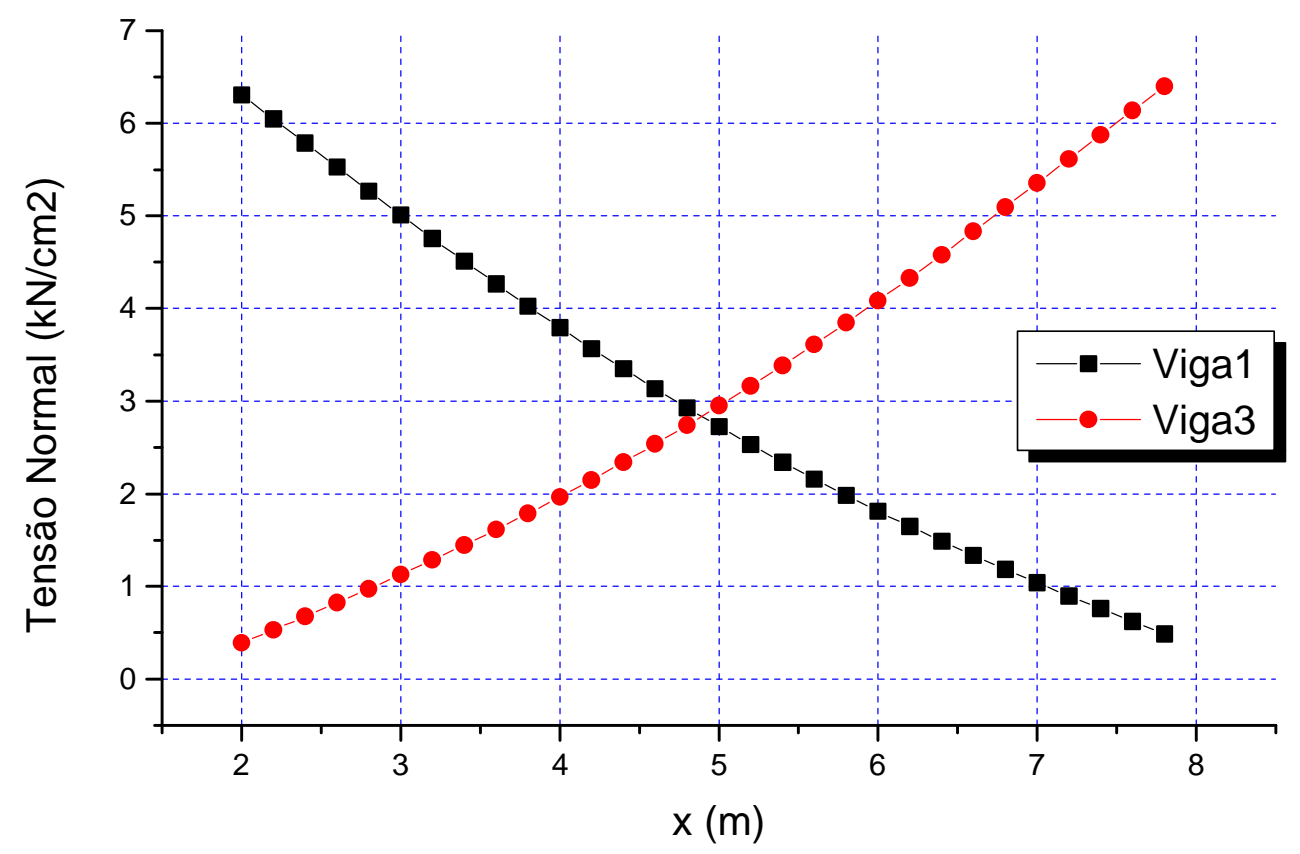

FIGURA C.15 - Linhas de influência para vão de 26 m.

\section{C.2.2 - VIGA INTERNA}

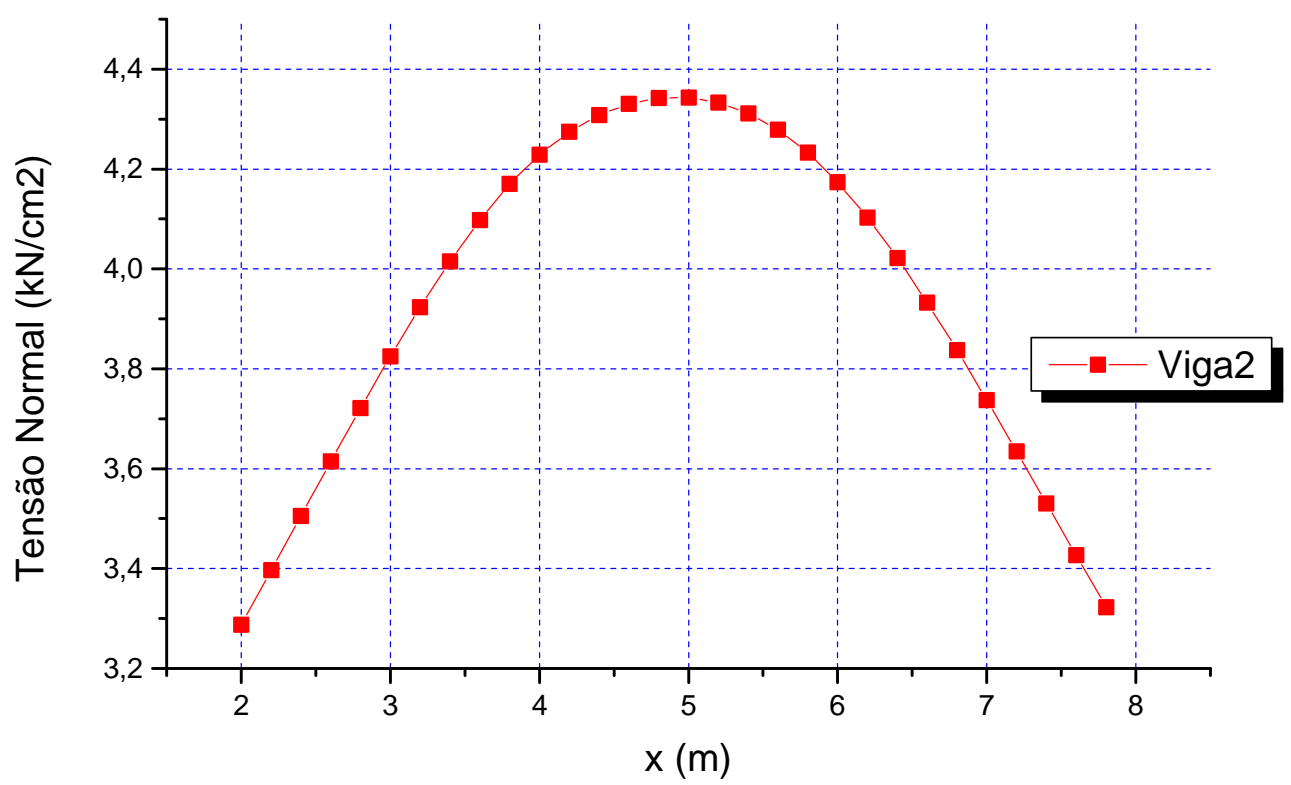

FIGURA C.16 - Linha de influência para vão de 18 m. 


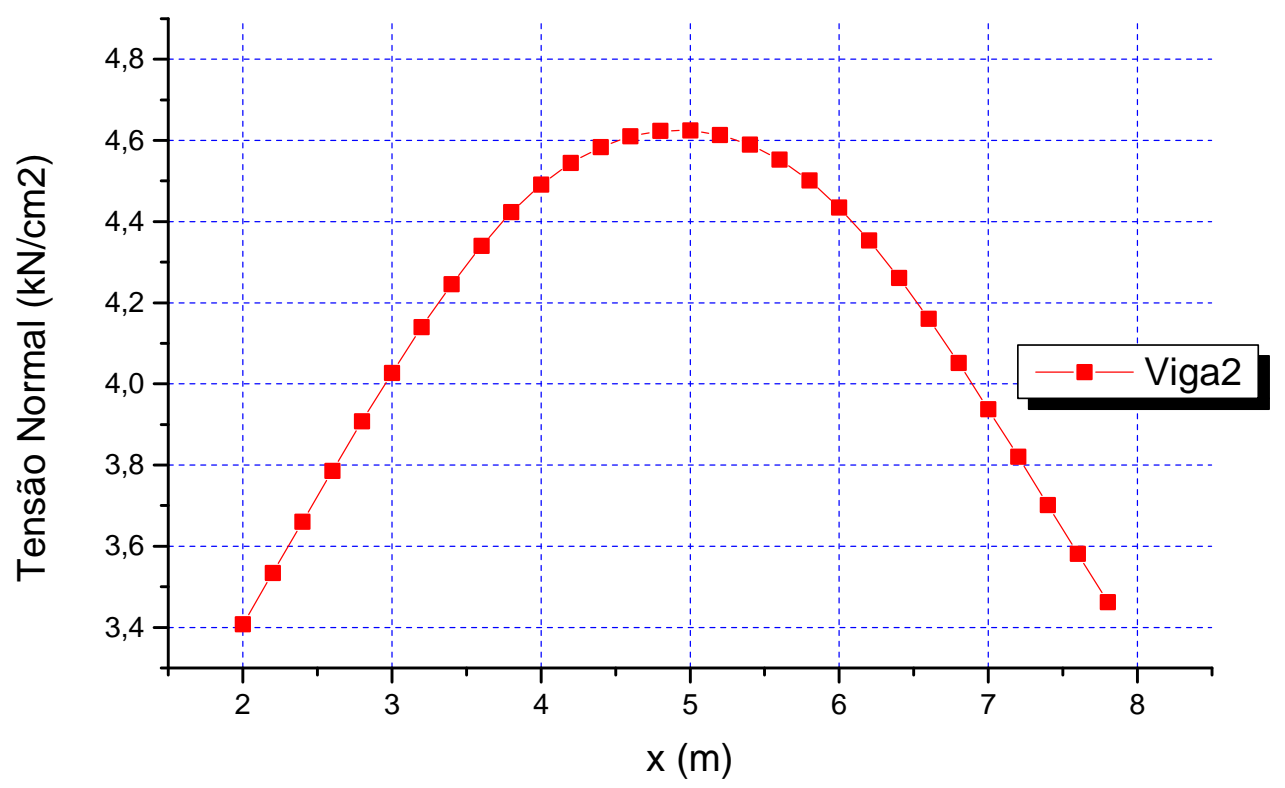

FIGURA C.17 - Linha de influência para vão de 20 m.

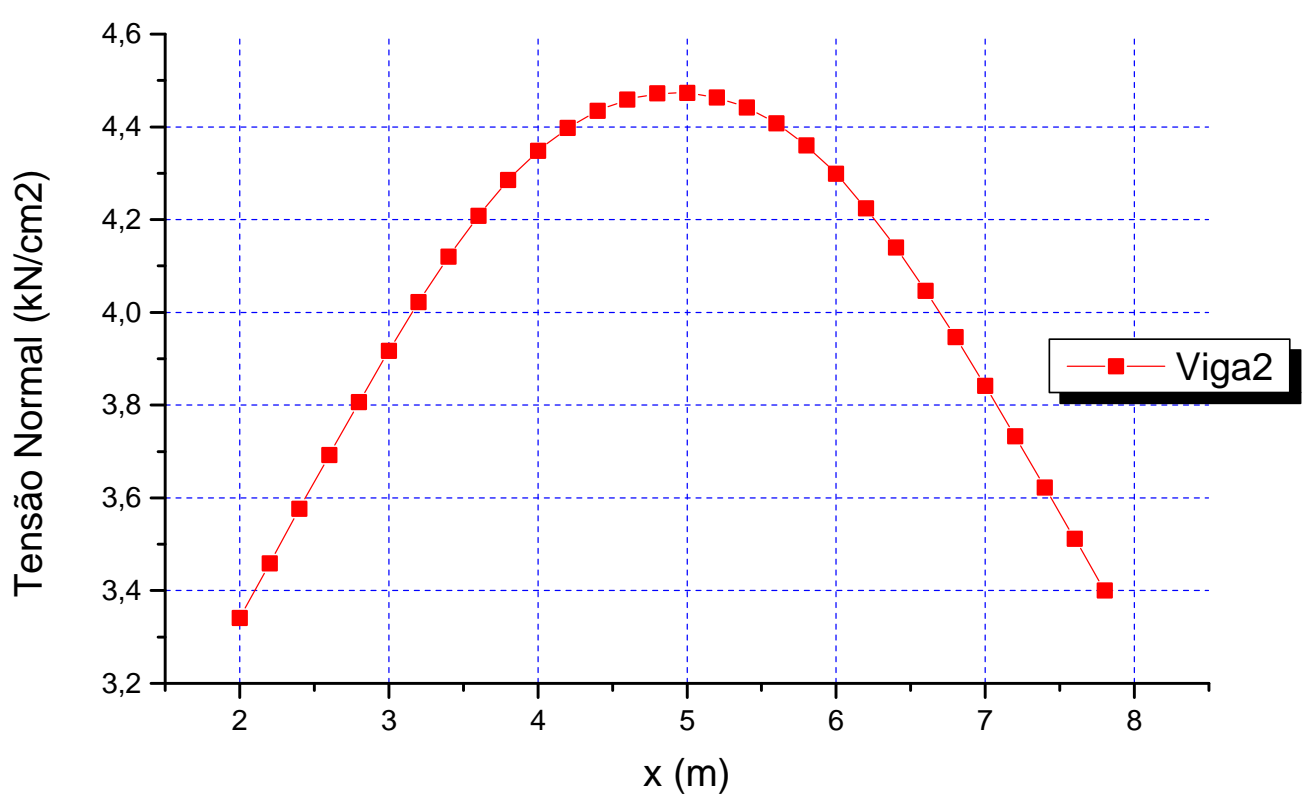

FIGURA C.18 - Linha de influência para vão de 22 m. 


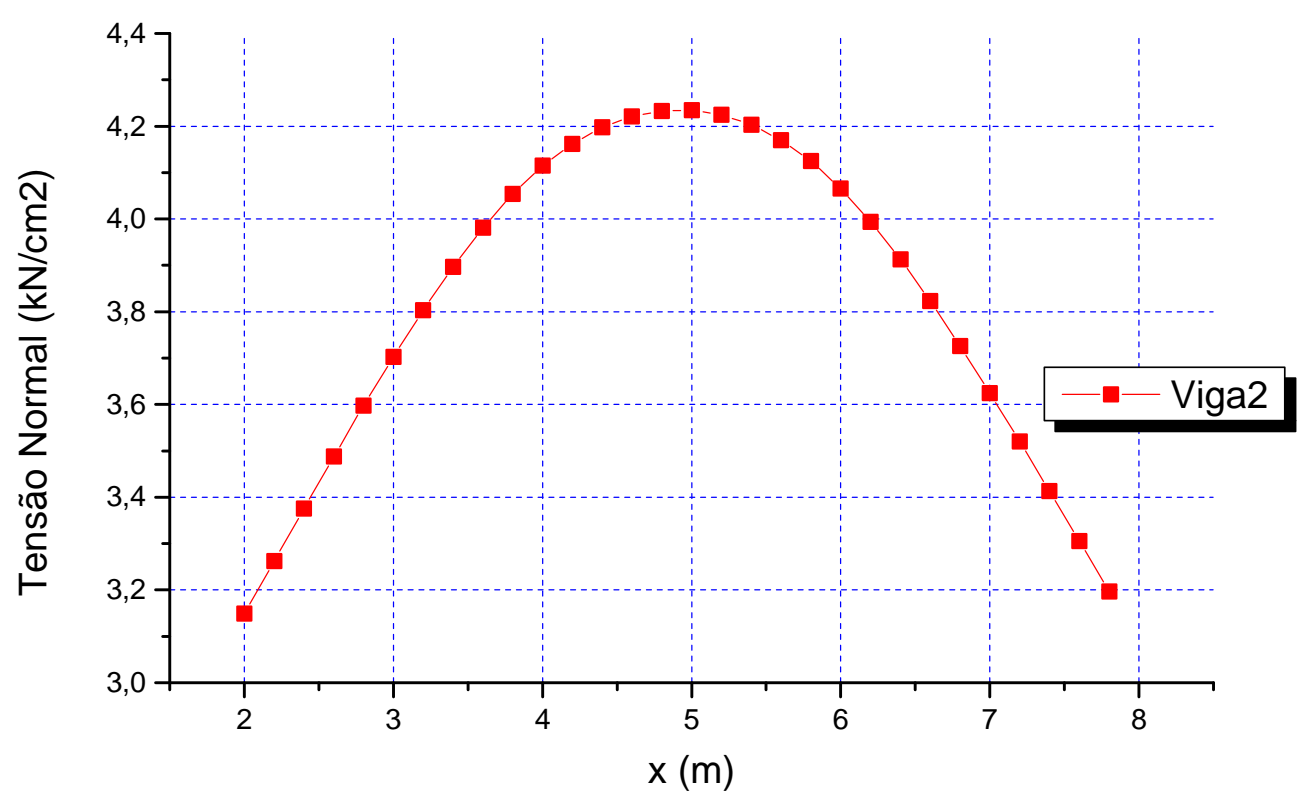

FIGURA 6.19 - Linha de influência para vão de 24 m.

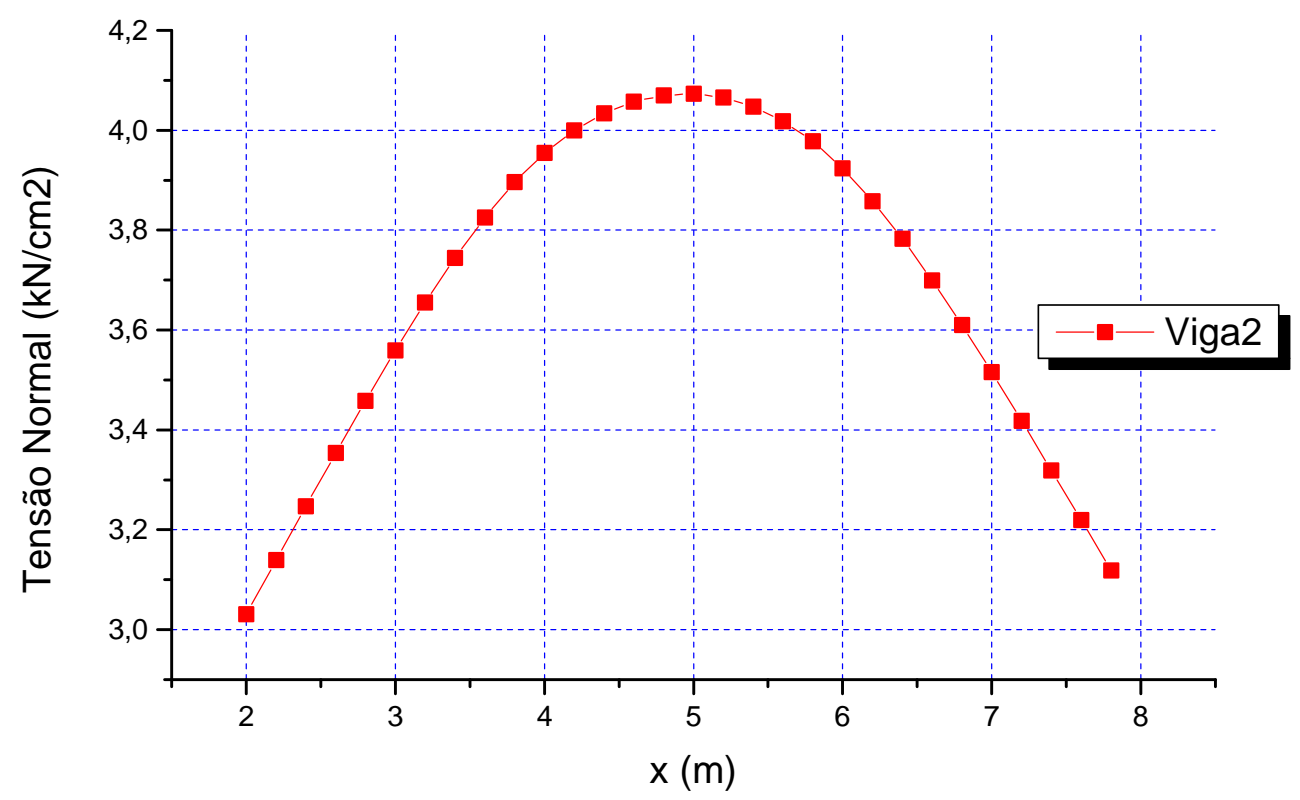

FIGURA C.20 - Linha de influência para vão de 26 m. 